A QUALITATIVE STUDY OF MALE STUDENTS' EXPERIENCES IN

COUNSELING PROGRAMS AND MALE PROFESSIONAL COUNSELORS'

EXPERIENCES POST-GRADUATION

A Dissertation
presented to
the Faculty of the Graduate School
at the University of Missouri-Columbia
In Partial Fulfillment
of the Requirements for the Degree
Doctor of Education
Dr. Sandy Hutchinson, Dissertation Supervisor
MAY 2018


C Copyright by Amber F. Lancaster 2018

All Rights Reserved 
The undersigned, appointed by the dean of the Graduate School, have examined the thesis or dissertation entitled

\section{A QUALITATIVE STUDY OF MALE STUDENTS' EXPERIENCES IN COUNSELING PROGRAMS AND MALE PROFESSIONAL COUNSELORS' EXPERIENCES POST-GRADUATION}

presented by Amber F. Lancaster, a candidate for the degree of Doctor of Education in

Educational Leadership and Policy Analysis, and hereby certify that, in their opinion, it is worthy of acceptance.

Dr. Sandy Hutchinson

Dr. Janelle Cowles

Dr. Joyce Downing

Dr. Barbara Martin 


\section{DEDICATION}

There were people who encouraged me along the way. Since I was young, I was blessed with family members and a few teachers who helped me believe I could do anything, if I put my mind to it; and so I tried. I knew this journey would be tough, but I did not know it would be this tough. I was a first generation college student, and I did not know what I did not know. I did not know who to ask to find out what I did not know and the larger problem was I did not know what to ask. This led to many mistakes.

While I was making these mistakes, I sometimes felt like giving up because the costs, in more ways than materialistically, seemed to outweigh the eventual benefits. It was during some of these times I remembered the words of those who encouraged me. Therefore, I continued. I wanted those who believed in me to know they were correct; that little girl could accomplish whatever she set her mind to. Their belief in me was the catalyst for this journey.

Two of the most influential catalysts were my grandmothers, Pansy Irene and Ona Fay. I appreciate them both for role modeling determination, perseverance, honesty, kindness, and love. Their existence in my life has been vital in who I am today, and will be. Thanks, grandma.

This journey was also important to me because I wanted to be a role model to my siblings, cousins, and nieces and nephews. Much to my chagrin, the educational pursuit took longer than anticipated. During some of the challenging times, I thought about role modeling perseverance in goal attainment. I wanted to be able to say someday, despite the challenges, "Your sissy did it; your cousin did it; your Auntie Amber did it; and you can too, if you choose." 
There are those who inspire and there are those who maintain. Many people do not know the daily grind of a doctoral student, and the challenges of one in the throes of the dissertation process. Kale and Karl Harris do. They were there during the sleepless nights, which resulted in exhaustion, too much coffee, irritability, and stressed days. They are intimate with the topic because the dissertation was discussed as often as determining when the last time the dogs were let out, if the dishes in the dishwasher were clean, and what was for dinner. They were the ones who received the latest update on progress, whether they wanted it or not. They were the ones who asked for an update, and demanded it, whether I wanted to give it or not. I know they made many sacrifices to help me accomplish this life goal. I cannot imagine this process without Kale and Karl Harris on my team. Your love and support got me through. You were my sustenance. Thanks to Karl Harris for being my best friend, favorite person, and biggest supporter. Thanks for holding me accountable even though sometimes I just wanted the world to go by. Thanks for being there for me in all my emotions in this process. I know I expressed all of them sometimes within the same day, hour, or even minute. Thanks for loving me even on days I engaged in unlovable behavior. Thanks for everything, my love, always. 


\section{ACKNOWLEDGMENTS}

There are several who are important to acknowledge. I would like to thank my dissertation committee for their leadership. This research would not have been possible without Dr. Sandy Hutchinson, Dr. Janelle Cowles, Dr. Joyce Downing, and Dr. Barbara Martin. Each committee member's contribution was invaluable. From the beginning to the end, the committee made clear their dedication in offering expertise, guidance, and support. There are not enough words to convey my gratitude. A dissertation committee can make all the difference in a doctoral student's journey. I know it did in mine.

Dr. Sandy Hutchinson, Chair of the Dissertation Committee, was vital in all aspects of the dissertation process, from the details to the big picture. She encouraged me when I felt discouraged. She assisted me in looking forward to the future and not losing sight of the present. She helped me to see what I was not seeing. Thank you, Dr. Sandy Hutchinson, for always knowing what I needed to be successful. I am forever grateful for you.

It is imperative to acknowledge the men who shared themselves to produce this research. They were honest and authentic in their disclosures about their experiences. I am honored to learn from each one. Thank you for helping me to better understand men's experiences in counseling programs and the profession. Thanks for sharing your voice. I will never be the same educator, counselor educator, and leader. I appreciate you more than you will ever know. 


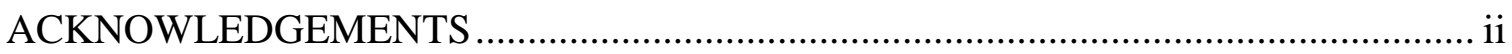

LIST OF ABBREVIATIONS .............................................................................. vii

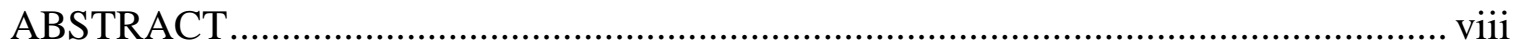

Section

1. INTRODUCTION TO THE DISSERTATION IN PRACTICE ……………….............1

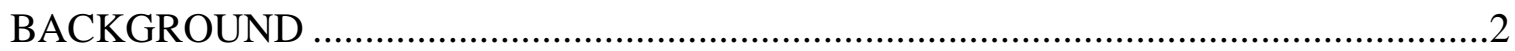

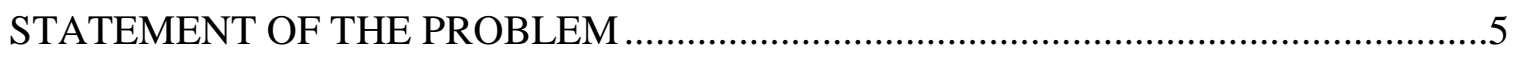

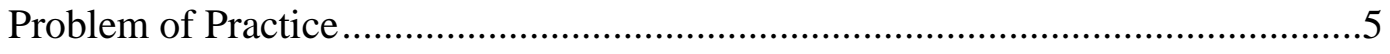

Existing Gap in the Literature .........................................................................

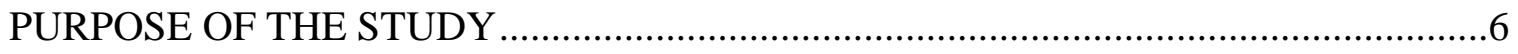

RESEARCH QUESTIONS .............................................................................6

CONCEPTUAL/THEORETICAL FRAMEWORK …………………...........................

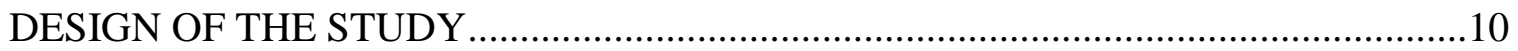

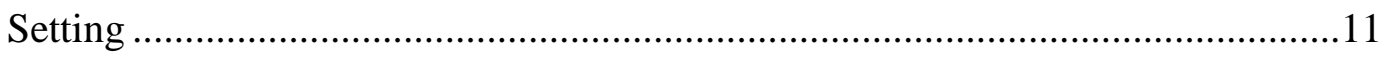

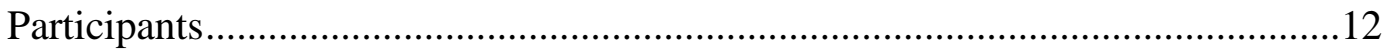

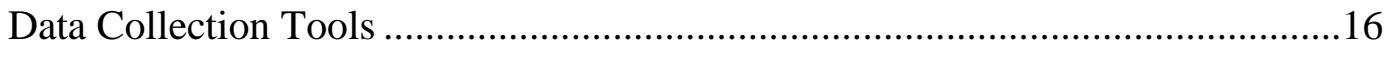

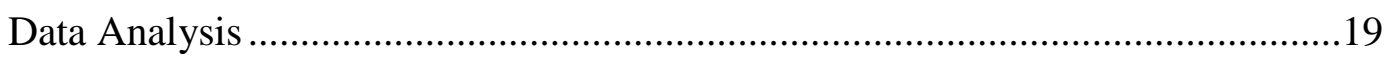

LIMITATIONS, ASSUMPTIONS, AND DESIGN CONTROLS...................................22

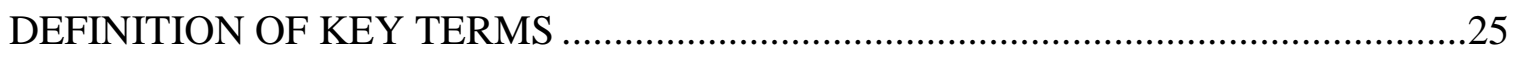

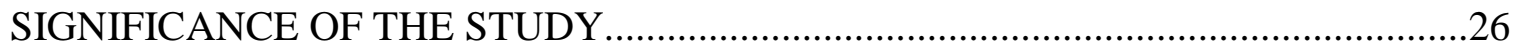

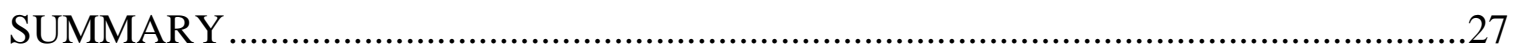




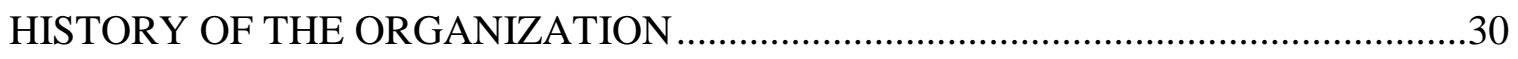

CACREP Counseling Programs .................................................................. 30

Men in Counseling Programs................................................................. 31

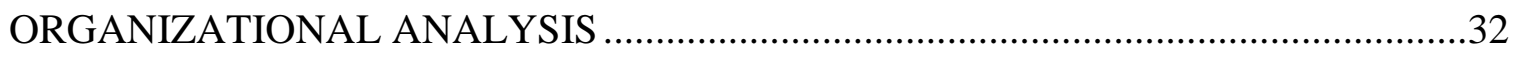

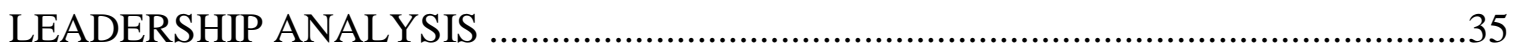

IMPLICATIONS FOR RESEARCH IN THE PRACTIONER SETTING ......................37

Implications within the History of the Organization ........................................37

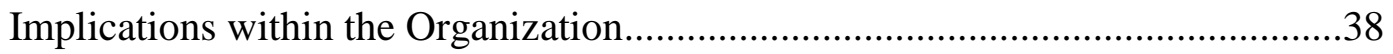

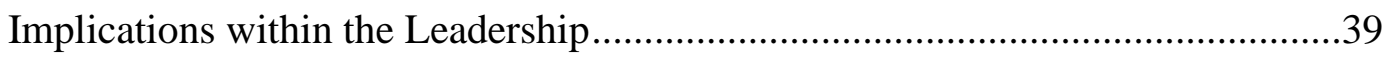

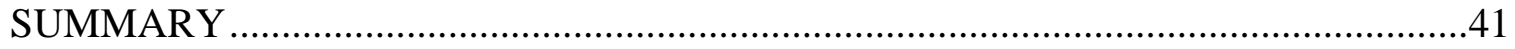

3. SCHOLARLY REVIEW FOR THE STUDY ….............................................42

LACK OF RESEARCH ON MALES IN COUNSELING .......................................44

MALE DISPARITY IN COUNSELING FIELDS ..................................................47

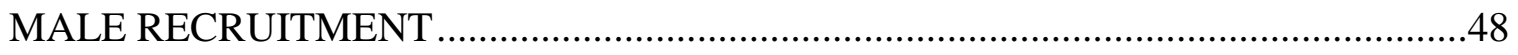

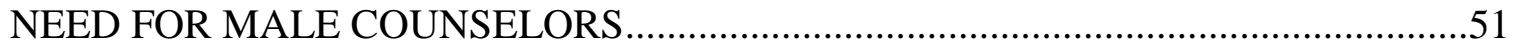

MALE EXPERIENCE IN COUNSELING PROGRAMS AND THE PROFESSION ....53

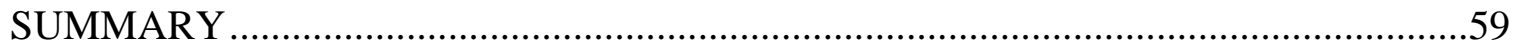

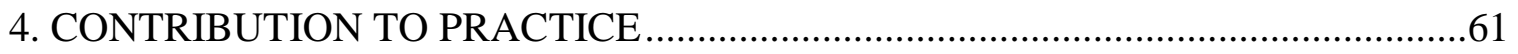

DISSEMINATION OF PRACTIONER CONTRIBUTION .....................................62

PRESENTATION FOR DISSEMINATION AT CONFERENCES .............................65

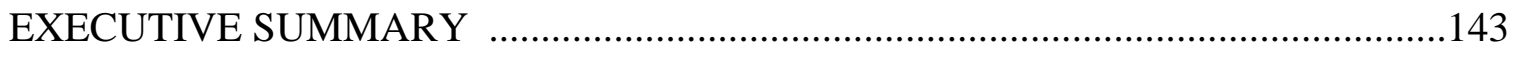

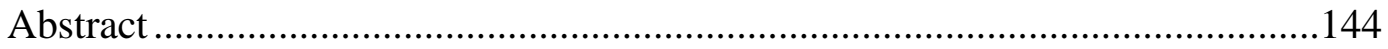




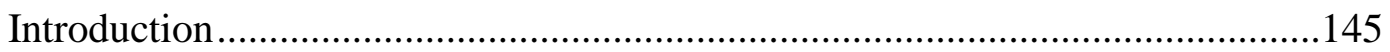

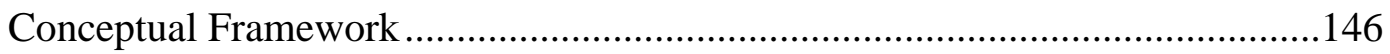

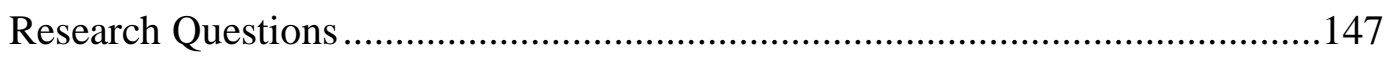

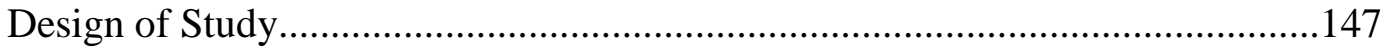

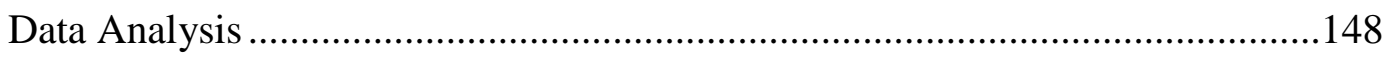

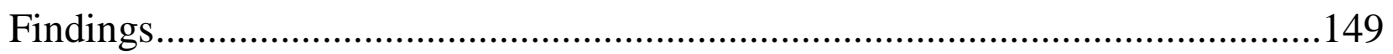

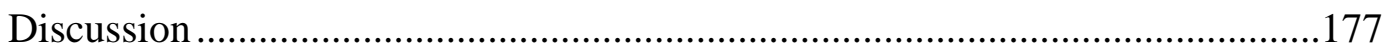

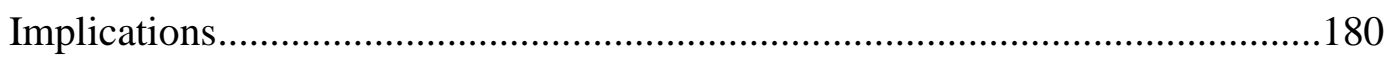

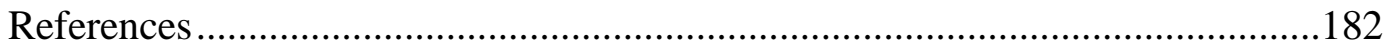

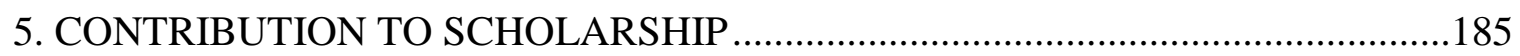

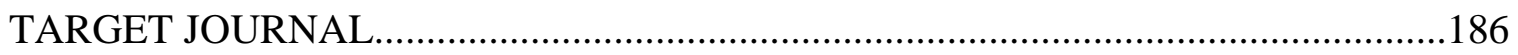

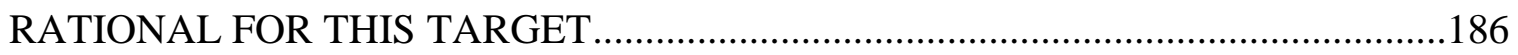

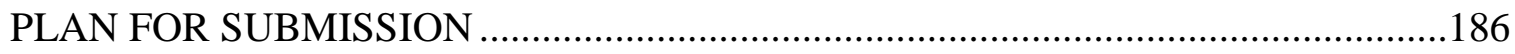

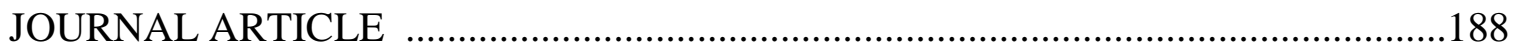

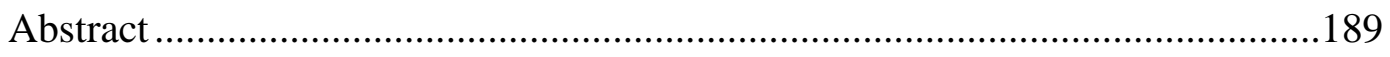

Conceptual/Theoretical Framework.................................................................192

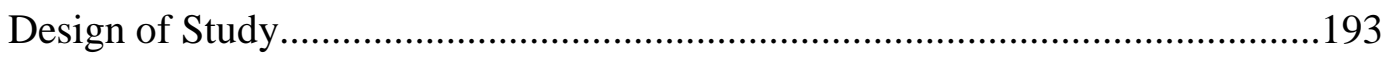

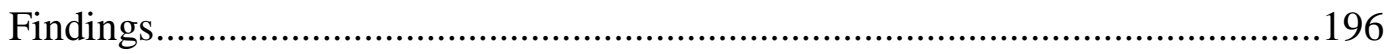

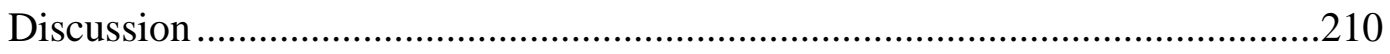

Limitations and Future Research ..............................................................213

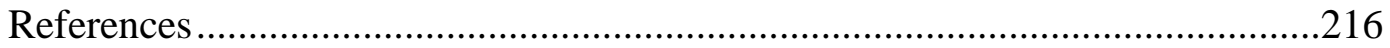

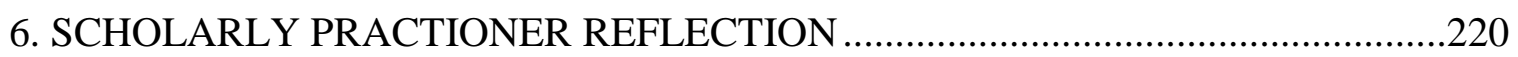

DISSERTATION INFLUENCE ON PRACTICE AS EDUCATIONAL LEADER ......221 


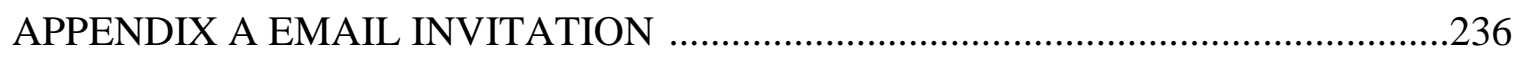

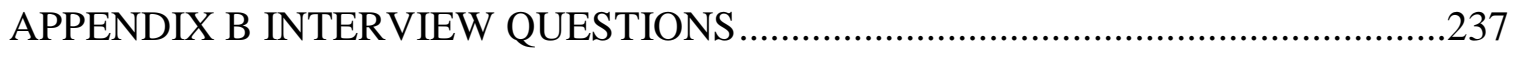

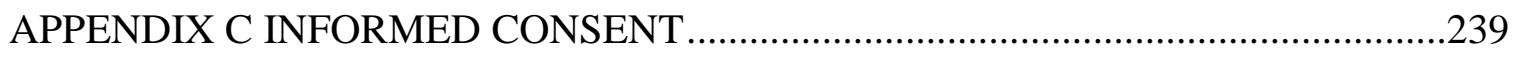

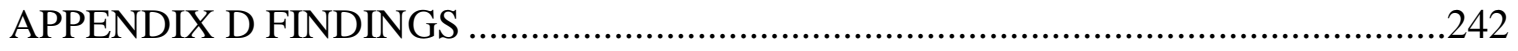

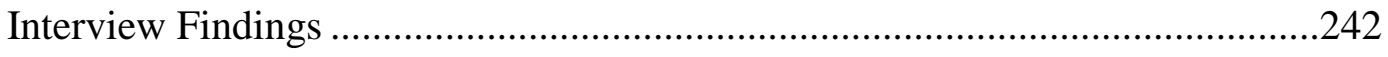

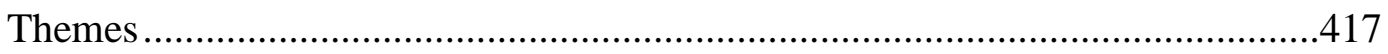

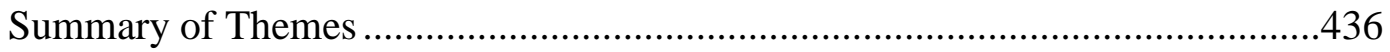

Research Questions Answered.........................................................436

Conceptual/Theoretical Framework.............................................................460

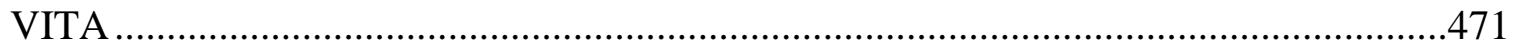




\section{LIST OF ABBREVIATIONS}

American Counseling Association (ACA)

American Foundation for Suicide Prevention (AFSP)

Association for University and College Counseling Center Directors (AUCCCD)

Counselor Educators and Supervisors Network Listserv (CESNET-L)

Center for Disease Control and Prevention (CDC)

Clinical Mental Health Counselors (CMHCs)

Council for Accreditation of Counseling and Related Educational Programs (CACREP)

Social Cognitive Career Theory (SCCT)

U.S. Bureau of Labor Statistics (BLS) 


\begin{abstract}
Little is known about what attracts men to the counseling profession and what their experiences are in counseling programs and the profession post-graduation. This qualitative case study examines what attracts men to the counseling profession, recruitment strategies, and proposed recruitment strategies that could affect prospective male students. It also reveals the experiences of males in counseling programs and the counseling profession, after graduation. Findings indicated men are attracted to the field for various reasons. Most participants did not notice any specific recruitment strategies directed toward males. The participants shared ideas for future male recruitment. Findings also indicated there are benefits and challenges associated with being a gender minority in counseling programs and the profession. Implications for counselor preparation programs are presented.
\end{abstract}




\section{SECTION ONE}

INTRODUCTION TO THE DISSERTATION-IN-PRACTICE 


\section{Background}

A disproportionally low number of males make up the population of counselors. This includes men who apply to counseling programs, who are in counseling educational programs, and who are in the counseling profession (Reetz, Bershad, LeViness, \& Whitlock, 2015; Schweiger, Henderson, McCaskill, Clawson, \& Collins, 2011; U.S. Bureau of Labor Statistics [BLS], 2011). There are approximately three women to every one man in mental health fields (BLS, 2011). The Association for University and College Counseling Center Directors (AUCCCD) reported only $26 \%$ of college counseling center professional staff is male (Reetz et al., 2015). In addition, there are approximately two women to every one man in master's counseling programs (Schweiger et al., 2011). This represents an unfortunate significant difference in the number of men and women in counseling programs and professional counseling.

More males are needed in the helping fields, specifically more male counselors (Paul \& Paul, 2015). This gender disparity "limits the voice of male counseling students, affects client options, and influences the perception of the counseling profession" (Michel, Hall, Hays, \& Runyan, 2013, p. 475) in a variety of ways. First, male counselors are important for some clients' treatment. A lack of male counselors limits client opportunities (Michel et al., 2013; Paul \& Paul, 2015). This may be particularly vital for men seeking help for sexual concerns and parenting (Rochlen \& McKelley, 2009). In addition, evidence has indicated males who were sexually abused may prefer male counselors to discuss sexual abuse (Paul \& Paul, 2015). This is an important consideration since the incidence of sexual abuse for males is approximately one in six (Briere \& Elliot, 2003; Dube, Anda, Whitfield, Brown, Felitti, Dong, \& Giles, 2005). 
It is posited men may be more open to counseling if there are more male counselors available (Michel et al., 2013; Paul \& Paul, 2015; Pederson, 2015). This is especially important considering the suicide rates of men, which is approximately four times as high as the suicide rate for women in the United States (American Foundation for Suicide Prevention [AFSP], 2017). The rate of suicide is highest amongst middle age men. In 2015, White males accounted for seven of 10 suicides. According to the Center for Disease Control and Prevention (CDC, 2016), although the suicide rate is consistently rising across many demographics, there was a staggering $43 \%$ increase in suicide deaths of men aged 45-64 between 1997 and 2014. In 2015, a total of 12,107 men between the ages of 45 and 64 died from suicide. There were 44,193 suicides in the United States, 33,994 of which were males (Drapeau \& McIntosh, 2016). Of the 33,994 male suicides, White males numbered 30,658 suicides. Men need to have their mental health needs met in order to decrease the number of completed male suicides in the United States.

Males have described varying experiences in the counseling field. Some researchers have found men experience marginalization in female-concentrated graduate programs (Fujikura, 2008; Huntington, 2012; Michel et al., 2013; Willyard, 2011). Male counseling students sometimes find it challenging to share their opinions and, when they do share, they do not always feel "heard" (Michel et al., 2013, p. 477). Counselor educators believe low numbers of men in classrooms results in male students not feeling safe enough to share their ideas on some topics (Fujikura, 2008; Huntington, 2012; Michel et al., 2013). There is evidence that low numbers of male students in the classroom can have a negative effect on the learning environment. 
There is additional evidence male students may also be recipients of privilege or receive benefits in counseling programs (Michel et al., 2013). This is consistent with research findings that men may experience favoritism in female dominated programs and careers (Simpson, 2004). Furthermore, some counselor educators have found female peers "shielded and protected" male peers (Michel et al., 2013, p. 477). As a result, men may not be challenged to explore topics in-depth and at the level required of female peers.

There are also conflicting views related to the advantages and disadvantages for male counseling students' learning (Fujikura, 2008; Huntington, 2012; Michel et al., 2013). Some faculty believed that being a male, as a minority in counseling programs, is advantageous because it helps men to understand the communication and relationship qualities of many women (Michel et al., 2013). However, others expressed concern that although there are advantages, there are also drawbacks (Fujikura, 2008; Huntington, 2012; Michel et al., 2013). These may include feeling a lack of respect for their male communication and relationship styles and the need to conform.

In summary, there are significantly fewer men in the counseling field than women (BLS, 2011; Fujikura, 2008; Reetz et al., 2015). The results of prior studies provide mixed and contradictory conclusions, as evidenced by the research of Fujikura (2008), Huntington (2012), and Michel et al. (2013). Furthermore, very little is known about how men decide to enter a feminized career field and how male counselors describe their educational and professional experiences in the counseling field. 


\section{Statement of the Problem}

\section{Problem of Practice}

Men comprise a minority population in counseling education programs and the professional counseling field (BLS, 2011; Reetz et al., 2015; Schweiger et al., 2011). This is a significant issue in the counseling profession. First, many clients need male counselors (Michel et al., 2013; Paul \& Paul, 2015; Rochlen \& McKelley, 2009). Some reasons may include help with sexual concerns and parenting (Rochlen \& McKelley, 2009), and history of sexual abuse (Paul \& Paul, 2015). In addition, according to some researchers, it is probable that men would be more likely to seek counseling services if there were more male counselors available (Michel et al., 2013; Paul \& Paul, 2015; Pederson, 2015). This is important to consider due to the high suicide rates of men in the United States, which is approximately four times as high as for women (AFSP, 2017).

\section{Existing Gap in the Literature}

A gap exits in the literature related to men in counseling programs and in professional counseling. First, there is a paucity of research on what attracts men to counseling programs. Although researchers have started to look at recruitment of men into the counseling field (Michel et al., 2013), the findings are limited to what steps should be taken to increase effectiveness of male recruitment strategies and student retention. A greater understanding of what attracts men to the counseling profession is an important step to increase the number of male applicants and students in counseling programs.

There is also very little research on male counseling students' experiences in counseling programs and as professional counselors. Although there is more research in 
this area than in recruitment of males into counseling programs, the amount of research in this area is still relatively insignificant (Fujikura, 2008; Huntington, 2012; Michel et al., 2013; Paul \& Paul, 2015). In addition, the available research is contradictory. In other words, some men stated their experiences were chiefly of marginalization (Fujikura, 2008; Huntington, 2012; Michel et al., 2013), whereas others stated their experiences were privileged (Michel et al., 2013), and some stated they experienced both (Michel et al., 2013). Additional research is needed to elucidate the experiences of men in counseling programs and in the counseling field. This will inform counseling programs in their recruitment and retention of male students.

\section{Purpose of the Study}

The purpose of this study was to explore the perceptions of men in the counseling field. More specifically, the purpose was to increase understanding of males' decisions to apply to counseling programs, despite the counseling profession being female dominated (BLS, 2011; Reetz et al., 2015; Schweiger et al., 2011). In addition, the study's purpose was to increase the understanding of male experiences, as a minority population, in master's counseling programs. Finally, the researcher sought to increase the current knowledge base about post-graduate men in the counseling field to determine what attracted them to the profession, what their experiences were in counseling programs and as professionals, and what changes in their perceptions and experiences, if any, occurred post-graduation.

\section{Research Questions}

The purpose of this qualitative case study was to understand the shared experiences of male counseling students and male counseling graduates as related to their 
decisions to apply to counseling programs, while in counseling programs, and after graduation. The research questions guiding this inquiry are as follows:

1. What attracts men to the counseling field?

a. What role did overt or covert recruitment strategies play in choosing a counseling program?

b. What recruitment strategies could be beneficial to attract men?

2. What is the experience of men in counseling programs?

3. What is the experience of professional male counselors?

\section{Conceptual/Theoretical Framework}

The lens through which this study was conducted is the social cognitive career theory (SCCT) (Lent, Brown, \& Hackett, 1994). Bandura's social cognitive theory (1986) is the foundation for SCCT. Both theories stress the interaction among cognitiveperson variables. These include self-efficacy, outcome expectations, and goals (Bandura, 1986; Lent et al., 1994). Furthermore, SCCT examines how these factors interact with other personal characteristics such as gender, ethnicity, and culture, as well as environmental contexts such as social support, barriers, and educational experiences. The theory proposes it is the interactional dynamic of these components that affect career pursuits and career selection.

Social cognitive theory (Bandura, 1986) SCCT is divided into complementary levels in SCCT (Lent et al., 1994, 2000). The first level is the cognitive-personal variable, which includes self-efficacy and outcome expectations. Self-efficacy is the belief one has the ability to accomplish a goal. Outcome expectations reflect what individuals believe will be the result of their efforts (e.g., If I become a counselor, then 
...). Finally, there are personal goals for educational or occupational pursuits. If individuals have self-efficacy and believe their efforts will produce a positive outcome, then interest in a particular career choice is developed and the goal is pursued.

Self-efficacy, outcome expectations, and personal goals allow individuals to exercise personal control, or agentic capacity, over their career choices (Lent et al., 1994). Nonetheless, there are some factors individuals do not have control of in their educational and career endeavors. This is because educational and career supports take place in social environments where others are involved in the process (Lent \& Brown, 2013). When others are included in the process, there is likelihood they, too, may exert agentic capacity and limit the agentic capacity of others. For example, a prospective student may have self-efficacy, positive outcome expectations, and personal goals that lead to the student pursuing the counseling field. However, the student's parents do not believe counseling is a suitable educational goal. Therefore, they do not provide financial support. The parents have exercised their agentic capacity, which has led to restricted agency of the prospective student.

The second complementary level of the theory is composed of components that also influence career choice (Lent et al., 1994). These are physical attributes such as gender and race, and characteristics of the environment such as educational quality and financial status. The influence of second level factors on career choice are categorized as objective and perceived environmental factors (Lent et al., 2000). Objective environmental factors, such as financial resources and quality of education, tend to have a great influence on educational and career pursuits. However, how the person perceives these objective factors also affects the educational and career decisions of the individual. 
For example, monetary availability during one's education is an objective environmental factor. However, how the individual perceives it as sufficient or insufficient may, in turn, determine if personal power, or agentic capacity, is exercised and if the educational or career goal is pursued (Lent et al., 2000).

Environmental influences are also further categorized into distal and proximal influences. Distal environmental factors, such as career role models, financial and emotional support, "cultural and gender role socialization," affect the learning experience of the individual (Lent et al., 1994, p. 107) and, therefore, influence the development of self-efficacy and outcome expectations (Lent et al., 2000). Proximal factors are more important during active goal pursuits of education or career. Examples include discriminatory hiring practices and adequate or inadequate networking contacts. Again, how the individual perceives these factors affects if agentic capacity is exercised and if the educational or career goal is pursued (Lent et al., 2000).

If the individual sees environmental factors as positive with few barriers, then career interests are translated into pursuit of the goal (Lent et al., 1994). However, if the person perceives the goal to have too many barriers or the barriers to be insurmountable, then despite an interest in a particular career, the education or career goal will not be pursued. Barriers include intrapersonal or environmental situations or characteristics that make educational and career goal attainment challenging, if not impossible. For example, regardless of interest, if a student does not feel valued or respected in an educational program, the educational goal may not be pursued.

The cognitive-personal and environmental variable interactions are significant in three phases of the career development process (Lent et al., 1994). The first phase is 
when the individual is in the process of forming and eventually developing educational and career interests. The second phase is when the person reflects upon and finally makes the decision to pursue a particular educational degree or career. The third phase takes place when the person is persistent in goal attainment of a specific educational program or career (Lent et al., 1994). Furthermore, the impact of barriers on educational and career goals is influenced by not only the number and type of barriers, but also by the phase in which they are encountered (Lent et al, 2000).

SCCT (Lent et al., 1994) was chosen as the lens through which to view this study for a few specific reasons. First, there are few men in the counseling field (BLS, 2011; Evans, 2013; Reetz et al., 2015; Schweiger et al., 2011) and gender inequality is likely a central reason. SCCT (Lent \& Brown, 2013; Lent et al., 1994, 2000; Lent, Brown, Brenner, Chopra, David, Talleyrand, \& Suthakaran, 2001) recognizes individuals may not be able to or are unwilling to choose careers, even though there is an interest. Furthermore, SCCT acknowledges there are additional factors that have a significant influence on career choice such as personal characteristics (e.g., age, gender, and race) and environmental factors (e.g., support, barriers). It is possible there are men who are interested in counseling, but as a result of person-cognitive and environmental factors, may not pursue or persist in the counseling field. SCCT (Lent et al., 1994) is a useful lens through which to view this problem in practice.

\section{Design of the Study}

In order to study the experiences of male counselors in a feminized profession, a qualitative case study was determined to be an appropriate methodology. Participants belonged to a narrowly defined system of males in master's and doctoral counseling 
programs and male professional counselors. Specifically, this highly bounded system is characteristic of qualitative case studies (Creswell, 2013, 2014, 2016; Merriam \& Tisdell, 2016; Seidman, 2013). These methods included individual interviews, observations, and artifact/document analysis. Data analysis was begun as soon as data collection started. The researcher produced an analytical memo about findings or possible categories, which was supported by the data collected. This method is endorsed by qualitative research experts (Creswell, 2013, 2014, 2016; Merriam \& Tisdell, 2016; Seidman, 2013). Per the recommended qualitative research structure, this process continued until completion of the research study (Merriam \& Tisdell, 2016).

\section{Setting}

\section{Council for Accreditation of Counseling and Related Educational Programs} (CACREP) accredited counseling programs. The setting for the study was CACREP accredited counseling programs. Accreditation is a "quality assurance and enhancement mechanism" (Urofsky, 2013, p. 6). CACREP is the largest accrediting body to regulate counseling programs. Furthermore, CACREP promotes the development and growth of the counseling field (Urofsky, Bobby, \& Ritchie, 2013). This is accomplished, in part, through the development of standards to incorporate the needs of a diverse society and the application of these standards in the preparation of students in counseling programs. This promotes the development of counseling students who are prepared to provide ethical, culturally competent services to clients (CACREP, 2017).

All CACREP accredited counseling programs have eight core curricular areas applicable to all areas of specialization (CACREP, 2017). These include Professional Counseling Orientation and Ethical Practice, Social and Cultural Diversity, Human 
Growth and Development, Career Development, Counseling and Helping Relationships, Group Counseling and Group Work, Assessment and Testing, and Research and Program Evaluation.

A quality assurance process is required of all CACREP accredited programs to ensure all students, regardless of program, receive consistency in the quality of education (CACREP, 2017). For initial accreditation, programs voluntarily submit a self-study with evidence to demonstrate CACREP standards were met. A multi-stage process for reviewing the self-study is also required and includes a three-day site visit by a CACREP review team. Ultimately, the CACREP Board of Directors determines whether to grant accreditation (CACREP, 2017).

After initial accreditation, maintenance of CACREP accreditation includes continuous self-study and external peer review by CACREP. Programs are granted twoyear or eight-year accreditations. It is common for many programs to receive a two-year accreditation first and then follow-up with an eight-year accreditation (CACREP, 2017). Programs that earn a two-year accreditation must produce a follow-up report with evidence addressing standards not initially met. Full accreditation is eight years.

\section{Participants}

The participants of this study were 23 men who were students currently in CACREP counseling programs, master's or doctoral, and graduates of CACREP accredited counseling programs, master's or doctoral level, who specialized in school counseling, clinical mental health counseling, and/or counselor education and supervision. As a result of the uniformity of the CACREP accreditation process, and the consistent curriculum requirements across counseling programs, only students currently 
in CACREP programs and those who graduated from CACREP accredited programs were selected for this study.

Although school counselors and clinical mental health counselors have many commonalities, they also have some unique qualities related to their work settings. School Counselors may work in private and public schools at the elementary, middle, and high school levels (CACREP, 2017). School Counselors provide services to kindergarten through twelfth grade students and support their academic, career, and social/emotional development. To accomplish this goal, School Counselors design and implement comprehensive counseling programs that encompass individual and group counseling; classroom lessons; individual planning for educational, personal and career goals, and consultations with teachers, administrators, and students' families.

Clinical Mental Health Counselors work with clients with diverse mental and emotional disorders (CACREP, 2017). However, they also promote mental health and wellness of individuals, couples, families, and groups. They may work in community mental health agencies, hospitals, private practice, and other treatment settings. Clinical Mental Health Counselors frequently work with others such as psychiatrists, psychologists, and social workers; engage in practices preventive in nature; and diagnose and treat mental health and emotional disorders.

Prior to the implementation of the 2009 CACREP standards, Clinical Mental Health Counseling programs may have also been known as Community Counseling or Mental Health Counseling (CACREP, 2017). The 2009 CACREP standards combined the standards of Community Counseling and Mental Health Counseling. Therefore, all Community Counseling and Mental Health Counseling programs that apply for 
reaccreditation after 2009 will eventually adhere to the Clinical Mental Health Counseling standards for their next accreditation review, if they do not already. Therefore, some Clinical Mental Health Counselors may have graduated from community counseling or mental health programs. However, the standards are very similar and both Community Counseling and Community Mental Health counselors adhere to the same state licensing requirements for professional practice.

Graduates of master's counseling programs may further their education in counseling by pursuing a doctorate in counselor education and supervision. Therefore, doctoral students and graduates of counselor education and supervision programs were also selected to participate in this study. CACREP accredited counselor education and supervision programs prepare students for careers as counselor educators; supervisors, for students and professionals; research; and academic and clinical practice (CACREP, 2017).

The researcher used non-probability sampling to ensure participants were representative of the population being studied (Creswell, 2013, 2014, 2016; Merriam \& Tisdell, 2016; Seidman, 2013). In other words, men were selected who were in counseling programs or graduates from counseling programs and those practicing in the counseling field. This method constituted purposeful sampling (Merriam \& Tisdell, 2016). Counseling professionals who were graduates of counseling programs were recruited from the Counselor Educators and Supervisors Network Listserv (CESNET-L), which is hosted by Dr. Marty Jencius at Kent State University (2017). CESNET-L's purpose is to provide an open forum for discussing topics related to the counseling field, sharing resources amongst counseling professionals, and research recruitment. The 
listserv has approximately 3,400 members who subscribe to the listserv and receive emails. CESNET-L members are counselor educators, professional counselors, supervisors, and students (Jencius, 2017).

The researcher emailed Dr. Jencius and first asked for permission to solicit participants from the listserv and received permission to do so. The researcher posted an invitation to participate in the study on CESNET-L. In order to submit the request per CESNET requirements, the researcher submitted an email to CESNET-

L@listserv.kent.edu with the topic in the subject field of the email (Jencius, 2017). Once Dr. Jencius at Kent State received the email, it was disseminated to all subscribers of CESNET-L (see appendix A). The interested participants contacted the primary researcher via the primary researcher's email address provided in the CESNET post. Once participants made initial contact with the researcher, a follow-up email was sent with the informed consent (see appendix B for an example). Participants were encouraged to email or call the researcher with questions about the study and informed consent. Times and dates for possible interviews were also provided in the email.

The researcher asked initial participants to inform others who might have been willing to participate. This method of utilizing participants to identify future participants, snowball sampling, is a form of purposeful sampling and appropriate for qualitative case studies (Merriam \& Tisdell, 2016). This increased the number of participants who were available for the study.

The researcher is employed as a counselor educator at a CACREP accredited program. The researcher's place of employment was not utilized to recruit participants in order to decrease potential researcher bias and adhere to American Counseling 
Association's ethical codes (ACA, 2014). According to ACA code of ethics F.3.a (2014), teachers in counseling programs should avoid entering into dual relationships that extend the conventional supervisory relationship due to the power differential between teachers and students (2014). Research participants must also be able to decline participation according to code G.2.a (ACA, 2014). However, because of the power differential between the researcher and students, students may not have believed they could decline. Therefore, students from the researcher's place of employment were not recruited for the study in order to avoid potential harm.

\section{Data Collection Tools}

Consistent with qualitative research, several primary methods of data collection were utilized. These included individual personal interviews, observations in CACREP programs, and artifacts or documents (Creswell, 2013, 2014, 2016; Merriam \& Tisdell, 2016; Seidman, 2013). Each form of data collection lends itself to rich and thick descriptions, which is one of the primary characteristics sought in qualitative research (Merriam \& Tisdell, 2016).

Individual interviews. Individual interviews took place with 23 men who are currently in CACREP accredited counseling programs, master's or doctoral, or who with those who have graduated from CACREP accredited counseling programs, master's or doctoral level. The individual interviews averaged 30-60 minutes, but the time was dependent on participants' availability and the amount of time they needed to answer the interview questions. Interviews took place via phone and in person, dependent on the needs and the location of the participant. 
The participants were 23 individuals who identified as male. They were current students in master's or doctoral counseling programs, and/or professionals working in a school, clinical mental health setting, counselor education, or other counseling related field (see table 1 participant profiles in appendix D).

Individual interviews (see Appendix $\mathrm{C}$ for interview protocol) were conducted in a conversational style exploration of participants' personal stories (Merriam, 2009; Seidman, 2013). The questions were organized to "yield descriptive data" (Merriam, 2009, p. 99) and were semi-structured. In other words, questions were presented, but the researcher sometimes formulated additional questions in the interview to follow-up with questions not thoroughly answered by the participant (Merriam, 2009; Seidman, 2013).

Observations. Observation is a common form of data collection in qualitative studies (Merriam \& Tisdell, 2016). Observations take place in the natural setting so that researchers are able to gain a direct account of a phenomena of interest. In order to study the experiences of male students in CACREP counseling programs, observation was utilized as a qualitative research tool. Observations allow researchers to gain a firsthand perspective. Therefore, the researcher drove to and visited three different CACREP counseling programs to collect recruitment material and to observe the environment.

\section{Researcher's role in the setting.}

The researcher's role in the setting was a complete observer at two of the universities (Merriam \& Tisdell, 2016). The researcher was not completely out of the students' or faculty's sight because she was within their view. However, they were not aware they were being observed. The researcher walked through the facility, looked at wall hangings and viewed into classrooms. Another characteristic of being a complete 
observer is the researcher does not talk to anyone observed, which she did not. The researcher only took notes, watched, and listened.

Although the goal of the researcher was that of a complete observer, the role in one of the settings became that of observer as participant (Merriam \& Tisdell, 2016). The researcher had difficulty locating the exact location of the counseling program so staff assisted in locating it. This led to staff and faculty engaging with the researcher and for the researcher's actions to be interpreted as a prospective student. The researcher did not feel comfortable because this felt dishonest and misleading. Therefore, the researcher disclosed her intentions.

Artifacts/documents. In qualitative studies, a useful and easy form of data collection is "mining data from documents" (Merriam \& Tisdell, 2016, p. 162). This form of data collection allows for confirmation of common themes from other sources of information. There are numerous types of documents available to researchers, which include "written, visual, digital, and physical material" (p. 162). Various documents were utilized to study the experiences of men in the counseling field. These included recruitment material from CACREP counseling programs. Fliers and pamphlets were collected from three CACREP accredited programs. In addition, the researcher accessed the websites of CACREP counseling programs through the CACREP website. These websites were scanned for recruitment material and were included in the data collection and analysis process.

Institutional Review Board (IRB) and ethics. There were ethical research considerations for the research study. First, it was necessary to gain IRB consent prior to collecting data according to ACA (2014); American Educational Research Association 
ethical standards ([AERA], 2011); American Psychological Association ([APA], 2009); and CACREP (2016). In addition, participants were provided a copy of the informed consent prior to individual interviews. The researcher was able to guarantee confidentiality of information in individual interviews because there was only the researcher and the participant present (Krueger \& Casey, 2009) (see Appendix D). In addition, pseudonyms were assigned to ensure confidentiality of all participants.

According to ACA code of ethics F.3.a (2014), teachers in counseling programs are to avoid entering into any dual relationship that extends the conventional supervisory relationship due to power differentials between teachers and students (2014). In addition, according to ACA code F.10.d, teachers in counseling programs are to avoid entering into any dual relationship that extends the nonacademic relationship (2014). Both codes are to be implemented to avoid potential harm of students. Research participants must also be able to decline participation according to code G.2.a (ACA, 2014). However, because of the power differential between the researcher and students, students may not believe they can decline. Therefore, students from the researcher's counseling program where she teaches were not recruited for the study to decrease the potential of harm to students.

\section{Data Analysis}

With the aim of increasing the probability of understanding the experiences of men in the counseling field, the researcher utilized a conventional structure employed in qualitative data analysis (Creswell, 2013, 2014, 2016; Merriam \& Tisdell, 2016; Seidman, 2013). The researcher started data analysis as soon as data collection began. First, the interviews were transcribed, which is an important step and often one of the first phases to begin data analysis (Creswell, 2013, 2014, 2016; Merriam \& Tisdell, 2016; 
Seidman, 2013). A vital element of data analysis is coding, defined as assigning a label that corresponds with different components of the data (Merriam \& Tisdell, 2016; Seidman, 2013). Specifically, the researcher utilized open coding (Creswell, 2013, 2014, 2016; Merriam \& Tisdell, 2016; Seidman, 2013). This process produced numerous categories or themes, or repeating patterns, across various forms of data. Therefore, the researcher had to reduce the number of categories by using axial coding (Merriam \& Tisdell, 2016).

The researcher utilized a constant comparative method until the study was completed. To clarify, the researcher utilized a cyclical process of moving between open and axial coding (Merriam \& Tisdell, 2016). More specifically, as categories emerged, the researcher determined if they fit within larger ones. This process reduced the number of themes and made each theme more encompassing.

A number of methods were utilized to increase reliability and validity of the findings. Qualitative reliability is an approach utilized that is "consistent across different researchers and different projects" (Creswell, 2014, p. 201). The researcher maintained a chain of evidence to increase reliability (Yin, 2014). This researcher documented as many of the research steps as possible so others can see the procedures of the researcher. The dissertation chair of this study acted as an external observer. In addition, the researcher of this study made all evidence available to the dissertation chair. According to Yin (2014), the external observer should be able to trace the evidentiary chain backward and forward, from research questions to conclusions and vice versa. No evidence was lost because of irresponsible actions or bias of the researcher. 
The constant comparative method was utilized in data analysis to increase qualitative reliability (Creswell, 2014). In this process, the researcher checked data against current developed codes. This process keeps the definition of codes consistent and makes "sure that there is not a drift in the definition of codes, a shift in the meaning of the codes during the process of coding" (Creswell, 2014, p. 203). In addition, an analytical memo was utilized to keep notes about the codes and how the codes are defined (Merriam \& Tisdell, 2016).

As a final strategy to increase qualitative reliability, the researcher reread transcripts to check for accuracy in the transcription process (Creswell, 2014). This straightforward step helped the researcher find obvious mistakes in the transcript. Avoiding errors is important since they could affect the coding process and, ultimately, the findings.

A number of methods were also utilized to increase qualitative validity, which is defined as measures researchers take to "ensure the accuracy of the findings" (Creswell, 2014, p. 201). Triangulation of data also took place through synthesis of data gathered from multiple sources including interviews, observations, artifacts, and documents (Merriam \& Tisdell, 2016; Yin, 2014). The more forms of evidence a case study has, the higher the quality of the study (Yin, 2014). In the current research, the researcher had three different types of evidence, which augments construct validity and "increases the overall quality of the case study" (Yin, 2014, p. 127).

The researcher utilized member checks to increase validity of the data and, therefore, the trustworthiness of the findings (Creswell, 2013, 2014, 2016; Merriam \& Tisdell, 2016; Seidman, 2013). This took place by asking the participants to read 
interview transcripts for accuracy. This feedback would have been incorporated into the final transcripts and the data would have been analyzed again. However, the participants did not request the researcher to make any changes to the transcripts.

The researcher used rich, thick descriptions in the findings. According to Creswell (2014), when the researcher provides details, "the results become more realistic and richer" (p. 202). Readers may be able to identify more with the material when the researcher conveys findings in this way. This also increases qualitative validity (Creswell, 2014).

Another method the researcher used to increase validity was disclosure of negative or discrepant findings. Creswell (2014) recommended qualitative researchers present evidence that is supportive of a theme, as well as information that is not. This method provides a more realistic account of participants and increases the validity of the qualitative findings.

Another step the researcher took to increase qualitative validity was disclosure of possible biases. By being authentic about possible biases, readers may see the researcher as authentic and credible (Creswell, 2014). The researcher's interpretations of the findings can be influenced by a number of factors. Therefore, it is important readers have this information available to them. These factors are detailed below in the next section.

\section{Limitations, Assumptions, and Design Controls}

\section{Limitations}

Limitations of this study are related to the nature of the research design. First, the researcher has chosen to focus on males in CACREP accredited counseling programs and male professional counselors who graduated from CACREP accredited counseling 
programs. This narrow focus, which is characteristic of case studies, decreases the transferability of the findings (Creswell, 2013). More specifically, the findings of this study may not be transferred to other non-CACREP accredited counseling programs. In addition, because the research is specific to males, the findings may not be transferable to females in counseling programs, CACREP, or non-CACREP accredited.

Finally, the author is a female counselor educator in a CACREP accredited master's level program. It is possible the researcher holds biases related to being a female, graduating from a CACREP accredited counseling program, as well as being a counselor educator in a CACREP accredited counseling program. These biases may be rooted in the design of the study, as well as the future interpretation of the findings.

\section{Assumptions}

CACREP accredited counseling programs were chosen owing to consistent curriculum requirements. Therefore, an assumption of the researcher was the participants of the study would have consistent educational backgrounds. However, it was possible the participants' educational backgrounds would vary for a few different reasons. First, although the participants were current students or graduated from a counseling CACREP accredited program, they may have completed a wide variety of undergraduate degrees since many counseling programs do not require any specific undergraduate degree. In addition, the students who were currently enrolled in counseling programs may have completed varying numbers of graduate credit hours in their counseling programs. Third, participants who graduated may have had a different number of graduate credit hours because CACREP has steadily increased the number of required hours for degree completion over the years (CACREP, 2017). Currently, school counseling specialization 
requires 48 graduate credit hours and clinical mental health requires 60 graduate credit hours. Therefore, depending upon when the participant graduated, the total number of educational graduate hours accrued could have varied.

\section{Design Controls}

There were a number of design controls utilized in the study. First, purposeful sampling was utilized because all participants needed to identify as men in a CACREP accredited counseling program or identify as a graduate of a CACREP accredited counseling program. Second, qualitative studies are an emergent design, which means the qualitative process emerges as the study progresses (Creswell, 2014). Therefore, a semi-structured interview protocol was utilized with the individual interviews for design control, but also so the protocol would not restrict the participants' answers either.

A number of methods were also utilized to increase reliability and validity. Specific steps the researcher utilized to increase reliability included a chain of evidence and an external observer, who is the dissertation chair (Yin, 2014). A constant comparative method of data analysis (Creswell, 2014) and an analytical memo are additional tools the researcher used to increase reliability (Merriam \& Tisdell, 2016). In addition, the researcher checked the transcripts for accuracy (Creswell, 2014).

The researcher also took additional steps to increase validity of the findings. The researcher utilized member checks by asking participants to check the transcripts for accuracy (Creswell, 2016; Merriam \& Tisdell, 2016; Seidman, 2013). Triangulation of the data was also important in design control, as well as the use of rich, thick description (Merriam \& Tisdell, 2016; Yin, 2014). As recommended by Creswell (2014), the researcher presented evidence that was both supportive of the themes and information 
that was not. The researcher has already taken a safeguard to increase validity by disclosing in Limitations her possible biases.

\section{Definition of Key Terms}

Clinical Mental Health Counselors (CMHCs): Counselors who work with clients with diverse mental and emotional disorders (CACREP, 2017). They promote mental health and wellness of individuals, couples, families, and groups. They work in community mental health agencies, hospitals, private practice, employee assistance programs, and other treatment settings. Clinical Mental Health Counselors frequently work with others such as psychiatrists, psychologists, and social workers; engage in practices preventive in nature; and diagnose and treat mental health and emotional disorders.

\section{Council for Accreditation of Counseling and Related Educational Programs}

(CACREP): Accrediting body that sets training standards for counselors. CACREP curricula standards are required education for counseling licensure in most states.

Counseling: "A professional relationship that empowers diverse individuals, families, and groups to accomplish mental health, wellness, education, and career goals" (ACA, 2017b, para. 2).

Counseling programs: Education programs, master's or doctoral level, with a focus on training students for careers in addiction counseling; clinical mental health counseling; clinical rehabilitation counseling; marriage, couple, and family counseling; career counseling; college counseling and student affairs; school counseling; and other human services specializations. For the purposes of this study, school counseling and clinical mental health counseling will be the focus of the educational specialization. 
School counselors: Work in private and public schools at the elementary, middle, and high school levels (CACREP, 2017). School Counselors provide services to kindergarten through twelfth grade students and support their academic, career, and social/emotional development. They design and implement comprehensive school counseling programs that encompass individual and group counseling; classroom lessons; and consultations with teachers, administrators, and students' families.

\section{Significance of the Study}

Men are a minority in the counseling field (BLS, 2011; Reetz et al., 2015; Schweiger et al., 2011). This is a noteworthy issue for the counseling profession. More male counselors are needed in the helping fields (Fujikura, 2008; Michel et al., 2013; Paul \& Paul, 2015) because a lack of male counselors limits client options in a variety of ways (Michel et al., 2013; Paul \& Paul, 2015). In addition, many clients need male counselors (Michel et al., 2013; Paul \& Paul, 2015; Rochlen \& McKelley, 2009). It is an ethical responsibility of the counseling profession to meet the needs of its clients (ACA, 2014).

This study will make significant contributions to educational leaders, counseling programs, and to the existing literature. This study will contribute to the practice of educational leaders by increasing counselor educators' understanding of what attracts men to counseling programs. Furthermore, this information can aid counseling programs in utilizing effective recruitment strategies. This is an important step to increase the number of male applicants and students in counseling programs.

This study will also contribute to the practice of educational leaders in counselor education by assisting counselor educators in understanding male counselors' 
experiences in counseling programs and the larger counseling field. This study will also make a difference at the institution where the researcher is employed by increasing the understanding of program faculty about male counseling students' experiences. This will help program faculty to make informed decisions about meeting the needs of male students in their educational experience, as well as their future professional practice, after graduation.

The study will contribute to the existing literature base. Currently, there is a lack of research on male recruitment, as well as male experiences in counseling programs and the profession. This study will add to the existing literature base, which could be beneficial to counseling programs since there are contradictory research findings on male counseling students and professional male counselors' experiences.

Finally, it is an ethical responsibility (ACA, 2014) of counselor educators, as well as a required accreditation standard (CACREP, 2016), for counseling programs to recruit diverse populations, including gender. Overall, there is a paucity of research on male counseling applicants, students, and counselors. Currently, the male voice is not adequately represented in counseling programs and counselor education and supervision research. This study seeks to rectify this situation.

\section{Summary}

In summary, there are a disproportionally low number of males in the counseling profession. This includes men who apply to counseling programs, who are in counseling programs, and who are in the counseling profession (AUCCCD, 2016; BLS, 2011; Reetz et al., 2015; Schweiger et al., 2011). More male counselors are needed in the helping fields (Fujikura, 2008; Michel et al., 2013; Paul \& Paul, 2015) because a lack of male 
counselors limits client options in a variety of ways (Michel et al., 2013; Paul \& Paul, 2015). In addition, male counselors are central to some clients' treatment (Rochlen \& McKelley, 2009) and some male clients prefer male counselors (Paul \& Paul, 2015). Furthermore, it is believed men may be more open to counseling if there were more male counselors available to choose from (Michel et al., 2013; Paul \& Paul, 2015; Pederson, 2015). This is an important consideration when coupled with the high number of men who commit suicide in the United States (AFSP, 2017; CDC, 2016; Drapeau \& McIntosh, 2016).

There are also conflicting views and evidence related to the advantages and disadvantages for men counseling students' learning in counseling programs (Fujikura, 2008; Huntington, 2012; Michel et al., 2013). Some researchers have found men experience marginalization in female-concentrated graduate programs (Fujikura, 2008; Huntington, 2012; Michel et al., 2013; Willyard, 2011). However, there is also evidence males may be recipients of privilege in counseling programs (Michel et al., 2013).

This research sought to address gaps in the literature. First, the findings of prior studies vary (Fujikura, 2008; Huntington, 2012; Michel et al., 2013). Furthermore, little is known about men's experiences in the counseling field, educationally and professionally. Counseling programs are compelled to investigate this matter further (ACA, 2014; CACREP, 2016). This author also sought to provide additional information to counseling programs. This evidence can then be utilized by counselor educators to make informed decisions to benefit male counseling students specifically, and the counseling profession in general. 


\section{SECTION TWO}

PRACTIONER SETTING FOR THE STUDY 


\section{Introduction}

Counselor educators in CACREP accredited programs are compelled to recruit and retain a diverse student population (CACREP, 2016). Therefore, knowledge on effective male recruitment strategies is needed to increase adherence to this accreditation standard. In order to attract and retain male counseling students, counselor educators must be aware of what is necessary to promote and maintain a good fit between the organization and the individual (Bolman \& Deal, 2013). By using the human resource frame, counseling programs can view and analyze the problem in practice to determine strategies to meet the needs of male students, as well as the counseling program.

The following section will chronicle the history of the organization. In addition, the organization will be explored by applying the human resource frame (Bolman \& Deal, 2013). Leadership and how it relates to males in counseling programs will be analyzed. Finally, implications for research related to males and CACREP accredited programs will be discussed.

\section{History of Organization}

\section{CACREP Counseling Programs}

In the late 1960s and 1970s, the Association for Counselor Education and Supervision (ACES) developed standards to assist them in conducting accreditation of counseling programs (CACREP, 2017). ACES collaborated with the American Personnel and Guidance Association (APGA), an antecedent to ACA, about cooperative accreditation. CACREP was formed shortly thereafter in 1981 (CACREP, 2017).

CACREP is an accreditor of counseling programs (CACREP, 2017). The agency accredits counseling master's and doctoral programs in a number of specialization areas 
in the United States, as well as the world. Specializations include master's level counseling programs in Addiction Counseling; Career Counseling; Clinical Mental Health Counseling; Clinical Rehabilitation Counseling; College Counseling and Student Affairs; Marriage, Couple, and Family Counseling; and School Counseling. At the doctoral level, CACREP accredits Counselor Education and Supervision programs.

Since its establishment, CACREP has promoted the development and growth of the counseling field (Urofsky, Bobby, \& Ritchie, 2013). Standards were developed to incorporate the needs of a diverse society, which leads to the preparation of students in counseling programs who are able to ethically provide services to clients (CACREP, 2017). In addition, there is a quality assurance process for all accredited programs to ensure students receive a quality education (CACREP, 2017). For initial accreditation, programs voluntarily submit a self-study, which is then compared to the current CACREP standards by a CACREP team of counselors and counselor educators. After initial accreditation, maintenance of CACREP accreditation includes continuous selfstudy and external peer review by a CACREP team. There are financial requirements for maintaining accreditation. These include annual fees, hiring faculty to meet core faculty requirements, maintaining student-to-faculty ratios, and costs for writing self-studies for each accreditation cycle (Paradise et al., 2011). There are currently over 750 programs accredited by CACREP (CACREP, 2017).

\section{Men in Counseling Fields}

There has been a growing gender gap in helping professions (BLS, 2011). The counseling field is an example of a helping profession. In the 1970s, men accounted for approximately half of professional counselors (BLS, 2011). Currently, approximately 
$30 \%$ identify as men. This is a significant issue because CACREP (2016) standards require faculty and students to engage in practices to increase multicultural awareness, including gender differences. In addition, recruitment and retention of diverse students is a requirement of CACREP accredited counseling programs according to CACREP standard 1.K. (2016). This is an accreditation issue for counseling programs where men are a minority.

\section{Organizational Analysis}

Organizations tend to be multifaceted, diversely structured, and laden with dilemmas (Bolman \& Deal, 2010, 2013; Bolman \& Gallos, 2011; Levi, 2014; Mintzberg, 1979/2005). Counseling programs are no exception. Reframing, by utilizing different frames or lenses to view a problem, can increase effectiveness in analysis of issues, problem solving, and goal attainment (Bolman \& Deal, 2010, 2013). Reframing aids leaders in strategizing by thinking about a dilemma in different ways. In this case, the problem in practice, low numbers of men in the counseling field, can be viewed in a different way or through different lenses.

Four frames can be utilized to analyze situations or challenges. These include human resource, symbolic, structural, and political (Bolman \& Deal, 2013). All of these frames could be utilized to view the problem in practice because each frame "has its own image of reality" (p. 18). However, for the purposes of this study, the human resource frame was utilized because it focuses on how people and organizations treat one another.

There are some basic tenets of the human resource frame (Bolman \& Deal, 2013). The first is the concept that human needs are to be served by organizations rather than the other way around. Second, organizations and people need each other. It is a symbiotic 
relationship. Third, the fit between the individual and the organization determines if the relationship is negative or positive. Fit is influenced by the way the organization provides for individual drives, the level of freedom allowed in self-expression as well as abilities, and how well financial provisions allow for needs and desires to be met.

The first tenant of the human resource frame is the organization is there to serve the needs of individuals (Bolman \& Deal, 2013). The same can be said about educational counseling programs existing to serve the needs of its students. The program would not be in existence if it were not for the students. If students do not enroll, and graduation rates are not maintained, the programs can and likely will be eliminated from the university (Reynolds, 2016). This is especially true during budgetary challenges. Therefore, university counseling programs must meet the needs of its students in order for students to be attracted to the profession, as well as retention in counseling programs, if counseling programs are to survive.

The second core assumption of the human resource frame is organizations and people need each other (Bolman \& Deal, 2013). The first assumption and the second assumption are related because counseling programs exist to serve their students. However, students also need the counseling program to meet their needs. Students seeking to become professional counselors must meet certain curriculum requirements to become certified by the state to become a School Counselor (ACA, 2012) or to become a Licensed Professional Counselor (ACA, 2010). Therefore, students seek out counseling programs qualified to meet this need.

The third core assumption of the human resource frame involves the fit between the individual and the organization; this fit determines if the relationship is negative or 
positive (Bolman \& Deal, 2013). When a good fit does not exist between the two, one or both may suffer. The individual and organization may even exploit one another. In fact, “individuals may feel neglected or oppressed” (Bolman \& Deal, p. 135).

Some research has indicated men in counseling programs have not experienced a good fit. They find it challenging, at times, to share their views (Fujikura, 2008; Huntington, 2012; Michel et al., 2013) because they believed peers and faculty were unwilling to hear their views (Fujikura, 2008; Huntington, 2012) and sometimes felt “attacked” (Fujikura, 2008, p. 86). Unfortunately, some male counseling students reported not sharing who they really were because they did not feel safe enough to be genuine (Fujikura, 2008; Huntington, 2012). The level of freedom allowed in selfexpression directly affects the goodness of the fit between the individual and the counseling program (Bolman \& Deal, 2013).

Regrettably, there tend to be victims when there is not a good fit (Bolman \& Deal, 2013). In a counseling program, if the fit does not work, the student may not be successful and either exits the program by choice or fails out of the program. Ultimately, this could affect the diversity of the program, which may, in turn, affect accreditation (CACREP, 2016). In addition, attrition rates are reviewed by universities, which may affect the sustainability of a counseling program (Reynolds, 2016).

However, if the fit is good, and it works for the organization and the individual, both benefit. "Individuals find meaningful and satisfying work, and organizations get the talent and energy they need to succeed" (Bolman \& Deal, 2013, p. 117). Students receive the education they need so they are able to pursue a degree in the counseling field. In 
addition, the counseling program continues to survive, which is the fundamental goal of organizations, including counseling programs (Bolman \& Deal, 2013).

\section{Leadership Analysis}

Organizations are impacted by the type of leadership within them. Leadership is fundamental within effective and productive organizations (Kotter, 1990; Northouse, 2016). To be an authentic leader takes self-knowledge and genuineness, or authenticity (George, Sims, McLean, \& Mayer, 2007; Goffee \& Jones, 2000; Northouse, 2016). Genuineness is integral in building trust in others. Authentic leaders do so by being themselves and being genuine (George, Sims, McLean, \& Mayer, 2007). Furthermore, authentic leaders are not necessarily born. Instead, they often develop through selfreflection and learning from their life experiences (George, Sims, McLean, \& Mayer, 2007). In order for individuals to come to know their genuine self, it "requires the courage and honesty to open up and examine their experiences. As they do so, they become more humane and willing to be vulnerable" (George, Sims, McLean, \& Mayer, 2007, p. 168). It is common for difficult life experiences to be the catalyst for authentic leaders' motivation to lead others.

In counseling, leadership and advocacy are considered paramount to the quality of services offered to clients, as well as the persistence of the counseling field (Chang, Minton, Dixon, Myers, \& Sweeney, 2012). Leadership is an important role of counselors, whether it is in a school or clinical mental health setting (Joe, Becan, Knight, \& Flynn, 2017; Meany-Walen, Carnes-Holt, Minton, Purswell, \& Pronchenko-Jain, 2013). In fact, leadership and advocacy are required core standards in the curriculum in CACREP accredited counseling programs (CACREP, 2016). 
Similar to authentic leadership qualifications, self-reflection and becoming selfaware are important to being an ethical counselor (Herlihy \& Corey, 2015; Sue \& Sue, 2016). Just as authentic leaders are not necessarily born (George, Sims, McLean, \& Mayer, 2007), counselors are not either. Instead, counselors often develop through selfreflection and learning from their life experiences (Bernard \& Goodyear, 2014; Bitter, 2014; Sue \& Sue, 2016). Counseling students and professional counselors are implored to engage in self-exploration to become aware of their biases and values during their counseling program and throughout their professional career (ACA, 2014; Bitter, 2014; Sue $\&$ Sue, 2016). In addition, students are encouraged to reflect on their life experiences and the effect experiences have had, continue to have, and might have in the future, on their biases and values. As with authentic leaders, knowing one's genuine self takes courage and honesty, but taking the risk tends to produce a more authentic and empathetic counselor. Self-reflection and authenticity are vital in the development of ethical and competent counselors as leaders and advocates (Sue \& Sue, 2016).

Similar to authentic leadership in organizations, a common essential characteristic of counselors who facilitate successful change in clients is genuineness or authenticity because it promotes trust and the facilitation of the counseling relationship (Rogers, 1961). Moreover, the relationship between client and counselor tends to be a predictor of client outcomes (Tasca, Compare, Zarbo, \& Brugnera, 2016; Xu \& Tracey, 2015). If there is a positive relationship between counselor and client, positive client outcomes take place more frequently than when there is no or little relationship between the client and the counselor. Therefore, authentic counselors promote relationships and 
relationships are catalysts for positive client outcomes. Hence, authenticity is vital in counseling relationships.

\section{Implications for Research in the Practitioner Setting}

Investigating the setting for the study, in particular the history of the organization, organizational analysis, and leadership analysis has implications for the research in the practioner setting. This researcher seeks to increase counseling programs' understanding about factors that attract men to the counseling profession, as well as their experiences in counseling programs and as professionals. In addition, counselor programs have an obligation to promote diversity within their recruitment of students, as well as retention (CACREP, 2016). Therefore, counseling programs need supplementary knowledge that will inform recruitment practices of diverse students, including men. In addition, research is needed so counseling programs can make informed decisions on how to provide quality educational experiences to male students.

\section{Implications within the History of the Organization}

Historically, it is obvious there is an ever-widening gender gap in the counseling field, in both education programs and the profession (BLS, 2011; Schweiger et al., 2011). Some men continue to enter the counseling field and become professional counselors, but little is known about successful counseling program recruitment strategies (Michel et al., 2013). Although there is some information on what male counseling students would like to see in recruitment, to this researcher's knowledge, there are no studies to investigate recruitment strategies that attract or repel male students from counseling programs. Moreover, research has indicated many counselor educators are interested in recruiting more men $(n=166,76.5 \%)$. Many counselor educators also see a need to recruit more 
men $(n=163,75.1 \%)$, but almost half of counselor educators surveyed indicated no gender-based efforts were being made in their programs $(n=104,47.9 \%)$ (Michel et al., 2013). Furthermore, some counselor educators questioned the need or value of additional male counselors in counseling programs.

An important implication for practioners in counseling programs is the adherence to accreditation standards for programs to earn and maintain accreditation (CACREP, 2016). In particular, CACREP counseling programs are required to recruit and retain diverse student populations. One way to meet this standard is for counseling programs to be informed on recruitment strategies to attract male students. This effort could increase male student enrollment and, therefore, increase the diversity within the program.

\section{Implications within the Organization}

The process of reframing can be utilized to view the problem in practice (low numbers of men in the counseling profession) through different lenses (Bolman \& Deal, 2013). For the purposes of this study, the human resource frame was appropriate to view the problem in practice because the needs of the individuals and the organization are central in this research study. Reframing can increase effectiveness in analysis of issues, problem solving, and goal attainment (Bolman \& Deal, 2010, 2013). Specific to this study, counselor educators need to analyze the issue of low numbers of males in counseling programs and the profession. Counseling programs need to examine what attracts males to the profession and retains them through graduation. The ultimate goal is to increase the number of males in the counseling field.

In the context of the human resource frame, counseling program faculty must be aware of the needs of the individuals it serves and provide for those needs (Bolman \& 
Deal, 2013). In order for male students to be attracted to the profession and maintain or increase retention, university counseling programs must first be aware of those needs and desires. In addition, counseling program faculty must be aware of what constitutes a good fit between the counseling program and male students as the fit between the individual and the organization determines if the relationship is negative or positive (Bolman \& Deal, 2013). Students may feel mistreated and persecuted when the relationship between counseling programs and male students is not a good fit, (Fujikura, 2008; Huntington, 2012; Michel et al., 2013). This could lead to male student attrition, which can have a direct negative impact on the counseling program. It could affect the diversity of the program, which may affect accreditation (CACREP, 2016). In addition, attrition of men students may affect the sustainability of counseling programs (Reynolds, 2016). Counseling programs, and the students they serve, could greatly benefit from an increase in knowledge on increasing the goodness of fit between male students and counseling programs.

\section{Implications within Leadership}

Leadership is fundamental within effective and productive organizations (Kotter, 1990; Northouse, 2016). In counseling, effective leadership is considered paramount in providing services and the continuation of the counseling field (Chang, Minton, Dixon, Myers, \& Sweeney, 2012). In addition, leadership and advocacy are required core standards to be addressed within the curriculum in CACREP accredited counseling programs (CACREP, 2016).

To be an authentic leader takes self-knowledge and genuineness (George, Sims, McLean, \& Mayer, 2007; Goffee \& Jones, 2000; Northouse, 2016). Analogous to 
authentic leadership characteristics, self-reflection and self-awareness are important to the development of counselors (Bernard \& Goodyear, 2014; Bitter, 2014; Herlihy \& Corey, 2015; Sue \& Sue, 2016). Counseling programs are called to provide educational opportunities to students that promote self-exploration, which facilitate self-awareness and genuineness (Bitter, 2014; Sue \& Sue, 2016). As with authentic leaders, knowing one's genuine self takes courage and honesty, which tends to produce a more authentic counselor (Bernard \& Goodyear, 2014; Bitter, 2014; Sue \& Sue, 2016).

Unfortunately, some research has indicated male counseling students may not be authentic in their interactions with peers and faculty because they do not feel safe enough to do so (Fujikura, 2008). This finding may have serious implications for counseling programs and male students because freedom in self-expression directly affects the goodness of the fit between the individual and the organization (Bolman \& Deal, 2013). Male students must feel safe enough to self-reflect because it is a significant component in leadership development (George, Sims, McLean, \& Mayer, 2007; Goffee \& Jones, 2000; Northouse, 2016) and counselor development (Bernard \& Goodyear, 2014; Bitter, 2014; Sue \& Sue, 2016).

It is imperative counselor educators increase understanding about male students' experiences in counseling programs and how their experiences relate to male students' willingness and ability to present authentically. This is vital because genuineness is related to the development of counseling relationships, which are significant in positive client outcomes (Tasca, Compare, Zarbo, \& Brugnera, 2016; Xu \& Tracey, 2015). The findings from this study can be utilized to inform educational counseling program environments in these areas. 


\section{Summary}

The counseling field has changed over the years. One significant change is that the number of men has dwindled resulting in men becoming a minority population in the profession (BLS, 2011). In order to change this trend, counseling programs need information on what male counseling students and professionals believe are effective recruitment strategies. In addition, counselor educators must be aware of what is necessary to promote and maintain a good fit between the counseling program and male students to retain male counseling students (Bolman \& Deal, 2013). By using the human resource frame, counseling programs can analyze the problem in practice to determine strategies to meet the needs of the counseling program, as well as their male students. Furthermore, it is the responsibility of counseling programs to promote leadership and advocacy skills of counseling students. Counseling programs must be aware of how to provide environments conducive to educational opportunities that include self-reflection and authentic interactions. Due to the paucity of research with men in the counseling field, there is a need for research in this area to inform counseling programs how to meet the needs of male students. 


\section{SECTION THREE}

SCHOLARLY REVIEW FOR THE STUDY 


\section{Introduction}

The number of men in the counseling profession has decreased since the 1970s (BLS, 2011). Depending on the source, there are varying statistics of the actual number of males in the mental health profession. However, regardless of the approximation, it is clear males are a minority in the counseling field. Some important statistics to consider include there are approximately two women to every one man in master's counseling programs (Schweiger et al., 2011), 17\% of students in CACREP accredited counseling programs are male (Evans, 2013), three women to every one man in mental health fields in general (BLS, 2011) and only 26\% of ACA members identify as male (Evans, 2013).

Not only are males a minority in the counseling profession, research on males is also scarce. Moreover, available research is inconsistent in its findings. Some researchers have found men experience unintentional marginalization in femaleconcentrated graduate programs (Fujikura, 2008; Huntington, 2012; Michel et al., 2013; Willyard, 2011). However, there is additional evidence males may also be recipients of privilege in counseling programs (Fujikura, 2008; Michel et al., 2013). Furthermore, there are conflicting views related to the advantages and disadvantages for men counseling students' learning in a feminized learning environment (Fujikura, 2008; Huntington, 2012; Michel et al., 2013). As a result of the lack of research, as well as the discrepancy in research findings, it is evident there is a need for additional research on what attracts men to the profession, as well as their experiences in counseling programs and in the counseling profession.

The relevant literature will be presented in this chapter. First, the lack of research on males in counseling will be explored. Next, the male disparity or gender imbalance in 
counseling programs and the profession will be presented. Third, an argument for the need for more male counselors will be posed. Finally, the research on the experiences of men in counseling programs will be discussed.

\section{Lack of Research on Males in Counseling}

In 1981, a special issue about men in counseling was published to recognize the unique needs and characteristics of male clients in counseling (Scher, 1981). The author argued specialized training is necessary to effectively serve male clients. Therefore, Scher encouraged counselors to increase their understanding of men and the necessary skills to effectively counsel and meet the needs of male clients. Counselors were implored to learn more about the distinctive needs of males including sex role development; lifespan development; educational and career needs and interests; gender role conflict; masculinity; and reluctance in seeking supportive assistance, including mental health services.

In 2013, a content analysis of published research was conducted on research on men in counseling (Evans, 2013). This research acted as a follow-up to the 1981 call for additional male counseling research that was deemed necessary in order to improve counseling services for the male population (Scher, 1981). Specifically, the purpose of the content analysis was to determine if the 1981 plea for research had been answered (Evans, 2013). It was clear there was a need to know if the call had been heeded because the national population of men is approximately half at 49.1\% (U.S. Census, 2011).

The content analysis consisted of Evans (2013) examining two leading counseling journals' publications from 1981 to 2011. One journal was the Journal of Counseling and Development (JCD), which is the official journal of the American Counseling 
Association (ACA). It is blind-peer-reviewed and published quarterly. It is a free benefit of membership in ACA. Articles include information and research on counseling practice, theory, assessment and diagnosis, and current trends. The other was the Counselor Education and Supervision journal (CES). It is the journal for the Association for Counselor Education and Supervision (ACES), which is a division of ACA. It is also blind-peer-reviewed and published quarterly. The focus of CES is similar to JCD with emphasis on applications for counselors, supervisors, and counselor educators. Specifically, it is concentrated on the training and supervision of counselors.

Evans (2013) found JCD had a male research focus of 4.4\%, whereas CES publications had $0.5 \%$ male focus. Despite the large number of publications during those years, this was a starkly low number of articles focused specifically on men in counseling. Evans (2013) stated, "The lack of counseling literature that addresses issues specifically encountered by men indicates we are missing a very important group of individuals with diverse needs" (p. 472).

Additionally, Evans pondered if the lack of research on males in counseling is attributable to the low number of men in national counseling associations such as ACA, as well as the low number of men in counseling programs (Evans, 2013). In 2011 and 2012, Evans determined 26\% of ACA members identified as male, whereas $74 \%$ identified as female. In addition, men in CACREP accredited counseling programs constituted $16.96 \%$ and women comprised $83.04 \%$. Evans (2013) speculated a lack of research on men in counseling may be because "there is a lack of interest by women in conducting research that is focused on men" (Evans, 2013, p. 472) and there are more women than men to in the profession to do the research. 
Evans stated her motives were questioned when she shared with peers her male research concentration. ACA members' responses to her research interests were related to the perception that there was no need for male focused research because of the preponderance of male privilege in society (Evans, 2013). Privilege is defined as unearned advantages individuals or groups have, but they did not ask for (McIntosh, 1990). Types of privileges are White, male, ability, age, sexual, socioeconomic status, age, ethnicity, religion, as well as others. Men tend to have higher salaries than women, despite the same job description, and they tend to be promoted more often and more quickly than women (Sue \& Sue, 2016). Despite male privilege, men still have mental health needs that must be addressed (Evans, 2013). Counselors must be trained to meet male clients' unique needs. Therefore, additional research must take place in order for counselors to be effective and ethical with this population.

Evans' (2013) content analysis makes clear there is a paucity of research on men in counseling and the counseling profession. Evans utilized content analysis, which is a sound methodology for analyzing large amounts of data to draw conclusions (Krippendorff, 2013). This was a strength of Evans' study because it is an objective process owing to its use of a systematic counting method. In Evans' (2013) case, key words were utilized to determine if a study was primarily focused on males. Only articles that had $50 \%$ or more of the keywords in the article were included in the analysis. This is a possible limitation of Evans' study because some research on males may have been overlooked. Therefore, the number of research studies on males may be higher than concluded. However, even if the numbers were larger, it is still certain there is very little research on males in the counseling research. 
There have been calls for additional research on males in counseling as clients, students, and professionals for decades (Scher, 1981). Regardless of whether it is research on males in counseling or males in the counseling profession, there is a shortage. The reason a scarcity of research on males exists, as related to counseling, remains unclear. However, there is speculation, as supported by the following quote:

Accurate understanding of the specific needs and challenges, especially those based on trainees' gender in counselor education programs, may have been overlooked or under-researched due to the current emphasis on the more apparent racial, ethnic and sexual orientation minorities in this country. While counselors and their educators were busy advocating minorities' rights with passion and eloquence, the profession may have neglected the gender-specific needs of trainees. The field dedicated little effort to recruit more male applicants or to explore the gender imbalance in the field. (Fujikura, 2008, p. 9)

\section{Male Disparity in Counseling Fields}

There has been a growing gender gap in helping professions (BLS, 2011). This is also true for the counseling field. In the 1970s, men accounted for approximately half of professional counselors (BLS, 2011). According to some estimates, currently an estimated $30 \%$ identify as men. The Association for University and College Counseling Center Directors (AUCCCD) reported $26 \%$ of college counseling center professional staff are male (Reetz et al., 2015). In addition, there are approximately two women to every one man in master's counseling programs (Schweiger et al., 2011). Regardless of the source, men are the minority in the counseling profession. 
This is an unfortunate difference in the number of men and women in counseling programs and the professional counseling field. This is a significant issue for counseling programs because ACA (2014) has ethical codes and CACREP (2016) has accreditation standards requiring faculty and students to engage in practices to increase multicultural awareness, which includes gender. Furthermore, recruitment of diverse populations, students and faculty, is a requirement of CACREP accreditation (2016) and ACA (2014). In fact, ACA (2014) and CACREP (2016) “compel counselor educators to encourage individuals of varying backgrounds, including gender, to enter the counseling profession" (Michel et al., 2013, p. 475). According to ACA ethical code F.11.b (2014), counselor educators must demonstrate their commitment to multicultural competence by acknowledging and valuing students' diverse cultures and different abilities. It is apparent a gender-imbalance in counseling programs is an ethical issue and an accreditation concern.

\section{Male Recruitment}

Little is known about what attracts men to the female dominated counseling field and what their experiences are in the profession. In order to learn more Michel et al. (2013) investigated views held by male students and counselor educator professors about male student recruitment and males in the counseling profession. Ten male students were interviewed and qualitative methods were utilized, whereas 217 counselor educators completed an online survey and quantitative methods were used for analysis. Participants included 109 (50.2\%) female, 104 (47.9\%) male, and four (1.8\%) individuals who did not report their gender identification. Many participants were from CACREP accredited counseling programs $(\mathrm{n}=164,75.6 \%)$. 
Through qualitative interviews, the researchers explored recruitment of males into counseling programs. The male graduate students shared what they believed were important for future recruitment of male students. The suggestions included targeted recruitment strategies that highlight male success stories, a welcoming environment, support networks, and faculty committed to male recruitment and retention in counseling programs. However, the Michel et al. (2013) study did not investigate what attracted male students to the counseling field.

Through a researcher developed survey, researchers found that although many counselor educators expressed an interest and a need to take steps to recruit more males into the counseling profession (76.5\%), almost half (47.9\%) stated no efforts were being made in their programs (Michel et al., 2013). Some programs made specific efforts to target male recruitment $(n=27,12.4 \%)$, some were gender neutral $(n=34,15.7 \%)$, but most recruitment strategies depicted numerous diverse cultural characteristics and were not gender specific. One male counselor educator explained it in the following way. $\mathrm{He}$ stated, "Our marketing materials aim at being more inclusive of men, as well as other diverse populations. Any of our recruitment initiatives have been aimed at a wider audience with the hope that men will also take interest" (Michel et al., 2013, p. 479).

Other counselor educators in Michel et al.'s 2013 study were against male specific recruitment efforts, as indicated by one female counselor educator "I think there is a need to be careful about saying we are intentionally going to recruit men. I think we need to recruit individuals to the field regardless of gender, getting the strongest individuals we can....Studying men is important, recruiting men is important, favoring one gender over another is not acceptable" (p. 480). Furthermore, some counselor 
educators questioned the need or value of additional male counselors and male recruitment, as evidenced by the following quotes. A male counselor educator participant stated, "I'm not convinced at this point that [the number of male counselors] is a problem for the profession" (p. 480). In addition, a female counselor educator participant reported, "I don't know that the gender imbalance is an ultimate tragedy" (p. 480). In summary, it appears male students and counselor educators believe increased efforts of male recruitment would be beneficial for increasing male counseling student numbers. However, there is also some disagreement if it should be specific to males. Male counseling students believed male specific recruitment would be beneficial to recruitment strategies. However, many counselor educators thought it should not be gender specific and, instead, recruitment strategies need to be gender neutral.

There were quantitative strengths of Michel et al.'s (2013) research. For example, the Male Recruitment Survey-Counselor Version (MRS-C; Hall et al., 2011) was developed for the study (Michel et al., 2013). It included scaled questions and openended questions. The survey was piloted prior to dissemination to the participants, which resulted in Cronbach's alpha of .89. This is considered a good indicator of a reliable scale (Creswell, 2013).

An important finding from Michel et al.’s (2013) study was learning male students' perspectives on what they believe would lead to increased numbers of males in counseling programs. Although the information is informative, there remains a gap in the literature about male recruitment in counseling programs. Michel et al. did not specifically address what attracts or repels males to and from the counseling profession. 
Counseling programs could benefit from a knowledge base that informs male recruitment strategies.

\section{Need for Male Counselors}

More male counselors are needed in the counseling profession (Evans, 2013; Michel et al., 2013; Paul \& Paul, 2015). The current gender imbalance affects the profession in a number of ways because it "limits the voice of male counseling students, affects client options, and influences the perception of the counseling profession" (Michel et al., 2013, p. 475). Specifically, many counselor educators believe a lack of male counselors limits client options in counseling services $(n=71,32.7 \%)$. One male counselor educator stated, "It's always helpful to have diversity. Males and females, through either nature or nurture, often view the world differently. Each perspective is valuable, particularly in this profession where we are attempting to better understand the human condition" (Michel et al., 2013, p. 478).

Michel et al. (2013) also found some counselor educators believe that if more male counselors were available, male clients might be more receptive to receiving counseling. In essence, "With an increase in the number of male counselors available for clients, we might anticipate an increase in the use and efficacy of treatment services by male clients" (p. 478). Furthermore, Michel et al. suggested male client receptivity could be increased by male counselors' influence on decreasing the stigma of counseling, counselor-client gender match could increase rapport between the client and counselor, and some topics may be easier for male clients to discuss with male counselors.

Paul and Paul (2015) sought to study counselors' beliefs about effective counseling with sexually abused men. The researchers utilized a conjoint analysis to 
provide a rank ordered model of factors counselors believe are necessary for effective treatment of men who were sexually abused. The participants $(n=41)$ were professional counselors and included males $(n=21)$ and females $(n=20)$. Two findings from this study are of particular importance to the current research. First, the counselor gender was found to be the fourth most important factor on beliefs of effectiveness in professional practice when working with men who have a history of sexual abuse. Second, male counselors were preferred to female counselors when male clients addressed sexual abuse (Paul \& Paul, 2015).

The findings from Paul and Paul's (2015) research are significant when the incidence of sexual assault and abuse are considered. Sexual abuse prevalence is approximately one in six males (Briere \& Elliot, 2003; Dube et al., 2005). According to Black et al. (2011), $27.8 \%$ of male rape victims were raped when they were age 10 or younger. In addition, 1 in 71 adult men (1.4\%) reported experiencing rape. Approximately $5.3 \%$ of men stated they experienced sexual violence such as forced penetration of someone, sexual coercion, unwanted sexual contact, or unwanted noncontact sexual experiences in the year before the survey was conducted. Regrettably, these statistics may be low due to underreporting because males are less likely to disclose sexual assault or abuse occurrences (Holmes, Offen, \& Waller, 1997).

The studies presented thus far have clearly indicated the importance of increasing the number of male counselors (Michel et al., 2013; Paul \& Paul, 2015). One significant reason is male clients' receptivity to mental health services might be increased if they were not as limited in client-counselor gender matching options. Furthermore, increasing male client opportunities is vital when the suicide rates of men are taken into 
consideration. The incidence of suicide among men is approximately four times as high as the rate for women (AFSP, 2017). The rate of suicide is highest amongst middle age men. White males accounted for seven of 10 suicides in 2015. The CDC (2016) found that although the suicide rate is rising across demographics, there has been a $43 \%$ increase in completed suicide attempts of men aged 45-64 between 1997 and 2014. In 2015, a total of 12,107 men between the ages of 45 and 64 died from suicide. The number is even more alarming when one compares the number of male suicides to the number of national suicides. In 2015, in the United States, there were 44,193 suicides, of which 33,994 were males (Drapeau \& McIntosh, 2016). White males numbered 30,658 of the 33,994 suicides.

Research has indicated there is a need for more male counselors. It is posited that if men had more options in whom their counselor was, such as gender matching, men might be more receptive to counseling (Michel et al., 2013; Paul \& Paul, 2015). Increasing male clients' options is important because some males prefer to talk to a male about their concerns (Paul \& Paul, 2015; Rochlen \& McKelley, 2009). When this is coupled with the incidence of sexual abuse and assault of males, as well as the alarming rates of male suicide, effort is unmistakably warranted to increase the number of males in the counseling profession.

\section{Male Experience in Counseling Programs and the Profession}

There are varying perceptions of men's experiences in counseling programs and in the counseling profession. Some researchers have found men experience marginalization in female-concentrated graduate programs (Fujikura, 2008; Huntington, 2012; Michel et al., 2013; Willyard, 2011). These studies are challenging to find because 
often the experiences of male and female counseling students or counselors are studied jointly and men and women are not explored separately.

Fujikura's (2008) research purpose was to explore the experiences of both men and women in counseling programs. Unlike many studies on counseling programs, the unique experiences of men were delineated from women students' experiences. A primary finding in this qualitative study was men described negative experiences associated with being the male minority. A primary theme was they believed they stand out as a minority. Therefore, male students believed they were called to be the spokesperson for males during class discussions. These experiences were described as frustrating by the men (Fujikura, 2008). Participants stated when women explained their perspectives, they were accepted as a particular woman's unique experience or view. However, when men described their experiences, the men believed the women generalized the male view as one of all men and hence the feeling of being the spokesperson for the male population.

Fujikura (2008) identified another theme: the views of men were different from women in the program and often led to negative experiences. Participants reported they were treated as "sexist" if views were not aligned with the majority of female classmates (Fujikura, 2008, p. 85) or the men felt dismissed, invalidated, and unimportant. Some males reported female peers and faculty appeared unwilling to hear the views of the male students. This resulted in male counseling students often finding it challenging or not worth the effort to share their opinions. This finding parallels another study where some male counseling students reported that when they did take a risk and share their views, they did not feel "heard" (Michel et al., 2013, p. 477). 
Another theme found amongst the male counseling students was not sharing who they really were, or lacking authenticity or genuineness because they did not feel safe enough to do so (Fujikura, 2008). The male counseling students reported females in the counseling program appeared intolerant of differences in views if it were a male who expressed the dissenting opinion. In addition, the men stated women appeared to be allowed to express different views without critical responses from peers or faculty.

The male students also reported when there was another man in the group, they felt more supported by him, and they might speak up and share more often (Fujikura, 2008). Because there were rarely other men in the classroom, or the men did not speak up when they were present when the male student shared a different view, the men often felt unsupported in taking risks and being a part of discussions (Fujikura, 2008). Instead, men counseling students reported feeling "attacked" by peers and sometimes faculty, if their views were different (Fujikura, 2008, p. 86). As a result of these challenges, male students stated they would not share what they were actually thinking and feeling. In addition, they needed support from faculty in adjusting to the female concentrated learning environment (Fujikura, 2008).

Male counseling students were found to believe the dismissiveness portrayed by female peers and faculty were, in part, due to male counseling students' representation of male privilege in society (Fujikura, 2008). These experiences further led to feelings of isolation and frustration. The following quote is an example of one male student's experience.

So much attention and so much respect will be given to someone that comes from a different cultural background or something, but there is no or very little 
tolerance for us representing ourselves as men. You know, we are expected to become more feminine in order to fit into the environment versus acknowledging us for being men. Yes, just acknowledge the fact that I am a man, I am different, I was cultured very differently by society. I've been brought up differently. (Fujikura, 2008, p. 87)

Another participant stated, "The female quality is that more about changing my maleness into becoming more female, instead of changing the system to recognize and incorporate the differences of my maleness" (Fujikura, 2008, p. 103). Consistent with the statements of male counseling students in Fujikura's (2008) study, counselor educators reported they believe low numbers of men in counseling programs results in male students not feeling safe enough to share their ideas on some topics including male privilege (Michel et al., 2013).

Relatively few men stated they received positive attention as the minority (Fujikura, 2008). However, sometimes participants stated being the minority male had some benefits. Three of the six participants reported some positive outcomes they attributed to being a male. They stated that they felt valued because they were called on when a male perspective was needed. They stated they believed it to be because their male perspectives were different from the female perspective.

Michel et al. (2013) also found some male students reported they felt "privileged status" (p. 477). Some counselor educators have found female peers "shielded and protected" male peers (Michel et al., 2013, p. 477). As a result, these male students may not have been challenged to explore topics in-depth and at the level required of female peers. Moreover, there is evidence, per counselor educator reports, men may be given 
additional credit in the admissions' process, provided more positive feedback, and receive increased assistance from faculty (Michel et al., 2013). Although this reported privilege may initially appear to be a benefit, it could actually lead to male students not receiving the same educational rigor that their female peers receive. This is consistent with research findings that men in female dominated programs and/or careers may experience favoritism or preferential treatment (Simpson, 2004).

Fujikura (2008) found incidents of privilege appeared to primarily take place in professional settings rather than the classroom. For example, some male participants stated they felt more respected at their internship sites and received more power as well. One participant stated he was told of his importance because he is able to provide a male role model to clients, but also because the male counselor view is rare in the profession. According to these findings, it is possible the negative experiences in counseling programs, described by the men in Fujikura's (2008) research, do not carry over into the professional counseling field.

It is unclear if marginalization continues after graduation. The Fujikura (2008) and Michel et al. (2013) studies appear to indicate a positive change in experience, feeling valued and heard, after the man leaves the counseling program. This information could be utilized to inform counseling programs on useful recruitment strategies, as well as creating effective and safe learning environments.

Huntington (2012) explored men's perceptions within counseling programs. The research was specific to male students' views on female clients, peers, and faculty and how those views may affect their actions toward women. Some parallels can be drawn between Fujikura's (2008) study and Huntington's study. However, the focus of Fujikura 
and Huntington's inquiries were quite different in many respects. Nonetheless, both had a purpose to inform the counseling profession.

In Huntington's (2012) qualitative case study, 10 male participants were interviewed to explore their perspectives. First, some male counseling students reported that female faculty appeared reluctant to discuss topics related to gender. In addition, female faculty appeared adversely sensitive to gender or cultural topics when they were discussed by male students (Huntington, 2012). As a result of negative responses from faculty, for example grade reduction and/or admonishment, male counseling students stated they were less likely to share their views and more likely to avoid class discussions (Huntington, 2012). This theme was also found in Fujikura's (2008) study because men were afraid to openly share due to fear of negative evaluations from faculty. In both studies, participants stated they learned to keep their mouths "shut" (Fujikura, 2008; p. 90; Huntington, 2012, p. 93).

Another finding from Huntington's (2012) study was male counseling students were at times confused about relationships with female peers and faculty. Male students expressed concerns about what their peers believed their motives were. In particular, they were uncertain if their female peers believed they were sexually attracted to them and expressed concern on how their actions were interpreted (Huntington, 2012). They also reported they were uncertain how to interpret female actions such as physical touch. Overall, male students were confused and unsure if they could trust female peers and faculty. These findings further demonstrate challenges of being a male minority in a profession with a majority of women. 
There are conflicting views related to the advantages and disadvantages for men counseling students' learning in counseling programs (Fujikura, 2008; Huntington, 2012; Michel et al., 2013). Some faculty reported the gender disparity is advantageous because it helps men understand the communication and relationship qualities of women (Michel et al., 2013). This knowledge is important and will be useful because most male counselors will work with female clients during their careers. However, other research has indicated concern that although there are advantages, there are also drawbacks (Fujikura, 2008; Huntington, 2012; Michel et al., 2013). These include males in counseling programs feeling a lack of respect for their communication and relationship styles, the need to conform to the majority view (female), as well as feeling unsupported and isolated from peers and faculty. These disadvantages might limit learning and portray the message males are not welcome in counseling programs and the counseling field (Fujikura, 2008; Huntington, 2012; Michel et al., 2013).

\section{Summary}

In summary, there are very few males in the counseling profession (Reetz et al., 2015; BLS, 2011; Evans, 2013; Fujikura, 2008; Reetz et al., 2015; Schweiger et al., 2011). This is unfortunate because more male counselors are needed (Evans, 2013; Michel et al., 2013; Paul \& Paul, 2015). Low numbers of male counselors decreases client options. Male clients could benefit from having more choices when it comes to choosing a counselor because it could increase their receptivity to counseling. In addition, male counselors can be central to clients' treatment (Evans, 2013; Paul \& Paul, 2015; Rochlen \& McKelley, 2009). This is an important consideration when coupled with the high number of men who commit suicide in the United States (AFSP, 2017; 
CDC, 2016; Drapeau \& McIntosh, 2016) and the incidence of sexual abuse and assault (Black et al., 2011; Briere \& Elliot, 2003; Dube et al., 2005).

There is contradictory evidence as to the experiences of men in the counseling field. Researchers have found many men experience marginalization in femaleconcentrated graduate programs (Fujikura, 2008; Huntington, 2012; Michel et al., 2013). There is also evidence males may be recipients of privilege or receive benefits in counseling programs and the profession (Fujikura, 2008; Michel et al., 2013). Overall, there are conflicting views and evidence related to the advantages and disadvantages for men counseling students' learning experiences in counseling programs (Fujikura, 2008; Huntington, 2012; Michel et al., 2013).

What is apparent from the review of the literature is there are issues related to males in the counseling profession that need to be addressed by further research. Counseling programs have a number of questions that need answers in order to attract male students and retain them. This research seeks to address these gaps in the literature and clarify contradictory information (Fujikura, 2008; Huntington, 2012; Michel et al., 2013). Counseling programs are compelled to investigate this matter further because it is an ethical responsibility (ACA, 2014) of counselor educators, as well as required accreditation standards (CACREP, 2016) to incorporate diverse populations, including gender, into counseling programs. 
SECTION FOUR

CONTRIBUTION TO PRACTICE 


\section{Dissemination of Practitioner Contribution}

The plan for dissemination of practitioner contribution is to share the qualitative research studies results with counselors, counselor supervisors, and counselor educators. The researcher presents at state, regional, and national conferences annually. The number of conferences at which the researcher will present is dependent on program proposal acceptance.

The possibilities include three state conferences. The first is the Missouri Mental Health Counselors Association (MMHCA). The primary purpose of MMHCA is to “advocate for the interests of Licensed Professional Counselors” (MMHCA, n.d.a, para. 1). The annual conference takes place in the fall in Springfield, Missouri (MMHCA, n.d.b).

The second state conference is American Counseling Association of Missouri (ACAM). The mission of the organization is to "promote the development and support of mental health professionals to ensure high quality counseling care for individuals, couples and families in Missouri" (ACAM, 2016, para. 1). The annual conference takes place in the spring in Lake Ozark, Missouri.

The third state conference is the Missouri School Counseling Association (MSCA) conference. The organization was "founded to help persons interested in school counseling make the most effective use of their skills and talents in services to students, parents, school personnel, and community members" (MSCA, 2016, para. 1). The annual conference takes place in the fall in Lake Ozark, Missouri.

The researcher will also submit a conference proposal to Association of Counselor Education and Supervision (ACES, 2017) and North Central Association of 
Counselor Education and Supervision (NCACES, 2016). ACES is a national organization and a division of the American Counseling Association (ACA). The primary purpose of ACES, in alignment with the purpose of ACA, is to "advance counselor education and supervision in order to improve the provision of counseling services in all settings of society" (ACES, 2017, para. 3). The conference takes place in odd-numbered years. NCACES is a regional division of ACES, has the same primary purpose as ACES, and takes place in even-numbered years. Members in NCACES come from 13 states including Illinois, Indiana, Iowa, Kansas, Michigan, Minnesota, Missouri, Nebraska, North Dakota, Ohio, Oklahoma, South Dakota, and Wisconsin. Both conferences take place in the fall at various cities in the United States and Canada.

All four conferences have professional counselors of varying specialties, as well as counselor educators, in attendance. MMHCA and ACAM tend to have a higher number of practioners in attendance. ACES and NCACES tend to have a higher number of counselor educators and counseling supervisors in attendance. Therefore, the researcher will disseminate the information to a wide variety of counselors. The researcher has presented at all of the above conferences and anticipates a high probability of proposal acceptance.

The researcher will also share the results of the study with her current counseling program colleagues where she is employed. The counseling program consists of two other counselor educators who make program decisions, in conjunction with the researcher, in a collaborative manner. Therefore, it will be useful for the researcher to share the findings with her colleagues in order for the program to make informed decisions about male student recruitment and retention. The researcher will also share 
the information with the department chair and the dean of the college at the university at which she is employed. Both of them are instrumental in supporting and promoting the counseling program. They also have a vested interest in seeing the counseling program grow and meeting the needs of all students. 


\title{
A Qualitative Case Study of Male Students' Experiences in Counseling Programs and Male Professional Counselors' Experiences Post Graduation
}

\author{
Amber F. Lancaster
}




\title{
Statement of the Problem
}

\author{
Problem of Practice
}

- Men are the minority in counseling programs and counseling field (BLS, 2011; Reetz et al., 2015;

Schweiger et al., 2011)

- Many clients need male counselors (Michel et al., 2013; Paul \& Paul, 2015; Rochlen \& McKelley, 2009).

- Sexual concerns \& parenting (Rochlen \& McKelley, 2009), and sexual abuse (Paul \& Paul, 2015)

- Men more likely to seek counseling if more male counselors available (Michel et al., 2013; Paul \& Paul, 2015; Pederson, 2015)

A disproportionally low number of males make up the population of counselors.

This includes men who apply to counseling programs, who are in counseling educational programs, and who are in the counseling profession (Reetz, Bershad, LeViness, \& Whitlock, 2015; Schweiger, Henderson, McCaskill, Clawson, \& Collins, 2011; U.S. Bureau of Labor Statistics [BLS], 2011). There are approximately three women to every one man in mental health fields (BLS, 2011). The Association for University and College Counseling Center Directors (AUCCCD) reported only 26\% of college counseling center professional staff are male (Reetz et al., 2015). In addition, there are approximately two women to every one man in master's counseling programs (Schweiger et al., 2011). This represents an unfortunate significant difference in the number of men and women in counseling programs and professional counseling. 
More males are needed in the helping fields, specifically more male counselors (Paul \& Paul, 2015). This gender disparity "limits the voice of male counseling students, affects client options, and influences the perception of the counseling profession" (Michel, Hall, Hays, \& Runyan, 2013, p. 475) in a variety of ways. First, male counselors are important for some clients' treatment. A lack of male counselors limits client opportunities (Michel et al., 2013; Paul \& Paul, 2015). This may be particularly vital for men seeking help for life role balance, sexual concerns, and parenting issues (Rochlen \& McKelley, 2009). In addition, evidence has indicated males who were sexually abused tend to prefer male counselors to discuss sexual abuse (Paul \& Paul, 2015). This is an important consideration since the incidence of sexual abuse for males is approximately one in six (Briere \& Elliot, 2003; Dube, et al., 2005).

It is posited men may be more open to counseling if there were more male counselors available (Michel et al., 2013; Paul \& Paul, 2015; Pederson, 2015). This is especially important considering the suicide rates of men, which is approximately four times as high as the suicide rate for women in the United States (American Foundation for Suicide Prevention [AFSP], 2017). The rate of suicide is highest amongst middle age men. In 2015, White males accounted for seven of 10 suicides. According to the Center for Disease Control and Prevention (CDC, 2016), although the suicide rate is consistently rising across many demographics, there was a staggering $43 \%$ increase in suicide deaths of men aged 45-64 between 1997 and 2014. In 2015, a total of 12,107 men between the ages of 45 and 64 died from suicide. There were 44,193 suicides in the United States, 33,994 of which were males (Drapeau \& McIntosh, 2016). Of the 33,994 male suicides, 
White males numbered 30,658 suicides. Men need to have their mental health needs met in order to decrease the number of completed male suicides in the United States.

\section{Existing Gap in the Literature}

- What attracts men to counseling programs?

- Findings are limited to steps some male counseling students believe should be taken to increase effectiveness of male recruitment and student retention (Michel et al., 2013) 


\section{Existing Gap in the Literature}

- It is unclear what men experience in counseling programs and the profession

- Some men's experiences were marginalization (Fujikura, 2008; Huntington, 2012; Michel et al., 2013)

- Others were privileged (Michel et al., 2013)

- Some experienced marginalization and privilege (Michel et al., 2013)

It is evident men are needed in the counseling profession. Therefore, it is

necessary to recruit them. Unfortunately, there is very little research on male recruitment in the counseling field. Michel et al. (2013) investigated views held by male students and counselor educators as related to male student recruitment and males in the counseling profession. Ten male students were interviewed and qualitative methods were utilized, whereas 217 counselor educators completed an online survey and quantitative methods were used for analysis.

The male graduate students shared ideas for male recruitment of male students, which included targeted recruitment strategies that highlight male success stories, a welcoming environment, support networks, and faculty committed to male recruitment and retention in counseling programs. Michel et al. (2013) did not investigate what attracted male students to the counseling field. 
Researchers found that although many counselor educators expressed an interest and a need to recruit more males into the counseling profession, almost half stated no efforts were being made in their programs (Michel et al., 2013). Some programs made specific efforts to target male recruitment $(\mathrm{n}=27,12.4 \%)$, some were gender neutral $(\mathrm{n}=$ $34,15.7 \%$ ), but most recruitment strategies depicted numerous diverse cultural characteristics and were not gender specific.

An important finding from Michel et al. (2013) was learning male students' perspectives on male recruitment. Michel et al. did not specifically address what attracts males to the counseling profession, and the focus appeared to be counselor educators' views on recruitment. Therefore, there remains a gap in the literature on male recruitment in counseling programs. A greater understanding of what attracts men to the counseling profession is an important step to increase the number of male applicants and students in counseling programs. In addition, counseling programs could benefit from a knowledge base that informs male recruitment strategies, which affects financial gains and viability of counseling programs. 


\section{Purpose of the Study}

- Increase understanding and knowledge of men's decision to apply to counseling programs, despite the counseling profession being female dominated (BLS, 2011; Reetz et al., 2015; Schweiger et al., 2011)

The purpose of this qualitative case study was to increase understanding of males'

decisions to apply to counseling programs; to increase understanding of the shared experiences in recruitment of males in the female-centric counseling profession (Reetz, Bershad, LeViness, \& Whitlock, 2015; Schweiger, Henderson, McCaskill, Clawson, \& Collins, 2011; U.S. Bureau of Labor Statistics [BLS], 2011). The research questions guiding this inquiry are as follows: What attracts men to the counseling field? What role did overt or covert recruitment strategies play in choosing a counseling program? and, What recruitment strategies could be beneficial to attract men? 


\section{Research Questions}

- What attracts men to the counseling field?

- What role did overt or covert recruitment strategies play in choosing a counseling program?

- What recruitment strategies could be beneficial to attract men to the counseling field?

- What is the experience of men in counseling programs?

- What is the experience of male professional counselors? 


\section{Conceptual/Theoretical Framework}

- Social Cognitive Career Theory (SCCT) (Lent, Brown, \& Hackett, 1994)

- Foundation - Bandura's Social Cognitive Theory (1986)

- Level 1: Cognitive-personal variable - self-efficacy, outcome expectations, and personal goals

- If one has self-efficacy and believes the outcome will be positive, then interest in a particular career choice is developed and the goal is pursued

- Self-efficacy, outcome expectations, and goals lead to individuals deciding to exercise personal control, or agentic capacity, over their career choice (Lent et al., 1994)

The lens through which this study was conducted is the social cognitive career

theory (SCCT) (Lent, Brown, \& Hackett, 1994). Bandura's social cognitive theory

(1986) is the foundation for SCCT. Both theories stress the interaction among cognitive-

person variables. These include self-efficacy, outcome expectations, and goals (Bandura,

1986; Lent et al., 1994). Furthermore, SCCT examines how these factors interact with

other personal characteristics such as gender, ethnicity, and culture, as well as

environmental contexts such as social support, barriers, and educational experiences. The theory proposes it is the interactional dynamic of these components that affect career pursuits and career selection.

SCCT divides the theory (Bandura, 1986) into complementary levels (Lent et al.,

1994, 2000). The first level is the cognitive-personal variable, which includes self-

efficacy and outcome expectations. Self-efficacy is the belief one has the ability to 
accomplish a goal. Outcome expectations reflect what individuals believe will be the result of their efforts (e.g., If I become a counselor, then ...). Finally, there are personal goals for educational or occupational pursuits. If individuals have self-efficacy and believe their efforts will produce a positive outcome, then interest in a particular career choice is developed and the goal is pursued.

Self-efficacy, outcome expectations, and personal goals allow individuals to exercise personal control, or agentic capacity, over their career choices (Lent et al., 1994). Nonetheless, there are some factors individuals do not have control of in their educational and career endeavors. This is because educational and career supports take place in social environments where others are involved in the process (Lent \& Brown, 2013). When others are included in the process, there is likelihood they, too, may exert agentic capacity and limit the agentic capacity of others. For example, a perspective student may have self-efficacy, positive outcome expectations, and personal goals that lead to the student pursuing the counseling field. However, the student's parents do not believe counseling is a suitable educational goal. Therefore, they do not provide financial support. The parents have exercised their agentic capacity, which has led to restricted agency of the perspective student. 


\section{Conceptual/Theoretical Framework}

- Level 2: physical attributes (e.g. gender and race) and characteristics of the environment (e.g. educational quality and financial status)

- Environmental factors: Objective \& Perceived

- E.g. Objective environmental factor - finances available during college. How it is perceived, sufficient or insufficient, may determine if agentic capacity exercised and if goal is pursued (Lent et al., 2000)

The second complementary level of the theory is composed of components that also influence career choice (Lent et al., 1994). These are physical attributes such as gender and race, and characteristics of the environment such as educational quality and financial status. The influence of second level factors on career choice are categorized as objective and perceived environmental factors (Lent et al., 2000). Objective environmental factors, such as financial resources and quality of education, tend to have a great influence on educational and career pursuits. However, how the person perceives these objective factors also affects the educational and career decisions of the individual. For example, monetary availability during one's education is an objective environmental factor. However, how the individual perceives it as sufficient or insufficient, may in turn 
determine if personal power, or agentic capacity, is exercised and if the educational or career goal is pursued (Lent et al., 2000).

\section{Conceptual/Theoretical Framework}

- Environmental Factors:

- Distal environmental factors - e.g. career role models, financial and emotional support, and "cultural and gender role socialization" (Lent et al., 1994, p. 107)

- Influence the development of self-efficacy and outcome expectations (Lent et al., 2000)

- Proximal factors - e.g. discriminatory hiring practices and adequate or inadequate networking contacts

- Perception affects if agentic capacity exercised and if goal is pursued (Lent et al., 2000)

Environmental influences are also further categorized into distal and proximal influences. Distal environmental factors, such as career role models, financial and emotional support, "cultural and gender role socialization," affect the learning experience of the individual (Lent et al., 1994, p. 107) and, therefore, influence the development of self-efficacy and outcome expectations (Lent et al., 2000). Proximal factors are more important during active goal pursuits of education or career. Examples include discriminatory hiring practices and adequate or inadequate networking contacts. Again, how the individual perceives these factors affects if agentic capacity is exercised and if the educational or career goal is pursued (Lent et al., 2000). 
If the individual sees environmental factors as positive with few barriers, then career interests are translated into pursuit of the goal (Lent et al., 1994). However, if the person perceives the goal to have too many barriers or the barriers are insurmountable, then despite an interest in a particular career, the education or career goal will not be pursued. Barriers include intrapersonal or environmental situations or characteristics that make educational and career goal attainment challenging, if not impossible. For example, regardless of interest, if a student does not feel valued or respected in an educational program, the educational goal may not be pursued.

The cognitive-personal and environmental variable interactions are significant in three phases of the career development process (Lent et al., 1994). The first phase is when the individual is in the process of forming and eventually developing educational and career interests. The second phase is when the person reflects upon and finally makes the decision to pursue a particular educational degree or career. The third phase takes place when the person is persistent in goal attainment of a specific educational program or career (Lent et al., 1994). Furthermore, the impact of barriers on educational and career goals is influenced by not only the number and type of barriers, but also by the phase in which they are encountered (Lent et al, 2000). Some students had barriers late in the third phase but decided there was no way they were going to quit at that point. 


\section{Design of the Study}

- Case study - highly bounded system characteristic of qualitative case studies (Creswell, 2013, 2014, 2016; Merriam \& Tisdell, 2016; Seidman, 2013)

In order to study the experiences of male counselors in a feminized profession, a qualitative case study was determined to be an appropriate methodology. Participants belonged to a narrowly defined system of males in master's and doctoral counseling programs and male professional counselors. Specifically, this highly bounded system is characteristic of qualitative case studies (Creswell, 2013, 2014, 2016; Merriam \& Tisdell, 2016; Seidman, 2013). These methods included individual interviews, observations, and artifact/document analysis. Data analysis was begun as soon as data collection started. The researcher produced an analytical memo about findings or possible categories, which was supported by the data collected. This method is endorsed by qualitative research experts (Creswell, 2013, 2014, 2016; Merriam \& Tisdell, 2016; Seidman, 2013). Per the 
recommended qualitative research structure, this process continued until completion of the research study (Merriam \& Tisdell, 2016).

\section{Setting}

- Council for Accreditation of Counseling and Related Educational Programs (CACREP) accredited counseling programs

- Largest accrediting body to regulate counseling programs (Urofsky, Bobby, \& Ritchie, 2013)

The setting for the study was CACREP accredited counseling programs.

Accreditation is a "quality assurance and enhancement mechanism" (Urofsky, 2013, p. 6). CACREP is the largest accrediting body to regulate counseling programs. Furthermore, CACREP promotes the development and growth of the counseling field (Urofsky, Bobby, \& Ritchie, 2013). This is accomplished, in part, through the development of standards to incorporate the needs of a diverse society and the application of these standards in the preparation of students in counseling programs. This promotes the development of counseling students who are prepared to provide ethical, culturally competent services to clients (CACREP, 2017). 


\section{Participants}

- Non-probability sampling - ensure participants are representative of the population being studied (Creswell, 2013, 2014, 2016; Merriam \& Tisdell, 2016; Seidman, 2013)

- Purposeful sampling (Merriam \& Tisdell, 2016)

- Snowball sampling after initial contact

- Male students in CACREP counseling programs

- Male graduates of CACREP counseling programs

- School counseling, clinical mental counseling programs, Counselor Education \& Supervision students or graduates

- Nation wide

The participants of this study were 23 men who were students currently in

CACREP counseling programs, master's or doctoral, and graduates of CACREP accredited counseling programs, master's or doctoral level, who specialized in school counseling, clinical mental health counseling, and or counselor education and supervision. As a result of the uniformity of the CACREP accreditation process, and the consistent curriculum requirements across counseling programs, only students currently in CACREP programs and those who graduated from CACREP accredited programs were selected for this study. 


\section{Sampling}

- Snowball sampling

- Face to face interviews

- Signed informed consent 


\section{Sampling}

- Counselor Educator Supervisor Network (CESNET) Listserv

- Approximately 3400 members

- Post with invitation - emailed informed consent

- Phone interviews

- Snowball sampling occurred

Counseling professionals who were graduates of counseling programs were recruited from the Counselor Educators and Supervisors Network Listserv (CESNET-L), which is hosted by Dr. Marty Jencius at Kent State University (2017). 


\section{Data Collection Tools}

- Individual interviews

- Observations

- Artifact/document analysis

There were 23 interviews. Observations took place in three counseling programs. The researcher looked at bulletin boards, gathered brochures, observed faculty and staff, and viewed into classrooms. Artifacts were gathered from three counseling programs and data collected from CACREP counseling program websites. 


\section{Individual Interviews}

- Conversational style exploration of participants' personal stories (Merriam, 2009; Seidman, 2013)

- Questions organized to "yield descriptive data" (Merriam, 2009, p. 99)

- Semi-structured - formulated additional questions to follow-up (Merriam, 2009; Seidman, 2013)

- Individual - via phone or in person

- 30-60 minutes - time dependent on participants' availability and amount of time needed to answer questions

Interviews were conducted in a conversational style exploration of participants'

personal stories (Merriam, 2009; Seidman, 2013). The questions were organized to "yield descriptive data" (Merriam, 2009, p. 99) and were semi-structured. In other words, questions were presented, but the researcher sometimes formulated additional questions in the interview to follow-up with questions not thoroughly answered by the participant (Merriam, 2009; Seidman, 2013). 


\section{Observations}

- Three CACREP counseling programs

- Complete observer role at two sites - took notes, looked into a classroom, viewed setting

- Participant observer at one site - talked to one staff member and faculty, viewed setting (Merriam \& Tisdell, 2016)

Observations. Observation is a common form of data collection in qualitative studies (Merriam \& Tisdell, 2016). Observations take place in the natural setting so that researchers are able to gain a direct account of a phenomena of interest. In order to study the experiences of male students in CACREP counseling programs, observation was utilized as a qualitative research tool. Observations allow researchers to gain a firsthand perspective. Therefore, the researcher drove to and visited three different CACREP counseling programs to collect recruitment material and to observe the environment.

Researcher's role in the setting. The researcher's role in the setting was a complete observer at two of the universities (Merriam \& Tisdell, 2016). The researcher was not completely out of the students' or faculty's sight because she was within their view. However, they were not aware the researcher was observing. She walked through 
the facility, looked at wall hangings and viewed into classrooms. Another characteristic of being a complete observer is the researcher does not talk to anyone observed, which she did not. She only took notes, watched, and listened.

Although the goal of the researcher was that of a complete observer, her role in one of the settings became that of observer as participant (Merriam \& Tisdell, 2016). The researcher had difficulty locating the exact location of the counseling program and was assisted in located it. This led to staff and faculty engaging with the researcher and for the researcher's actions to be interpreted as a prospective student. The researcher did not feel comfortable because this felt dishonest and misleading. Therefore, the researcher disclosed her intentions.

\section{Artifacts/documents}

- "Mining data from documents" (Merriam \& Tisdell, 2016, p. 162)

- Allows for confirmation of common themes from other sources

- Recruitment material - brochures and counseling program websites from counseling programs 
Artifacts/documents. In qualitative studies, a useful and easy form of data collection is "mining data from documents" (Merriam \& Tisdell, 2016, p. 162). This form of data collection allows for confirmation of common themes from other sources of information. Various documents were utilized to study the experiences of men in the counseling field. These included recruitment material from CACREP counseling programs. Fliers and pamphlets were collected from three CACREP accredited programs. In addition, the researcher accessed the websites of CACREP counseling programs through the CACREP website. These websites were scanned for recruitment material and were included in the data collection and analysis process.

\section{Institutional Review Board (IRB) and ethics}

- IRB approval prior to data collection

- Informed consent for individual interviews

- Researcher did not interview current students, or graduates of the program she used to instruct or advise, due to potential harmful dual relationships (ACA, 2014)

- Pseudonyms assigned 
There were ethical research considerations for the research study. First, it was necessary to gain IRB consent prior to collecting data according to ACA (2014); American Educational Research Association ethical standards ([AERA], 2011); American Psychological Association ([APA], 2009); and CACREP (2016). In addition, participants were provided a copy of the informed consent prior to individual interviews. The researcher was able to guarantee confidentiality of information in individual interviews because there was only the researcher and the participant present (Krueger \& Casey, 2009) (see Appendix C). In addition, pseudonyms were assigned to ensure confidentiality of all participants.

\section{Data Analysis}

- Conventional structure employed in qualitative data analysis (Creswell, 2013, 2014, 2016; Merriam \& Tisdell, 2016; Seidman, 2013)

- Begun data analysis with data collection

- Interviews transcribed

- Open coding - produced numerous categories or themes, or repeating patterns

- Axial coding - reduced the number of categories

- Constant comparative method - cyclical process of moving between open and axial coding - as categories emerge, determined if they fit within larger ones 


\section{Reliability}

- Utilized an approach "consistent across different researchers and different projects" (Creswell, 2014, p. 201)

- Maintained chain of evidence (Yin, 2014)

- Document research steps so others can see the procedures

- External observer - made all evidence available to dissertation chair

- Trace evidence backward and forward, from research questions to conclusions and vice versa

The constant comparative method was utilized in data analysis to increase

qualitative reliability (Creswell, 2014). In this process, the researcher checked data against current developed codes. This process keeps the definition of codes consistent and makes "sure that there is not a drift in the definition of codes, a shift in the meaning of the codes during the process of coding" (Creswell, 2014, p. 203). In addition, an analytical memo was utilized to keep notes about the codes and how the codes are defined (Merriam \& Tisdell, 2016). 


\section{Reliability}

- Constant comparative method (Creswell, 2014) checking data against current developed codes

- keeps the definition of codes consistent

- Analytical memo - keep notes about codes and how codes are defined (Merriam \& Tisdell, 2016)

- Reread transcripts to check for accuracy in transcription(Creswell, 2014)

The constant comparative method was utilized in data analysis to increase qualitative reliability (Creswell, 2014). In this process, the researcher checked data against current developed codes. This process keeps the definition of codes consistent and makes "sure that there is not a drift in the definition of codes, a shift in the meaning of the codes during the process of coding" (Creswell, 2014, p. 203). In addition, an analytical memo was utilized to keep notes about the codes and how the codes are defined (Merriam \& Tisdell, 2016).

As a final strategy to increase qualitative reliability, the researcher reread transcripts to check for accuracy in the transcription process (Creswell, 2014). This straightforward step helped the researcher find obvious mistakes in the transcript. 
Avoiding errors is important since they could affect the coding process and, ultimately, the findings.

\section{Validity}

- Qualitative validity - measures taken to "ensure the accuracy of the findings" (Creswell, 2014, p. 201)

- Triangulation of data - synthesis of data gathered from interviews, observations, and artifacts and documents (Merriam \& Tisdell, 2016; Yin, 2014)

- Member checks - ask participants to read interview transcripts for accuracy

Triangulation of data also took place through synthesis of data gathered from

multiple sources including interviews, observations, artifacts, and documents (Merriam \& Tisdell, 2016; Yin, 2014). The more forms of evidence a case study has, the higher the quality of the study (Yin, 2014). In the current research, the researcher had three different types of evidence, which augments construct validity and "increases the overall quality of the case study" (Yin, 2014, p. 127).

The researcher utilized member checks to increase validity of the data and therefore, the trustworthiness of the findings (Creswell, 2013, 2014, 2016; Merriam \& Tisdell, 2016; Seidman, 2013). This took place by asking the participants to read 
interview transcripts for accuracy. This feedback would have been incorporated into the final transcripts and the data would have been analyzed again. However, the participants did not request the researcher to make any changes to the transcripts.

\section{Validity}

- Use of rich, thick descriptions in the findings

- Disclosed negative or discrepant findings provides realistic account of participants

- Disclosed possible researcher biases

The researcher used rich, thick descriptions in the findings. According to Creswell (2014), when the researcher provides details, "the results become more realistic and richer" (p. 202). Readers may be able to identify more with the material when the researcher conveys findings in this way. This also increases qualitative validity (Creswell, 2014).

Another method the researcher used to increase validity was negative or discrepant findings were disclosed. Creswell (2014) recommended qualitative researchers present evidence that is supportive of a theme, as well as information that is 
not. This method provides a more realistic account of participants and increased the validity of the qualitative findings.

Another step the researcher took to increase qualitative validity was disclosure of possible biases. By being authentic about possible biases, readers may see the researcher as authentic and credible (Creswell, 2014). The researcher's interpretations of the findings can be influenced by a number of factors. Therefore, it is important readers have this information available to them. These factors are detailed below in the next section.

\section{Limitations}

- Focus on males in CACREP counseling programs and male professional counselors who graduated from CACREP counseling programs

- Narrow focus decreases transferability of findings (Creswell, 2013)

- May not transfer to non-CACREP programs

- May not transfer to females

- Possible biases as a female, graduate of a CACREP accredited counseling program, and counselor educator in a CACREP accredited counseling program

- Biases may be rooted in the design of the study and interpretation of findings

Limitations of this study are related to the nature of the research design. First, the researcher has chosen to focus on males in CACREP accredited counseling programs and male professional counselors who graduated from CACREP accredited counseling programs. This narrow focus, which is characteristic of case studies, decreases the 
transferability of the findings (Creswell, 2013). More specifically, the findings of this study may not be transferred to other non-CACREP accredited counseling programs. In addition, because the research is specific to males, the findings may not be transferable to females in counseling programs, CACREP or non-CACREP accredited.

Finally, the author is a female counselor educator in a CACREP accredited master's level program. It is possible the researcher holds biases related to being a female, graduating from a CACREP accredited counseling program, as well as being a counselor educator in a CACREP accredited counseling program. These biases may be rooted in the design of the study, as well as the interpretation of the findings.

\section{Assumptions}

- CACREP accredited counseling programs have consistent curriculum requirements

- Assumption: Participants have consistent educational backgrounds

- Variation in educational backgrounds

- Completed varying graduate credit hours

- Graduated with different number of graduate credit hours

- CACREP has steadily increased the number of required hours for degree completion (CACREP, 2017)

CACREP accredited counseling programs were chosen owing to consistent curriculum requirements. Therefore, an assumption of the researcher was the participants 
of the study would have consistent educational backgrounds. However, the participants' educational backgrounds varied for a few different reasons. First, although the participants were current students or graduated from a counseling CACREP accredited program, they completed a wide variety of undergraduate degrees since master's counseling programs do not require any specific undergraduate degree. In addition, the students who were currently enrolled in counseling programs had completed varying numbers of graduate credit hours in their counseling. Third, participants who had graduated with different graduate credit hours because CACREP has steadily increased the number of required hours for degree completion over the years (CACREP, 2017). Currently, school counseling specialization requires 48 graduate credit hours and clinical mental health requires 60 graduate credit hours. Therefore, depending upon when the participant graduated, the total number of educational graduate hours accrued varied. 


\section{Design Controls}

- Purposeful sampling

-identify as men in CACREP counseling programs

- graduates of CACREP counseling programs

- Semi-structured interview protocol

-provides design control without restricting participants 


\section{Design Controls}

- Reliability-

- chain of evidence

- external observer - dissertation chair (Yin, 2014)

- constant comparative method of data analysis (Creswell, 2014)

- analytical memo (Merriam \& Tisdell, 2016)

- check the transcripts for accuracy (Creswell, 2014)

Specific steps the researcher utilized to increase reliability included a chain of

evidence and an external observer, who is the dissertation chair (Yin, 2014). A constant comparative method of data analysis (Creswell, 2014) and an analytical memo are additional tools the researcher used to increase reliability (Merriam \& Tisdell, 2016). In addition, the researcher checked the transcripts for accuracy (Creswell, 2014). 


\section{Design Controls}

- Validity -

- member checks (Creswell, 2016; Merriam \& Tisdell, 2016; Seidman, 2013)

- triangulation of the data

- use of rich, thick description (Merriam \& Tisdell, 2016; Yin, 2014)

- present evidence that is both supportive and nonsupportive

- disclosed possible biases

The researcher utilized member checks by asking participants to check the transcripts for accuracy (Creswell, 2016; Merriam \& Tisdell, 2016; Seidman, 2013). Triangulation of the data was also important in design control, as well as the use of rich, thick description (Merriam \& Tisdell, 2016; Yin, 2014). As recommended by Creswell (2014), the researcher presented evidence that was both supportive of the themes and information that was not. The researcher has already taken a safeguard to increase validity by disclosing in Limitations her possible biases. 


\section{Significance of the Study}

- Increase understanding of what attracts men to counseling programs - aid in effective recruitment strategies

- Increase understanding of male counselors' experiences in counseling programs and the counseling field - aid in recruitment and retention

- Will inform the institution where the researcher is employed and larger counseling field

- Contribute to the existing literature base

- Ethical responsibility (ACA, 2014) of counselor educators and an accreditation standard (CACREP, 2016) for counseling programs to recruit diverse populations, including gender

This study will make significant contributions to educational leaders, counseling programs, and to the existing literature. This study will contribute to the practice of educational leaders by increasing counselor educators' understanding of what attracts men to counseling programs. Furthermore, this information can aid counseling programs in utilizing effective recruitment strategies. This is an important step to increase the number of male applicants and students in counseling programs. 


\section{Significance of the Study}

- Will inform the institution where the researcher is employed and larger counseling field

- Contribute to the existing literature base

- Ethical responsibility (ACA, 2014) of counselor educators and an accreditation standards (CACREP, 2016) for counseling programs to recruit diverse populations, including gender

The study will contribute to the existing literature base. Currently, there is a lack

of research on male recruitment, as well as male experiences in counseling programs and the profession.

In addition, it is an ethical responsibility (ACA, 2014) of counselor educators, as well as a required accreditation standard (CACREP, 2016), for counseling programs to recruit diverse populations, including gender. Overall, there is a paucity of research on male counseling applicants, students, and counselors. Currently, the male voice is not adequately represented in counseling programs and counselor education and supervision research. This study seeks to rectify this situation. 


\section{Findings}

- Research Question One

-What attracts men to the counseling field?

All of the participants discussed their inspiration to pursue an education and career in counseling. Although participants' motivation to enter the counseling field was not the same, each was inspired in some way to pursue counseling. The desire to help others was a general theme that emerged. At first, it seemed that all of the themes related to what attracts men to the field could fall under this theme. However, many of the participants had specific catalysts that led to their desire to help others. These included a calling, personal or family experience, and role models. 


\section{Research Question One}

- Inspired in some way to pursue counseling

- Desire to help others was a general theme

- Many of the participants had specific catalysts that led to their desire to help others

- A calling, personal or family experience, and role models. 


\section{Help others}

A primary reason men were attracted to counseling was the desire to impact and help others

- Quincy wanted to help people and he wanted to do "altruistic work."

- Rusty said, "I knew from an early age that I held a lot of people's confidences and at the time didn't know what to do with that. So, I had a want to be in the helping profession."

- Mac stated, "I decided that I would do something selfless and rewarding and noble."

- Neal said, "I wanted to help people in some kind of meaningful way."

A primary reason men were attracted to counseling was the desire to impact and help others. These participants did not emphasize other factors that influenced their attraction to the counseling field. 


\section{A calling}

- A calling or called to serve

- Spiritual or religious in nature

- Led to desire to help and support individuals

- Calling led to pursuit of the counseling profession

- demonstrative of social-cognitive factors (Lent et al., 1994, 2000)

Some of the participants described their attraction to the counseling field as a calling or called to serve, which was spiritual or religious in nature. Their calling led them to want to help and support individuals. Due to their calling, these participants had self-efficacy and pursued the counseling profession, which is demonstrative of socialcognitive factors (Lent et al., 1994, 2000). 


\section{Personal or family experience}

- Attracted due to their life experiences with substance abuse and mental health issues

- either their own experience or someone they knew

- Affected by life experience - desire to use their experiences to help others who were going through similar circumstances.

- Life challenges manifested confidence in ability to help others

Some men were attracted to the counseling field due to their life experiences with substance abuse and mental health issues, either their own experience or someone they knew. They were affected by their life experience and they wanted to use their experiences to help others who were going through similar circumstances. Despite how challenging some of these life occurrences had been, it was these experiences that manifested confidence in their ability to help others. Therefore, these participants pursued the educational goal of the counseling field. 


\section{Role models}

- Attraction due to role models

- Books, mentors, and counseling experience

- Environmental influences, such as career role models affect goal pursuit (Lent et al., 1994)

- Influence the development of self-efficacy and outcome expectations (Lent et al., 2000)

Some of the participants' attraction to the counseling field was due to role models who came from books, mentors, and counseling experience. Environmental influences, such as career role models affect goal pursuit (Lent et al., 1994) and, therefore, influence the development of self-efficacy and outcome expectations (Lent et al., 2000). Role models were clearly an important factor in some men's attraction to the counseling field. 


\section{Findings}

- Research question one, sub question one

- What role did overt or covert recruitment strategies play in choosing a counseling program? 


\section{Research Question One Sub Question One}

- Majority did not notice any type of overt or covert strategies

- Many did not see anything that was "welcoming"

- Some men shared that they didn't feel welcomed, but they did not feel unwelcomed - recruitment strategies neutral

- Importance of seeing men on the counseling program's website

- Significance of male faculty in their interviews - important factor in the participants' initiation of the career development process; the process of forming and eventually developing educational and career interests (Lent et al., 1994)

The majority of the participants stated they did not notice any type of overt or covert strategies that were useful in the recruitment of males. Many participants did not see anything that was "welcoming" toward men. Some men shared that they did not feel welcomed, but they also did not feel unwelcomed. Instead, these participants thought the recruitment strategies were neutral. Some participants discussed the importance of seeing men on the counseling program's website. Other participants discussed the significance of male faculty in their interviews. Regardless of where the participants saw the men associated with the counseling field, they were an important factor in the participants' initiation of the career development process; the process of forming and eventually developing educational and career interests (Lent et al., 1994). 


\section{Findings}

- Research question one sub question two

-What recruitment strategies could be beneficial to attract men to the counseling field? 


\section{Research Question Two Sub Question}

- Agreement male recruitment is needed to increase prospective males

- Participants' suggestions for male recruitment

- Men are needed

- Highly marketable

- Visibility of men on program websites, brochures, and programs

- Increase awareness of the counseling field

- Change recruitment

- Small number of participants who were not sure how to recruit more males

Participants shared ideas on recruitment of males into the counseling profession.

All participants agreed that male recruitment is needed in order to increase the number of males attracted to counseling programs and the profession. Most participants had ideas for male recruitment. Participants'suggestions for male recruitment included informing perspective students they are needed and highly marketable; visibility of men on program websites, brochures, and programs; and increase awareness of the counseling field. Some participants believed recruitment techniques might need to be changed in order to reach more men. There were a small number of participants who were not sure how to recruit more males.

Each of these recruitment strategies addresses integral pieces of SCCT (Lent, et al., 1994). The suggested recruitment strategies portrays the message that the counseling 
profession is a viable option for males. These recruitment methods likely promote selfefficacy in counseling; the belief males can and will be effective in pursuit of a counseling profession.

\section{Male counselors are needed}

- Men need to know they are needed

- Male perspectives are needed - different viewpoint

- Clients need and sometimes prefer male counselors

- Male counselors can be useful to some male and female clients, depending on the presenting issue.

Many of the participants stated that if men knew they were needed, counseling programs would likely recruit more males. The participants indicated male perspectives are needed because they bring another viewpoint that is important in counseling programs as well as the profession. Participants also shared male counselors are needed because clients need and sometimes prefer male counselors. Participants said male counselors can be useful to some male and female clients, depending on the presenting issue. 


\section{Highly marketable}

- Highly marketable as a male minority in the counseling profession

- Inform prospective male students how marketable they are

Most participants shared that they are highly marketable as a male minority in the counseling profession. Participants believed it could be beneficial to inform prospective male students how marketable they are. 


\section{Male presence on websites/brochures, and programs}

- Visual of males on websites, brochures, and in programs

- Male presence needed (peers and faculty)

- Instrumental in feelings of connection, commonality, and someone they could relate

- Significant factor in recruitment

Some of the participants thought having a visual of males on websites, brochures, and in programs could be useful in recruitment. They thought more male presence would recruit more male students. Participants stated that male peers were instrumental in feelings of connection, commonality, and someone they could relate. Participants shared that seeing and having male faculty was important for the same reasons. This was a significant factor in their recruitment, and could be in the recruitment of future male students. 


\section{Increased awareness about the counseling field}

- Increase awareness about the counseling field

- Increase public awareness

- Recruit in undergraduate programs

- educate about counseling programs to decrease stigma

- Increase viability of counseling as an option

Some participants shared the belief that in order to recruit men, there is a need to increase awareness about the counseling field. Participants said that many people do not understand the differences between the helping professions. In order to recruit more men, participants believed it is important to increase public awareness. Participants also suggested reaching out to undergraduate programs to educate about counseling programs in order to help decrease the stigma associated with counseling profession. 


\section{Need to recruit differently}

- Use different terminology

- Lower stigma

- Increase viability

Some participants believed men need to be recruited differently. These participants believed using different terminology could help to reach and recruit more men, and lower the stigma associated with counseling. 


\section{Not sure how to recruit}

- Not sure how to recruit men into counseling programs and the profession

- Men need to be recruited, uncertain how

- Lack of males larger societal issue

- Recruitment will most likely not address the problem

Some of the participants were not sure how to recruit men into counseling programs and the profession. These participants believed more men need to be recruited, but did not have ideas on how to recruit. These participants expressed the lack of males as a larger issue, and recruitment will most likely not address the problem. 


\section{Findings}

- Research question two

- What is the experience of men in counseling programs? 


\section{Research Question Two}

- Experiences varied with peers and faculty

- Some benefits and privilege - acceptance into counseling programs, obtaining internships easily, asked for perspectives and receiving attention, and behaviors interpreted more positively than female peers' behaviors

- Some challenges - feelings of being lonely or isolated, feelings of invalidation and/or discrimination, male stereotypes, male spokesperson, and challenging topics

Participants' experiences varied with peers and faculty. Some experienced benefits due to being a male minority, and some experienced challenges. Benefits included acceptance into counseling programs, obtaining internships easily, asked for perspectives and receiving attention, and behaviors interpreted more positively than female peers' behaviors. Participants also experienced challenges, which included feelings of being lonely or isolated, feelings of invalidation and/or discrimination, male stereotypes, male spokesperson, and challenging topics. 


\section{Female peers}

- Many were positive

- Purposeful in being equitable with female peers - acknowledged privilege did not use it as leverage

- Varied - determined by the personality of the peer

- Challenging

Female peers. Experiences with female peers varied. Many were positive. Some participants were purposeful in being equitable with female peers; they acknowledged their privilege and tried to not use it as leverage. Many said their relationships with female peers was determined by the personality of the peer. Some participants said their relationships with female peers were challenging. 


\section{Male peers}

- Limited due to low numbers

- Positive - sense of comradery

- Challenging due to communication, competition, or insecurity

Male peers. Male peer interactions were limited due to low numbers. They varied: Some were positive and there was a sense of comradery; some were challenging due to communication, competition, or insecurity. 


\section{Experiences with faculty}

- Some experiences with male and female faculty were positive

- Some no differences in interactions, based on gender of the faculty

- Many of the participants experiences varied due peer/faculty gender or personality interaction

Experiences with faculty. Some participants' experiences with male and female faculty were positive and there were no differences in interactions, based on gender of the faculty. Many of the participants stated their experiences with faculty varied due to the peer/faculty gender interaction or personalities. This interaction could lead to a positive or negative experience for the students. 


\section{No differences}

- No difference in experiences related to gender of the faculty member

- Vincent stated, "I think my experiences with my female faculty have been very positive. We only have one male professor in program. I would say that my experiences with all our faculty members has been fairly uniform. I don't think there were any significant changes or different interactions because they happen to be male or female." 


\section{Female faculty}

- Many positive experiences

- some felt supported

- Many experiences depended on the faculty member

- Some negative experiences - oppressive and/or invalidating

Female faculty. Participants' experiences with female faculty varied. Many said they had positive experiences, and some said they were not only positive, but they felt supported. However, many participants stated their experiences depended on the faculty member. Some participants shared some negative experiences. 


\section{Male faculty}

- Varied interactions with male faculty

- Some positive

- Some challenging

- Importance of male faculty recruitment and retention

Male faculty. The participants shared varied interactions with male faculty.

Some of the relationships were positive and some were challenging. Some of the participants discussed the importance of male faculty in their recruitment and retention.

No participants discussed the importance of female faculty in their recruitment and retention. 


\section{No privilege or benefits}

- Few did not experience benefits or privilege due to being a male in their counseling program

Privilege or benefits of minority gender in counseling programs. Some participants did not experience benefits or privilege due to being a male in their counseling program and some believed they did.

No benefits. There were few participants who believed they received no benefits or privileges due to being a male or minority gender in their counseling programs. 


\section{Privilege or benefits}

- Benefits may have received due to being a male and/or as a minority gender in their counseling programs

- Entry into counseling programs

- Obtainment of internships

- Asked for perspectives and attention

- Behaviors interpreted more positively than female peers' behaviors

Benefits. Many of the participants shared benefits they may have received due to being a male and/or as a minority gender in their counseling programs, which included entry into counseling programs, obtainment of internships, asked for their perspectives and attention, and behaviors interpreted more positively than female peers' behaviors. 


\section{Challenges}

- Challenges to being a male minority in counseling programs

- Some did not experience any challenges

- Some experienced challenges

- Feeling lonely and/or isolated

- Feelings of invalidation and/or discrimination

- Coping with and addressing male stereotypes

- Called on as spokesperson of men

Challenges. There are challenges to being a male minority in counseling programs. Some participants stated they did not experience any challenges related to being a gender minority in their program. Some participants shared challenges, which included feeling lonely and/or isolated; feelings of invalidation and/or discrimination; coping with and addressing male stereotypes held by others in the program; and called on as spokesperson of men. 


\section{Findings}

- Research question three

- What is the experience of male professional counselors? 


\section{Experience in profession}

- Benefits associated with being a male minority

- Challenges

- Many of experiences similar to the student participants' experiences

Experiences with colleagues in the counseling profession varied. There are benefits and challenges associated with being a male minority. Many of these experiences were similar to the student participants' experiences. 


\section{Experiences with female colleagues}

- Primarily positive

- Some experienced challenges - oppressive and/or invalidating 


\section{Experiences with male colleagues}

- Many participants' professional experiences with male colleagues were positive

- Some participants said male colleague relationships were needed

- Some participants had challenging male colleague relationships - communication

Experiences with male colleagues. Many participants' professional experiences

with male colleagues were positive, and some participants said their male colleague relationships were needed. No male participant said they needed female colleague relationships. Other participants had some male colleague relationships that were challenging - this was due to communication styles, impacted by societal norms. 


\section{Benefits}

- Benefits to being the minority gender in the counseling profession

- Clients need and want to see male counselors

- Highly marketable

Benefits. Many of the participants stated there are benefits to being the minority

gender in the counseling profession. The benefits were primarily that clients need and want to see male counselors, and they are highly marketable. 


\section{Challenges}

- Challenges associated with being a male minority in the counseling profession

- Lack of trust of male counselor

- Female clients possibly preferring female counselors

- Pigeonholed to male clients

Challenges. There are challenges associated with being a male minority in the counseling profession. Many were similar to challenges associated with being a male in counseling programs, but some were unique.

Lack of trust of male counselor.

Female clients possibly preferring female counselors.

Pigeonholed to male clients. 


\section{Discussion}

- Male counseling student and professional experiences examined through a social cognitive career theory framework (Lent, et al., 1994).

- Social-cognitive factors influenced educational and career goals

- Primary factors - cognitive-person variables of self-efficacy, outcome expectations, and goals (Bandura, 1986; Lent et al., 1994)

Men are a minority in the counseling field (BLS, 2011; Reetz et al., 2015;

Schweiger et al., 2011), which is a noteworthy issue for the counseling profession because male counselors are needed (Fujikura, 2008; Michel et al., 2013; Paul \& Paul, 2015). A lack of male counselors limits client options in a variety of ways (Michel et al., 2013; Paul \& Paul, 2015), and some clients need or prefer male counselors (Michel et al., 2013; Paul \& Paul, 2015; Rochlen \& McKelley, 2009). It is an ethical responsibility (ACA, 2014) of counselor educators, as well as a requirement of accreditation standards (CACREP, 2016) for counseling programs to recruit diverse populations, including gender. Therefore, it is imperative that counseling programs are informed on how to effectively recruit males. 
The male counseling student and professional experiences were examined through a social cognitive career theory framework (Lent, et al., 1994). Social-cognitive factors influence educational and career goals, and this was true of the male participants' educational pursuits and career interests in this study. The primary influential factors were related to cognitive-person variables of self-efficacy, outcome expectations, and goals (Bandura, 1986; Lent et al., 1994). SCCT was utilized to examine how these factors interacted with gender, and environmental contexts such as social support, barriers, and educational experiences.

\section{Future Recruitment}

- Make it known men are needed in the field and highly marketable.

- Increase visibility of men on websites and brochures

- Programs need more male faculty and students increases feelings of connectedness, and alleviating fears of isolation and loneliness

- Provide more information about the counseling field - could help inform perspective students of the unique qualities of counseling, and make clear the counseling profession is a viable career option.

- Recruitment may need to change to decrease stigma associated with men entering a workforce that is primarily women

Due to their experiences in selecting the counseling field and choosing a counseling program, participants had ideas about strategies they believed could be effective in recruiting more men. Participants suggested that counseling programs make 
it known men are needed in the field and highly marketable. It was also recommended that websites, brochures, and programs have more male faculty and students. Michele et al. (2013) also heard this recommendation from male students in their study. Participants in the current study said this was important in increasing feelings of connectedness, and alleviating fears of isolation and loneliness. It was also suggested that it would be beneficial to male recruitment if programs provided more information about the counseling field and made the knowledge more common. Participants in Michele et al.'s study declared this to be the case as well (2013). Participants in the current study believed this could help inform perspective students of the unique qualities of counseling, and also make clear the counseling profession is a viable career option. Closely related, was the suggestion that recruitment may need to change so stigma associated with men entering a workforce that is primarily women is decreased.

These recruitment methods incorporate characteristics of SCCT (Lent, et al., 1994). Integrating these suggestions into current recruitment strategies could promote self-efficacy in prospective students, the belief they will be effective in pursing the counseling field. This initial positive belief can lead to pursuit of counseling as a career. If the individual sees environmental factors as positive with few barriers, then career interests are translated into pursuit of the goal (Lent et al., 1994). However, if the person perceives the goal has too many barriers or the barriers are insurmountable, despite an interest in a particular career, the education or career goal will not be pursued. It is in counseling programs' power to promote counseling as a positive and viable career choice and decrease perceived barriers. 


\section{Discussion}

- Knowing common male inspirations or what attracts men to the counseling field can inform current and future recruitment strategies

- Male inspirations can be marketed - lead to enrollment gains

- Many men do not notice recruitment strategies

- New recruitment strategies could be useful

- If programs elect to not use new methods of recruitment, counseling programs should remain neutral in their recruitment

- Use strategies that indicate no one population is valued over any other

- Many attracted to programs with male students and faculty

- Counseling programs should have males on websites and brochures

The findings of this study were clear. Men are inspired to go into a counseling career. Knowing common male inspirations can inform current and future recruitment strategies. Those inspirations that can be marketed could lead to enrollment gains.

Second, many men do not notice current counseling program recruitment strategies.

Therefore, new recruitment strategies could be useful in male recruitment. However, if programs elect to not use new methods of recruitment, counseling programs should remain neutral in their recruitment. In other words, use strategies that indicate no one population is valued over any other should be utilized. In addition, many participants were attracted to programs where male students and faculty were evident. In order to attract more male prospective students, counseling programs should have males on their 
websites and brochures. Programs would also likely attract more men if they have some male faculty in the program.

\section{Discussion}

- Knowing common male experiences in counseling programs and the profession can inform recruitment strategies and determine changes that need to take place

- Many male experiences with male and female peers and faculty are positive - important and should continue

- There are benefits or privileges to being a male minority in counseling programs

- Benefits of being a male minority could be utilized in the recruitment process

- Unearned male privilege should be addressed

- Counseling programs examine biases within the program, faculty and students

- Implement change to increase equity amongst students and decrease male privilege

Knowing common male experiences in counseling programs and the profession can inform recruitment strategies and determine changes that need to take place. Many male experiences with male and female peers and faculty are positive, which is important and should continue. However, there are issues that need to be addressed. There are benefits or privileges to being a male minority in counseling programs. Benefits of being a male minority could be utilized in the recruitment process. However, unearned male privilege should be addressed. It is important that counseling programs examine biases within the program, faculty and students, and implement change to increase equity amongst students and decrease male privilege. 


\section{Discussion}

- Increased awareness of challenges could inform counseling programs and the profession about needed changes

- Counseling programs need to address:

- male's feelings of loneliness or isolation

- feelings of invalidation and/or discrimination

- the perpetuation of male stereotypes, compelling males to be male spokespersons

- the need to create safe environments for challenging topics

- Addressing these issues would positively affect the learning environment of all counseling students, and not only male counseling students

Although there are benefits and privileges, there are also challenges. Increased awareness of these challenges could inform counseling programs and the profession about possible changes that could, and in many cases should take place. Counseling programs need to address male's feelings of loneliness or isolation, feelings of invalidation and/or discrimination, the perpetuation of male stereotypes, compelling males to be male spokespersons, and the need to create safe environments for challenging topics. Addressing these issues would positively affect the learning environment of all counseling students, and not only male counseling students. 


\section{Discussion}

- Challenges in counseling sites more difficult to address

- These include the lack of trust of male counselors, female clients possibly preferring female counselors, and pigeonholing male counselors

- Counseling practices need to consider the many positive qualities male counselors bring to the profession for all clients, not only boys and men clients

There are challenges in counseling sites that are more difficult to address. These include the lack of trust of male counselors, female clients possibly preferring female counselors, and pigeonholing male counselors. Counseling practices need to consider the many positive qualities male counselors bring to the profession for all clients, not only boys and men clients. 


\section{Implications}

- Participants' experiences likely reflect experiences of prospective, current, and past counseling students

- should be considered in counseling programs' recruitment strategies, teaching practices, and counseling program environments

- Implementation of participant suggested recruitment changes could make counseling programs more attractive to incoming students, resulting in increased male student enrollment

- Counseling programs should address privileges and challenges of male students in order to attract and retain male students

- Promoting an inclusive learning environment

- Increased male enrollment and retention could lead to financial gains and viability of counseling programs

- leads to more male counselors serving diverse populations

The experiences of participants likely reflect experiences of prospective, current, and past counseling students and should be considered in counseling programs' recruitment strategies, teaching practices, and counseling program environments. Implementation of participant suggested recruitment changes could make counseling programs more attractive to incoming students, resulting in increased male student enrollment. In addition, counseling programs should address privileges and challenges of male students in order to attract and retain male students, as well as promoting an inclusive learning environment. Lastly, increased male enrollment and retention could lead to financial gains and viability of counseling programs, which in turn leads to more male counselors serving diverse populations. 


\section{References}

- Available via email - please notify presenter 


\section{Executive Summary}

A Qualitative Case Study of Male Students' Experiences in Counseling Programs and Male Professional Counselors' Experiences Post-Graduation

Amber F. Lancaster 


\begin{abstract}
Little is known about what attracts men to the counseling profession and what their experiences are in counseling programs and the profession post-graduation. This qualitative case study examines what attracts men to the counseling profession, recruitment strategies, and proposed recruitment strategies that could affect prospective male students. It also reveals the experiences of males in counseling programs and the counseling profession, after graduation. Findings indicated men are attracted to the field for various reasons. Most participants did not notice any specific recruitment strategies directed toward males. The participants shared ideas for future male recruitment. Findings also indicated there are benefits and challenges associated with being a gender minority in counseling programs and the profession. Implications for counselor preparation programs are presented.
\end{abstract}




\section{Introduction}

The number of men in the counseling profession has decreased since the 1970s (BLS, 2011). Depending on the source, there are varying statistics of the actual number of males in the mental health profession. However, regardless of the approximation, it is clear males are a minority in the counseling field. Some important statistics to consider is there are approximately two women to every one man in master's counseling programs (Schweiger, Henderson, McCaskill, Clawson, \& Collins, 2011), 17\% of students in Council for Accreditation of Counseling and Related Educational Programs (CACREP) accredited counseling programs are male (Evans, 2013), three women to every one man in mental health fields in general (Bureau of Labor Statistics [BLS], 2011) and only 26\% of ACA members identify as male (Evans, 2013).

Not only are males a minority in the counseling profession, research on males is scarce. Moreover, available research is inconsistent in its findings. Some researchers have found men experience unintentional marginalization in female-concentrated graduate programs (Fujikura, 2008; Huntington, 2012; Michel, Hall, Hays, \& Runyan, 2013; Willyard, 2011). However, there is additional evidence males may also be recipients of privilege in counseling programs (Fujikura, 2008; Michel et al., 2013). Furthermore, there are conflicting views related to the advantages and disadvantages for men counseling students' learning in a feminized learning environment (Fujikura, 2008; Huntington, 2012; Michel et al., 2013). As a result of the lack of research, as well as the discrepancy in research findings, it is evident there is a need for additional research on what attracts men to the profession, as well as their experiences in counseling programs and in the counseling profession. 


\section{Conceptual Framework}

The lens through which this study was conducted is the social cognitive career theory (SCCT) (Lent, Brown, \& Hackett, 1994). Bandura’s social cognitive theory (1986) is the foundation for SCCT. Both theories stress the interaction among cognitiveperson variables. These include self-efficacy, outcome expectations, and goals (Bandura, 1986; Lent et al., 1994). Furthermore, SCCT examines how these factors interact with other personal characteristics such as gender, ethnicity, and culture, as well as environmental contexts such as social support, barriers, and educational experiences. The theory proposes it is the interactional dynamic of these components that affect career pursuits and career selection.

SCCT (Lent et al., 1994) was chosen as the lens to view this study for a few specific reasons. First, there are few men in the counseling field (BLS, 2011; Evans, 2013; Reetz, Bershad, LeViness, \& Whitlock, 2015; 2015; Schweiger et al., 2011) and gender inequality is likely a central reason. SCCT recognizes individuals may not be able to or are unwilling to choose careers, even though there is an interest (Lent \& Brown, 2013; Lent et al., 1994, 2000; Lent, Brown, Brenner, Chopra, David, Talleyrand, \& Suthakaran, 2001). Furthermore, SCCT acknowledges there are additional factors that have a significant influence on career choice such as personal characteristics (e.g., age, gender, and race) and environmental factors (e.g., support, barriers). It is possible there are men who are interested in counseling, but as a result of person-cognitive and environmental factors may not pursue or persist in the counseling field. 


\section{Research Questions}

1. What attracts men to the counseling field?

a. What role did overt or covert recruitment strategies play in choosing a counseling program?

b. What recruitment strategies could be beneficial to attract men to counseling programs?

2. What is the experience of men in counseling programs?

3. What is the experience of male professional counselors?

\section{Design of Study}

- Purposeful sampling - males in master's and doctoral counseling programs and male professional counselors

- Individual interviews, observations, and artifact/document analysis

- 23 men -students currently in CACREP counseling programs, master's or doctoral, and graduates of CACREP accredited counseling programs, master's or doctoral level

- Non-probability sampling - representative of the population being studied (Creswell, 2013, 2014, 2016; Merriam \& Tisdell, 2016; Seidman, 2013)

- Most participants recruited from the Counselor Educators and Supervisors Network Listserv ([CESNET-L]; Jencius, 2017); snowball sampling

\section{Data Collection Tools}

- Personal interviews, observations in counseling programs, and artifacts/documents (Creswell, 2013, 2014, 2016; Merriam \& Tisdell, 2016; Seidman, 2013) 
- Interviews 30-60 minutes, by phone or in person

- Observation - three counseling programs; collected recruitment material; observed environment

- Websites of counseling programs through CACREP website - scanned for recruitment material

\section{Data Analysis}

- Constant comparative method; open and axial coding

\section{Qualitative reliability.}

- Chain of evidence - access to all information to external observer (Yin, 2014)

- Constant comparative method

- Analytical memo - kept notes about codes and how codes defined (Merriam \& Tisdell, 2016)

- Reread transcripts to check for accuracy in transcription process (Creswell, 2014) Qualitative validity.

- Triangulation of data - through synthesis of data from interviews, observations, and artifacts/documents (Merriam \& Tisdell, 2016; Yin, 2014)

- Member checks

- Rich, thick descriptions in the findings

- Negative or discrepant findings shared

- Researcher biases disclosed (Creswell, 2014) 


\section{Findings}

\section{Research Question One}

Participants were inspired in some way to pursue counseling. The desire to help others was a general theme. Many of the participants had specific catalysts that led to their desire to help others. These included a calling, personal or family experience, and role models.

Help others. A primary reason men were attracted to counseling was the desire to impact and help others.

- Quincy wanted to help people and do "altruistic work."

- Rusty said, "I knew from an early age that I held a lot of people's confidences and at the time didn't know what to do with that. So, I had a want to be in the helping profession."

- Mac stated, "I decided that I would do something selfless and rewarding and noble."

- Neal said, "I wanted to help people in some kind of meaningful way."

A calling. Some of the participants described their attraction to the counseling field as a calling or called to serve, which was spiritual or religious in nature. Their calling led them to want to help and support individuals. Due to their calling, these participants had self-efficacy and pursued the counseling profession, which is demonstrative of social-cognitive factors (Lent et al., 1994, 2000).

- Glen stated, "I think it's a calling. You can be very entrepreneurial. You can be creative. You can do all the things that you can do in almost any career in the counseling profession. That it's a good calling, life choice." 
- Ivan stated, "I think I was honestly called to it. I was attracted to it by being open to it, by being open to other forces than just the world, and I think I was drawn to it by God. Yeah, I do think it was a calling. My life prepared me for this."

Personal or family experience. Some men were attracted to the counseling field due to their life experiences with substance abuse and mental health issues, either their own experience or someone they knew. They were affected by their life experience and they wanted to use their experiences to help others who were going through similar circumstances. Despite how challenging some of these life occurrences had been, it was these experiences that manifested confidence in their ability to help others.

- Frank stated that part of the reason he was attracted to the counseling field is because he is in "recovery." Furthermore, he has experience working in mental health facilities specializing in substance abuse recovery. This is where he found "that he got good at it. Because I've been in recovery, I know the language or I know the world from an experiential perspective." Frank said, "I got probably a Ph.D. in the school of hard knocks. So, I'm pretty well versed in the chaos of addiction and depression and learning disorders. Yeah, experience is very valuable at this point."

- Ivan stated, "I've had mental health issues and addiction issues in my family and not necessarily a stranger to addiction issues myself." Ivan continued, "My job, my goal was to get a degree that would allow me to help people who were addicted to drugs and alcohol. That was my focus."

Role models. Some of the participants' attraction to the counseling field was due to role models who came from books, mentors, and counseling experience. 
Environmental influences such as career role models affect goal pursuit (Lent et al., 1994) and, therefore, influence the development of self-efficacy and outcome expectations (Lent et al., 2000). Role models were clearly an important factor in some men's attraction to the counseling field.

- Otto shared how important role models were in his recruitment, "I've always had really phenomenal male mentors, and they have cleared the way and opened up some obstacles. Even before they knew that I was a trans guy, because like my professors didn't know, I wasn't out just yet. Even before they knew, they absolutely took me under their wing, and helped me out in ways that I am supremely grateful for. Without their help, I think I would have left the field a long time ago."

- Neal was influenced by a male author in the counseling field, as well as a male helping professional. "Victor Frankl was a male. So, I think my introduction into the field was actually from a male writer, male psychiatrist, and then, someone I consulted with, when I was considering this profession, was also a male. He was a psychologist ... and he had been in the psychology field for a long time, and really kind of helped me understand some of the differences between the different disciplines, and their approach to helping people. So, in that sense, I had some male figures, that played prominent roles, as I made that transition, and decision." Neal said these role models "lessened some of that stigma around being a male, and making the decision to enter the counseling field."

Some participants were attracted to the counseling field due to the influence of their counseling experience. Their experiences with their counselors were the catalyst for 
attraction to the field.

- Uri communicated that his personal counselor was paramount in his attraction to the counseling field, "I had seen a counselor in the previous semesters for some personal stuff I was going through and I thought about how much I liked that experience and enjoyed it and how much it changed my life. I decided that might be something I'm good at, and so, I started applying to master's programs in counseling. I was specifically interested in the counseling profession as opposed to the psychology, social worker, something like that, just because the person I saw was a counselor."

\section{Research Question One, Sub Question One}

The majority of the participants stated they did not notice any type of overt or covert strategies in the recruitment of males. Many participants did not see anything that was "welcoming" toward men. Some men shared that they didn't feel welcomed, but they also did not feel unwelcomed. Instead, these participants thought the recruitment strategies were neutral. Some participants discussed the importance of seeing men on the counseling program's website. Other participants discussed the significance of male faculty in their interviews. Regardless of where the participants saw the men associated with the counseling field, they were an important factor in the participants' initiation of the career development process; the process of forming and eventually developing educational and career interests (Lent et al., 1994).

No specific male recruitment. Most participants did not recall any specific recruitment strategies that seemed directed toward men or welcomed men. 
- Leroy did not notice recruitment strategies that welcomed men. He said, "I never got that message like 'Hey, you guys, we want to have you here."' Otto's response was "No. God no, not even a little bit" when he was asked if there was anything he saw or heard that sent the message of men being welcome in the counseling profession. Winston stated, "There was no overt message about 'Men apply here.' I didn't get that message."

Neutral recruitment. Some of the men stated that they did not necessarily see anything that indicated men were welcome. However, there was not anything that indicted men were not welcome.

- Quincy stated, "I wouldn't say that anyone went out of their way to do that. I don't know that I got the opposite impression either." Percy shared, "Nothing that said, 'Hey, men can be counselors, too,' or nothing to that effect, and nothing that was exclusionary either that said, 'You know, we really just kind of want females, so thanks, but no thanks.' I think that's fair to say as well." Ivan reported that he did not see or hear any recruitment strategies that were welcoming toward men. However, he said, “I didn't ever not feel welcome. It felt pretty neutral, which I appreciate.”

Male faculty in recruitment. Some of the participants discussed the importance of male faculty in recruitment.

- Male faculty were instrumental in some men's decision to apply to particular counseling programs. Neal said, "When I was looking at different programs, and considering my options, in terms of applying to master's programs in counseling, I do remember looking at their faculty pages, and just getting a general sense of 
who was teaching at these different programs...I can't remember a single one where there wasn't at least one male there. And I think that did help me feel like, Okay, this isn't ... it's not just something that women do is enter the counseling field." Neal continued, "Someone that looks like me, someone who fits demographically, fits some of the categories that I fit into, did make me feel like, 'alright, this is probably an okay place for me to go and learn."”

\section{Research Question One, Sub Question Two}

All participants agreed that male recruitment is needed in order to increase the number of males attracted to counseling programs and the profession. Most participants had ideas for male recruitment. Participants' suggestions for male recruitment included informing prospective students they are needed and highly marketable; visibility of men on program websites, brochures, and in programs; and increased awareness of the counseling field. Some participants believed recruitment techniques might need to change. A small number of participants were not sure how to recruit males.

Male counselors are needed. Many of the participants believed men need to know they are needed, and counseling programs would likely recruit more males. Participants indicated male perspectives are needed because they provide another important viewpoint. Male counselors are also needed because clients need and sometimes prefer male counselors.

- Jasper shared that he believes men need to know "their presence and perspectives are needed."

- Derek stated, "Men are really needed. I mean, in the field they are vastly underrepresented. I think a lot of clients want male counselors." 
- Percy shared, "Just as much as we need to have multiculturalism as part of our continuing dialogue as a profession, there needs to be an open understanding that men bring qualities to the field that women cannot, just like any other individual from some other cultural group can bring to the field and to serve clients too." Percy expanded, "I think it's a benefit to our profession that those points of views exist and that it's not all one-sided, but that there's a balance...to a given issue."

Highly marketable. Most participants shared that they are highly marketable as

a male minority in the counseling profession. Participants believed it could be beneficial to inform prospective male students how marketable they are.

- Barry stated, "You don't have to be at the top, you can be average and you're going to be wanted...I had people interested in me just because I was a male and they wanted a male in that spot."

- Neal said, "When I was looking at internship positions...both of the places said they would be happy to have a male because they had a shortage, and they had male clients who specifically wanted to see a male counselor."

Male presence on websites/brochures and programs. Some participants suggested having a visual of males on websites, brochures, and in programs. They thought more male presence would recruit more male students. Male peers were instrumental in feelings of connection, commonality, and someone they could relate. Seeing and having male faculty was important for the same reasons. This was a significant factor in their recruitment, and could be in the recruitment of future male students.

- Neal stated, "If you can have pictures of students or pictures of male therapists 
somewhere on the website that might be helpful, again, just to give another visual of some kind of norm that males are welcome, as counselors." Neal elaborated, "If you look at the faculty webpage, and see that there are a variety of people there, there's a male there, a female there, I think that helps to encourage males to enter the field. And, I think maybe just a simple statement about the program, or about the type of students that are welcome to apply to the program, and including males in that. Just explicitly saying that the program wants to foster a diversity of demographics, whether it be gender, or ethnicity, or sexual orientation, or whatever, that the program really thrives when they have that diversity."

- Winston stated, "Having males on faculty or the graduate program's website in the photos and things like that." Winston said, "I think maybe just acknowledging in an open way through recruiting that men are welcome here. This is a great place for males."

Increased awareness about the counseling field. Some participants shared the belief that in order to recruit men, there is a need to increase awareness about the counseling field. Participants believed many people do not understand the differences between the helping professions. Participants also suggested reaching out to undergraduate programs to educate about counseling programs to decrease stigma associated with the counseling profession.

- Vincent said, "I think a greater public awareness would help a lot. I think a lot of people are still not really sure of what counseling is, especially compared to some of the other mental health fields." Vincent said he believes men are more attracted to psychology or social work so increased knowledge about counseling 
could be beneficial to male recruitment. Vincent stated, "I think greater public awareness and more information that it is a viable career choice for anyone that is interested in it."

- Elliot suggested increasing awareness in undergraduate programs to attract males and "reduce the fear of going into professions like this, that that may draw them in a little bit more, that it's not just the engineering and the construction and all these stereotypical male professions."

Need to recruit differently. Some participants believed men need to be recruited differently. These participants believed using different terminology could help to reach and recruit more men, and lower the stigma associated with counseling.

- Mac stated, "Well, I know that strategies for getting men into counseling, in general, to attend as clients, using verbiage such as coaching, like men coaching or live coaching, those are less threatening terms." Furthermore, "Maybe a bigger focus on career counseling" and "describing it as a way to help people with everyday problems or assist people in becoming better versions of themselves or helping people achieve the goals that they want in their life versus working with emotionally focused trauma therapy."

- Jasper suggested counseling be promoted "as a trade, almost like going back to a trade school to learn welding, construction, to become a mechanic. In large part, that is what counseling is kind of like. It is the welding, construction, the mechanics of people, of relationships."

Not sure how to recruit. Some of the participants believed more men need to be recruited, but did not have ideas on how to recruit. These participants expressed the lack 
of male counselors as a larger issue, and recruitment will most likely not address the problem.

- Otto shared his exasperation about the lack of males in counseling and its connection to a larger societal issue, "There's this hidden bias in American society that men are supposed to go more for the doctorate degrees. Psychology programs tend to do a little bit of a better job of having men and women photos, and on their panels, and in their professorships. Master's degree programs are more filled by women, and therefore I think schools are just responding to that. That if $80 \%$ of our incoming students have consistently been women, then we should probably advertise more towards women. I understand why it's happening. I don't know how to fix it."

- Winston mirrored similar sentiments in that he does not think recruitment strategies are going to be effective in male recruitment because it is a societal issue. "There are all these notions about men as being breadwinners, as being the primary earner in their families, and counseling isn't it. That's not going to get you there. I think it's more complex than just recruiting men. I think it comes down to salary. It comes down to stereotypes about what it means to be a man and what profession they should take."

\section{Research Question Two}

Participants' experiences varied with peers and faculty. Some experienced benefits due to being a male minority, and some experienced challenges. Benefits included acceptance into counseling programs, obtaining internships easily, being asked for perspectives and receiving attention, and behaviors interpreted more positively than 
female peers' behaviors. Participants also experienced challenges, which included feelings of being lonely or isolated, feelings of invalidation and/or discrimination, male stereotypes, male spokesperson, and challenging topics.

Female peers. Experiences with female peers varied. Many were positive. Some participants were purposeful in being equitable with female peers; they acknowledged their privilege and tried to not use it as advantage. Many said their relationships with female peers was determined by the personality of the peer. Some participants said their relationships with female peers were challenging.

\section{Purposeful.}

- Kyle stated, "From my perspective, I think I did okay with my female peers. Because of this one professor making me aware of my privilege, I think I tried very hard to do things like be aware of not dominating conversations and stuff

like that. And I can only speak for my own perspective of how successful I was at that."

- Vincent stated, "I think they have overall been very good. I know that I have tried to be very equitable, I'm very aware of the position that men have in our society."

\section{Varied.}

- Jasper stated, “They've been positive, but I don't know if I would encapsulate interactions with women so generally because I really think it depends on the individual. Because I have had great, I would say that the majority of my experiences have been positive, but there have been some interactions with women that I have butted heads with." 


\section{Challenging.}

- Leroy shared that his experiences have been mostly positive, but a "screening process" takes place. Leroy stated, "My female peers have all been pretty supportive. They've all been pretty good. I think initially, when we get to meet each other, they're kind of feeling me out to see 'Okay, well what level of knowledge does this person have about counseling?'....and 'Okay, why is this guy here in counseling?' I think sometimes, they can be quite grateful and quite welcoming that they have the male presence. But, there is definitely no 'There's a guy here! Let's embrace the person.' I think there's usually this feeling of 'Okay, what do you know? Why are you here? Are you qualified to do it?'” Male peers. Male peer interactions were limited due to low numbers. They varied: some were positive and there was a sense of comradery; some were challenging due to communication, competition, or insecurity.

\section{Positive/comradery.}

- Quincy spoke of a common shared experience with his male peers. Quincy stated, "In my doctoral program, I have some male peers who I really connect with. We share a lot of worthwhile ideas with each other, work on publications together, and things like that. There weren't that many male peers...there were only two other men in my cohort in my master's program." Quincy expounded, "I think that there can be male bonding that can occur if you are the only men in a program and it's primarily female, that there's a shared experience there."

Challenging. Some participants stated relationships with male peers could be 
challenging.

- Elliot said, "I did identify a couple male peers that I probably talked to more closely than probably any other males... I probably wasn't really connected.” Elliot shared, "I was still maybe trying to prove to myself that I knew what I was doing, and I wanted to try to portray that. I was hesitant to speak up with males if I didn't know something. Like, if I say this and they know it then I'm inferior to them." Elliot expounded that he had a fear of "saying something stupid or something that gets this reaction of, 'What were you thinking?"'

- Percy said he experienced some competition with male peers, "My male counterparts, not all of us, but we were maybe a bit more competitive with each other. Again, not terribly overt, and I'm not saying they were microaggressions either, but we were more sizing each other up in terms of competition for jobs. Again, not in an unhealthy way. It wasn't unhealthy to me because we were mutual about it, but I didn't get that from my female counterparts."

Experiences with faculty. Some participants' experiences with male and female faculty were positive and there were no differences in interactions, based on gender of the faculty. Many of the participants stated their experiences with faculty varied due to the peer/faculty gender interaction or personalities. This interaction could lead to a positive or negative experience for the students.

No differences. Some participants stated there was no difference in their experiences as related to the gender of the faculty member.

- Vincent stated, "I think my experiences with my female faculty have been very positive. We only have one male professor in program. I would say that my 
experiences with all our faculty members has been fairly uniform. I don't think there were any significant changes or different interactions because they happen to be male or female."

Male faculty. The participants shared varied interactions with male faculty. Some of the relationships were positive and some were challenging. Some of the participants discussed the importance of male faculty in their recruitment and retention.

Positive.

- Neal stated, "I have been lucky enough to have some really great faculty, of both genders, throughout my master's and doctoral program. I will say, again, similar to my cohort, the one, I find myself gravitating towards males, in terms of mentorship, and collaborative work. Some of that has been around just interest areas. But I think other parts have been around it is just a different comfort level, different kind of experience, a relational experience, with a male, than there is with a female"..."So, I think that I found it easier to connect with male faculty members, as a student, than female faculty members. That's not to say I had negative experiences, or relationships, with females. I had some great relationships with supervisors, and with instructors, and faculty members, in both my master's and doctoral programs that were female. When I reflect back on it now, the ones that I really connected with, that I still stay in touch with, are male."

- Leroy stated, "I probably had about three male professors in my graduate experience. So, when you come across some of these men, 'It's you, look,' and they give you kind of a code wink, like 'Wow! You're here, me too.' And it's 
almost kind of like we're going to try to make this work for each other. 'I want you to do really well here.' So, I think that when I get the male faculty, not that they favor me, but I do think like, 'Oh wow! There's another guy here.'”

\section{Varied.}

- Quincy stated, "I'd say it varies. I'm still close with one of the male faculty members in my master's program." Quincy said, "I had another male faculty member who I had some particular disagreements with that run along the lines of some of the things I've already shared. There was almost an evangelism to his beliefs about the world. I felt like it was very much not a classroom environment that was open to differing ideas. It was very much that this is how the world works and you must believe this, otherwise you are $\mathrm{X}$. Obviously, $\mathrm{X}$ is not a, you can imagine the words, but it's not described in a positive way, what you would be if you don't agree with him. I found that pretty unpleasant, generally, to be in that environment, because I don't like that. I particularly don't like feeling manipulated, like somebody's trying to force me to believe something. That's not a pleasant experience for me."

\section{Challenging.}

- Kyle stated, "We had very few male faculty in the program I was in...there were two male faculty." Kyle said of one of the male faculty, "I got along with him" at first, but "I thought he ended up being a total prick... because he had this whole frat boy approach...of, 'Well, if you're going to go through this, I was hazed, so I'm going to haze you' type of thing." Kyle stated, "He did things that I thought were unfair. So, that wasn't good." 
Female faculty. Participants' experiences with female faculty varied. Many said they had positive experiences, and some said they were not only positive, but they felt supported. However, many participants stated their experiences depended on the faculty member. Some participants shared some negative experiences.

\section{Positive.}

- Quincy stated his experiences with female faculty were positive. Quincy said, "I would say I had pretty overwhelmingly positive experiences with at least one of the faculty members there in my master's program. The other one I didn't know all that well, so I just didn't take a lot of classes with her. I would say my experiences, at least in my master's, were overwhelmingly positive. In my $\mathrm{PhD}$ program, about the same. Again, it depends on the individual. I connect more with certain faculty members than with others, but I don't have any particular qualms with my female faculty in either department that I've occupied."

Varied.

- Glen shared that his experiences with faculty depended on the faculty member. Glen stated, "I think in my current program, I have both ways. I have some faculty that see me as, really just give me the benefit of the doubt, really positive towards my gender, and then I think I have both. And I have to really be careful to figure out what that is." Glen continued, "So, I have a professor...that I've not had before and I'm a little bit worried about it. I just don't know how I'll be perceived.” Glen said, “All females, I have to feel them out to figure out what's going on before I know if I feel safe or not. And that might be my own personal issues." Glen stated, "I just don't know how I will be experienced. And again, it 
can be my own issues. It can be their issues. It's always hard to tell. But I do know that I think I am aware because of our profession and our emphasis on multi-cultural, which I love, I also am very much aware of what I look like and how I present, and I can be off on that too, but I think that also gives me a little bit of a pause in some ways." Glen stated, "I think there's always in this profession, I share most of who I am, $80 \%$ I would say, but there is a part of myself that I do hold back because I do exist within such a female centric culture."

\section{Challenging.}

- Ivan also shared one experience he had with a female faculty. Ivan stated, "From day one, we were taught to check our biases. I think that professors understand there's a power differential. This last semester was the first time, in over 2 years, I experienced a professor taking advantage of a power differential, and it wasn't a good feeling."

- Otto shared about a negative experience with a female faculty member, "She told me that there was no way that I did as much work as the woman, my partner, and that I need to take care of my high horse and if I didn't like it I could go fly a kite." Otto stated, "I didn't have enough, I was still trying to shrink myself and be small, and not rock the boat and try to learn and navigate this world of mostly women and civilians. I didn't have enough voice to report that really wretched woman to the dean and I should have, but I didn't and that one sticks with me. That's some bullshit. I got a different grade because of what? Because of her bullshit because of no other reason." 


\section{Privilege or benefits of minority gender in counseling programs. Some}

participants did not experience benefits or privilege due to being a male in their counseling program and some believed they did.

No benefits or privilege. There were few participants who believed they received no benefits or privileges due to being a male or minority gender in their counseling programs.

Benefits and/or privilege. Many of the participants shared benefits they may have received due to being a male and/or as a minority gender in their counseling programs, which included entry into counseling programs, obtainment of internships, asked for their perspectives and attention, and behaviors interpreted more positively than female peers' behaviors.

- Ivan stated, "When I went into the initial information meeting, I knew I was going to apply and I noticed there was me and another guy and everybody else was a woman. There's just me and one other guy out of 20 people. I thought maybe my chances of getting in are...I thought maybe my chances are going to be better that I'm going to be accepted. I figured when I applied to the doctoral program that it would give me a tiny edge. Now, I needed everything else too, but I knew that it wasn't going to hurt me being a male."

- Vincent stated, "I am aware of the fact that sometimes I feel as though I get a little more attention because I'm a guy."

- Jasper stated, "Some of the things are subtle. I think that if I wanted to get out of some certain responsibilities I could have, like certain duties within the department, or some things that haven't been mandatory that I have stepped up 
and volunteered for. I think I definitely could have gotten out of those responsibilities. They could have fallen on other people, potentially other women in my department."

- Mac said, "There would be times in one of my classes, like I'm a very, very relaxed and I don't want to say aloof, but just like laid back kind of guy, and there'll be times in classes where we're doing role plays, and I'm stretched out and make myself very comfortable. I think if a girl were to do that, this is like a male feature, maybe she might have responded differently to that, maybe she might say, 'She's not as invested,' but that's speculation. I don't know."

Challenges. There are challenges to being a male minority in counseling programs. Some participants stated they did not experience any challenges related to being a gender minority in their program. Some participants shared challenges, which included feeling lonely and/or isolated; feelings of invalidation and/or discrimination; coping with and addressing male stereotypes held by others in the program; and called on as spokesperson of men.

Lonely or isolated.

- Leroy stated, "We're special in this field and we can do really good work, even though sometimes it's going to be lonely and it's going to be isolating." Leroy stated, "I think in my graduate study, it is good because it does make you a bit rare, but it can get very lonely, very quickly. You're like 'Geez, I haven't seen another man in a year, in the class.' That's not uncommon at all." 


\section{Feelings of invalidation and/or discrimination.}

- Quincy stated, “There are times where I've found that people just dismiss ideas as being male ideas or White people's ideas. I find that pretty hurtful sometimes because I embody that, and it feels like it closes off the room to me, I guess."

- Ivan stated, "If the goal is for everybody's voice to be free and equal, as tempting as it might be, you can't try to get back at a person that was once leaving you voiceless because I went through it as a White male. When I felt voiceless, and when I felt like I didn't have a voice, I felt resentment and all that did was it didn't settle anything. So, it's tempting and I think it's tempting when people feel oppressed to get back at other people, but if equality and equity are the goal, then there can't be any revenge."

- Rusty said, "I was struggling because I didn't have a male identified role model in our program to kind of say like, 'Am I crazy? Like is this real? Is this going on? Because this feels really similar to when we were having conversations about discrimination in our classroom, like these are the same themes.' And also holding the fact that I come from a really, really privileged background, White, heterosexual. There was a lot of guilt wrapped up in, especially, gosh, when I started my first year, last year. A lot of guilt around should I even, can I even identify this as an oppression? And over the past year, I've talked with different male colleagues and female therapists, and was 'No, this is oppression. There are different themes and that power of control. No, you're not crazy. This is what's up."” 
Male stereotypes.

- Derick stated, "When I would talk to some professors at the master's level, I would...say, 'Hey I want to...research male victims.' And like one of my female professors kept switching it in her head. It was really weird because she's like, 'Oh yeah, yeah, we need a lot of help with male offenders.' It was like this automatic switch when I said 'male sex abuse victims' it was like there could only be male offenders in her mind. And it happened in more than one conversation. I don't think she was intentional on her part...there's that gender scripting surrounding certain topics."

- Sherman stated a woman "told me that being a male therapist that once I graduate I'm going to be in high demand. Then they added something that I thought was strange. Is that they added to that statement, their full statement was something like, 'Being a guy, as long as you're able to keep ethical boundaries you'll be in high demand.'" Sherman stated, "If you can make it and keep your boundaries then you'll be in high demand. Instead of just telling me, 'As a male you're going to be in high demand.' I didn't really respond at the time. I was just like, 'Yeah that seems right I guess.' Thinking about it in this context, it certainly reinforces the idea that maybe I would be more inclined to, I don't know, ethical failure I guess. That's the only term I could think for it."

- Winston stated, "I found that when we were doing case consultations about specific clients, who were men, I noticed that the women often stereotyped males and had a hard time acknowledging the limitations that come with being a male in 
society. I think woman see men as often the ones who have power in relationships and have power over women. I think that's also a struggle men have, too, and it creates a lot of anxiety. Men often feel inept and weak in a lot of situations because they find it hard to achieve the stereotypical male characterization in their relationships and their families and their careers. I found myself empathizing with a lot of men in our case studies, and I found some of the female students undercutting them in their challenges."

\section{Male spokesperson.}

- Glen stated, "In the counseling program where I was the minority person in my classes, often I had to speak from the male perspective, as one person, and that was challenging at times. And also, I'm Caucasian so understanding privilege and how I'm perceived and not being always how I appear, as I'm pretty hypermasculine in terms of my appearance, and being privileged or the White majority and the power differentials. Sometimes I felt like I had a label of who I needed to speak for, but wasn't actually who I was.”

- Leroy stated, "Sometimes, what will happen is I'll be in a class and they'll be talking about something, and they'll be like 'Well, let's get the male perspective from Leroy.' Therefore, I represent the entire male perspective, right? That's big load to carry. From my perspective, I'm a man of color, I'm a liberal...that's going to be very different from maybe another man who's had a different experience. So, sometimes, it can be kind of hard. I want to give you guys information about a male perspective, but I'm only one guy and I don't know if I'm the best representation of a sample of generally, but I'm what we have 
available here so let's do it. That means sometimes one or two of the voices in there. There won't be room for diversity there in this work."

\section{Challenging topics.}

- Leroy stated, "I think specifically when we come up to topics like if we're talking about something like post-abortive counseling and things like that. You can sense that, not that it's not a place that men cannot speak, but it's a place that men have to be very careful in the way that they broach the topic, the way that we talk about it. I think for good reason. It's a part of the process that ... It's something that we can't experience in the way another woman can. So, I do understand that to a degree. But, it's certainly not treated the same way as like if my female colleagues had an opinion; I think it'd be looked at differently than if I said something. It's almost like screening process.” Leroy stated, “I don't think it's coming from a negative or discriminatory place, but I do recognize that I am the odd man out most of the time."

Privilege. Some participants stated the most challenging discussions were related to male identity, male privilege, and White privilege.

- Quincy stated that discussions related to gender and race were challenging. Quincy shared, "I think that topics around identity, gender, race, and things like that were often difficult topics. I think I'm just generally an inquisitive person and a skeptical person, so I don't warm up to ideas very quickly. I need to sit there and weigh them. Sometimes, I do that out loud." Quincy said, "I often felt, around topics of gender, that those were the specific topics where I had to hold very specific viewpoints, and if I didn't, then it wasn't a very comfortable 
experience for me. I had all sorts of insinuations made about my character and things like that, both from students and faculty."

\section{Research Question Three}

Experiences with colleagues in the counseling profession varied. There are benefits and challenges associated with being a male minority. Many of these experiences were similar to the student participants' experiences.

Experiences with female colleagues. Primarily positive, but some experienced challenges.

Positive.

- Percy's relationships were “wonderful.” He said, "I'm very comfortable with women, working with women, so having female as the majority that I work with in the field is all fine and good with me. I don't have any negative feelings of, 'Oh, jeez, I'm in this female-dominated profession and it's a struggle for me,' it's actually quite comfortable.”

\section{Challenging.}

- Rusty stated, "Power and control knows no gender. It operates very similar to different inner-psych identities that pressure tactics can happen to anyone...We had an executive director who openly discriminated against male colleagues. And very similar to the victim blaming we see in sexual violence, the same thing happens often as, I've learned from other male colleagues who've experienced that victim blaming of a male colleague being harassed by a female supervisor who totally gets away with it because there's the assumption that men want it or that it couldn't possibly happen because men hold all the power. If it could be in 
a message in a bottle, it would be that oppression, again, it doesn't discriminate.

It goes against everyone.”

Experiences with male colleagues. Many participants' professional experiences

with male colleagues were positive, and some participants said their male colleague

relationships were needed. Other participants had some male colleague relationships that were challenging.

- Glen stated, "I am more comfortable in female settings. I've noticed that about myself. It's just been, kind of my whole career. But at times, I miss male settings, as well. But I also know that male settings aren't great all the time either. So, I think that one of the things that we talk about in my office, here, is just getting time to be males." Glen expounded, "We don't actually talk about male issues, we just spend time together. And so, that might indicate to me that there are times where being in a completely female environment and switching over to a male one for a while is nice."

- Leroy stated, "I think male colleagues, we can be very tribal and even cut off from each other. And I don't know if that's a function of being a male or a function of, I guess, we get so busy and sort of wrapped up, it can be hard for us to communicate and network with each other. I do notice my female colleagues seem to communicate much better. And my male colleagues, if I do see them or I do reach out to them, it's very much in passing. I don't think we value networking in the way that female colleagues do network. But I also think that we do talk about things such as, okay, well obviously we are men, sometimes we're counseling women, these are challenges that come up, these are some of the 
good things that come up as well. And I think we are able to share those stories and interact and sometimes bounce difficult situations off each other that are related to our sex or to our gender."

Benefits. Many of the participants stated there are benefits to being the minority gender in the counseling profession. The benefits were primarily that clients need and want to see male counselors, and they are highly marketable.

\section{Clients need and want to see male counselors.}

- Winston stated, "I always assumed that men would want female counselors, maybe it's just me because I like the mothering type of relationship. I find that a lot of my clients who are men prefer men counselors. They're like, 'I feel like I could talk to you about things.' I've noticed that they don't feel as open with females. I never would have imagined that would be the case."

- Kyle stated, "For a long time in the agency I was working at, for a long time I was the only male in the practice, which was interesting because it got me clients that other people wouldn't take. Some of them were interesting, some of them I took them because I was male, and the client particularly was male and looking for a male therapist."

\section{Highly marketable.}

- Abbot said the school he applied to was looking for a male counselor, "I think that at that time the school I am at now had three previous female counselors, prior to me, over the span of six or seven years. Not that they didn't do a good job. I'm sure they did a wonderful job. I think at that point though that was something, maybe they were looking for. Not that they told me that, I just kind of got that 
feeling."

Challenges. There are challenges associated with being a male minority in the counseling profession. Many were similar to challenges associated with being a male in counseling programs, but some were unique. The challenges were lack of trust of male counselors, female clients possibly preferring female counselors, and being pigeonholed to male clients.

\section{Lack of trust of male counselor.}

- Mac shared about an experience he had with a female client's mother when they were discussing video recording the counseling session. Mac stated, "She made a comment..., 'Oh, you know, well you got to in this day and age, everything's got to be recorded to make sure nothing happens.' So, I experienced that as maybe her being concerned that, as a male, I might take advantage of the client or not being trusted; whereas a female might be." Mac stated, "I guess, for me, it was more like, 'Oh, wow.' Like, sometimes I forget that I am a man, being a gay man. Sometimes I forget that I am a full man and people are going to have their ideas of what men do, or have done, to them. And so, it was just like a, 'Huh.' It was a wake-up or a reminder."

- Leroy stated, "Some of the challenges in my counseling profession are, usually if I get a mother who calls me and they want treatment for their child, and this is like a 12-year-old girl, mothers are very uncomfortable with me working with their 12-year-old child, particularly unsupervised."

- Otto stated, "Particularly working in the rape crisis field, there's an idea with a lot of the people who work and/or volunteer at rape crisis centers that it should only 
be a safe space for women ... There was a woman that called and all I said was 'Hi, my name's Otto... I'm returning your phone call.' Then she informed me that there's no, I'm going to curse here, there's no fucking way I was going to work with her daughter and fuck all men. I mean she's screaming at me, and I was like 'okay.' It's so weird in those moments."

\section{Female clients possibly preferring female counselors.}

- Leroy stated, "Sometimes, women, I did have a lady that was working with me and then fired me the next session because she said she had a lot of things that she only thought a female could discuss with her. It was something related to fertility, I think. It was something about anatomy and maybe reproduction that she felt a bit shy about talking to a man about. There are instances where it can be disqualifying, but I think that's okay. I think people are going to look for who they look for."

\section{Pigeonholed to male clients.}

- Neal stated, “One thing I've found, in the clinical work I've done, is that in being one of the few males at the places I have worked at, clinically, I have been kind of pigeonholed, as the male who sees the males. And so, I don't think I've had quite the diversity of clientele, or maybe even an accurate representative sample of clients, in terms of who's receiving counseling... one of my doctoral internships, I literally did not have a female client, the entire time I was there. It was all males because there was such a high demand for it, and such a short supply of male therapists. So, in terms of my...clinical exposure, I think that might've been a disadvantage, the flip side of the coin, that I was seeing mainly males." 


\section{Discussion}

Male counseling student and professional experiences examined through a social cognitive career theory framework (Lent et al., 1994)

- Social-cognitive factors influenced educational and career goals

- Primary factors - cognitive-person variables of self-efficacy, outcome expectations, and goals (Bandura, 1986; Lent et al., 1994)

\section{Attraction to Counseling Field}

Men are inspired to pursue counseling due to a desire to help others

- Catalytic factors that led to desire to help - a calling, spiritual or religious; personal or family experiences; and role models

\section{Current recruitment.}

- Most participants did not notice any recruitment strategies, overt or covert, directed toward or welcoming of males

- Many participants said the recruitment strategies were neutral, and not directed toward any one particular group of people.

- The importance of seeing men on counseling program websites and in the program, male professors and peers, was significant in some participants' recruitment

\section{Future recruitment.}

- Make it known men are needed in the field and highly marketable

- Increase visibility of men on websites and brochures

- Programs need more male faculty and students - increases feelings of connectedness, and subsides fears of isolation and loneliness 
- Provide more information about the counseling field - could help inform prospective students of the unique qualities of counseling, and make clear the counseling profession is a viable career option

- Recruitment may need to change to decrease stigma associated with men entering a workforce that is primarily women

Knowing common male inspirations can inform current and future recruitment strategies. Male inspirations that can be marketed could lead to enrollment gains. Many men do not notice current counseling program recruitment strategies. Therefore, new recruitment strategies could be useful in male recruitment. However, if programs elect to not utilize new methods of recruitment, counseling programs should remain neutral in their recruitment. In other words, use strategies that indicate no one population is valued over any other. In addition, many participants were attracted to programs where male students and faculty were evident. In order to attract more male students, counseling programs should have males on their websites and brochures. Programs would likely attract more men if they have some male faculty in the program.

\section{Experiences in Counseling Programs}

- Experiences with female peers varied. Many were positive, some varied due to personality, some were challenging

- Interactions with male peers limited due to low numbers

- Relationships with male peers varied. Many were positive, sense of comradery; some male/male peer relationships were challenging due to communication, competition, or insecurity

- Experiences with male and female faculty varied. Many relationships were 
positive, and there were no differences in interactions, based on gender of the faculty. Some of the participants' experiences with faculty varied due to the peer/faculty gender interaction, which led to some positive and negative experiences

- Importance of male faculty in their recruitment and retention

- Benefits or privileges included acceptance into counseling programs, obtaining internships easily, asked for perspectives and receiving attention, and behaviors interpreted more positively than female peers' behaviors

- Challenges included feelings of being lonely or isolated, feelings of invalidation and/or discrimination, male spokesperson, and challenging topics

\section{Experiences in the Counseling Profession}

- Experiences with female colleagues varied. Many were positive, some varied due to personality, some were challenging

- Relationships with male peers varied. Many were positive, sense of comradery; some male/male colleague relationships were challenging due to communication

- Benefits included clients need and want male counselors and highly marketable

- Lack of trust of male counselors, female clients possibly preferring female counselors, and pigeonholed to male clients

Knowing common male experiences in counseling programs and the profession can inform recruitment strategies and determine changes that need to take place. Many male experiences with male and female peers and faculty are positive, which is important and should continue. However, there are issues that need to be addressed. There are benefits or privileges to being a male minority in counseling programs. Benefits of being 
a male minority could be utilized in the recruitment process. However, unearned male privilege should be addressed. It is important that counseling programs examine biases within the program, faculty and students, and implement change to increase equity amongst students and decrease male privilege.

Although there are benefits and privileges, there are also challenges. Increased awareness of these challenges could inform counseling programs and the profession about possible changes that could, and in many cases should take place. Counseling programs need to address male's feelings of loneliness or isolation, feelings of invalidation and/or discrimination, the perpetuation of male stereotypes, compelling males to be male spokespersons, and the need to create safe environments for challenging topics. Addressing these issues would positively affect the learning environment of all counseling students, and not only male counseling students. There are challenges in counseling sites that are more difficult to address. These include the lack of trust of male counselors, female clients possibly preferring female counselors, and pigeonholing male counselors. Counseling practices need to consider the many positive qualities male counselors bring to the profession for all clients, not only boys and men clients.

\section{Implications}

- The experiences of participants likely reflect experiences of prospective, current, and past counseling students and should be considered in counseling programs' recruitment strategies, teaching practices, and counseling program environments.

- Implementation of participant suggested recruitment changes could make counseling programs more attractive to incoming students, resulting in increased male student enrollment 
- Counseling programs should address privileges and challenges of male students in order to attract and retain male students, as well as promoting an inclusive learning environment

- Increased male enrollment and retention could lead to financial gains and viability of counseling programs, which, in turn, leads to more male counselors serving diverse populations 


\section{References}

Bandura, A. (1986). Social foundations of thought and action: A social cognitive theory. Englewood Cliffs, NJ: Prentice Hall.

Creswell, J. W. (2013). Qualitative inquiry and research design: Choosing among five approaches. Thousand Oaks, CA: Sage Publications.

Creswell, J. W. (2014). Research design: Qualitative, quantitative, and mixed methods approaches. Thousand Oaks, CA: Sage Publications.

Creswell, J. W. (2016). 30 Essential skills for the qualitative researcher. Thousand Oaks, CA: Sage Publications.

Evans, M. P. (2013). Men in counseling: A content analysis of the Journal of Counseling \& Development and Counselor Education and Supervision 1981-2011. Journal of Counseling \& Development, 91, 467-474.

Fujikura, Y. (2008). Exploration of gendered patterns in counseling students' perception of training experiences. Dissertation Abstracts International Section A, 69, 2155.

Huntington, J. L. (2012). Male counseling student's perceptions of female clients, peers, and faculty (Order No. 3523432). Available from ProQuest Central; ProQuest Dissertations \& Theses Global. (1044378454). Retrieved from https://login.cyrano.ucmo.edu/login?url=http://search.proquest.com/docview/1044 378454 ? accountid $=6143$

Jencius, M. (2017). Counselor Educator and Supervision Network - Listserv. http://www.cesnet-1.net/

Lent, R. W., \& Brown, S. D. (2013). Social cognitive model of career self-management: Toward a unifying view of adaptive career behavior across the life span. Journal 
of Counseling Psychology, 60(4), 557-568. doi:10.1037/a0033446

Lent, R. W., Brown, S. D., \& Hackett, G. (1994). Toward a unifying social cognitive theory of career and academic interest, choice, and performance. Journal of Vocational Behavior, 45(1), 79-122. doi:10.1006/jvbe.1994.1027

Lent, R. W., Brown, S. D., \& Hackett, G. (2000). Contextual supports and barriers to career choice: A social cognitive analysis. Journal of Counseling Psychology, 47(1), 36-49. doi:10.1037/0022-0167.47.1.36

Lent, R. W., Brown, S. D., Brenner, B., Chopra, S. B., Davis, T., Talleyrand, R., \& Suthakaran, V. (2001). The role of contextual supports and barriers in the choice of math/science educational options: A test of social cognitive hypotheses. Journal of Counseling Psychology, 48(4), 474-483.

Merriam, S. B, \& Tisdell, E. J (2016). Qualitative research: A guide to design and implementation.(4th ed.). San Francisco, CA: Jossey-Bass.

Michel, R. E., Hall, S. B., Hays, D. G., \& Runyan, H. I. (2013). A mixed methods study of male recruitment in the counseling profession. Journal of Counseling \& Development, 91(4), 475-482. doi:10.1002/j.1556-6676.2013.00120.x

Reetz, D. R., Bershad, C., LeViness, P., \& Whitlock, M. (2015). Association for University and College Counseling Center Directors Annual Survey. Association for University and College Counseling Center Directors. Retrieved from Retrieved from http://www.cacrep.org/

Schweiger, W. K., Henderson, D. A., McCaskill, K., Clawson, T. W., \& Collins, D. R. (2011). Counselor preparation (13th ed.). New York, NY: Routledge.

Seidman, I. (2013). Interviewing as qualitative research: A guide for researchers in 
education and the social sciences (4th.ed). New York, NY: Teachers College Press.

U.S. Bureau of Labor Statistics. (2011). Annual report: Women in the labor force.

Retrieved from http://bls.gov/cps/demographics. htm\#women

Willyard, C. (2011, January). Men: A growing minority? gradPSYCH Magazine:

American Psychological Association. Retrieved from

http://www.apa.org/gradpsych

Yin, R. K. (2014). Case study research: Design and methods (5th ed.). Thousand Oaks, CA: Sage. 


\section{SECTION FIVE}

CONTRIBUTION TO SCHOLARSHIP 


\section{Target Journal}

The Journal of Counseling and Development (JCD) is the official publication of the American Counseling Association (ACA, 2017a). It is published quarterly in January, April, July, and October. ACA has 20 divisions that provide leadership and resources unique to the division's area of specialization. ACA is divided into four regions that serve members in different geographical locations. In addition, ACA has 56 branches in the United States, Europe, and Latin America. The Journal of Counseling and Development publishes articles on practice, theory, research, assessment and diagnosis, and profiles of individuals who have contributed to the profession.

\section{Rationale for this Target}

This journal was chosen because it is the premier journal of counselors and counselor educators (ACA, 2017a). This journal reaches a large number of professionals in the counseling profession. It is a free on-line publication to all members, but members can also request a hard copy for a $\$ 35$ fee. It can also be accessed through libraries with a subscription to the article for individuals who are not members of ACA. Therefore, numerous counseling students and professionals will have access to the findings.

\section{Plan for Submission}

According to the JCD (ACA, 2017a), manuscripts are submitted on-line. A website specific for this process is available. A user ID and password will be obtained during the first sign-in. If challenges are experienced, additional support is available via email or phone. The review process is blind peer review. Therefore, authors must not submit manuscripts with identifying information. A title page will be submitted 
separately from the manuscript through the submission process to mask the author's identity.

The plan for submission of the article is for the researcher to submit to JCD as soon as the dissertation is complete. Two reviewers will decide if an article is accepted. If the article is accepted, rewrites are typical (ACA, 2017a). Per JCD article submission requirements, the researcher will not be able to submit to another journal until the article has been rejected. However, if it is accepted, the researcher cannot submit a substantially similar article to any other journal. 


\section{Journal Article}

A Qualitative Case Study of Male Recruitment in Counseling Programs

Amber F. Lancaster

University of Central Missouri 


\begin{abstract}
Little is known about what attracts men to the counseling profession. This qualitative case study examines what attracts men to the counseling profession, recruitment strategies, and proposed recruitment strategies that could affect prospective male students. Findings indicated men are attracted to the field for various reasons. Most participants did not notice any specific recruitment strategies directed toward males. The participants shared ideas for future male recruitment. Implications for counselor preparation programs are presented.
\end{abstract}

Key words: male, men, counselor, counseling, recruitment

A disproportionally low number of males make up the population of counselors. This includes men who apply to counseling programs, who are in counseling programs, and who are in the counseling profession (Reetz, Bershad, LeViness, \& Whitlock, 2015; Schweiger, Henderson, McCaskill, Clawson, \& Collins, 2011; U.S. Bureau of Labor Statistics [BLS], 2011). There are approximately three women to every one man in mental health fields (BLS, 2011). The Association for University and College Counseling Center Directors (AUCCCD) reported only $26 \%$ of college counseling center professional staff are male (Reetz et al., 2015). In addition, there are approximately two women to every one man in master's counseling programs (Schweiger et al., 2011). This represents an unfortunate significant difference in the number of men and women in counseling programs and professional counseling.

More males are needed in the helping fields, specifically more male counselors (Paul \& Paul, 2015). This gender disparity "limits the voice of male counseling students, affects client options, and influences the perception of the counseling profession" 
(Michel, Hall, Hays, \& Runyan, 2013, p. 475) in a variety of ways. First, male counselors are important for some clients' treatment. A lack of male counselors limits client opportunities (Michel et al., 2013; Paul \& Paul, 2015). This may be particularly vital for men seeking help with sexual concerns and parenting (Rochlen \& McKelley, 2009). In addition, evidence has indicated males who were sexually abused may prefer male counselors to discuss sexual abuse (Paul \& Paul, 2015). This is an important consideration since the incidence of sexual abuse for males is approximately one in six (Briere \& Elliot, 2003; Dube et al., 2005).

It is posited men might be more open to counseling if there were more male counselors available (Michel et al., 2013; Paul \& Paul, 2015; Pederson, 2015). This is especially important considering the suicide rates of men, which is approximately four times as high as the suicide rate for women in the United States (American Foundation for Suicide Prevention [AFSP], 2017). The rate of suicide is highest amongst middle age men. In 2015, White males accounted for seven of 10 suicides. According to the Center for Disease Control and Prevention (CDC, 2016), although the suicide rate is consistently rising across many demographics, there was a staggering $43 \%$ increase in suicide deaths of men aged 45-64 between 1997 and 2014. In 2015, a total of 12,107 men between the ages of 45 and 64 died from suicide. There were 44,193 suicides in the United States, 33,994 of which were males (Drapeau \& McIntosh, 2016). Of the 33,994 male suicides, White males numbered 30,658 suicides. Men need to have their mental health needs met in order to decrease the number of completed male suicides in the United States.

It is evident men are needed in the counseling profession. Therefore, it is necessary to recruit them. Unfortunately, there is very little research on male recruitment 
in the counseling field. Michel et al. (2013) investigated views held by male students and counselor educators as related to male student recruitment and males in the counseling profession. Ten male students were interviewed and qualitative methods were utilized, whereas 217 counselor educators completed an online survey and quantitative methods were used for analysis.

Researchers found that male graduate students' ideas for male recruitment included targeted recruitment strategies that highlight male success stories, a welcoming environment, support networks, and faculty committed to male recruitment and retention in counseling programs. Researchers also found that although many counselor educators expressed an interest and a need to take steps to recruit more males into the counseling profession, almost half stated no efforts were being made in their programs (Michel et al., 2013). Some programs made specific efforts to target male recruitment ( $\mathrm{n}=27,12.4 \%)$, some were gender neutral $(\mathrm{n}=34,15.7 \%)$, but most recruitment strategies depicted numerous diverse cultural characteristics and were not gender specific.

An important finding from Michel et al. (2013) was learning male students' perspectives on male recruitment. Michel et al. did not specifically address what attracts males to the counseling profession, and the focus appeared to be counselor educators' views on recruitment. There remains a gap in the literature on male recruitment in counseling programs. A greater understanding of what attracts men to the counseling profession is an important step to increase the number of male applicants and students in counseling programs. In addition, counseling programs could benefit from a knowledge base that informs male recruitment strategies, which affects financial gains and viability of counseling programs. 
The purpose of this qualitative case study was to increase understanding of males' attraction to counseling programs: to increase understanding of the shared experiences in recruitment of males in the female-centric counseling profession (Reetz, Bershad, LeViness, \& Whitlock, 2015; Schweiger, Henderson, McCaskill, Clawson, \& Collins, 2011; U.S. Bureau of Labor Statistics [BLS], 2011). The research questions guiding this inquiry were as follows: 1) What attracts men to the counseling field? 2) What role does overt or covert recruitment strategies play in recruitment of males? and, 3) What recruitment strategies could be beneficial to attract future men?

\section{Conceptual/Theoretical Framework}

The lens through which this study was conducted was the social cognitive career theory (SCCT) (Lent, Brown, \& Hackett, 1994). Bandura's social cognitive theory (1986) is the foundation for SCCT. Both theories stress the interaction among cognitiveperson variables. These include self-efficacy, outcome expectations, and goals (Bandura, 1986; Lent et al., 1994). Furthermore, SCCT examines how these factors interact with other personal characteristics such as gender, ethnicity, and culture, as well as environmental contexts such as social support, barriers, and educational experiences. The SCCT proposes it is the interactional dynamic of these components that affect career pursuits and selection.

SCCT (Lent et al., 1994) was chosen as the lens to view this study for a few specific reasons. First, there are few men in the counseling field (BLS, 2011; Evans, 2013; Reetz et al., 2015; Schweiger et al., 2011) and gender inequality is likely a central reason. SCCT recognizes individuals may not be able to or are unwilling to choose careers, even though there is an interest (Lent \& Brown, 2013; Lent et al., 1994, 2000; 
Lent, Brown, Brenner, Chopra, David, Talleyrand, \& Suthakaran, 2001). Furthermore, SCCT acknowledges there are additional factors that have a significant influence on career choice, such as personal characteristics (e.g., age, gender, and race) and environmental factors (e.g., support, barriers). It is possible there are men who are interested in counseling, but as a result of person-cognitive and environmental factors, they may not pursue or persist in the counseling field.

\section{Design of the Study}

In order to study the experiences of male counselors in a feminized profession, a qualitative case study was determined to be an appropriate methodology. Participants belonged to a narrowly defined system of males in master's and doctoral counseling programs and male professional counselors. This highly bounded system is characteristic of qualitative case studies (Creswell, 2013, 2014, 2016; Merriam \& Tisdell, 2016; Seidman, 2013). The methods included individual interviews, observations, and artifact/document analysis. Data analysis started as soon as data collection began.

\section{Participants}

Prior to data collection, Institutional Review Board approval was received. The participants of this study were 23 men who were current students in programs accredited by Council for Accreditation of Counseling and Related Educational Programs (CACREP), master's or doctoral, and graduates of CACREP accredited counseling programs, master's or doctoral level. As a result of the uniformity of the CACREP accreditation process, and the consistent curriculum requirements across counseling programs, students in CACREP programs and graduates of CACREP accredited programs were selected for this study. 
The researcher used non-probability and purposeful sampling to ensure participants were representative of the population being studied (Creswell, 2013, 2014, 2016; Merriam \& Tisdell, 2016; Seidman, 2013). Men were selected who were in counseling programs or graduates from counseling programs and those practicing in the counseling field. Most participants were recruited from the Counselor Educators and Supervisors Network Listserv ([CESNET-L]; Jencius, 2017). Snowball sampling was also utilized by asking participants to inform others of the opportunity to take part in the study (Merriam \& Tisdell, 2016).

\section{Data Collection Tools}

Consistent with qualitative research, a number of data collection tools were utilized, which included individual personal interviews, observations in CACREP programs, and artifacts or documents (Creswell, 2013, 2014, 2016; Merriam \& Tisdell, 2016; Seidman, 2013). Prior to interviewing participants, the researcher provided the informed consent and allowed participant questions. It was made clear to all participants they could withdraw from the study at any time. The individual interviews averaged 3060 minutes, via phone or in person, dependent on the needs and the location of the participant. Individual interviews were conducted in a conversational style exploration of participants' personal stories (Merriam, 2009; Seidman, 2013). The questions were organized to "yield descriptive data" (Merriam, 2009, p. 99) and were semi-structured.

Observation is a common form of data collection in qualitative studies (Merriam \& Tisdell, 2016) and was utilized as a research tool in this study. The researcher visited three CACREP counseling programs to collect recruitment material and to observe the environment. The researcher's role in the setting was a complete observer at two of the 
universities (Merriam \& Tisdell, 2016). The researcher was not completely out of the students' or faculty's sight, but they were not aware of the observation. The researcher walked through the facility, looked at bulletin boards, and viewed into classrooms. Although the goal of the researcher was that of a complete observer in all three programs, the researcher's role in one of the settings became that of observer as participant (Merriam \& Tisdell, 2016). The researcher had difficulty locating the exact location of the counseling program and was assisted in located it. This led to staff and faculty engaging with the researcher and the researcher's actions were interpreted as a prospective student. The researcher felt uncomfortable because this seemed dishonest and misleading. Therefore, the researcher disclosed her research intentions.

Various documents were utilized to mine data (Merriam \& Tisdell, 2016). These included recruitment material from CACREP counseling programs. Fliers and pamphlets were collected from three CACREP accredited programs. The researcher accessed the websites of CACREP counseling programs through the CACREP website. These websites were scanned for recruitment material and were included in the data collection and analysis process.

\section{Data Analysis}

The researcher utilized a conventional structure employed in qualitative data analysis (Creswell, 2013, 2014, 2016; Merriam \& Tisdell, 2016; Seidman, 2013). Analysis was started as soon data collection was initiated. Participants were assigned pseudonyms to ensure confidentiality. Interviews were transcribed and coded. The researcher utilized open coding, which produced numerous categories or themes, across the various forms of data (Creswell, 2013, 2014, 2016; Merriam \& Tisdell, 2016; 
Seidman, 2013). The researcher reduced the number of categories through axial coding (Merriam \& Tisdell, 2016). In addition, the researcher utilized a constant comparative method until the study was completed (Merriam \& Tisdell, 2016). In other words, as categories emerged, the researcher determined if they fit within larger ones. This method reduced the number of themes and made each theme more encompassing.

A number of methods were utilized to increase qualitative reliability and validity of the findings (Creswell, 2014, p. 201). In order to increase qualitative reliability, procedures included maintaining a chain of evidence and providing access to an external observer (Yin, 2014). The constant comparative method was utilized in data analysis (Creswell, 2014). An analytical memo was utilized to keep notes about the codes and how the codes were defined (Merriam \& Tisdell, 2016). Lastly, the researcher reread transcripts to check for accuracy in the transcription process (Creswell, 2014).

A number of methods were also utilized to increase qualitative validity (Creswell, 2014, p. 201). Triangulation of data took place through synthesis of data gathered from interviews, observations, and artifacts/documents (Merriam \& Tisdell, 2016; Yin, 2014). Member checks were also utilized to increase trustworthiness of the findings (Creswell, 2013, 2014, 2016; Merriam \& Tisdell, 2016; Seidman, 2013). Furthermore, the researcher used rich, thick descriptions in the findings; negative or discrepant findings were shared; and the researcher disclosed possible biases (Creswell, 2014).

\section{Findings}

The following section presents the findings. It includes the research questions and the themes that emerged under each research question. These themes became evident 
from the triangulation of data from interviews, observations, and artifact/document analysis.

\section{Research Question One}

Research question one sought to determine what attracts men to the counseling field. All of the participants discussed their inspiration to pursue an education and career in counseling. Although participants' motivation to enter the counseling field was not the same, each was inspired in some way to pursue counseling. The desire to help others was a general theme that emerged. At first, it seemed that all of the themes related to attraction to the field could fall under this theme. However, many of the participants had specific catalysts that led to their desire to help others. These included a calling, personal or family experience, and role models.

Help others. A primary reason men were attracted to counseling was the desire to impact and help others. These participants did not emphasize other factors that influenced their attraction to the counseling field. Quincy wanted to help people and he wanted to do "altruistic work." He "wanted to be able to give, as well, with my career." Rusty's sentiments were similar, "I knew from an early age that I held a lot of people's confidences and at the time didn't know what to do with that. So, I had a want to be in the helping profession." Mac stated, "I decided that I would do something selfless and rewarding and noble." Neal said, "I wanted to help people in some kind of meaningful way."

A group of the participants described the desire to help as specific to children. Mac stated, "Imagine these people who are adults and come to therapy what their lives might look like had they been seen as children or had someone intervened in some way 
when they were younger." Chris stated he was attracted to counseling because he wanted to support children and believed he was equipped to do so. Chris said, "I decided that with my experience and gifts that I could better serve students if I was a counselor."

Jasper stated, "I always had this inclination toward working with kids. So, I just tried to harness things that I felt I was good at and/or enjoyed." Jasper's self-efficacy is indicative of social-cognitive factors at work. If individuals have self-efficacy and believe their efforts will produce a positive outcome, then interest in a particular career choice is developed and the goal pursued (Lent et al., 1994, 2000).

A calling. Some of the participants described their attraction to the counseling field as a calling, which was spiritual or religious in nature. Their calling led them to want to help and support individuals. Due to their calling, these participants had selfefficacy and pursued the counseling profession, which is demonstrative of socialcognitive factors (Lent et al., 1994, 2000). Chris said, "It is amazing when a human being has a calling and you get to do what you love, and have an income, and may even have a retirement income. That is pretty cool."

Glen stated, "I think it's a calling. You can be very entrepreneurial. You can be creative. You can do all the things that you can do in almost any career in the counseling profession. That it's a good calling, life choice." Ivan stated,

I think I was honestly called to it. I was attracted to it by being open to it by being open to other forces than just the world, and I think I was drawn to it by God. Yeah, I do think it was a calling. My life prepared me for this. Trent stated, "I enjoy helping people and felt like God was leading me into counseling. So, I went there and I enjoy it a lot so far." 
Personal or family experience. Some men were attracted to the counseling field due to their life experiences with substance abuse and mental health issues, either their own experience or someone they knew. They were affected by their life experience and they wanted to use their experiences to help others who were going through similar circumstances. Despite how challenging some of these life occurrences had been, it was these experiences that manifested confidence in their ability to help others. Therefore, these participants pursued the educational goal of the counseling field.

Ivan stated, "I've had mental health issues and addiction issues in my family and not necessarily a stranger to addiction issues myself." Ivan continued, "My job, my goal was to get a degree that would allow me to help people who were addicted to drugs and alcohol. That was my focus."

Leroy shared that his family had issues with mental health and substance abuse that went untreated due to limited access and stigma of seeking mental health help. Leroy said,

Nowadays, you see the thing with the opiate crisis, as like this really national crisis for people, but back in my day, when there was less information, it was primarily people of color and primarily people of a low social economic habit. The opiate crisis, they would just call them junkies. And we kind of relegated them to being moral failures, moral defects that needed to be rejected or to be in church. I saw that and even though I was a young child, I knew there was a component here missing. There had to be somebody who works on these things within the community. 
Role models. Some of the participants' attraction to the counseling field was due to role models who came from books, mentors, and counseling experience. Environmental influences, such as career role models affect goal pursuit (Lent et al., 1994) and, therefore, influence the development of self-efficacy and outcome expectations (Lent et al., 2000). Role models were clearly an important factor in some men's attraction to the counseling field.

Otto shared how important role models were in his recruitment. I've always had really phenomenal male mentors and they have cleared the way and opened up some obstacles. Even before they knew that I was a trans guy, because like my professors didn't know, I wasn't out just yet. Even before they knew they absolutely took me under their wing, and helped me out in ways that I am supremely grateful for. Without their help, I think I would have left the field a long time ago.

Neal also shared that he was influenced by a male author in the counseling field as well as a male helping professional.

Victor Frankl was a male. So, I think my introduction into the field was actually from a male writer, male psychiatrist, and then, someone I consulted with, when I was considering this profession, was also a male. He was a psychologist ... and he had been in the psychology field for a long time, and really kind of helped me understand some of the differences between the different disciplines, and their approach to helping people. So, in that sense, I had some male figures, that played prominent roles, as I made that transition, and decision. 
Neal said these role models "lessened some of that stigma around being a male, and making the decision to enter the counseling field."

Some participants were attracted to the counseling field due to the influence of their counseling experience. Vincent discussed his experience with his counselor as a catalyst for his attraction to the field. Vincent said, "That experience really was the first because we talked about it briefly when I was seeing him. And so, that was really the first moment where I was thinking maybe this is something that I would be interested in.

Uri communicated that his personal counselor was paramount in his attraction to the counseling field.

I had seen a counselor in the previous semesters for some personal stuff I was going through and I thought about how much I liked that experience and enjoyed it and how much it changed my life. I decided that might be something I'm good at, and so, I started applying to master's programs in counseling. I was specifically interested in the counseling profession as opposed to the psychology, social worker, something like that, just because the person I saw was a counselor.

\section{Research Question Two}

Research question two explored overt or covert recruitment strategies that

affected male recruitment. The majority of the participants stated they did not notice any type of overt or covert strategies that were useful in the recruitment of males. Many participants did not see anything that was "welcoming" toward men. Some men shared that they did not feel welcomed, but they also did not feel unwelcomed. Instead, these participants thought the recruitment strategies were neutral. Some participants discussed the importance of seeing men on the counseling program's website. Other participants 
discussed the significance of male faculty in their interviews. Regardless of where the participants saw the men associated with the counseling field, they were an important factor in the participants' initiation of the career development process; the process of forming and eventually developing educational and career interests (Lent et al., 1994).

No specific male recruitment. Most participants did not recall any specific recruitment strategies that seemed directed toward men or welcomed men. Leroy did not notice recruitment strategies that welcomed men. He said, "I never got that message like 'Hey, you guys, we want to have you here."” Otto's response was "No. God no, not even a little bit" when he was asked if there was anything he saw or heard that sent the message of men being welcome in the counseling profession. Winston stated, "There was no overt message about 'Men apply here.' I didn't get that message.”

Neutral recruitment. Some of the men stated that they did not necessarily see anything that indicated men were welcome. However, there was not anything that indicted men were not welcome. Quincy stated, “I wouldn’t say that anyone went out of their way to do that. I don't know that I got the opposite impression either." Percy said his experience was similar, "Nothing that said, 'Hey, men can be counselors, too,' or nothing to that effect, and nothing that was exclusionary either that said, 'You know, we really just kind of want females, so thanks, but no thanks.' I think that's fair to say as well." Ivan reported that he did not see or hear any recruitment strategies that were welcoming toward men. However, he said, “I didn't ever not feel welcome. It felt pretty neutral, which I appreciate." 
Male faculty in recruitment. Some of the participants discussed the importance of male faculty. Neal said that seeing male faculty was instrumental in his decision to apply to certain programs.

When I was looking at different programs, and considering my options, in terms of applying to master's programs in counseling, I do remember looking at their faculty pages, and just getting a general sense of who was teaching at these different programs...I can't remember a single one where there wasn't at least one male there. And I think that did help me feel like, Okay, this isn't ... it's not just something that women do is enter the counseling field.

Neal continued, "Someone that looks like me, someone who fits demographically, fits some of the categories that I fit into, did make me feel like, 'Alright, this is probably an okay place for me to go and learn."”

Frank said that being interviewed by a male faculty member was important in his recruitment. Frank said, "I think I felt like I would be taken more seriously because it was a man. I kind of hate saying that, but that ... I felt like it was a little more legitimized. Yeah. I don't know why, honestly."

Winston shared a similar experience in having male faculty present in the recruitment process.

I found myself drawn to the graduate school I accepted and went to because there were several men in the faculty. I compared that with some other faculties at other universities that were predominantly women. I did not feel being in a room full of women prospective students and women faculty members...I wouldn't say 
I felt uncomfortable, but it didn't feel like a good spot for me. Then when I went to my current university that I graduated from, I spoke with the male professors there and something felt right. It felt, "Okay, I can be here." There are other men here who share my perspective on the world. They're not hyper-masculine. They are engaged in the counseling profession, and it gave me a sense of belonging that, "Yeah, you can do this as a male, most definitely."

\section{Research Question Three}

Research question three sought recruitment strategies male participants believed could be beneficial to attract future men. Participants shared ideas on recruitment of males into the counseling profession. All participants agreed that male recruitment is needed in order to increase the number of males attracted to counseling programs and the profession. Derek shared his thoughts on the importance of male recruitment.

Recruiting male counselors is a great idea... when you asked me the questions, I drop a blank half the time, which says something in itself. Like, "Oh yeah, we should recruit more males." I mean I know it's an issue, but nobody's really done anything about it.

Most participants had ideas for male recruitment. Participants' suggestions for male recruitment included informing prospective students they are needed and highly marketable; visibility of men on program websites, brochures, and programs; and increase awareness of the counseling field. Some participants believed recruitment techniques may need to be changed in order to reach more men. There was also a small number of participants who were not sure how to recruit more males. 
Each of the suggested recruitment strategies addresses integral pieces of SCCT (Lent et al., 1994). These recruitment strategies portray the message that the counseling profession is a viable option for males. These recruitment methods likely promote selfefficacy in counseling with the belief males can and will be effective in pursuit of a counseling profession.

Male counselors are needed. Many of the participants stated that if men knew they were needed, counseling programs would likely recruit more males. The participants indicated male perspectives are needed because they bring another viewpoint that is important in counseling programs as well as the profession. Participants also shared male counselors are needed because clients need and sometimes prefer male counselors. Participants said male counselors can be useful to male and female clients, depending on the presenting issue.

Jasper shared that he believes men need to know "their presence and perspectives are needed." Derek stated, "Men are really needed. I mean, in the field they are vastly underrepresented. I think a lot of clients want male counselors." Winston said, "I've noticed there's a need. I've heard several times men who've felt relieved to have a male counselor to talk to...I was surprised. I didn't expect that. I think that's maybe something that should be explored, the need for male counselors for male clients. I think there is a need for it and I think it's important."

Percy shared that if men knew they were needed they might decide to enter the counseling program.

That just as much as we need to have multiculturalism as part of our continuing dialogue as a profession, there needs to be an open understanding that men bring 
qualities to the field that women cannot, just like any other individual from some other cultural group can bring to the field and to serving clients too.

Percy expanded, "I think it's a benefit to our profession that those points of views exist and that it's not all one-sided, but that there's a balance...to a given issue." In sum, Percy believed "There's a value in balancing the profession and encouraging men to pursue the profession as well."

Highly marketable. Most participants shared that they are highly marketable as a male minority in the counseling profession. Participants believed it could be beneficial to inform prospective male students how marketable they are. Barry stated, "You don't have to be at the top, you can be average and you're going to be wanted...I had people interested in me just because I was a male and they wanted a male in that spot.”

Neal shared that being a male was advantageous in his placement in internship sites, "When I was looking at internship positions... both of the places said they would be happy to have a male because they had a shortage, and they had male clients who specifically wanted to see a male counselor."

Glen shared similar sentiments about being in high demand, "I often do have opportunities because they are looking for a male counselor, and that would be, actually, my current opportunity. I feel like there's not enough males in the field and there's demand for it." Glen said, "We're always looking to recruit more male therapists."

Male presence on websites/brochures, and programs. Some of the participants thought having a visual of males on websites, brochures, and in programs could be useful in recruitment. They thought additional male presence would recruit male students. Participants communicated that male peers were instrumental in feelings of connection, 
commonality, and someone they could relate. Participants shared that seeing and having male faculty was important for the same reasons. This was a significant factor in their recruitment, and could be in the recruitment of future male students. Winston shared the importance of males in recruitment. Winston stated, "Having males on faculty or the graduate program's website in the photos and things like that." Winston said, "I think maybe just acknowledging in an open way through recruiting that men are welcome here. This is a great place for males."

Neal discussed the importance of his male peers. Furthermore, he suggested that programs should make a conscious effort in balancing male and female numbers.

Having male peers was very helpful. So, I think if counselor education programs can be intentional about when they're putting their cohort model, or they're just developing admissions criteria, I think trying to aim for having a mix of genders would be helpful. Make sure that there's not a lone male in a group of females. Neal elaborated on the importance of male faculty in his recruitment.

I started noticing that, at least at the professorial level, there are quite a few men. So, I think that provided maybe a little comfort, around that discomfort of thinking about entering a profession that's, at least in my perception, was dominated by females.

Trent also believed additional men would be beneficial in the recruitment of men. Trent said, "I think maybe the professors or maybe getting other men counselors, that would make me feel like 'Why can't I be one too?"”

Increased awareness about the counseling field. Some participants shared the belief that in order to recruit men, there is a need to increase awareness about the 
counseling field. Participants said that many people do not understand the differences between the helping professions. In order to recruit more men, participants believed it is important to increase public awareness. Participants also suggested reaching out to undergraduate programs to educate about counseling programs in order to help decrease the stigma associated with counseling profession.

Vincent said, "I think a greater public awareness would help a lot. I think a lot of people are still not really sure of what counseling is, especially compared to some of the other mental health fields." Vincent said he believes men are more attracted to psychology or social work, so increased knowledge about counseling could be beneficial to male recruitment. Vincent stated, "I think greater public awareness and more information that it is a viable career choice for anyone that is interested in it."

A group of men believed male recruitment should take place in undergraduate programs. Elliot's idea for recruitment was to reach potential male candidates earlier and, in turn, decrease the stigma associated with counseling. Elliot suggested increasing awareness in undergraduate programs that might draw some males and "reduce the fear of going into professions like this, that that may draw them in a little bit more, that it's not just the engineering and the construction and all these stereotypical male professions."

Need to recruit differently. Some participants believed men need to be recruited differently all together. These participants believed using different terminology could help to reach and recruit more men, and lower the stigma associated with counseling. Mac stated, "Well, I know that strategies for getting men into counseling, in general, to attend as clients, using verbiage such as coaching, like men coaching or live coaching, those are less threatening terms." Furthermore, "Maybe a bigger focus on career 
counseling" and "describing it as a way to help people with everyday problems or assist people in becoming better versions of themselves or helping people achieve the goals that they want in their life versus working with emotionally focused trauma therapy."

Jasper stated he believes recruitment needs to be addressed differently for men too. Jasper suggest that counseling be promoted "as a trade, almost like going back to a trade school to learn welding, construction, to become a mechanic. In large part, that is what counseling is kind of like. It is the welding, construction, the mechanics of people, of relationships." Jasper continued, "A part of me wants to almost get outside of the realm of the obvious ways of promotion" and "using gender socialization as a means to recruit. How do stereotypically, how do men navigate relationships with other men and how do they stereotypically find meaning in work? Almost harnessing those and maybe to recruit more men."

Not sure how to recruit. Some of the participants were not sure how to recruit men into counseling programs and the profession. These participants believed more men need to be recruited, but did not have ideas on how to recruit. These participants expressed the lack of males as a larger issue, and recruitment will most likely not address the problem.

Winston did not think recruitment strategies would be effective in male recruitment because it is a societal issue.

There are all these notions about men as being breadwinners, as being the primary earner in their families, and counseling isn't it. That's not going to get you there. I think it's more complex than just recruiting men. I think it comes down to 
salary. It comes down to stereotypes about what it means to be a man and what profession they should take.

Winston shared that he believes the counseling profession will continue to struggle with male recruitment.

It's going take a certain kind of male who is attracted to giving up that value of finances or giving up that expression of hyper-masculinity in a profession or dominant authority or whatever it is that they're seeking in a profession. The counseling profession is, I think, type casted as being a female profession like education and teaching. I think a social shift is what probably needs to occur in order to recruit men into the profession.

\section{Discussion}

Men are a minority in the counseling field (BLS, 2011; Reetz et al., 2015;

Schweiger et al., 2011), which is a noteworthy issue for the counseling profession because male counselors are needed (Fujikura, 2008; Michel et al., 2013; Paul \& Paul, 2015). A lack of male counselors limits client options in a variety of ways (Michel et al., 2013; Paul \& Paul, 2015), and some clients need or prefer male counselors (Michel et al., 2013; Paul \& Paul, 2015; Rochlen \& McKelley, 2009). It is an ethical responsibility (ACA, 2014) of counselor educators, as well as a requirement of accreditation standards (CACREP, 2016) for counseling programs to recruit diverse populations, including gender. Therefore, it is imperative that counseling programs are informed on how to effectively recruit males.

The male counseling student and professional experiences were examined through a social cognitive career theory framework (Lent et al., 1994). SCCT proposes that 
social-cognitive factors influence educational and career goals, and this was true of the male participants' educational pursuits and career interests in this study. The primary influential factors were related to cognitive-person variables of self-efficacy, outcome expectations, and goals (Bandura, 1986; Lent et al., 1994). SCCT was utilized to examine how these factors interacted with gender, and environmental contexts such as social support, barriers, and educational experiences.

It was determined that there are common reasons men are attracted to the counseling field. Each of the participants were inspired to pursue counseling due to a desire to help others. However, some of them had some form of catalyst that affected their desire to help others. These catalytic factors included a calling, spiritual or religious; personal or family experiences; and role models.

Most participants did not notice any recruitment strategies, overt or covert, directed toward or welcoming of males. However, many participants said the recruitment strategies were neutral, and not directed toward any one particular group of people. The importance of seeing men on counseling program websites and in the program, male professors and peers, was significant in some participants' recruitment. Michel et al. (2013) also found that students expressed the importance of males on websites and brochures, as well as male faculty in recruitment.

Due to their experiences in selecting the counseling field and choosing a counseling program, participants had ideas about strategies they believed could be effective in recruiting more men. Participants suggested that counseling programs make it known men are needed in the field and highly marketable. It was also recommended that websites, brochures, and programs have more male faculty and students. Michel et 
al. (2013) also heard this recommendation from male students in their study. Participants in the current study said this was important in increasing feelings of connectedness, and alleviating fears of isolation and loneliness. Participants also suggested that it would be beneficial to male recruitment if programs provided more information about the counseling field and made the knowledge more common. Participants in Michel et al.'s study declared this to be the case as well (2013). Participants in the current study believed this could help inform prospective students of the unique qualities of counseling, and also make clear the counseling profession is a viable career option. Closely related, was the suggestion that recruitment may need to change so stigma is decreased that is associated with men entering a workforce that is primarily women.

These recruitment methods incorporate characteristics of SCCT (Lent et al., 1994). Integrating these suggestions into current recruitment strategies could promote self-efficacy in prospective students; the belief they will be effective in pursing the counseling field. This initial positive belief can lead to pursuit of counseling as a career. If the individual sees environmental factors as positive with few barriers, then career interests are translated into pursuit of the goal (Lent et al., 1994). However, if the person perceives the goal has too many barriers or the barriers are insurmountable, despite an interest in a particular career, the education or career goal will not be pursued. It is in counseling programs' power to promote counseling as a positive and viable career choice and decrease perceived barriers.

The findings of this study were clear. Men are inspired to go into a counseling career. Knowing male inspirations or what attracts men to the field can inform current and future recruitment strategies. Those inspirations that can be marketed could lead to 
enrollment gains. Second, many men do not notice current counseling program recruitment strategies. Therefore, new recruitment strategies could be useful in male recruitment. However, if programs elect to not use the suggested methods of recruitment, counseling programs should remain neutral in their recruitment. In other words, use recruitment strategies that indicate no one population is valued over any other. In addition, many participants were attracted to programs where male students and faculty were evident. In order to attract more male prospective students, counseling programs should have males on their websites and brochures. In addition, programs will likely attract more men if they have some male faculty in the counseling program.

There are important implications of this study. The experiences of this study's participants likely reflect experiences of prospective, current, and past male counseling students. These participants' experiences should be considered in counseling programs' recruitment strategies. Implementation of suggested recruitment changes could make counseling programs more attractive to incoming male students, resulting in increased male student enrollment. Furthermore, increased male enrollment could lead to financial gains and viability of counseling programs.

\section{Limitations and Future Research}

There are some limitations of the study. The researcher chose to focus on males in CACREP accredited counseling programs and male professional counselors who graduated from CACREP accredited programs. This narrow focus, which is characteristic of case studies, decreases the transferability of the findings (Creswell, 2013). Specifically, the findings of this study may not be transferred to non-CACREP accredited counseling programs. In addition, because the research is specific to males, 
the findings may not be transferable to females in counseling programs, CACREP or nonCACREP accredited.

CACREP accredited counseling programs were chosen owing to consistent curriculum requirements. Therefore, an assumption of the researcher was the participants of the study would have somewhat consistent educational backgrounds. However, the participants' educational backgrounds varied. First, they completed a wide variety of undergraduate degrees since master's counseling programs do not require any specific undergraduate degree. In addition, the students who were currently enrolled in counseling programs had completed different numbers of graduate credit hours. Third, participants who graduated may have had different graduate credit hours because CACREP has steadily increased the number of required hours for degree completion over the years (CACREP, 2017).

The author is a female counselor educator in a CACREP accredited master's level program. It is possible the researcher holds biases related to identifying as a female, graduating from a CACREP accredited counseling program, as well as being a counselor educator in a CACREP accredited counseling program. These biases may be rooted in the design of the study, as well as the interpretation of the findings.

Future studies may want to explore diversity factors within male recruitment. There was some diversity amongst the male participants. For example, diversity included sexuality, socioeconomic status, and ethnicity. However, the diversity within the participants' identity was not examined as a factor in their attraction to counseling or recruitment. In addition, future research could be focused on men's experiences in counseling programs that leads to their retention in counseling programs. This 
knowledge could be useful in making informed decisions in the recruitment process as well. 


\section{References}

American Counseling Association. (2014). ACA code of ethics. Alexandria, VA: Author. American Foundation for Suicide Prevention (2017). Suicide Statistics. Retrieved from https://afsp.org/about- suicide/suicide-statistics/

Bandura, A. (1986). Social foundations of thought and action: A social cognitive theory. Englewood Cliffs, NJ: Prentice Hall.

Briere, J., \& Elliot, D. M. (2003). Prevalence and psychological sequelae of self-reported childhood physical and sexual abuse in a general population sample of men and women. Child Abuse \& Neglect, 27, 1205-1222.

Centers for Disease Control and Prevention (2016). National suicide statistics. Retrieved fromhttps://www.cdc.gov/violenceprevention/suicide/statistics/index.html

Council for Accreditation of Counseling and Related Educational Programs. (2016). 2016 CACREP Standards. Alexandria, VA: Author.

Council for Accreditation of Counseling and Related Educational Programs (2017). Retrieved from http://www.cacrep.org/

Creswell, J. W. (2013). Qualitative inquiry and research design: Choosing among five approaches. Thousand Oaks, CA: Sage Publications.

Creswell, J. W. (2014). Research design: Qualitative, quantitative, and mixed methods approaches. Thousand Oaks, CA: Sage Publications.

Creswell, J. W. (2016). 30 Essential skills for the qualitative researcher. Thousand Oaks, CA: Sage Publications. 
Drapeau, C. W., \& McIntosh, J. L. (2016). U.S.A. suicide 2015: Official final data. Washington, DC: American Association of Suicidology. Retrieved from http://www.suicidology.org

Dube, S. R., Anda, R. F., Whitfield, C. L., Brown, D. W., Felitti, V. J., Dong, M., \& Giles, W. H. (2005). Long-term consequences of childhood sexual abuse by gender of victim. American Journal of Preventive Medicine, 28, 430-438.

Evans, M. P. (2013). Men in counseling: A content analysis of the Journal of Counseling \& Development and Counselor Education and Supervision 1981-2011. Journal of Counseling \& Development, 91, 467-474.

Jencius, M. (2017). Counselor Educator and Supervision Network - Listserv. http://www.cesnet-l.net/

Lent, R. W., \& Brown, S. D. (2013). Social cognitive model of career self-management: Toward a unifying view of adaptive career behavior across the life span. Journal of Counseling Psychology, 60(4), 557-568. doi:10.1037/a0033446

Lent, R. W., Brown, S. D., \& Hackett, G. (1994). Toward a unifying social cognitive theory of career and academic interest, choice, and performance. Journal of Vocational Behavior, 45(1), 79-122. doi:10.1006/jvbe.1994.1027

Lent, R. W., Brown, S. D., \& Hackett, G. (2000). Contextual supports and barriers to career choice: A social cognitive analysis. Journal of Counseling Psychology, 47(1), 36-49. doi:10.1037/0022-0167.47.1.36

Lent, R. W., Brown, S. D., Brenner, B., Chopra, S. B., Davis, T., Talleyrand, R., \& Suthakaran, V. (2001). The role of contextual supports and barriers in the choice 
of math/science educational options: A test of social cognitive hypotheses. Journal of Counseling Psychology, 48(4), 474-483.

Merriam, S. B. (2009). Qualitative research: A guide to design and implementation. San Francisco, CA: Jossey-Bass.

Merriam, S. B, \& Tisdell, E. J (2016). Qualitative research: A guide to design and implementation. (4th ed.). San Francisco, CA: Jossey-Bass.

Michel, R. E., Hall, S. B., Hays, D. G., \& Runyan, H. I. (2013). A mixed methods study of male recruitment in the counseling profession. Journal of Counseling \& Development, 91(4), 475-482. doi:10.1002/j.1556-6676.2013.00120.x

Paul, J., \& Paul, W. (2016). Counselor attitudes of effectiveness with sexually abused men. Community Mental Health Journal, 52(8), 1057-1063. doi:10.1007/s10597015-9838-8

Pedersen, A. (2015, Sep 22). A campus call for mental health - Colleges try outreach for men to help with depression and anxiety; Meet them at fraternities. Wall Street Journal. Retrieved from https://login.cyrano.ucmo.edu/login?url=http://search.proquest.com/ docview/1714 145632? accountid=6143

Reetz, D. R., Bershad, C., LeViness, P., \& Whitlock, M. (2015). Association for University and College Counseling Center Directors Annual Survey. Association for University and College Counseling Center Directors. Retrieved from Retrieved from http://www.cacrep.org/ 
Rochlen, A. B., \& McKelley, R. A. (2009). Working therapeutically with stay-at-home fathers. In C. Oren \& D. Oren (Eds.), Counseling fathers (pp. 207-230). New York, NY: Routledge.

Schweiger, W. K., Henderson, D. A., McCaskill, K., Clawson, T. W., \& Collins, D. R. (2011). Counselor preparation (13th ed.). New York, NY: Routledge.

Seidman, I. (2013). Interviewing as qualitative research: A guide for researchers in education and the social sciences (4th ed.). New York, NY: Teachers College Press.

U.S. Bureau of Labor Statistics. (2011). Annual report: Women in the labor force. Retrieved from http://bls.gov/cps/demographics. htm\#women

Yin, R. K. (2014). Case study research: Design and methods (5th ed.). Thousand Oaks, CA: Sage. 


\section{SECTION SIX}

\section{SCHOLARLY PRACTIONER REFLECTION}


A dissertation can change an individual. I remember a former professor who explained to me that a dissertation takes the writer over like vines (G. Mimms, personal communication, 2005). I did not understand what she meant by the metaphor at the time. However, I understand now how the dissertation process can resemble vines. My dissertation took me over and the vines grew, slithered, and creeped into almost every crevice of my existence. The dissertation and the participants have not been far from my thoughts since the process started. The men who shared their experiences with me have been on my mind, day in and day out. As a result of these metaphorical vines, the dissertation process has influenced me in ways that were incomprehensible before the undertaking. In the following sections, I will present how the dissertation has influenced my practice as an educational leader and as a scholar.

\section{Dissertation Influence on Practice as an Educational Leader}

One of the goals I set with this dissertation was to become a more prepared, informed, and facilitative educational leader. More specifically, I wanted to increase my understanding of men's experiences in counseling programs and the counseling profession. I believed this information could assist me in meeting the needs of male students in their educational experience, which could lead to retaining them in the counseling program. Retention of male students is necessary because these students will become counselors who are needed in the counseling profession.

As an educational leader, I am an integral component in developing a learning culture that could meet the needs of male students (Merriam \& Bierema, 2014). Due to the dissertation process, I am changed as an educational leader. I am more prepared to create a learning culture for students, which has always been my goal. I have worked 
diligently to create a safe environment where self-reflection, discussion, risk-taking, and sharing one's authentic self takes place. As a counselor educator, I am called to value and respect individuals' cultures, both students' and clients' cultures (ACA, 2014; Sue \& Sue, 2016); and I have persistently made this a goal. However, I needed additional information in order to take into consideration all of the diverse qualities of the students I teach, including gender.

After the dissertation process, I feel more prepared to provide the learning culture men may need in order to gain as much as possible from their educational experience. As an educational leader, it is important I create a trusting educational environment to facilitate student learning (Ettling, 2012). According to Ettling (2012), one way I can help increase the safety of the environment is to engage in personal self-disclosure. The leader's effort in self-disclosure tends to increase trust in students as well as increase their disclosure. My disclosure is one of the ways I try to impress upon students that I am willing to take a risk and share, I am safe, and the environment is safe for them to do so as well, when they are ready.

One new disclosure I will make in the future is to state the obvious; there are few men in this room and this program. I learned from the men in this study that many want this difference to be acknowledged and gender differences discussed. They do not want the elephant in the room to be ignored. This idea is in alignment with being a culturally competent counselor (Sue \& Sue, 2016). Ethical, culturally competent counselors and counselor educators value the differences of their clients and their students (ACA, 2014; Sue \& Sue, 2016). Differences include gender identity. Educational leaders should role 
model these same qualities to their students to promote a learning environment that meets the needs of students.

\section{Dissertation Process Influence as a Scholar}

I have been a counselor educator for almost 10 years. I noticed some time ago, in my own educational programs, that men were the minority gender. As a counselor educator and supervisor, I needed to increase my awareness on how to recruit more males because some clients need and prefer male counselors (Paul \& Paul, 2015; Rochlen \& McKelley, 2009); and I needed to know how to best meet the needs of male students. I decided to look for research on male counseling students to achieve increased understanding and then modify my practices. However, I found that there was a paucity of research in this area. It was then I realized I had my dissertation topic because the male voice is not adequately represented in counselor education and supervision research (Evans, 2013; Scher, 1981).

As an educational leader, I make changes to my teaching and curriculum based on current research. This increases my utilization of "best theories and practices until new information verifies, refines, or refutes them” (Merriam \& Bierema, 2014, p. 251). Unfortunately, there was very little research on how to best address the needs of male counseling students. As an educational leader of male students, I took it upon myself to engage in research. As I saw it, because I am an educational leader, it was my responsibility to learn more so I could engage in best practices.

After reviewing the scant literature available on men in counseling programs and the profession, I realized that a quantitative study was not going to be able to dig deep enough to uncover their voices and opinions to discover what I needed to know to best 
serve male students. Quantitative research designs are utilized when researchers want to utilize numerical data and statistical analysis (Creswell, 2014). After a search of possible instruments, and finding nothing that was appropriate for the research topic, I realized I needed to complete a qualitative study.

Although I had an opportunity to practice a qualitative study in my educational program prior to the dissertation, I was still skeptical of using qualitative studies. The first reason I was leery of qualitative studies was the amount of time I heard qualitative studies take. I found, through the dissertation process, that the amount of time is extensive and what I heard was accurate. However, I also discovered that the amount of time invested is well worth it! There simply was no other way I could have increased my awareness, at this level on this topic, through quantitative means. Engaging with the participants in the interviews allowed for learning in a way that was extremely powerful. I feel honored by the extent the men in this study allowed me to learn from their experiences.

Although I have found qualitative studies to be interesting to read, another reason I was skeptical about utilizing the method was because I heard qualitative studies were less trustworthy because reliability and validity are measured differently. From personal experience with this dissertation, I found that although the methods for addressing trustworthiness are different, they are rigorous and extensive when addressed properly and ethically. I no longer believe qualitative methods are less trustworthy, and I find them more interesting than ever before.

Another goal I had with this dissertation was to contribute to the practice of educational leaders in counselor education. It is important, to me, to support and assist 
counselor educators in understanding men's experiences in counseling programs and the counseling profession. One of the best ways to do so is to share my scholarly endeavors. This information could contribute to counseling program faculty making informed decisions in the recruitment of men into counseling programs, as well as meet the needs of male students in their educational experience, which could lead to retention. I believe this dissertation has achieved that goal. This process has led me to understand that this is just the beginning of my research on this topic, and likely other topics as well. Through the dissertation process, I found educational leadership and scholarly work are closely intertwined.

I have a newfound passion in research because it increases my abilities as a leader. Engaging in, sharing of, and incorporating research findings is an integral component of effective educational leadership (Merriam \& Bierema, 2014). Engagement in scholarly efforts allows for educational leaders, specifically counselor educators and supervisors, to advocate for those they serve, whether students or clients. In counseling, leadership and advocacy are considered paramount to the quality of services offered to clients (Chang, Minton, Dixon, Myers, \& Sweeney, 2012). Leadership is an important role of counselors, whether it is in a school or clinical mental health setting (Joe, Becan, Knight, \& Flynn, 2017; Meany-Walen, Carnes-Holt, Minton, Purswell, \& PronchenkoJain, 2013), as well as counselor education. Leadership and advocacy are required core standards in the curriculum of CACREP accredited counseling programs (CACREP, 2016), and an ethical requirement of counselors and counselor educators (ACA, 2014). It is evident that educational leaders must engage in scholarly endeavors to most effectively meet the needs of those they serve. 
In sum, the dissertation process has changed me as an educational leader and a scholar. In fact, I will never be the same. I found a passion I did not know existed, which is using research in the utilization of best practices in educational leadership, as well as qualitative research. My abilities as a counselor educator can directly affect the educational environment of the students I serve. It is clear to me that "the design and facilitation of adult learning is the moment we bridge theory and practice to engage the educator, learner, process, and context in meaningful ways for diverse learners" (Merriam \& Bierema, 2014, p. 258). Through the dissertation process, I have become more fully engaged and equipped as an educational leader and scholar. 


\section{References}

American Counseling Association. (2010). Licensure requirements for professional counselors - 2010. Retrieved from http://www.counseling.org/docs/licensure/72903_excerpt_for_web.pdf?sfvrsn=2

American Counseling Association. (2012). A guide to state laws and regulations on professional school counseling. Alexandria, VA: Author. Retrieved from http://www.counseling.org/PublicPolicy/SchoolCounseling Regs2012.pdf

American Counseling Association. (2014). ACA code of ethics. Alexandria, VA: Author.

American Counseling Association. (2017a). Guidelines for authors. Journal of Counseling and Development, 45. 478-479. Retrieved from https://www.counseling.org/publications/journalguidelines/jcd.pdf documentlibrary/acajcad_v95_n4_1017guidelines.pdf?sfvrsn=5d944e2c_0

American Counseling Association. (2017b). 20/20: Consensus definition of counseling. Retrieved from http://www.counseling.org/knowledge-center/20-20-a-vision-forthe-future-of-counseling/consensus-definition-of-counseling

American Counseling Association of Missouri (2016). Retrieved from https://acaom.wildapricot.org/

American Educational Research Association (AERA) (2011). Code of ethics. Educational Researcher, 40(3), 145-156. doi: 10.3102/0013189X11410403

American Foundation for Suicide Prevention (2017). Suicide Statistics. Retrieved from https://afsp.org/about- suicide/suicide-statistics/

American Psychological Association (2009). Publication manual of the American Psychological Association (6th ed.). Washington, DC: Author. 
Association of Counselor Education and Supervision (2017). About ACES. Retrieved from http://www.acesonline.net/about-aces

Bandura, A. (1986). Social foundations of thought and action: A social cognitive theory. Englewood Cliffs, NJ: Prentice Hall.

Bernard, J. M., \& Goodyear, R. K. (2014). Fundamentals of clinical supervision (5th ed.). New York, NY: Pearson.

Bitter, J. R. (2014). Theory and practice of family therapy and counseling. Belmont, CA: Brooks/Cole.

Black M. C., Basile, K. C., Breiding, M. J., Smith, S. G., Walters, M. L., Merrick, M. T., Chen, J., \& Stevens, M. R. (2011). The National Intimate Partner and Sexual Violence Survey (NISVS): 2010 summary report. Atlanta, GA: National Center for Injury Prevention and Control, Centers for Disease Control and Prevention.

Bolman, L. G., \& Deal, T. E. (2010). Reframing the path to school leadership. (2nd ed.). Thousand Oaks, CA: Corwin.

Bolman, L. G., \& Deal, T. E. (2013). Reframing organizations (5th ed.). San Francisco, CA: Jossey-Bass.

Bolman, L. G., \& Gallos, J. V. (2011). Reframing academic leadership. San Francisco, CA: Jossey-Bass.

Briere, J., \& Elliot, D. M. (2003). Prevalence and psychological sequelae of self-reported childhood physical and sexual abuse in a general population sample of men and women. Child Abuse \& Neglect, 27, 1205-1222.

Centers for Disease Control and Prevention (2016). National suicide statistics. Retrieved from https://www.cdc.gov/violenceprevention/suicide/statistics/index.html 
Chang, A. Y., Barrio Minton, C. A., Dixon, A. L., Myers, J. E., \& Sweeney, T. J. (2012). Professional counseling excellence through leadership and advocacy. New York, NY: Routledge.

Council for Accreditation of Counseling and Related Educational Programs. (2016). 2016 CACREP Standards. Alexandria, VA: Author.

Council for Accreditation of Counseling and Related Educational Programs (2017). Retrieved from http://www.cacrep.org/

Creswell, J. W. (2013). Qualitative inquiry and research design: Choosing among five approaches. Thousand Oaks, CA: Sage Publications.

Creswell, J. W. (2014). Research design: Qualitative, quantitative, and mixed methods approaches. Thousand Oaks, CA: Sage Publications.

Creswell, J. W. (2016). 30 Essential skills for the qualitative researcher. Thousand Oaks, CA: Sage Publications.

Drapeau, C. W., \& McIntosh, J. L. (2016). U.S.A. suicide 2015: Official final data. Washington, DC: American Association of Suicidology. Retrieved from http://www.suicidology.org

Dube, S. R., Anda, R. F., Whitfield, C. L., Brown, D. W., Felitti, V. J., Dong, M., \& Giles, W. H. (2005). Long-term consequences of childhood sexual abuse by gender of victim. American Journal of Preventive Medicine, 28, 430-438.

Ettling, D. (2012). Educator as change agent: Ethics of transformative learning. In E. W. Taylor \& P. Cranton (Eds.). The handbook of transformative learning (pp. 536551). San Francisco, CA: Jossey-Bass. 
Evans, M. P. (2013). Men in counseling: A content analysis of the Journal of Counseling \& Development and Counselor Education and Supervision 1981-2011. Journal of Counseling \& Development, 91, 467-474.

Fujikura, Y. (2008). Exploration of gendered patterns in counseling students' perception of training experiences. Dissertation Abstracts International Section A, 69, 2155.

George, B. Simms, P. McLean, A. N., \& Mayer, D. (2007). Discovering your authentic leadership. In Harvard Business Review. (2011). HBR's 10 must reads: On leadership (pp. 163-177). Boston, MA: Harvard Business Review Press.

Goffee, R., \& Jones, G. (2000). Why should anyone be led by you? In Harvard Business Review. (2011). HBR's 10 must reads: On leadership (pp. 79-95). Boston, MA: Harvard Business Review Press.

Hall, S. B., Hancock, R., Hays, D., Kerns, K., Michel, R. E., Runyan, H., \& Washington, C. (2011). The Male Recruitment Survey - Counselor Version. Unpublished instrument.

Herlihy, B., \& Corey, G. (2015). ACA ethical standards casebook (7th ed.). Alexandria, VA: American Counseling Association.

Holmes, G. R., Offen, L., \& Waller, G. (1997). See no evil, hear no evil, speak no evil: Why do relatively few male victims of childhood sexual abuse receive help for abuse-related issues in adulthood? Clinical Psychology Review, 17, 69-88.

Huntington, J. L. (2012). Male counseling student's perceptions of female clients, peers, and faculty (Order No. 3523432). Available from ProQuest Central; ProQuest Dissertations \& Theses Global. (1044378454). Retrieved from 
https://login.cyrano.ucmo.edu/login?url=http://search.proquest.com/docview/1044 378454 ?accountid $=6143$

Joe, G. W., Becan, J. E., Knight, D. K., \& Flynn, P. M. (2017). A structural model of treatment program and individual counselor leadership in innovation transfer. BMC Health Services Research, 17 doi:http://dx.doi.org/10.1186/s12913-0172170-y

Kotter, J. P. (1990). What do leaders really do? In Harvard Business Review. (2011). HBR's 10 must reads: On leadership (pp. 37-55). Boston, MA: Author.

Krippendorff, K. (2013). Content analysis: An introduction to its methodology (3rd ed.). Thousand Oaks, CA: Sage.

Krueger, R. A., \& Casey, M. A. (2009). Focus groups: A practical guide for applied research (5th ed.). Thousand Oaks, CA: Sage.

Lent, R. W., \& Brown, S. D. (2013). Social cognitive model of career self-management: Toward a unifying view of adaptive career behavior across the life span. Journal of Counseling Psychology, 60(4), 557-568. doi:10.1037/a0033446

Lent, R. W., Brown, S. D., \& Hackett, G. (1994). Toward a unifying social cognitive theory of career and academic interest, choice, and performance. Journal of Vocational Behavior, 45(1), 79-122. doi:10.1006/jvbe.1994.1027

Lent, R. W., Brown, S. D., \& Hackett, G. (2000). Contextual supports and barriers to career choice: A social cognitive analysis. Journal of Counseling Psychology, 47(1), 36-49. doi:10.1037/0022-0167.47.1.36

Lent, R. W., Brown, S. D., Brenner, B., Chopra, S. B., Davis, T., Talleyrand, R., \& Suthakaran, V. (2001). The role of contextual supports and barriers in the choice 
of math/science educational options: A test of social cognitive hypotheses. Journal of Counseling Psychology, 48(4), 474-483.

Levi, D. J. (2013). Group dynamics for teams (4th ed.). Los Angeles, CA: Sage.

Meany-Walen, K., Carnes-Holt, K., Minton, C. A. B., Purswell, K., \& Pronchenko-Jain, Y. (2013). An exploration of counselors' professional leadership development. Journal of Counseling and Development: JCD, 91(2), 206-215. Retrieved from https://login.cyrano.ucmo.edu/login?url=http://search.proquest.com/docview/1330 852041 ? accountid=6143

Merriam, S. B. (2009). Qualitative research: A guide to design and implementation. San Francisco, CA: Jossey-Bass.

Merriam S. B. \& Bierema L. L. (2014). Adult learning: Linking theory and practice. San Francisco, CA: Jossey-Bass.

Merriam, S. B, \& Tisdell, E. J (2016). Qualitative research: A guide to design and implementation. (4th ed.). San Francisco, CA: Jossey-Bass.

Michel, R. E., Hall, S. B., Hays, D. G., \& Runyan, H. I. (2013). A mixed methods study of male recruitment in the counseling profession. Journal of Counseling \& Development, 91(4), 475-482. doi:10.1002/j.1556-6676.2013.00120.x

Mintzberg, H. (2005). The five basic parts of the organization. In Y. S. Jang, J. S. Ott, \& J. M. Shafritz, Classics of organizational theory (pp. 219-230). Belmont, CA: Wadsworth. (Reprinted from The structure of organizations: A synthesis of research, pp. 18-34, by H. Mintzberg, 1979, Upper Saddle, NJ: Prentice Hall). Missouri Mental Health Counselors Association (n.d.a). MMHCA 2017 Annual Conference. Retrieved from http://mmhca.com/trainingevents.html 
Missouri Mental Health Counselors Association (n.d.b). What makes MMHCA Different? Retrieved from http://mmhca.com/join-mmhca.html

Missouri School Counselor Association (2016). About us. Retrieved from http://moschoolcounselor.org/

North Central Association of Counselor Education and Supervision (2016). Retrieved from http://www.ncaces.org/

Northouse, P. G. (2016). Leadership: Theory and practice (7th ed.). Thousand Oaks, CA: Sage.

Paradise, L. V., Lolan, A., Dickens, K., Tanaka, H., Tran, P., \& Doherty, E. (2011, June). Program coordinators react to CACREP standards. Counseling Today, 53(12), $50-52$.

Paul, J., \& Paul, W. (2016). Counselor attitudes of effectiveness with sexually abused men. Community Mental Health Journal, 52(8), 1057-1063. doi:10.1007/s10597015-9838-8

Pedersen, A. (2015, Sep 22). A campus call for mental health - Colleges try outreach for men to help with depression and anxiety; Meet them at fraternities. Wall Street Journal. Retrieved from https://login.cyrano.ucmo.edu/login?url=http://search.proquest.com/docview/1714 145632 ?accountid $=6143$

Reetz, D. R., Bershad, C., LeViness, P., \& Whitlock, M. (2015). Association for University and College Counseling Center Directors Annual Survey. Association for University and College Counseling Center Directors. Retrieved from 
https://www.aucccd.org/assets/documents/aucccd\%202016\%20monograph\%20\%20public.pdf

Reynolds, D. B. (2016). Deep knowledge: A strategy for university budgetary cuts. Contemporary Issues in Education Research, 9(4), 145-158.

Rochlen, A. B., \& McKelley, R. A. (2009). Working therapeutically with stay-at-home fathers. In C. Oren \& D. Oren (Eds.), Counseling fathers (pp. 207-230). New York, NY: Routledge.

Rogers, C. R. (1961). On becoming a person: A therapist's view of psychotherapy. Boston, MA: Houghton Mifflin.

Schweiger, W. K., Henderson, D. A., McCaskill, K., Clawson, T. W., \& Collins, D. R. (2011). Counselor preparation (13th ed.). New York, NY: Routledge.

Seidman, I. (2013). Interviewing as qualitative research: A guide for researchers in education and the social sciences (4th ed.). New York, NY: Teachers College Press.

Simpson, R. (2004). Masculinity at work: The experiences of men in female dominated occupations. Work, Employment and Society, 18, 349-368.

Sue, D. W., \& Sue, D. (2016). Counseling the culturally diverse: Theory and practice. (7th ed.). Hoboken, NJ: John Wiley \& Sons, Inc.

Urofsky, R. I. (2013). The Council for Accreditation of Counseling and Related Educational Programs: Promoting quality in counselor education. Journal of Counseling \& Development, 91, 6-14. doi:10.1002/j.1556-6676.2013.00065.x 
Urofsky, R. I., Bobby, C. L., \& Ritchie, M. (2013). CACREP: 30 years of quality assurance in counselor education: Introduction to the special section. Journal of Counseling and Development, 91, 3-5. doi:10.1002/j.1556-6676.2013.00064.x

U.S. Bureau of Labor Statistics. (2011). Annual report: Women in the labor force. Retrieved from http://bls.gov/cps/demographics. htm\#women

Willyard, C. (2011, January). Men: A growing minority? gradPSYCH Magazine: American Psychological Association. Retrieved from http://www.apa.org/gradpsych

Xu, H., \& Tracey, T. G. (2015). Reciprocal influence model of working alliance and therapeutic outcome over individual therapy course. Journal of Counseling Psychology, 62(3), 351-359. doi:10.1037/cou0000089

Yin, R. K. (2014). Case study research: Design and methods (5th ed.). Thousand Oaks, CA: Sage. 
Appendix A

Email to Counseling Students and Counseling Professionals on CESNET

Dear counseling students and counseling professionals,

I am doctoral candidate under the supervision of Dr. Sandy Hutchinson

(Hutchinson@ucmo.edu) at University of Missouri and seeking participants to fulfill degree requirements for my study titled: A qualitative study of male students' experiences in counseling programs and male professional counselors' experiences postgraduation. Through this qualitative case study, I am attempting to increase understanding about male students' experiences in counseling programs and the counseling profession. I am inviting current counseling students in CACREP accredited counseling programs and counseling professionals who graduated from a CACREP accredited counseling program, in school counseling, community or clinical mental health specializations.

Participants will be invited to participate in an individual interview or a focus group, lasting approximately 30 to 60 minutes. Confidentiality will be kept by removing any identifiable information from the data collection process and data analysis. There are no anticipated risks in participating in this study. The benefits of participating in this study are you may enjoy the opportunity to express your experiences in counseling programs and in the counseling profession. You may withdraw from the study at any time. This study has been approved by the University of Missouri Health Sciences Institutional Review Board.

If you are interested in speaking about your experiences as a male student in a counseling program or as a male counseling professional, I hope you will please consider participating in this study. Please contact me, Amber F. Lancaster, via email at Lancaster@ucmo.edu or by phone 660-864-4926 to participate and/or with any questions. Thank you for your time and consideration. I look forward to hearing from you.

Amber F. Lancaster 
Appendix B

Male Counseling Program Student Interview Questions and Format

\section{Research Question 1: What attracts men to the counseling field?}

1. What attracted you to the counseling field?

2. What concerns, if any, did you have about going into the counseling field? Did you experience any pressure, familial, cultural, societal, etc. about pursuing a field where women are the majority?

3. What did you know about the number of men versus the number of women in counseling programs? In the counseling profession?

4. What recruitment strategies were useful in attracting you to your counseling program?

Was there anything you found to be welcoming toward men? What would you have liked to have seen in the recruitment strategies? What do you think would increase male student enrollment in counseling programs? What is your advice to counseling programs on how to effectively recruit males?

\section{Research Question 2: What is the experience of men in counseling programs?}

5. What has been your experience as a man in your counseling program? What challenges do you believe you have experienced due to being a male? Were there any topics that were challenging to discuss?

6. What do you believe you have experienced with ease due to being a male?

7. What experiences, if any, have led to your retention in the counseling program?

8. What experiences, if any, have led you to think about leaving the counseling program?

9. What has been your experience with female peers? Male peers? 
10. What has been your experience with female faculty? Male faculty?

11. What is your advice to female faculty about men in counseling programs? To male faculty?

12. What do you wish would change, if anything, in counseling programs that could directly affect male students?

13. What would you like future male counseling students to know about counseling programs and the profession?

14. What would you like share about your experiences I have not asked?

\section{Research Question 3: What is the experience of male professional counselors?}

15. As a professional counselor, what has been your experience in the counseling field?

16. What has been your experience with males in the counseling profession?

17. How similar or different from your experiences in your counseling program?

18. How are your professional experiences similar or different from your experiences in your counseling program? What would you like future male counseling students to know about counseling programs and the profession?

19. What would you like share about your experiences I have not asked? 


\section{Appendix C \\ Individual Interview Consent Form \\ CONSENT Form to Participate IN A Research STUdY}

Researcher's Name(s): Amber F. Lancaster

Project Number:

Project Title: A qualitative case study of male students' experiences in counseling programs and male professional counselors' experiences post-graduation

\section{INTRODUCTION}

You are being asked to participate in a research study. This research is being conducted to investigate the experiences of male students in counseling programs and professional male counselors. When you are invited to participate in research, you have the right to be informed about the study procedures so that you can decide whether you want to consent to participation. This form may contain words that you do not know. Please ask the researcher to explain any words or information that you do not understand.

You have the right to know what you will be asked to do so that you can decide whether or not to be in the study. Your participation is voluntary. You do not have to be in the study if you do not want to. You may refuse to be in the study and nothing will happen. If you do not want to continue to be in the study, you may stop at any time without penalty or loss of benefits to which you are otherwise entitled.

\section{WHY IS THIS STUDY BEING DONE?}

The purpose of this research is to investigate the shared experiences of men in counseling programs and the experiences of professional male counselors.

\section{WHAT AM I BEING ASKED TO DO?}

This research involves being asked questions about your experiences related to being a male in the counseling profession. You will be asked to participate in an individual interview and perhaps a group discussion. During the individual and group discussions, I will take notes and audio record the discussions.

\section{HOW LONG WILL I BE IN THE STUDY?}

This study will take 30 minutes to an hour for each individual and group interview that you take part. You can stop participating at any time without penalty.

\section{WHAT ARE THE BENEFITS OF BEING IN THE STUDY?}

Your participation will benefit counseling programs by increasing the counseling profession's understanding of men in counseling programs and the counseling profession. You may also enjoy sharing your experiences. 


\section{WHAT ARE THE RISKS OF BEING IN THE STUDY?}

The risks to this study are similar to the risks of everyday life discussions.

\section{WHAT ARE THE COSTS OF BEING IN THE STUDY?}

There is no cost to you.

\section{CONFIDENTIALITY}

The interviews and discussions will take place behind closed doors to maintain confidentiality. You will be assigned a pseudonym as an additional safeguard in your confidentiality. The researcher will maintain confidentiality in all meetings, the researcher cannot guarantee participants in the group meetings will maintain confidentiality. The audio recordings will be destroyed after the project is completed. There will be no visual recordings.

Information produced by this study will be stored in the investigator's file and identified by a pseudonym only. Information contained in your records may not be given to anyone unaffiliated with the study in a form that could identify you without your written consent, except as required by law.

\section{WILL I BE COMPENSATED FOR PARTICIPATING IN THE STUDY?}

You will receive no payment for taking part in this study.

\section{WHAT ARE MY RIGHTS AS A PARTICIPANT?}

Participation in this study is voluntary. You do not have to participate in this study. You will also be informed of any new information discovered during the course of this study that might influence your health, welfare, or willingness to be in this study.

\section{WHO DO I CONTACT IF I HAVE QUESTIONS, CONCERNS, OR COMPLAINTS?}

Please contact Sandy Hutchinson, Dissertation Chair, Hutchinson@ucmo.edu if you have questions about the research. Additionally, you may ask questions, voice concerns or complaints to the researcher.

\section{WHOM DO I CALL IF I HAVE QUESTIONS OR PROBLEMS?}

If you have any questions regarding your rights as a participant in this research and/or concerns about the study, or if you feel under any pressure to enroll or to continue to participate in this study, you may contact the University of Missouri Campus Institutional Review Board (which is a group of people who review the research studies to protect participants' rights) at (573) 882-9585 or umcresearchcirb@ missouri.edu. 
You may ask more questions about the study at any time. For questions about the study, contact Amber F. Lancaster and Sandy Hutchinson 660-543-4341.

A copy of this Informed Consent form will be given to you before you participate in the research.

\section{SIGNATURES}

I have read this consent form and my questions have been answered. My signature below means that I do want to be in the study. I know that I can remove myself from the study at any time without any problems.

Participant

Date 


\section{Appendix D}

The purpose of this qualitative case study was to understand the shared experiences of male counseling students and male counseling graduates as related to their decisions to apply to counseling programs, while in counseling programs, and after graduation. In the following section, the findings will be presented first. Next, themes will be presented with supporting data. Last, the research questions will be answered.

\section{Interview Findings}

Individual interviews took place with 23 men. The participants included students and professionals in the counseling field. Some of the participants were current students in master's or doctoral counseling programs. Some of the doctoral students were also working in the counseling profession. Some of the participants were working in the counseling profession and no longer students (see table 1 participant profiles). The interviews were approximately 30 minutes to one hour. The following section reflects the participants' answers to the researcher's interview questions.

Table 1. Participant Profiles

\begin{tabular}{|c|l|l|l|l|}
\hline pseudonym & Master's & doctorate & $\begin{array}{l}\text { Professional } \\
\text { experience }\end{array}$ & $\begin{array}{l}\text { Current } \\
\text { student }\end{array}$ \\
\hline 1. Abbot & $\mathrm{x}$ & & school & No \\
\hline 2. Barry & $\mathrm{x}$ & $\begin{array}{l}\text { school, } \\
\text { professional } \\
\text { counseling } \\
\text { organization }\end{array}$ & No \\
\hline 3. Chris & $\mathrm{x}$ & $\mathrm{x}$ & school & No \\
\hline 4. Derek & $\mathrm{x}$ & $\mathrm{x}$ & $\begin{array}{l}\text { CMH, } \\
\text { academia }\end{array}$ & No \\
\hline 5. Elliot & $\mathrm{x}$ & $\mathrm{x}$ & $\mathrm{CMH}$ & Yes \\
\hline 6. Frank & $\mathrm{x}$ & & $\mathrm{CMH}$ & Yes \\
\hline 7. Glen & $\mathrm{x}$ & $\mathrm{x}$ & $\mathrm{CMH}$ & Yes \\
\hline 8. Harry & $\mathrm{x}$ & & $\mathrm{CMH}$ & Yes \\
\hline 9. Ivan & $\mathrm{x}$ & $\mathrm{x}$ & $\mathrm{CMH}$ & Yes \\
\hline 10. Jasper & $\mathrm{x}$ & $\mathrm{x}$ & $\mathrm{CMH}$ & Yes \\
\hline
\end{tabular}




\begin{tabular}{|l|l|l|l|l|}
\hline 11. Kyle & $\mathrm{x}$ & $\mathrm{x}$ & $\begin{array}{l}\text { CMH, } \\
\text { academia }\end{array}$ & No \\
\hline 12. Leroy & $\mathrm{x}$ & & CMH & No \\
\hline 13. Mac & $\mathrm{x}$ & & CMH & Yes \\
\hline 14. Neal & $\mathrm{x}$ & $\mathrm{x}$ & $\begin{array}{l}\text { CMH, } \\
\text { academia }\end{array}$ & No \\
\hline 15. Otto & $\mathrm{x}$ & & CMH & No \\
\hline 16. Percy & $\mathrm{x}$ & & $\begin{array}{l}\text { school, } \\
\text { professional } \\
\text { counseling } \\
\text { organization }\end{array}$ & No \\
\hline 17. Quincy & $\mathrm{x}$ & $\mathrm{x}$ & CMH & No \\
\hline 18. Rusty & $\mathrm{x}$ & $\mathrm{x}$ & CMH & Enrolled \\
\hline 19. Sherman & $\mathrm{x}$ & & CMH & Yes \\
\hline 20. Trent & $\mathrm{x}$ & & CMH & Yes \\
\hline 21. Uri & $\mathrm{x}$ & $\mathrm{x}$ & CMH & Yes \\
\hline 22. Vincent & $\mathrm{x}$ & & CMH & Yes \\
\hline 23. Winston & $\mathrm{x}$ & & CMH & No \\
\hline
\end{tabular}

\section{What Attracts Men to the Counseling Field}

All of the participants discussed their inspiration to pursue an education and career in counseling. Although participants' motivation to enter the counseling field was not the same, each was inspired in some way to pursue counseling. The desire to help others was a general theme that emerged. At first, it seemed that all of the themes related to what attracts men to the field could fall under this theme. However, many of the participants had specific catalysts that led to their desire to help others. These included a calling, personal or family experience, and role models.

Some participants were attracted to the field due to a calling. Participants frequently stated this was a religious or spiritual calling. Some of the participants were also attracted to the profession due to family experience, which varied a great deal from family members who were in helping professions to family with mental health disorders. Some participants were attracted to the field due to role models from various sources. 
Help others. A primary reason men get into counseling is the desire to make an impact and help others. This was the reason Sherman and Elliot entered the counseling field. Elliot stated, "I love talking to people. I love just getting to know them because everybody's got their reasons why they do things." Rusty's sentiments were similar, "I knew from an early age that I held a lot of people's confidences and at the time didn't know what to do with that. So, I had a want to be in the helping profession."

Mac reported that he came from a family of helpers and "It's just in my blood to want to help people." Mac also had a negative experience in his first career choice so he switched to the counseling field. Mac said,

I am helping not just one person, but affecting many lives; and hopefully, if a child comes with their family, I'm helping to set up that family for success and that child's success for the future for many, many years to come.

Otto wanted to help veterans and men. These two groups were important to him. Otto stated,

There's a large number of men who have experienced sexual violence, either by men or women. They don't feel like they have a place to go. And so, that particular population really resonated because it's the same thing here with some combat veterans, is they don't feel like they fit anymore.

Otto continued,

It's really important to me that the rape crisis centers I work at are inclusive of the entire population that experience sexual violence, not just Whites, gendered 18 to 25 year old women, which sexual violence impacts everybody, everybody deserves equal care that means everybody deserves equal care. 
Some of the participants' desire to help was specific to children. Winston was working as a teacher when he noticed that children needed support in more ways than academically. He wanted to be able to address students' more personal issues because he knew it was affecting the children's academic performance. Winston stated,

I was noticing that the human and the developmental issues were getting in the way of academics. I was just finding myself dealing with much more than teaching students on a day-to-day basis. I was just like, “Well, if I can’t teach them, I should probably just engage in counseling with them."

Prior to moving into the counseling field, Abbot was working in a school too, but wanted to do something different within the school system because of his passion for working with children. Abbot stated, "I thought that I would go back and work on my counseling degree because that would give me a chance to still work with kids in the school and not be in the classroom."

Mac also spoke of wanting to help children. He stated, "Imagine these people who are adults and come to therapy what their lives might look like had they been seen as children or had someone intervened in some way when they were younger."

Glen also had a passion for working children. He said he was attracted to the counseling field due to experience in working with high school children. Glen wanted to continue his work with this age of children.

Chris was attracted to counseling because he wanted to support children and believed he was equipped to do so. Chris said, "I decided that with my experience and gifts that I could better serve students if I was a counselor. So, I went into the counseling program." Chris was attracted to becoming a school counselor because he wanted to 
financially support his family, he would have the same schedule as his own children, and employment benefits. However, he summed his attraction to the counseling field as, "Probably the main thing though was my sense of giftedness. I think one of my greater gifts is to listen and encourage."

A calling. Some of the participants described their attraction to the counseling field as a calling. Ivan shared about his calling. Ivan stated,

I think I was honestly called to it. I was attracted to it by being open to other forces than just the world, and I think I was drawn to it by God. Yeah, I do think it was a calling. My life prepared me for this.

Trent was also attracted to the counseling profession due to a calling. Trent stated, "I enjoy helping people and felt like God was leading me into counseling. So, I went there and I enjoy it a lot so far."

Kyle said the counseling profession was a calling for him as well.

For me, I talk about this as not being a profession, I talk about this being a vocation, and so that's what I try and model, is you don't get into this because you want to make money or anything like that, you get into this because it's a calling.

Harry's reason for his attraction to the counseling field was similar. He was influenced by a close family member, who was in a counseling program. Counseling was a commonality they shared, and it led to a "lifelong interest in it." Harry said, I kind of always thought it was eventually what I was going to do, so I put it off, if that makes sense, because I knew that if it didn't end up working there wasn't really anything else to go for, or anything else that I really wanted to do. 
Harry went on to say, "I'm not like a fate or God person, but if a person has meaning, it's kind of mine."

Personal or family experience. Some men were attracted to the counseling field due to a life experiences with substance abuse and mental health issues, either their own experience or someone they knew. Ivan stated, "I've had mental health issues and addiction issues in my family and not necessarily a stranger to addiction issues myself." Ivan went on to say, "My job, my goal was to get a degree that would allow me to help people who were addicted to drugs and alcohol. That was my focus."

Leroy's family has experienced untreated issues with mental health and substance abuse. According to Leroy, lack of treatment was due to limited access and stigma of mental health services. Leroy said,

Nowadays, you see the thing with the opiate crisis, as like this really national crisis for people. But back in my day, when there was less information, it was primarily people of color and primarily people of a low social economic habit. The opiate crisis, they would just call them junkies. And we kind of relegated them to being moral failures, moral defects that needed to be rejected or to be in church. I saw that and even though I was a young child, I knew there was a component here missing. There had to be somebody who works on these things within the community.

Role models. Some of the participants' reasons for pursing the counseling profession were due to role models who came from books, mentors, and counseling experience. Neal discussed the impact of changing careers and the influence of male role models. Neal stated, 
I think I still had a pretty strong sense of self, in terms of ... it took me a while to come to that decision. It wasn't like I read Victor Frankl's book, and then, the next day, I was like, “Oh, I'm going to become a counselor." It was a pretty lengthy process, of really thinking about, "Is this a transition I want to make?" Because it involved leaving a job that paid well, and going back to school. And so, yeah, it wasn't enough to deter me. It did pop up, a few times. But then, I would just kind of push through it. And I think another thing that just popped in my head, was ... Victor Frankl was a male. So, I think my introduction into the field was actually from a male writer, male psychiatrist. And then, someone I consulted with, when I was considering this profession, was also a male. He was a psychologist ... and he had been in the psychology field for a long time. And really kind of helped me understand some of the differences between the different disciplines, and their approach to helping people. So, in that sense, I had some male figures, that played prominent roles, as I made that transition, and decision. Neal said these role models "lessened some of that stigma around being a male, and making the decision to enter the counseling field."

Some entered the counseling field due to the influence of their own counseling experience. For example, Mac had worked with a counselor since he was a teenager. His experience was important in his decision to enter the field. Vincent was attracted to the profession due to his own counseling too. Vincent said,

That was really the first moment where the idea of being a therapist really kind of came into mind. When I thought previously it was all about the research and the clinical side and more of the scientific parts of it, but that experience really was 
the first because we talked about it briefly when I was seeing him. And so, that was really the first moment where I was thinking maybe this is something that I would be interested in. As I continued my undergrad, it just continued to foster that idea and then when I was applying for different graduate programs I just liked looking at the program description and listening to what other people in the program actually do and I said, "This is what I have always wanted. This is what I want to do."

Uri's counselor influenced his attraction to the counseling field as well. Uri shared,

I had seen a counselor in the previous semesters for some personal stuff I was going through and I thought about how much I liked that experience and enjoyed it and how much it changed my life. I decided that might be something I'm good at. And so, I started applying to master's programs in counseling. I was specifically interested in the counseling profession as opposed to the psychology, social worker, something like that, just because the person I saw was a counselor. As I looked more into the profession, I really liked the mission behind counseling, its developmental and wellness focus. That really jived with my personal feelings.

Derek's family, who are in the mental health field, in part, influenced his attraction. He stated, “It's something I'm naturally good at, growing up in my family, at least I thought I had some skills and knowledge of mental health issues and all that stuff." What Men Knew about the Number of Men and Women in the Counseling Field 
The participants were asked to share what they knew about the number of men versus women in the counseling profession. This question was asked to explore if being a male minority had any influence on their decisions to pursue the counseling field.

Knew there were more women. Many of the participants had some idea or knew there were more women than men in the counseling field. The majority of the participants stated that this knowledge had no bearing on their decision to enter the counseling field. Some participants knew they were the minority gender, and believed it would benefit them in obtaining future employment. Therefore, being a male minority was seen as a benefit. Some participants knew they were the minority and had some trepidation.

Derek knew there were more females due to his experiences in working with female counselors. Derek stated,

Well from my own personal counseling experiences, not so much continued after I started learning about counseling, I knew as far as therapists, it was all girls most of the time for stuff I wanted to talk about, you know. So, I experienced that. In addition, it was not a concern for Derek due to his comfort with women. Derek stated, "I've always connected to females better than men. You know, it's easier for me to talk to a girl than to shop talk with the guys." Derek continued, "I felt comfortable in that setting, you know. Like my classes were all...mostly girls. It'll be me or one or two other guys, and I felt comfortable in that setting myself. But I don't know that all guys would."

Kyle was aware that men were the minority in the counseling field. Kyle stated, 
Oh, I knew I was going to be a massively small minority, at least at the master's level. Just from my experience, of the volunteers at the various programs I was working... the peer counseling stuff that was all predominantly women.

Typically, 60 to 80 percent women, so I was always in the minority, from a gender perspective, not from a dominant culture perspective. So, I was really aware of that reality. And then, when I started the program, it was pretty much the same way. I mean, my master's program, probably, I don't know, threequarters of my classes, I was the only male in the class...I was comfortable with that. Just from my own upbringing and everything, I've never been particularly comfortable with other males, quite honestly. So, I've always enjoyed that kind of environment. It was comfortable for me.

Otto knew there were more women than men in the counseling field too. He stated,

I'm a trans guy, so when I first entered the field I entered as a woman, well I entered as what people thought I was a woman because I had not corrected my gender yet, that wasn't on my radar as much as you would think. But being a trans guy, I definitely noticed that there were very few men. There were very few men in my bachelor's courses, and there were very few men in my, even less men in my master's.

Otto discussed his experiences in changing specializations in the counseling field and how the specialization changed the concentration of males. Otto stated, "It's been really interesting to go back and forth between this "Hey, there's a lot of men but, there's not a lot of men." 
Chris had some idea there were more women because he "knew that in education, in general, that it was primarily weighted toward females." Chris stated, "It was a nonissue."

Jasper had some idea there were more women than men in the counseling field. Jasper said,

I would say that it was a vague thought and honestly, it's too far back to know where the information initially came from, that vague notion. I would say that I generally kind of knew that there were more women in the field and then obviously, as I went through my program, and as I was in the field, and even more so now, and working at the doctoral level that is found. I'm understanding more of the implications, but I would say at the beginning it was just like this vague idea.

Winston shared similar sentiments about his knowledge as related to the number of women versus of men. Winston stated, Well, being a teacher I was pretty used to being the only male in the classroom. I did some research about counseling through, I believe, I think it was American Counseling Association before I applied. Then I think I came across some statistics that the field is heavily dominated by women. It was a familiar feeling. I was like, “Oh, it's probably going to be like my bachelor's degree program being the only male giving a male perspective in a lot of the situations." I knew that going in, that it was female dominated.

Vincent knew there were more women, but not the extent. Vincent stated, "If you don't already know, be prepared to be one of the only guys throughout the program. I 
expected it before I went into the program, but I can see how it would be a little bit of a culture shock for someone who might not be aware of that." Vincent continued, I knew that it was skewed more towards women, which I've always found interesting. We've talked about this in classes, and when you look at theories books it's nothing but old White guys and until you get to some of the newer theories there are very few women in the field, which is interesting considering today, I don't know what the exact numbers are but, I am one of the few men overall. I think there have been two maybe three other men who I have seen since I started.

Vincent elaborated, I guess it's something I don't really think about often. I am aware that I am one of the few men in the program and some of the clients I have started seeing were specifically recommended to me because I am a man. In the general population, I am over represented and so it doesn't really come up here often. So, it's not something that occupies my thoughts or interactions too terribly in the program, at least I haven't found it coming up often.

Although Uri did not really know the number of males versus females in counseling programs, he assumed there were more females than males. Uri stated, Before I got into the counseling field, I don't know if I had any knowledge. I think my assumption probably would have been ... If somebody had asked me my assumption, probably it would've been that there were probably a lot more women than men in the profession. I can't say for sure that I had any knowledge, any distinction. It would just be an assumption I guess I would be making. 
Some men knew there were more women than men in counseling programs, but believed it could be to their benefit. Uri viewed more women than men in the program as a benefit. Uri stated,

Part of why I feel like I could fit in this profession is I've always been someone who hasn't felt like I fit standard gender norms. In my life, my biggest role models have been the women in my life. Like my women teachers and my mom and my female friends have really been the ones who have picked me up through life. I've always felt very comfortable in, actually more comfortable in female dominated spaces than male dominated spaces.

Percy knew there were more women and believed it would be a benefit for him when applying to his counseling program. Percy stated,

The guys were in the minority for sure. It was something that I didn't really hang my hat on, but I knew that if it was down and maybe some really, again, minute details between me and other candidates, that that might bode well for me. But it wasn't like “Oh, I'm a shoo-in for any job because I'm a guy," but I knew it wouldn't hurt me, let's put it that way.

Percy continued,

It was just the nature of the profession, so it didn't really have an impact on me one way or the other in terms of my decision to pursue this career. It was the one I wanted to do and whoever dominated the space wasn't going to stop me. Elliot had similar thoughts as Percy. Elliot stated, I guess I just kind of assumed it was going to be similar from my experience in the Master's in Social Work program. That it was going to be definitely a few of 
us in the profession. I kind of knew that going in and I don't know if it's accurate or not. I think with my M.S.W. program it actually was part of the reason they let me in because "Hey, we got a male that's applying. We need to make sure we capture some of the men that apply for the program too." I don't know if that was necessarily the same case with the counseling program, but I don't think it hurt, you know? The fact that I was a male coming into probably more of a female-dominated profession.

Neal shared that he had the impression there was a majority of women in the field. Neal said, I think I had a general impression that ... when I think of therapists, I traditionally ... I was just thinking of a female. I think that was just kind of the pop culture impression of what a therapist is. Which is, honestly, about as surface-level as my understanding was, at that point, in terms of the field, and having an in depth knowledge of what the makeup of the field was like. Neal initially experienced discomfort at entering a profession where he was the minority, but was able to find comfort when he saw there were male faculty. Neal stated, So, I did have a perspective this is a more feminine-geared profession. Like we're going in, and talking about feelings, and emotions. So, there was that impression, that it was a more female-oriented field. But that, even when I was looking at master's programs, I started noticing that, at least at the professorial level, there are quite a few men. So, I think that provided maybe a little comfort, around that discomfort of thinking about entering a profession that's, at least in my perception, was dominated by females. 
Neal continued,

I did know that males were probably a lower percentage, in the field. In some ways, that ... I don't know, that seemed advantageous to me. To be a male counselor and to be kind of in the minority, in terms of professionally out there, and be able to maybe provide a service, or an option for people that may not be the norm.

Harry shared the belief that being a minority gender in the profession could be beneficial. Harry stated,

At first thought, I would say traditionally women tend to be the more touchy feely types and I think people may have that assumption. So, when they're put in front of a male therapist, they may be less likely to, I don't know, share their feelings about it. I think that's going away. So, short answer, I guess, I'm not all that concerned about it. If anything I feel like it may even give me an edge because there are so few men. There are likely more clinics that have clients who want a male therapist who are willing to hire a male.

Did not know there were more women. Some of the participants did not know there were more women than men in the counseling field. The majority of these participants would not have changed their mind about entering the profession if they had known.

Trent stated that he did not know men were the minority until he entered his program. Instead, he believed it to be "50/50." He was not aware until he started his program and noticed there are approximately $75 \%$ women and $25 \%$ men in his classes. 
He "didn't really think anything of it." In addition, it would not have made a difference, if he had known, due to his calling to the profession.

Glen did not know there were more women than men, in counseling programs, before entering his program. Glen stated, "I still remember my first day in class, being one male with, I'd say, about 35 females, was my experience. I didn't know it was that way." Glen was not dissuaded and pursued the counseling profession anyway.

Barry did not know there were more women than men in the counseling field "but, it didn't take long to figure it out when I went to class." Barry said it probably would not have made a difference if he had known. In fact, he said, "I didn't realize what a commodity I was until later, but it wouldn't have discouraged me if I had known. It could be good actually."

Ivan did not know there were more women than men in the counseling field. $\mathrm{He}$ stated,

When I walked into my master's cohort, I noticed I was the only male of 15 . And I'm okay with that. I'm married, I have kids, I'm not on the market so to speak.

So, it was a very comfortable environment, non-threatening, no games, or anything else like that.

Ivan's decision to enter the counseling field would not have been any different if he had known he would be in the minority. He stated, "There was a force much greater than me directing me. There wasn't anything that was going to stop me."

Quincy stated, “I guess I didn’t know very much. I can’t say I was surprised when I wound up in my master's program and there were three or four guys in my cohort, but I didn't know that it would be quite that female-dominated." However, he said it 
probably would not have influenced his decision to enter the field if he had known men were the minority.

Harry did not know there were fewer men than women. Harry said, "I wasn't aware of the fact that there were fewer men in the profession than women. I didn't know that the average Joe thought therapists should be women. It never occurred to me." Harry said it would not have made a difference in his decision to enter the counseling field if he had known.

Rusty was a first generation student and believed this affected what he knew about the counseling field. He stated, "My knowledge around how many... what the differential between men and women was pretty limited at that point." Rusty said, "The number does not worry or bug me and it would not have back then" because he grew up with many women in his family "who were directly involved in my rearing."

Thought there were more men than women. Some of the participants expected there to be more males than females. The majority of these participants said this knowledge would not have affected their decision to enter the profession if they had known.

Sherman expected there to be more males than females, and so did Leroy. Leroy stated,

When I started to do some research into the field myself, on my own I should say, many of the main clinicians or theorists of counseling of psychology are male, right? You think of Freud, you think of Jung, you think of Beck. So, that kind of gives you the smallest idea that this is a field dominated by men, and it's not. Maybe from the leadership perspective, there's an imbalance there, but it's 
actually dominated by women. And women do great work in this field. So, I didn't know that until when I signed up for my graduate program. And after a while, this is different, turns out that I'm very rare in this field.

Leroy said he figured out very quickly there were more women than men in the counseling field. Leroy said, "I thought maybe I am in the wrong place. Maybe it's like a women's conference and it turns out, no, it's not." Leroy elaborated,

So, it really became more of a situation of, okay, well not a lot of people do this, right? That's sort of weird, but maybe that's not such a bad thing because it makes you more of a commodity in this area.

Mac believed there were more males than females for similar reasons as Leroy. Mac did not know there was a difference until he started his program. Mac stated, It's interesting because the counselors that I saw, the majority of them were men. So, I didn't know a lot about ... Now I'm aware that men make up a minority of the counseling field. But I assumed, you know what I mean, I think from culture and stuff like that, a lot of people are familiar with Freud and a lot of significant male figures in the psychology field. So, that, to me, seemed like an even split because there were those big names. Then if you watch movies or TV shows, it's usually women who are in the counseling field. So, it didn't strike me, I was surprised to hear when I did go into school that men made up a minority and that it would actually work in my benefit to be a male because we are sought after or we're in high demand.

Harry did not think about the issue very much before he entered the profession, but he assumed there were more males than females. Harry stated, 
Honestly, I had never really even considered it. It never occurred to me that, I mean I guess looking back most ... any of the like TED talks or other videos and stuff I had seen, it kind of or maybe it's just a societal thing, I kind of assumed that it was more of a male-dominated profession, but it wasn't really a factor in me wanting to do it. I hadn't ever really strongly considered one way or the other. Harry assumed there would be more males for another reason as well. Harry said, “The idea is that if you don't have the information, then the default is that it's most likely male dominated, because everything is, you know what I mean? Good, bad, or otherwise that's just how it works usually." He realized there were more females than males when he started his program and a professor pointed it out. Regardless of this difference, Harry would have entered the profession.

Frank believed there were more males than females in the counseling profession. Frank believed this in part due to his understanding of many male counselors in the city he resides, and

I know, personally, one, two, three, four male therapists. Then a lot of the famous kind of, I've picked up books in these facilities while I'm working overnight and many of the books are the famous therapists or psychologists or psychiatrist are often times men. I think the confusion that, this is just my own experience...but mine is that there is a lot of male helpers, but then I went to school and there was a lot of female people in the class. But there was literally maybe a five-second thought of "Wow, there are a lot of females here," but not that there was a problem with it or some type of concern in any way.

\section{Recruitment}


Participants were asked to discuss strategies, overt or covert, that welcomed them as men, or attracted them to the counseling profession as men. Many of the participants did not notice any type of recruitment strategies directed toward men. Kyle, Harry, Elliot, Abbot, Derek, and Glen did not recall any specific recruitment strategies. Rusty did not see any recruitment of males in his counseling program. He stated, "Not a single one. Not in the counseling, the ACA field."

Frank said, "I did not notice any flyers or any websites." However, Frank was interviewed by a male faculty member and this was important to him in his recruitment. Frank stated, "I think I felt like I would be taken more seriously because it was a man. I kind of hate saying that, but that ... I felt like it was a little more legitimized. Yeah. I don't know why, honestly." Frank shared that if it had been a woman who interviewed him he "would have felt less serious about the program maybe," and he believed this response "definitely was more subconscious. Definitely not conscious."

Winston did not notice any overt recruitment strategies or anything that seemed to welcome men. Winston stated,

There was no overt message about “men apply here.” I didn’t get that message. However, in my search for graduate schools ... I think I applied to four different graduate schools ... I found myself drawn to the graduate school I accepted and went to because there were several men in the faculty. I compared that with some other faculties at other universities that were predominantly women. I did not feel being in a room full of women prospective students and women faculty members, I did not feel ... I wouldn't say I felt uncomfortable, but it didn't feel like a good spot for me. Then when I went to my current university that I graduated from, I 
spoke with the male professors there and something felt right. It felt, "Okay, I can be here." There are other men here who share my perspective on the world. They're not hyper-masculine. They are engaged in the counseling profession, and it gave me a sense of belonging that, "Yeah, you can do this as a male, most definitely." But that wasn't an overt message. That was just through my experience of searching around and exploring a university and then finding by happenstance, serendipity, that finding a male faculty. Although there were females there too, I think it was probably about 50-50.

Uri did not recall any specific strategies that expressed men were welcome into the counseling program. However, Uri did note the presence of men during his interviews. Uri stated, I don't remember any specific recruitment strategies or anything like that that made me feel that men were welcome. For my master's program, I was interviewed by two women, but it was a group interview and there were other male candidates there. Then in my doctoral program, I was interviewed by a man and a woman. Yeah, I don't know if I ever felt any, especially going into the counseling program, I didn't feel any weirdness that I was male going into the profession or not feeling welcome or anything. I would say there might have been times in the program where I felt a little, maybe a little outside of what was going on, but not before I guess.

Leroy did not notice recruitment strategy that welcomed men either. Leroy stated, "No. No. Nothing. I never got that message like 'Hey, you guys, we want to have you here.' Like formerly in the recruiting process? No.” Otto expressed similar sentiments 
as Leroy. When Otto was asked if there was anything he saw or heard that sent the message of men being welcome his response was, "No. God no, not even a little bit." Mac did not see any male specific recruitment strategies, but did feel welcomed early because there was an invitation for males to convene for discussion. Mac stated, Not any recruitment, but on my first few semesters, there was an attempt at a group for men in counseling. It was just to discuss issues about being a man in the counseling field, and it was geared toward counseling students. I was interested in it. I don't know if I expressed an interest. I don't know what became of the group, but I remember there was an email that was sent around to all the students.

Vincent did not notice anything at the time he was looking at counseling programs. He stated, I can't think of any particular strategies. I know now that the website is very intentionally designed to try to welcome all people and that there's a clear focus on including anybody who might be interested or anybody who might qualify for the program but before entering the program I guess I didn't really notice or pay attention to any of those strategies that I'm sure they probably are using. Jasper did not see any overt welcoming messages toward men, but he believed he might have at the doctoral level. Jasper stated, Master's degree I would say no. I can't remember anything overtly. I'm trying to think of anything that might have been more subtle. I had never gone to my counselor at that time, so it wouldn't have come from that. No, I don't ever remember anything specific at the master's level. At the doctoral level, I think 
maybe subtly, maybe subtly, when I was applying to the doctoral program. I could go to the receptive schools' websites. I could see the current doctoral students and I could see that there were more women than men doctoral students. I could also see it in faculty.

Some of the participants did not necessarily see anything that indicated men were welcomed. However, there wasn't anything that indicted men were not welcome. Sherman said that was the case in his program. Quincy shared a similar experience. Quincy stated, 'I wouldn't say that anyone went out of their way to do that. I don't know that I got the opposite impression either."

Percy expressed a similar experience as Quincy. Recruitment appeared neutral. Percy said,

Nothing that said, "Hey, men can be counselors, too," or nothing to that effect, and nothing that was exclusionary either that said, "You know, we really just kind of want females, so thanks, but no thanks." I think that's fair to say as well. Neal said that although he had the perception men were the minority gender, there was some comfort that there were male counseling professionals. Neal said, When I was looking at master's programs, I started noticing that, at least at the professorial level, there are quite a few men. So, I think that provided maybe a little comfort, around that discomfort of thinking about entering a profession that's, at least in my perception, was dominated by females.

Trent thought the recruitment strategies welcomed everyone into the program. Trent stated, 
I want to say it was directly targeted towards men, but I thought everybody is welcome in the counseling field and maybe that is just because I did my undergrad in the same college too. So, maybe it was the Christian bubble that was like "everyone is welcome everywhere." I believe that is where I am coming from.

Possible recruitment strategies. Participants were asked to share ideas on possible recruitment of males into the counseling profession. Leroy communicated his belief that male recruitment is important, and yet it is unclear why it is not obviously taking place. Leroy disclosed about a fellowship he won. He stated, It's good to have a cohort of people that are with you, that are also of color. But then also there is something about the fact that people don't pay attention to the fact that you're a male therapist and how we can kind of utilize that and harness that. That can be somewhat frustrating at times. And the reason I say that is because I think there are people in my position, in a higher position than me also, that could really use their experience to really draw men in to be able to do this work, and we haven't. I'm not sure if that's because we haven't thought to. I'm not sure if that's because we want to keep it for ourselves, maybe for professionals being in this sort of role, or maybe we don't value other men also. I don't know.

Although few participants could think of specific recruitment strategies, overt or covert, directed toward potential male students, the participants had ideas they believed could be useful in male recruitment. These ideas included informing potential students that male counselors are needed. There are clients who need and prefer male counselors. 
In addition, participants thought it could be beneficial for prospective students to know they are highly marketable. Another possible recruitment strategy participants suggested was for men to be portrayed on counseling program websites and fliers. Somewhat related, participants stated it could be beneficial to have more male faculty and students. The participants shared that more males allows them to have someone they believe they can relate. Participants also suggested increased awareness about the counseling field. Specifically, how it is similar and different from other helping fields. Some participants suggested that recruitment might need to be changed in order to reach more men. Some participants were not sure how to recruit due to larger societal issues behind the low number of men in counseling programs. The following are some examples provided by the participants.

Male counselors are needed. Many of the participants believed that if men knew they were needed counseling programs would likely recruit more males. Jasper shared that he believes men need to know "their presence and perspectives are needed." Derek believes men are needed in the profession. He stated, recruiting male counselors is a great idea. I mean, it's kind of funny, because when you asked me the questions, I drop a blank half the time, which says something in itself. Like, "Oh yeah, we should recruit more males." I mean I know it's an issue, but nobody's really done anything about it. Kyle shared that he wants prospective students to know they are needed in the profession. Kyle stated, 
We desperately need more men, and we need more men who are going to be open and caring practitioners. Yeah, that's the big thing. I mean, I love having men in my classes. I love the balance they provide. That's the biggest thing

Kyle continued,

bringing the male perspective, bringing the positives of being male and then the positives of being open and honest about exploring your own self, the things that got dumped on you simply because you were male, and figuring out how to grow beyond that.

Winston also communicated the importance of men in the profession. Winston stated,

I've noticed there's a need. I've heard several times men who've felt relieved to have a male counselor to talk to. Like I said, I was surprised. I didn't expect that. I think that's maybe something that should be explored, the need for male counselors for male clients. I think there is a need for it and I think it's important. Chris shared similar beliefs about the importance of men in the profession. Chris stated,

I do think there is value to having men in the profession as counselors, but also as teachers because of the opportunity to serve as an example and as a role model for half of the population who are males. It is nice to have both genders represented in that respect, again it's not specific, if it is that individual's gift to listen or compassion, or encouraging others, I would definitely encourage them to consider this profession. 
Percy also shared that if men knew they were needed, they might decide to enter the counseling program. Percy stated,

When we look at the profession broadly and when we look at leadership roles, so say for example presidents of ACA, as they change year to year, I'm confident that men are in the majority and when you look at the CACREP board of director in CACREP's 35 year history, there has been a slight edge to men as chairs of the board of directors, not by much though.

However, Percy went on to say,

That just as much as we need to have multiculturalism as part of our continuing dialogue as a profession, there needs to be an open understanding that men bring qualities to the field that women cannot, just like any other individual from some other cultural group can bring to the field and to serving clients too.

Furthermore, Percy stated, "I think men and women, by nature, are intended to balance each other out, and so a healthy profession needs to strike that balance as well, and counseling's no different." Percy expanded, "I think it's a benefit to our profession that those points of views exist and that it's not all one-sided, but that there's a balance, in a sense, to a given issue." In sum, Percy believed "There's a value in balancing the profession and encouraging men to pursue the profession as well."

Glen discussed the importance of male counselors for male clients. He believed a role model, who is male, may make counseling feel safer. Glen pondered this idea and shared, "I wonder if the male way of accessing services is more informal sometimes? Or under the table because of stereotypes." Glen shared his experiences with his male friends. Glen stated, 
I think they are more likely to go if I tell them to. Does that make sense? They trust me. They see me as somebody in their life that has been a caring, loving, supporting presence, and if I tell them to go to counseling, they usually go. It may not work out, but they go.

Highly marketable. Most participants stated they are highly marketable as a male minority in the counseling profession. Many of the participants believed it could be beneficial to inform prospective male students how marketable they are.

Neal shared that men are highly marketable. Neal stated, When I was looking at internship positions, in my master's, and my doctoral program, both of the places said they would be happy to have a male because they had a shortage, and they had male clients who specifically wanted to see a male counselor. And they had a shortage of male counselors there. So, that played an advantage, in those roles.

Glen shared that he finds that he is also marketable in the counseling profession. Glen stated,

As a male counselor, I definitely never don't have opportunities because I am a little bit, and I thinks it's becoming more equal, in terms of traditional genders, but I think the one advantage to that is that I often do have opportunities because they are looking for a male counselor. And that would be, actually, my current opportunity. I feel like there's not enough males in the field and there's demand for it. Although $70 \%$ of people that access services, traditionally are females, I think there's still a definite need for male therapists, counselors. We're a center 
of about 26 therapists. There's about four males on staff. So, we're always looking to recruit more male therapists.

Leroy shared similar sentiments. Leroy stated, "There's a great opportunity to write your own course because you're going to have very low competition with respect to other men. They are out there, but they're very, very limited."

Men on websites, brochures, and in programs. Some of the participants thought having a visual of males on websites and/or brochures, and in counseling programs could be useful in recruitment. This was an important factor in some of the participants' recruitment, and they believed it could be in the recruitment of future male students. For example, Elliot shared that seeing more males could be beneficial in recruitment of more men. Elliot stated, I don't know if it'd be something more like pictures of men in action versus, I don't know, I'd have to see what websites out there are advertising. If it's more females and sends out the vibe that it's more female-dominated, which it is, but yet certainly male presence is needed.

Winston shared a similar idea about recruitment. He suggested a visual of males could be useful in recruitment. Winston stated, Maybe having males on faculty or the graduate program's website in the photos and things like that. Maybe as far as, I guess, I'm going back to the website again, when they're describing their program if they had a call for males. I've seen calls for minority students such as Asians and African-Americans and how important that is in the field, and it is. It is really important. But I haven't seen the same type of call for men. Winston went on to say, "So, I think maybe just 
acknowledging in an open way through recruiting that men are welcome here. This is a great place for males.”

Neal also believed a visual of males is important in male recruitment for counseling programs. Neal stated, I think it's visually, if you can have pictures of students, or pictures of male therapists, somewhere on the website, that might be helpful, again, just to give another visual of some kind of norm that males are welcome, as counselors. Some of the participants believed having more males in counseling programs would likely recruit more male students too. Some participants shared that seeing a male faculty member and having male peers was important in their decisions to enter a particular program and the counseling field in general.

Neal shared the importance of other males was beneficial in his experience in the field. Neal believed having additional males could be important for male recruitment. Neal stated, "I'm trying to think of some of the things that helped me, which was having at least one male around that a male student can identify with." Neal expounded, For me, having male peers was very helpful. So, I think if counselor education programs can be intentional about when they're putting their cohort model, or they're just developing admissions criteria, I think trying to aim for having a mix of genders would be helpful. Make sure that there's not a lone male in a group of females.

Glen shared his ideas related to males in male recruitment. He pondered this idea during the interview. Glen stated, 
I think it would be interesting to see what counseling programs would look like if they were equal gender...I just wonder, I don't know if things would be different, but I just wonder what it would look like if instead of me, one person with like 35 females, if it was completely equal. What would that look like? What would our classes look like? What would our conversations look like? I think it would really bring out, It would really help bring out both sides of gender. If we were to look at it from a really bimodal perspective, I think it would be interesting to see what an equal balance would look like.

Glen shared that it is possible he would have shared more and had been more active in discussions, if there were more men in the room. He said it likely would have felt safer. Vincent shared his experiences as related to this topic. Vincent stated, I feel like overall my experience with the program hasn't been particularly impacted by me being a male. I would like to see more men in the program itself, but I think that it's more of a societal thing that needs to be addressed first.

Vincent expounded,

I think it would be nice to have a greater variety of different perspectives. I feel like too often it could be easy to be, you know I represent all men's perspectives instead of my own individual perspective. I think with more representation it's easier to get a broader spectrum of perspectives of beliefs and experiences. So, I think that would help both the program as a whole produce a greater variety of experienced counselors and it would help my classmates. It would help all of us gain better perspectives and better experiences on people who come from different experiences. 
Sherman believed more male faculty would be beneficial in recruiting male students. Kyle also believed male faculty help with recruitment. Kyle stated, The past couple of semesters, I've been surprised at the number of men I've had in my classes. It's really increased, and I don't think it's anything in particular that we're doing that's having that affect, and I don't know, maybe with me on faculty, that encourages some of the men to keep going, I don't know.

Trent also believed additional men would be beneficial in the field of counseling. He said it is important to have role models that are similar to you. Trent stated, "I think maybe the professors or maybe getting other men counselors, that would make me feel like 'Why can't I be one too?'”

Rusty shared the importance of additional men in the counseling field as well. Rusty said,

I think visibility of men in the profession would be a great start. Letting middle schoolers, high schoolers, and college students know that this is a profession for men. For anyone and any way we identify. Talking about different ways that men can help be supported in their graduate education that identifies what their needs are compared to their female identified colleagues.

Neal communicated his belief that male faculty are important in male recruitment. Neal stated,

I think having a diverse faculty group helps. I don't think that's just for men. I think that's just in terms of encouraging diversity, across the board, but that includes men, men as counselors. So, I think that does help. Similar to what I just expressed, if you look at the faculty webpage, and see that there are a variety 
of people, there. There's a male there, a female there. I think that helps to encourage males to enter the field. And I think maybe just a simple statement about the program, or about the type of students that are welcome to apply to the program, and including males in that. Just explicitly saying that the program wants to foster a diversity of demographics, whether it be gender, or ethnicity, or sexual orientation, or whatever. That the program really strives when they have that diversity. It's probably helpful.

Neal also shared the importance of seeing men in recruitment and how it affected his decision to apply to particular counseling programs. Neal stated, When I was looking at different programs, and considering my options, in terms of applying to master's programs in counseling, I do remember looking at their faculty pages, and just getting a general sense of who was teaching at these different programs...I'm trying to remember all the programs that I looked at, but I can't remember a single one where there wasn't at least one male there. And I think that did help me feel like, Okay, this isn't ... it's not just something that women do, is enter the counseling field.

In addition, Neal stated, "Someone that looks like me, someone who fits demographically, fits some of the categories that I fit into, did make me feel like, 'Alright, this is probably an okay place for me to go, and learn."'

Leroy shared some similar ideas about male recruitment. In general, Leroy believed men are important in the recruitment of men. Leroy said, "You don't want to discriminate towards women or whomever else from coming to the program. How do we send that message to men specifically?" Leroy expounded, 
I think if it were like a program, like a doctorate program, and they ran a group specifically for men, and they had some male clinicians and they were able to sort of roll that into their attractions to get students into the program, or something like that. I think that could be really good. I just don't know what that would look like practically. To be able to use one to leverage the other. That's a good question. I'm not really sure how they could attract men specifically.

As Leroy pondered student recruitment further, he stated, I'm going to challenge you to do something. Look up in your local counseling program, at your school or whatever, and look at the images you see there. Do you see a lot of men in the brochure or in the literature? You only see what's being reflected, right? It's funny, in my graduate school, they have... on top of it, there is a picture of a woman. And that's kind of what the field is. It's very female driven and based even in advertising and literature. It's all about women. These are the people that do this work.

Elliot shared his concern about the lack of males in in counseling programs.

\section{Elliot said,}

A concern that I had was, "Am I going to be able to have another male that I can talk to that might be able to relate?" For me, growing up, it's kind of weird, I've had some friends ask me why I got into a profession that's really focused on emotions and thoughts. I wasn't exactly the most over-emotional or emotionally connected many moons ago, and probably still lack at some points now. I guess there was that concern "Am I going to be able to have another guy that I can relate to?" and "Hey, I'm struggling with this," you know? Rather than just kind 
of relying on a female. Plus, I think part of it was being newly married and I didn't want to necessarily really go and just have a bunch of females that I was confiding in. I didn't know how that might not mix so well in my marriage.

Increased awareness about the counseling field. Some participants said there is a need to increase awareness about the counseling field in order to recruit more men. Participants shared that many people do not understand the differences in the helping professions. The participants believed informing the public about counseling could make the profession a viable option to more men.

Vincent shared his ideas on increased awareness about the different helping professions. Vincent stated,

I think for at least the counseling field, I think a greater public awareness would help a lot. I think a lot of people are still not really sure of what counseling is, especially compared to some of the other mental health fields. So, I think that in and of itself, at least my perception, I think that is more of a stumbling block than men not entering the field.

Vincent continued, "I think it is more towards either social work or psychology. So, I think greater public awareness and more information that it is a viable career choice for anyone that is interested in it." Vincent said that before his experience with his own counselor, he didn't consider "the traditional therapy route as a career path and it was only because I utilized services that I found out more about it."

Abbot shared his ideas for male recruitment into school counseling programs. Abbot believed male teachers might be more interested in school counseling if they knew more about the school counseling field. He also believed male teachers may be more 
attracted to the field if teachers were aware that school counselors have a higher salary than teachers. Abbot said,

Maybe getting hold of students who are in their education program, teaching program and maybe providing information that if you feel like you want to broaden your horizons as an educator and maybe on down the line, and you are looking at getting an administrative degree as kind of a, I don't want to say fall back, but if I wanted to do something different, I would have this in my back pocket and I would have my master's degree as an educator. It would bump my salary up as well, even if I wasn't going into administration. It might be an idea of getting that type of idea out to male teachers for teacher candidates who are looking at it from the dollars-and-cents standpoint. So, in addition to looking at the masters in administration, maybe consider doing it in counseling instead. Elliot's idea was similar to other participants in that he believed men need to be reached earlier, and there needs to be a decrease in the stigma associated with counseling. Elliot stated,

Maybe even going back to, I don't know, if it's something even at the undergraduate level. Having it be a requirement to participate in some kind of ... I don't even know what it would be like, some kind of discussion where it's like a here and now, talking about what's on your mind, or maybe like an extra credit. Something just to get men opening up more around men or just other women. Talking about feelings and emotions. I teach a couple other classes and I can see at discussions that females are much more likely to talk openly about more thoughts and emotions. Guys are more of that, well the book says this, this, this, 
and this. That concrete, whereas maybe if there was something in undergraduate programs that might draw some or reduce the fear of going into professions like this, that that may draw them in a little bit more, that it's not just the engineering and the construction and all these stereotypical male professions.

Need to recruit differently. Some participants believed men need to be recruited differently than women. Participants shared some ideas as to how to reach more men. It was suggested that terminology change could assist in lowering the stigma of the counseling profession. Therefore, increasing the viability of the profession to men.

Mac stated, "Well, I know that strategies for getting men into counseling, in general, to attend as clients, using verbiage such as coaching, like men coaching or live coaching, those are less threatening terms." Furthermore, Mac said, "Just gearing it towards career decisions like maybe a bigger focus on career counseling" and "describing it as a way to help people with everyday problems or assist people in becoming better versions of themselves or helping people achieve the goals that they want in their life versus working with emotionally focused trauma therapy."

Jasper believed recruitment needs to be addressed differently for men too. Jasper said,

I think that it could be beneficial to start painting going into counseling programs almost as a trade, almost like going back to a trade school to learn welding, construction, to become a mechanic. In large part, that is what counseling is kind of like. It is the welding, construction, the mechanics of people, of relationships. Jasper shared additional ideas for recruitment of men into the counseling field.

Jasper stated, 
You know a part of me wants to almost get outside of the realm of the obvious ways of promotion and kind of use or almost use the negative gender stereotypes. Well not negative, but using gender socialization as a means to recruit. How do stereotypically, how do men navigate relationships with other men and how do they stereotypically find meaning in work? Almost harnessing those and maybe to recruit more men, almost taking tactics from something super stereotypical like the military, and looking at commercials like that, and almost in a way of enlisting men to go into the counseling field to better serve men, and to combat gender socialization because it can be very detrimental to everyone in society really. And so, it's almost like using those tactics to still get through to men and still meeting them at their level and as a way of getting them in. Then later on, we could have a commentary about those tactics that were initially used to get them in. I think if there is too large of a divide between the tactics used to get them in, then we might not ever get those numbers in there. I guess that's really a broader idea. Not sure how to recruit. Some of the participants were not sure how to recruit men into counseling programs and the profession. Most of these individuals related the low number of male counselors to a larger societal issue.

Uri stated, “I don't know. That's a good question. I think men come into counseling from many different places. I'm not sure exactly what could be done to improve that."

Winston did not believe recruitment strategies were the answer to attracting men into the counseling field either. Instead, he believed it was a societal issue. Winston stated, 
I've always wondered if it is a recruitment issue or a social shift or a social change issue. I don't know how counseling could recruit men without men themselves knowing that's a possibility. This is a heavy question. There are all these notions about men as being breadwinners, as being the primary earner in their families, and counseling isn't it. That's not going to get you there. I think it's more complex than just recruiting men. I think it comes down to salary. It comes down to stereotypes about what it means to be a man and what profession they should take. I feel like that question is so much bigger than simply recruitment. I think it's all about who is receiving those messages and if those men are acting on values that are about income and are about a way to express my gender in a job.

Winston went on to say, I think the counseling profession is always going to struggle with that because it's going to take a certain kind of male who is attracted to giving up that value of finances or giving up that expression of hyper-masculinity in a profession or dominant authority or whatever it is that they're seeking in a profession. The counseling profession is, I think, type casted as being a female profession like education and teaching. I think a social shift is what probably needs to occur in order to recruit men into the profession.

Glen could not think of recruitment strategies for attracting males into counseling programs either. Glen stated,

I'm trying to think what would attract males to this space. I mean, I definitely think that there are men who have a different temperament that would make really 
fantastic counselors. And then there's probably some that don't, just like anywhere else. But I can't think of a specific strategy that would attract a male to ... I've got to be honest, I don't know of one.

Information for future male counseling students. The participants were asked what they would like future male counselors to know about coming into counseling programs and the profession. The participants had a great deal to share with potential students. Some of the information was shared without being asked directly by the researcher. Information for future male counseling students included that it is rewarding. In addition, participants shared information about male stereotypes and the counseling profession. Again, the participants shared the importance of men in the counseling profession. Lastly, some participants shared that their counseling program was a place to learn about self and others.

Rewarding. Some of the participants wanted future students to know that although it can be challenging, the counseling profession is very rewarding. Trent stated, "It's hard, it's challenging, but you can do it. I don't know. It is rewarding so far. The fact that I have accomplished all that I have despite how hard and overwhelming it can be, it's rewarding." Ivan stated, "I go to...it would be just to go in with an open mind. You're going to hear things that you don't like, you're going to hear mostly stuff that's going to be great." Chris said, "I found that in education it's a really a great place to work, the culture, the environment, and great people to work with."

Elliot said he loves what he does. He shared that although it is challenging, it is also rewarding. Elliot stated, 
Each day certainly is challenging, you never know what's going to walk in the door or what's going to be thrown at your lap. But that's the part I love, too. I love not knowing what exactly I'm going to face that day. Certainly some is good, but keeping me on my toes and keeping me actively listening to people rather than just getting complacent and, "Oh yeah, here we go. Same old, same old." So yeah, I love what I do and I feel if there's even a small impact that I can have in somebody's life for the better, then I feel like I've given them, at least, that it's made an impact on their day in a positive way.

Male stereotypes. Some of the men wanted prospective students to know that all levels of masculinity are appreciated in counseling programs. Participants also wanted prospective students to disregard stereotypes about counselors and the profession. For example, Neal stated,

I think a big picture thing is you can still be very masculine, if that's how you identify, and be a good, effective counselor. I think there's an idea that getting in touch, having an emotional awareness, being open with that, being vulnerable, those are all things that, culturally, go against the stereotypical masculine picture. So, I think letting prospective students know, male students who might fit that masculine criteria, that "Hey, you can still wear your flannel, and have a beard, and play sports, and do whatever, and still have a high emotional awareness, of yourself, and help others develop that high emotional awareness." Those things aren't incongruent. They can happen together, and it'll really makes you a much more effective counselor. It'll make you a more effective whatever you want to do, if you have a higher emotional intelligence. 
Neal expounded,

I think also that not all counselors have to be these touchy, feely, emotionally driven clinicians. Honestly, that's where I've settled. That's just how I like to work. But as long as you're comfortable dealing with the emotional side of things, you don't have to be an emotionally focused therapist. There's lots of different theoretical frameworks to work within, that you don't have to be driven by the emotional side of things. So, letting males know that, that they may think of therapy as something that all you talk about is emotions, but we focus on so much more than that. It's much more holistic.

Winston shared his thoughts about being a male counselor. Winston stated counseling is, very empowering. That might sound like a funny word. Because it's interesting to think about a man doing a woman's job. It can feel weak, like you're no longer a man if you're doing a female's job. I think that what the stereotype or the stigma is. But I've found it very empowering.

Jasper also wanted men to know that counseling is a place for men and for prospective students to not worry about feminine stereotypes. Jasper stated, The stereotypes that you have about the counseling profession not being manly enough or masculine enough for you, those concerns will melt away once you're in it. Those concerns will be moot by just going through it. But, that is hard to tell someone to just do it and the concerns will go away just going through the program. 
Leroy shared some of his thoughts about male stereotypes and being a male counselor. Leroy stated,

I think it's important to be open-minded and to recognize that there is going to be a lot of times when you're the only guy in the room. And that's okay. That's going to be okay. It can be hard, but your ability to relate to women, I think, is going to be pretty strong because your professionals are mostly going to be women, a lot of your colleagues are going to be doing group projects, and you going to be able to see another part of humanity that's different, right? But at the same time, you're a man and whatever you decide that makes you a man, you want to keep a hold of that and bring that into your sessions and your experience with you, because that's rich and valuable also.

Leroy discussed an experience he had where a male professor shared an article on the importance of male counselors. Leroy stated,

The article was pretty much talking about how there are a lack of men in mental health counseling, and it was the first time I saw it in a positive way. I thought this is interesting. This is like an endangered species or something special as opposed to something that squeezes in where they don't belong. And it was a really good reframe when you think about these counseling concepts. And I was recommend that article to anyone, particularly men who are thinking about leaving the field, because it's very positive, right. And it really frames men and it really positions men to be able to say you can run with the fact that you're the only guy in your area that does this, or whatever. And I just think it's a small article, it's not super long, but I think it's super important for men to be able to 
read and to kind of recognize, "Yeah, we're special in this field and we can do really good work." It is...a message that I think men need to be able to get. But, then I'm also thinking about the other side. I don't want to marginalize women who are in the counseling program, but I do sometimes get concerned about the message men get that we don't, not that we don't get attention, but no one really reaches out to us and says “Hey, how are you doing?” I don't think there's a fellowship thing for men. I think there is one for women, but there is nothing for men to say "Hey we want to approach you in this particular way."

Quincy shared his experiences with male stereotypes as a male counseling student. Quincey stated,

I think that, for me, even after I was in the field of counseling, it felt like that was sort of expected of me, that I had to be this person that other people wanted me to be. It took me a while to realize that I didn't necessarily have to be that person. I could have emotions, I could express those when I was comfortable. I could be more stoic when I wanted to be. That that was probably good for my own mental health. That constantly talking about my feelings if I didn't really feel like it wasn't really necessarily to my own benefit.

Some of the men stated that the counseling field is a good fit for individuals who are empathetic. For example, Uri stated,

It's a great field to come into. I would say if you're thinking about entering the field ... For me, it's definitely felt like a home. The first time where I've felt qualities that I've beat myself up for having are now valued and important. It's a 
great place to use those sorts of skills if you're more sensitive or you're more empathic or vulnerable.

Uri continued, "Also to not be afraid to express your own feelings and your own experiences and stuff too in a compassionate and nice way."

While in his program, Winston questioned if he was empathic enough to be a counselor. Winston stated,

There's always that discussion of "Can males experience the subtle emotional experiences of other people?" Because I think the research shows that men are more comfortable or open with expressing anger. But as far as the emotional spectrum goes, then I think they are often stereotyped as being somewhat incompetent in emotional empathy and emotional expression. I went in with some insecurity. "Do I have that? Am I going to be able to empathize with women, other men, children?" Because I've been revered as a male. I found that to not be the case. I think that I am quite attuned for a lot of emotional empathy across this emotional spectrum. But I guess that was something that was always in the back of my mind as "Can men do this? Or are they more suited to more tactile professions like construction and engineering and things like that?" Elliot shared similar thoughts about the male experience in the counseling field. Elliot stated,

I think any man, or any male, going in needs to just be, not accessible, but them being able to have access to their own thoughts and emotions. I think that'll give them a better insight into struggles that other people are having. 
Elliot expanded, "It's listening to someone's thoughts, and emotions, and their struggles rather than just quickly jumping in and fixing the problem.” Furthermore, Elliot said, "You've got to be willing to kind of sit through that and go along with it, like a wave. Just got to ride the wave, man."

Men are needed. Many of the participants wanted men to know they are needed in the counseling profession. Participants said that clients need and sometimes prefer a male counselor. Neal stated, "You are needed, and your voice is also appreciated and honored equally as much as everyone else's is, and when you feel lonely to phone a friend." Sherman added to this sentiment, "Anybody who doubts, just that there's going to be a spot for them." Sherman went on to say, "There are a lot of male peers I guess that I have that are involved. I didn't really hear any of them having any second thoughts about whether or not they should enter the counseling field."

Percy also expressed how important males are in the counseling field. Percy stated,

Out in the field they are certainly needed and there's a place for them, but for them not to lose sight and not understand the value of having female counterparts in the profession as well, and not to feel intimidated by being in the minority. Derek believed it is important that prospective students know they are needed. Derek stated,

Men are really needed. I mean, in the field they are vastly underrepresented. I think a lot of clients want male counselors. So, if you take the example of say a female victim of sexual abuse. So, a lot of, initially, they really do want to talk to females, and that's understandable and they should. But at some point they've 
been abused by a male offender at some point, it might actually be therapeutic for them to deal with some of those transference, counter-transference issues with the male therapist, or if they have dad issues. And they can go for a male too. You know, if the male had a mom who was abusive, maybe it would be good to talk to a female therapist at some point about that. And then, men talking to men is a little bit different than men talking to women too. I think research shows, at least some article I read years ago, women typically open up more to other women, but men also open up to other women more than they do to men. So, I think when you talk about male communication, I think there's some men need healing with another man in the room, so to speak. Especially if it's an issue related to male issues or whatever. But there's not enough men to really, in the field.

A place to learn. Some of the participants were attracted to the counseling field because it was a place they believed they could learn about self and others. Many participants said they grew on a personal level due to their experiences in their counseling program.

Although Elliot was attracted to the counseling field to help others, he was also attracted for another reason. Elliot stated,

I think it was, for me too, just that never ending thirst for knowledge and trying to push myself to just always keep learning and learning and bettering myself. More so, at that point, as a counselor, but as I've realized over the years, I've pulled quite a bit of the information too, to help me just be a better person myself. Glen stated he was attracted to counseling to help people. However, he realized there was another benefit to going into the counseling field. Glen stated, "Also, kind of 
figuring out my own personal issues, in some ways, was maybe in my unconscious. I think that through my journey, in the master's level program, I realized that I had some work to do on myself."

Vincent also shared about growth in the program. Vincent stated, "I think it is important to be expected to really examine how being a male in society as a whole can impact what we do as counselors." Vincent said that growth "really impacted how I view the therapeutic relationship that we develop with our clients."

Uri shared a similar experience about growing in the program. Uri stated, "This is a great place to be. That to sit back and listen to other experiences of people different than yourself because there's a lot to learn."

Winston shared about his learning in the counseling program. Winston stated, I think how being a counseling student impacted me as a male was it helped me to be more comfortable being in a nontraditional male career. Talking about human development and talking about social justice and talking about gender expression in general, it made me feel a lot more comfortable with who I am. I found myself through my late teens and early twenties interacting more with female peers, female friends. I wouldn't say I was exactly comfortable with that, but I didn't really know why that was the case. I think going through a counseling program, I was asked to look inward at myself a lot to assess my own personal values, my own biases and where I come from, my privilege, my perspective. I think it has helped me become more comfortable with who I am and the type of male that have become and really harnessing being a male in a female dominated profession. I feel really good about it. I feel excited. I no longer doubt why am I in a female 
dominated profession? I don't have that question anymore. I'm just really excited to be here and feel like I have really something great to offer. I think if anything, I've benefited just from feeling proud about being a man in the profession.

\section{Experiences in Counseling Programs}

Participants were asked to share about their experiences in their counseling programs. Participants discussed relationships with peers and faculty. Participants also disclosed challenges and benefits, due to being the gender minority and a man. Participants shared that some of the challenges included feeling lonely or isolated; feelings of invalidation and/or discrimination, including male stereotypes; called on as the male spokesperson; financial concerns; challenging topics; and the role of husband/partner and/or father while going through the program.

Some participants discussed overall positive experiences in their programs. Rusty stated,

My program, I have to say I was fortunate enough to have a program that was pretty well adapted. They had had, and they recruit well for different men in the program. So, in the program I really was pretty dang fortunate. I had not had a ton of issues in my master's program.

Vincent discussed his positive educational experience in his counseling program. Vincent stated,

Overall, I really do think my program has been wonderful both in terms of just general competence and content and in terms of making me feel welcome. As I mentioned, I never really felt particularly singled out for being a man when we 
have had discussions concerning it. I feel like it has been appropriate, both academically and from a developmental point, in terms of getting our skills ready. So, I think we've done a great job at making a good program.

Rusty shared positive sentiments about his counseling program as well. Rusty stated,

Really the vast majority of my program was really, really positive. Most individuals treated me like a counselor, and I treated them like a counselor. You know as a colleague, someone to ask questions to, the vast majority, especially early on when we're practicing basic counseling skills, of reflecting feelings and advanced accurate empathy, they would just practice it with me. I did have one individual who did very similar things of patronizing. Saying 'It's okay, it's hard for guys to reflect feelings.' But one, that individual I didn't hang out with, and then two...they withdrew from the program. It was really positive. I was there to be trained in how to be a clinician, and they taught me, or treated me as such. Experiences with peers. Participants were asked to divulge information related to their experiences in their counseling programs. Participants discussed their positive and negative relationships with male and female peers, while progressing through their counseling program.

Kyle stated, "I loved most of the students that I went to school with. It was just a great fit for me; very rarely did I have unpleasant interactions with them." As for his experiences with male peers, Kyle stated they were,

Limited, just simply because I had so few of them...I think we got along pretty well. And it was interesting because, I'm trying to think, it's more appropriate for 
my doctoral program because there were actually a couple in my cohort who were male, so it was a little bit more balanced. And I think we got along pretty well. I think even in this profession, it's sort of the male way of doing things. We didn't really talk that much about what it is like being male in this kind of femaledominated profession, and all that kind of stuff. But I think we recognized in each other this interesting counter-cultural thing that we were doing, being male in this kind of profession, being in touch with feelings, and all of that kind of stuff. So, I think there was sort of an unspoken type of thing going on. Abbot described a positive experience with his male and female peers in his program too. Abbot stated, It was very collegial, very classmate like. There were usually, in each class, we had 10 or 15 in a class, there were usually one or two guys and the rest were women. In many cases, I knew a lot of them because some of them were also employed by the same school district. I would know maybe half of them and it's a small school. It is a small school and the area that it serves is fairly small so it was rare that someone was coming from far away to take the class. You got to know that you were all in similar situation.

Derek shared that in his counseling program, female peer experiences were positive. He stated,

Actually female peers are pretty supportive. I think that's an interesting question because yeah, if you're in a cohort...you have kind of a shared experience and shared suffering, for lack of a better word. Like, "Oh, we have to turn this final in, 
blah, blah, blah." Peers are pretty open and nice. And maybe that's more a generational thing?

Elliot shared how his experiences with his female and male peers were different from one another. Elliot stated, I was probably more vulnerable and less fearful of being criticized or being, or in my own head, thinking I was going to be criticized or not as stupid, I think there was less of that. Yeah, there was less of that with my female colleagues.

As for Elliot's experiences with males he stated,

I did identify a couple male peers that I probably talked to more closely than probably any other males, but I still, even still fourteen-something years ago, I probably wasn't really connected. I think, just my own personal maturity level was, granted it was mid-twenties or so, I don't know, I think there was just more of something with me rather than with my male peers, something that was just missing, some developmental piece that I hadn't been able to tap into and be more open and just kind of forthright. The relationship itself wasn't at that point and I didn't spend enough time with them, and I was still maybe trying to prove to myself that I knew what I was doing and I wanted to try to portray that. I was hesitant to speak up with males if I didn't know something. Like, if I say this and they know it then I'm inferior to them.

Elliot expounded that he had a fear of "saying something stupid or something that gets this reaction of, "What were you thinking?"”

Trent stated that his relationships with male peers, in his current relationship is "pretty good." Tent expounded, 
We are pretty good; we are all for the most part pretty quiet. I don't talk much in group settings. I would say most men in the group, in my class, don't talk much either. We all get along, we will talk during breaks in class, and I would say we are all friends.

Trent shared that he is not sure why the men on the program do not talk very much. Trent stated,

I know speaking from a personal standpoint, I don't like talking in big groups where all eyes are on me. I don't know if that's a characteristic all the men in my class have or if it's all different, but I know that's where I am coming from.

Trent elaborated, "I am friends with a lot of the girls in the program too, but I am friends with most of my class...I don't want to say it's any more special just because we are guys or men."

Winston shared about his experiences with female peers. Despite his desire for a relationship with the female peers, it did not occur. Winston stated, I struggled relating to my peers, being the only male in the classroom there. I found myself isolated. I don't want to sound insensitive or anything, but when I came into the counseling program I really, really was looking forward to bonding with my peers, then with people in the classroom and developing really great peer-to-peer relationships. I found it hard because I found that the girls, the females in the class, were bonding over things that were overtly female and I had a hard time connecting to. I found myself disconnected from my class, my cohort because the things that they were ... It made me realize I'm more of a man than I think. 
Winston elaborated, “It made me wonder, 'Maybe I'm not as open-minded as I once thought' or 'Maybe I'm not as flexible in my gender as I once believed.' There were some disconnections between me and my predominantly female cohort I noticed." Winston continued,

One of the reasons why I think I was so grieved by not connecting with my female peers in my program, in my cohort, was because I've always found it really easy to communicate with females. I've always felt at home in a social group of females. This was the first time in my life where I did not feel at home with my cohort. I think it's what made me connect really easily with the faculty members who were women. But another thing, I think you should know that I think kept me from interacting with my female peers in my cohort is they were a little younger than me, too...I often wondered if it was the development stage or some of them were right out of college. I had been in the field professionally doing different things, of course, but I had started a career and then a variety of different things. I've often wondered if that was, it didn't come down to gender, if it came down to an age difference.

Vincent shared that his relationships with female peers have been positive in his counseling program. Vincent stated,

I think they have overall been very good. I know that I have tried to be very equitable. I'm very aware of the position that men have in our society. I am aware of the fact that sometimes I feel as though I get a little more attention because I'm a guy. And I have been pretty forthright about those experiences with my female classmates and for the most part everyone has been very receptive 
and appreciative that I am trying to take those efforts to be aware of my own cultural experiences. So, I think overall things have been very good and it has been a great experience with all of them.

Jasper's experiences with his female peers have been mostly positive, but he believed it was due to personality and not gender. The majority of Jasper's relationships with female peers have been positive. However, he said it depended on the individual and did not think he could generalize his experience with females.

Jasper also shared about his experiences with males. Jasper said, Well there have been fewer male peers and I don't know if it would be the same. My first gut reaction is that there is a higher percentage of male peers that don't get it, period, compared to women peers. I think that there is a larger number of male peers that exercise some sort of misogyny or engage in acts that they can denigrate other groups, even if it's on some subtle plane. But, I guess I never really thought about it until you asked, but I would say that it is different because in general there have been less microaggressions coming from the women than the men.

Rusty’s experiences with male peers were similar to relationships with female peers. Rusty stated, In my program, it was very similar to my female identified peers. We were there as colleagues. We all support each other. We empathized with each other. I really can't say that I have a perception of it being different than my female identified colleagues. 
Percy shared that he had positive experiences with his female peers. He attributed his experience to being raised by a single mother. Percy said,

I'm very comfortable around women, individual or group. It's easy for me to relate to them in some sense, not everything obviously, but I can be very comfortable around women, in a group of women, it's just not a thing for me; it's very comfortable. It was easy for me to forge friendships with my female colleagues in that program and I still keep in contact with a couple of them to this day.

Percy said his experience with male peers was different than his experience with female peers. Percy stated,

My male counterparts, not all of us, but we were maybe a bit more competitive with each other. Again, not terribly overt, and I'm not saying they were microaggressions either, but we were more sizing each other up in terms of competition for jobs. Again, not in an unhealthy way. It wasn't unhealthy to me because we were mutual about it, but I didn't get that from my female counterparts.

Frank described his relationships with his male peers in his current counseling program. Frank stated, They're all younger. They have had little to no experience in the mental health field, which for whatever reason makes me feel better or stronger than them. But it's experience, it's not maleness. I mean, if that's a, I don't even know if that could be an adjective, but it is in this conversation, for me. Positive experiences, I feel listened to, both from my instructors and peers. I feel valued, definitely more 
towards the end of the first semester probably because my experiences kind of unfolded in the classroom. So, they didn't know me at first, and as we got to know each other through discussions and class projects, I feel like we built a stronger bond.

Frank also shared about his experiences with female peers. Frank stated, "So far, I've had a really positive experience. I've had no arguments."

Leroy shared that his experiences with female peers have been mostly positive, but a "screening process" takes place. Leroy stated, My female peers have all been pretty supportive. They've all been pretty good. I think initially, when we get to meet each other, they're kind of feeling me out to see "Okay, well what level of knowledge does this person have about counseling?" "What is the effect of" and "Okay, why is this guy here in counseling?" I think sometimes, they can be quite grateful and quite welcoming that they have the male presence. But, there is definitely no "There's a guy here! Let's embrace the person." I think there's usually this feeling of "Okay, what do you know? Why are you here? Are you qualified to do it?" Leroy elaborated,

That's kind of the way to look at it. You got a new client, you want to see if you're a good fit for each other because you want to protect the profession. You want to protect the classroom, or whatever it is. And I'm not sure if other men feel like that, but I feel it like that. And I'm okay with that because I do understand how serious the work is and I understand that this is kind of the population that dominates the field. I get that. And, I don't think it's coming 
from a negative or discriminatory place, but I do recognize that I am the odd man out most of the time.

Leroy also discussed his experiences with male peers. Leroy stated,

The men that I've been really fortunate enough to study with, particularly, are very progressive men. I think that they see, I think what they do is they see the field as work that's predominantly done by women, but that doesn't necessarily disqualify men from it. And I think what they see is opportunity to reach out to other men. I think there was a study recently I saw that said women engage in counseling much more than men, at a higher number it said I think. And we don't know what the reasons are that men don't do that, but if you go to your psychologist today or one of your local listings, I think you'll see the men to female therapists is very different. I'm willing to bet that there's a part of that that men kind mostly think “Ah, I've got this problem I'm dealing with but I don't want to talk about it," whether it's divorce or something physiological like erectile dysfunction. That can be hard to sit down and talk to another woman about. To another man it might be easier to sort of unravel that, if that makes sense. And I think other men in my program sense that as well.

Sherman discussed his experiences with his male and female peers. Sherman stated the following while discussing his experience with male peers, It's been interesting. There are less males in the program than female. I've had a couple classes where it'll be myself and another guy then the rest are women. It can be a 20 person class, between 12 and 20 . I think that they've mostly been good experiences. 
Sherman elaborated,

I think that there is an unspoken awareness that guys have that often came out in counseling courses. That we are aware of societal stereotypes and we're aware of expectations that are placed on men. Especially if you're the type of guy that goes against that, if you tend to be more emotional or not fit typical gender roles. As for his female peer relationships, Sherman stated, "I think overall they've been positive." He elaborated that there was just one just a one outlier situation of weirdness. I don't think that that's really the norm. I think there's something about being in a counseling program. I think typically whether you're a man or woman, the type of person that you're going to see in a counseling environment is going to be somebody that's more apt to...I have nothing to back that up other than just saying my experience, I would hope that the type of person in a counseling context, that is actually part of a master's program, I would expect them to be more aware culturally and socially about bias and that kind of thing.

Vincent discussed his experiences with male peers in his counseling program. Vincent stated, My experience with my male peers have been much more limited. When I first began the program, there was only one other male counselor who began at about the same time and we got along well. However, there was a pretty big age gap between us; he was significantly older than I was. We worked together fine but there were definitely some experiences that didn't translate quite exactly. Unfortunately, he is no longer in the program and then the small hand full of 
other male counselors that I have worked with, it was a situation where I was still very new to the program and they were on their way out. They were finishing up practicum and internship. So again, I worked well with them, but the difference in professional development, I think because I know I presented myself much more like shy and maybe differential to their experiences because I knew they had been through the program and they had a lot of more experience. So good, but a little more differential to their experiences.

Uri said there were some challenges in his relationships with male peers in his counseling program. Uri said, "In any other class, if there were any other men I almost felt more pressure in that sense than from maybe my women classmates or professors to talk about things I might face as a male counselor." Uri continued, It might just be a personal, my experience. I've always, since childhood, struggled a little more connecting and feeling comfortable around male peers. I'm not sure if that was a result explicitly of entering the counseling profession or if that's something I carried with me from childhood into the counseling profession, which tends to have you focus more on emotions and vulnerability and stuff like that, which aren't so in line with masculine norms. Yeah, I definitely feel more constrained around male peers. One of my interests is in male socialization and how boys and men resist masculine norms. I've definitely had cases where I've felt like I've heard other male peers agree to statements that I thought weren't necessarily true, but were just in line with male norms. Men always express their sadness as anger or something, which may be true, maybe a 
lot of men do because that's socially acceptable, but a lot of men don't. I think making those sweeping generalizations are not helpful.

Uri continued,

I think in the case, if I was in a class and a woman made that statement of all men express sadness as anger, I would feel more comfortable challenging that being the only male and saying, "Well, I've actually had different experiences in that." That if I were around other men because I would be afraid that other men would back that notion up even if they didn't feel that way just to ascribe to masculine norms.

Mac shared about his experiences with male peers. Mac said the relationships were "good." Mac stated,

A lot of them are very friendly, which I shouldn't be surprised. In this field, people have to be approachable. Not have to be, but it helps if they're approachable. I think those types of people are drawn to this field sometimes. I will say, I've had a lot of trouble with other gay male students. I have a lot of reactivity, which I think comes from unresolved internalized homophobia. So it's harder for me to open up and get close to them, even though I want to and I try to. I recognize a lot of resistance within myself. With straight men in general, I tend to be more closed off because of my relationship with my father and other men growing up, influential male figures. So, it's harder for me to try to get to know people, especially on an emotional level. I have found, in some cases, it's harder for some men to open up in a vulnerable way with me. I don't know about 
with other men, but generally amicable. I haven't had any outward hostility, which I guess I have to say, or it's interesting that I do make known, because I think that says a lot about my expectations of interactions with men.

Quincy spoke of a common shared experience with his male peers in his counseling program. Quincy stated, In my doctoral program, I have some male peers who I really connect with. We share a lot of worthwhile ideas with each other, work on publications together, and things like that. There weren't that many male peers in my, you know, there were only two other men in my cohort in my master's program.

Quincy expounded,

I got along pretty well with one of them and didn't get along quite as well with another one, but I don't know that they were all that noteworthy. I guess I'm still friends with one of my male peers. I think that there can be male bonding that can occur if you are the only men in a program and it's primarily female, that there's a shared experience there.

Quincy discussed his experience with his female peers in his counseling program too. Quincy stated, I would say that, particularly my doctoral program, they've been overwhelmingly positive and enjoyable. I'd say that my master's program, in particular, had some sort of political, it was some of the stuff I was talking about earlier, about feeling manipulated to have a very specific set of ideas. That definitely happened in that program. That certainly didn't only come from female peers, but it did come from some female peers. I found that to be unpleasant, at times, in that program. 
I didn't necessarily ascribe that specifically to their being female, they just seemed to have certain ideas about the world. I felt like, if I held anything but their views, I would be dismissed as this oppressive, terrible person kind of thing. Again, I don't know that I'd specifically ascribe that to their being female, because I certainly had those experiences with some male peers as well. Neal discussed the importance of male peers in his counseling programs. Neal stated,

I have found, in both my masters and my doctoral program cohort, the people I would identify with most, or say that I became the closest with were male. The ones that I still stay in contact with, I still do research with, and talk with happen to be male. And they also happen to be around my age. And so, I have found that, at least in those two educational experiences, I tended to bond more with the males in my cohorts. And just, again, because of the similarities in age, gender, personality, research interests, they just happen to all align, and we've made connections around those.

Neal also discussed his experiences with female peers. Neal said, "In my experience with my female peers, in my master's program, was largely positive." Neal was a part of a cohort where males made up one-third and females were two-thirds. Neal stated,

It was a nice ratio. I wasn't the only male in the room and I just got along, well, with those people. Demographically, we were pretty similar in age and personality-wise, I think we had a lot of similarities. So, our cohort just really bonded and I had a really positive experience, with the vast majority of females, 
in the master's program. The doctoral program was somewhat the same. I was a few years older than most of the females in my cohort. And my experience of that was there might have been some difference in maturity level, that I felt that there was a lot of things that they struggled with that I didn't and that created some disconnect. Struggled with, in just terms of workload, and managing workload and those kinds of things. Where having worked for several years in a really high-demand job, I felt pretty comfortable with managing a lot, in terms of my workload, and my work life balance, where I saw some other people struggle.

Experiences with faculty. Participants were asked to share about their experiences with faculty in their counseling program. Participants shared positive and negative experiences with male and female faculty.

Vincent shared his experiences with male and female faculty in his counseling program. Vincent stated, I think my experiences with my female faculty have been very positive. We only have one male professor in program. I would say that my experiences with all our faculty members have been fairly uniform. I don't think there were any significant changes or different interactions because they happen to be male or female.

Mac's experiences with male faculty have been "generally positive." Mac stated that his relationship with male faculty have been "very much one of fear and shame of being dismissed. Those are things I associate with it." However, Mac recently has had 
some positive experiences with male faculty. Mac expanded, “I don't think that I was given any special treatment or anything."

Mac shared that his experiences with female faculty vary, just as they did with male faculty. He believed this was due to personal experiences. He explained that he had "a lot of reactivity" toward his academic advisor because she reminded him of his mother. He stated, "There was some stuff between us that really I think, there was some stuff inside of me that made it easy for me to kind of project onto her." However, Mac has had positive experiences with faculty and reported most of his experiences to be positive with "female teachers." Mac also added, "I don't think that I have been treated differently, that I'm aware of."

Jasper shared his perceptions of male and female faculty in his counseling program. Jasper stated,

Going back to my master's program, I would say that the vibes I got from my male faculty in the master's program were that either what they said seemed like it was verbal gold to everyone in the class and so everyone was hanging on his every word and almost treated him like this all knowing guru. I really didn't see that taking place with any of the female faculty. Then there was this other male faculty that was kind of... what's the term? He seemed to kind of half-ass it, well not half-ass it...he didn't really put in $100 \%$. I didn't really get that vibe from the women faculty. Then in the doctoral experience, I would say the younger women faculty seem to be more aware of contemporary marginalization or oppression compared to those women faculty who have been in the field much longer, which makes sense because there has been an evolution in oppression, generally moving 
to more covert forms. Because when they got into the field, decades ago, they were looking at more overt forms. I don't know, maybe more slightly aloof in their voice of facilitation, not as willing to broach topics that are more uncomfortable.

Jasper continued,

When it comes to female faculty making it more comfortable for men, I don't know. It almost seems like an oxymoron to me. I don't think that women need to be doing anything to make it more comfortable for men. To be honest, it needs to be the other way around. I am trying to rack my brain for examples for instances where they need to make it more comfortable for men and I just can't think of any. Kyle discussed the importance of a particular female faculty member that was in his counseling program. Kyle stated,

Especially in my master's program, I had one professor who was just really, really good at helping me examine my dominant cultural privilege. And so, even though I'd never felt comfortable, in certain respects, as far as what society expects of men, this counterbalancing of "Yeah, okay, maybe not, but you're still part of dominant culture male, and so you have to deal with that." And so, that would help me with a good balance in my master's program. So no, I ate it up. I enjoyed it a lot. I didn't feel uncomfortable.

Kyle also shared some of his experiences with male faculty. He shared that although he learned from them, the relationships were often conflicted. Kyle stated, "When I went through my master's program, we had very few male faculty in the 
program I was in...there were two male faculty." Kyle said of one of the male faculty, "I got along with him" at first. Kyle expounded,

I thought he ended up being a total prick... because he had this whole frat boy approach...of, “Well, if you're going to go through this, I was hazed, so I'm going to haze you" type of thing. And in classes, I could deal with that, to me it was all a game in classroom environment. And lots of people, I knew lots of people, really didn't like him.

Kyle stated, "He did things that I thought were unfair. So, that wasn't good." Kyle also discussed another male faculty member. Kyle stated,

I think our bigger problem, there may have been some male-male stuff going on, but I think his bigger problem is he wasn't used to working with older students. He had sort of the typical traditional academic progression of undergrad, almost straight into grad, and then almost straight into Ph.D. study, and building a life in academia. And I'm sure, well, I don't know, I can't speak for him, but my impression is that his principle identification would be academic, not clinician, and even though I'm immersed in the academic world, my principle identification is clinician. And then being older, I just don't think he quite knew what to do with me.

Elliot shared his experiences with faculty during his doctoral counseling program. Elliot stated, "I felt like I had supportive supervisors that would challenge me." Elliot recollected an experience with a male faculty member and shared it with the researcher. Elliot stated, 
I remember one of my first times ... doctoral supervision and ... looking at the tape I submitted and saying, "Whoa, what the hell is that?" You know?

"What ... am I supposed to see here?" It was a punch in the gut, but it was also an honest assessment of where I was. He did a nice job, not only at that point, but just throughout, pointing out the development, where I was developmentally, and what I needed to focus on. That gave me the right level of intervention, whether it was books to read or people to talk to, other students, classes to take that could really help advance maybe some gaps that I had in my development.

Neal discussed his experience with faculty and specifically the importance of male faculty. Neal stated,

I have been lucky enough to have some really great faculty, of both genders, throughout my master's and doctoral program. I will say, again, similar to my cohort, the one, I find myself gravitating towards males, in terms of mentorship, and collaborative work. Some of that has been around just interest areas. But I think other parts have been around it is just a different comfort level, different kind of experience, a relational experience, with a male, than there is with a female. For me, at least, in terms of my educational experiences. So, when I think about the faculty members from my master's and doctoral program that I still stay in contact with, and I still check in with, and do research with, they are male. So, I think that I found it easier to connect with male faculty members, as a student, than female faculty members. That's not to say I had negative experiences, or relationships, with females. I had some great relationships with supervisors, and with instructors, and faculty members, in both my master's and 
doctoral programs that were female. When I reflect back on it now, the ones that I really connected with, that I still stay in touch with, are male.

Leroy discussed his relationships with male faculty in his counseling programs.

Leroy stated,

I probably had about three male professors in my graduate experience. So, when you come across some of these men, "It's you, look," and they give you kind of a code wink, like "Wow! You're here, me too." And it's almost kind of like we're going to try to make this work for each other. "I want you to do really well here." So, I think that when I get the male faculty, not that they favor me, but I do think like, "Oh wow! There's another guy here."

Leroy also discussed his experience with female faculty. Leroy stated, Female faculty have always been really supportive of me. I think they do recognize that it's rare to have a male in your counseling program, particularly, a male of color, so they are very much supportive of me. I think there have always been people that I can reach out to and I can be trustworthy. With the exception of that one professor in undergraduate, the TA should I say, but I've always found them to be supportive and wanting to push me forward and wanting to keep me in the field.

Ivan shared that he has one male faculty member in his program and that he looks forward to being in his classes in future semesters. Ivan stated,

He uses a strength-based approach. He is so positive and I'm sure he lets all of this stuff roll off of his back...I am going to make a point to sit and talk with him 
and say "Hey, talk to me about how to get along in a profession that is dominated by women. What are some of your tips?"

Rusty said his experiences with female faculty were positive. However, he had no male faculty in his program. Rusty stated,

My program didn't have any male faculty, which that part was a noticeable difference...I definitely identified in that my program that that was missing. Especially being, for me, that first generation piece that none of my family has ever been in that professional work. So, there are a lot of different idiosyncrasies that I had to pick up on. A majority of those I was able to get support from female professors, not all. I mean other than my interview process, I felt really well supported by my female identified professors. They, hands down, were amazing and I could clearly see that they treated me as equal as everyone else.

Rusty expounded,

I felt like if I had the skills, and I had the wherewithal to be a counselor, they were going to train me and teach to my ability levels and to my educational levels without any thought about my gender or sexual orientation.

Sherman shared about his experiences with female faculty in his counseling program. Sherman stated, I would say that overall, it's been mixed; it just depends. I would say that over all they've been positive. For me lately, with some of the struggles that I've had, experiences have not been great. I have a hard time blaming that on the faculty member. I think it's less about the individual and it's more about both the 
situation and just bigger things that are happening outside of our department. Just group think as a country or even as a society, going that big.

Glen shared that his experiences with faculty depended on the faculty member.

Glen stated,

I think in my current program, I have both ways. I have some faculty that see me as, really just give me the benefit of the doubt, really positive towards my gender, and then I think I have both. And I have to really be careful to figure out what that is. And again, same thing in my doctoral cohort, I am one of two males, that it plays that way. That my classmates, when we talk, it's interesting to hear our opinions of the faculty members because I think it also, in some ways we have all these intersections, but gender is definitely one of those that may very much dictate our experience of somebody.

Glen expounded,

I guess I'm telling you more about my classmates. So, my experience of a faculty member could be completely different than my classmates' maybe, based on the gender dynamic. I'm not saying that's always true, but it could be that one, or even, I mean there's other factors, other multi-cultural intersections could also play a part in how we experience somebody else. And I think in our profession, we're more aware of that.

Glen continued, "I have a professor this upcoming semester that I've not had before and I'm a little bit worried about it. I just don't know how I'll be perceived." Glen stated, "The professor doesn't have a great reputation in our program, and so I know that piece." Glen said, "All females, I have to feel them out to figure out what's going on before I 
know if I feel safe or not. And that might be my own personal issues." Glen shared that part of his concern is the instructor is female. Glen stated,

I just don't know how I will be experienced. And again, it can be my own issues. It can be their issues. It's always hard to tell. But I do know that I think I am aware because of our profession and our emphasis on multi-cultural, which I love, I also am very much aware of what I look like and how I present, and I can be off on that too, but I think that also gives me a little bit of a pause in some ways. Glen stated, "I think there's always in this profession, I share most of who I am, $80 \%$ I would say, but there is a part of myself that I do hold back because I do exist within such a female centric culture."

Trent said, in general, his experiences with female faculty were "good." Trent stated,

one of my all-time favorite professors was a woman. She got a different job... So seeing her go was really sad for me because she helped me a lot. Last year was really hard for me personally, and she was there for me to help me with my projects and assignments... The professor that replaced her is a woman too, and I think she is probably the worst professor I have ever had.

Trent shared it is her teaching style and "her personality is kind of annoying too, but I don't know exactly what it is about her."

Trent also discussed his experiences with male faculty. Trent stated, "I got along with the male faculty better in undergrad than I do in grad school right now. I guess this year in grad school, I don't think I have had one male professor this year so far." Trent 
said, "We don't have a lot of professors. I think we have maybe 6 or 7 full time professors. I would say it's 50/50."

Sherman discussed a challenging experience he had in his counseling program and shared how faculty responded. Sherman stated, Ironically, the least amount of support...was from a male faculty member. I think that that sounds a lot more offensive, but I mean it. That sounds like I expected it to be something, if there's a problem right now, where it's like the good old boys club where the men stick together, downplay horrific actions that somebody has undertaken. It's not like that at all. My expectation of that would have been that I expected ... I guess that I expected a little bit more benefit of the doubt from a male faculty member when I come to them and say, "Hey, this is my struggle that I'm having. There's an issue here and I'm not really sure how to approach it." Sherman said he felt more supported by female faculty versus male faculty during this challenging experience because to him, it seemed the female faculty member was more interested in hearing his perception than the male faculty member.

Rusty shared a negative experience he had with a faculty member. Rusty said the faculty member assumed he would be challenged when working with clients who were having an emotional reaction. Rusty explained to the faculty member that he would not be challenged because of his work experience. Rusty stated,

And they're like "Well no, no, no because it's like really hard for guys to sit through that." Or "How is it going to be for you to sit with a female identified individual who's been assaulted or harmed? How's that going to be for you because you are male?" 
Rusty stated he was irritated by this interaction and the faculty member's assumption because "It completely negated the work history that I was able to show the people before walking in. I mean it's very representative of any other kind of discrimination."

Uri reflected on his relationships with male and female faculty and how they were similar, but also different. Uri stated, My advisor on my master's program was a man. He was actually a really great...role model for me. He was a very gentle spirit and he was welcoming and warm, just warm counselor vibes. He was great to have. I probably felt more comfortable with him than I probably felt with any other authority male figure in my life actually. He was great. Then in my doctoral program, I have interacted with a few male faculty members. One is my advisor... I also feel very safe with him. He's definitely warm.

Uri elaborated,

I got other male faculty members who I definitely feel a little more constrained around, I feel a little more pressure or I feel like I want to impress. It feels like there's this notion that I need to impress them, earn their respect. I guess that's not a sweeping case of all male faculty members, it's just with some.

Uri spoke of his female faculty experiences too, and how it is different because he does not feel like he needs to impress them. Uri stated,

Then with my female faculty members, although she's not my advisor, I work with a professor in my doctoral program really closely; probably more than I work with my advisor. I feel comfortable around her too. In general, all my supervisors have been women and I feel very supported by them. I would say in 
general, there's less of a feeling that I need to step up and impress around female faculty members and supervisors than I feel around my male teachers and supervisors.

Percy spoke of his experiences with male and female faculty in his counseling programs. Percy stated,

We had about five full-time faculty and two were men, three were women. I got along great with everyone and,...the male faculty were a bit more, might've just been their personalities as individuals, but they were a bit more relaxed where I know two of my female faculty were a bit more intense and their expectations of us were very clear and they wanted to get the most out of it that they could and really that's just what made them good counselor educators. Again, there's that balancing act of having faculty who are not lackadaisical, but aren't cracking the whip, for lack of a better term, and then you had faculty that are. But, again, I had good experiences with both. Whatever negative experiences I did have, they were with female faculty, but they were adjunct and I think there were probably challenges to them being adjuncts, maybe, and not so much the fact that they were women.

Winston stated his relationships with female faculty "were great." He discussed collaborating with them in independent studies, co-presenting, and private conversations. Winston shared about one particular faculty relationship where, "We had private conversations, I guess, peer-to-colleague or peer-to-professor type discussions.” Winston stated, "I always wondered if they respected me as a male in the program, being really highly motivated... really motivated to do well." However, Winston stated, "My 
relationships with the male faculty were not as strong." Winston said he felt easily connected to the female faculty, "but with the males, I did not. Yeah, the same type of relationship didn't really happen for some reason. I don't know why."

Otto shared about a negative experience with a female faculty member he had. Otto explained that he earned a grade he did not understand and attempted to clarify. Otto stated, "As soon as I sat down she leaned across her desk and got up in my face and started screaming at me." Otto expounded, "She told me that there was no way that I did as much work as the woman, my partner, and that I need to take care of my high horse and if I didn't like it I could go fly a kite.” Otto said,

I didn't have enough, I was still trying to shrink myself and be small, and not rock the boat and try to learn and navigate this world of mostly women...I didn't have enough voice to report that really wretched woman to the dean and I should have, but I didn't and that one sticks with me. That's some bullshit. I got a different grade because of what? Because of her bullshit, because of no other reason. Frank spoke of an important male faculty relationship he has in his counseling program. Frank said he feels valued by his advisor, "not just because he's a man, but I definitely think there probably is something to that. Because he's a man, he's my age, maybe even a little older, and he respects my experience." Frank elaborated, He listens to my experiences and he listens to my confusion or my questions or my... I've even questioned some of his beliefs or a few things that he's taught. I mean, not in a challenging way like in class, but outside of class, pulled him aside. And he listened to me and he gave me an educated response not a blanketed kind of shallow, you know, just to get me off the conversation, which I've had in times 
because I'm not, again, the traditional student, I've been not respected for my beliefs or my ideas. I feel like he actually listens, which is what a therapist, as far as I'm concerned, what the job of a therapist is. He holds true to what I think of as, I mean actually a human being, not just a therapist. And that's important to me as far as what a university, I mean, I feel like we need people that actually communicate in universities opposed to dictate or preach.

Frank said he feels like he has "bonded" with his male advisor. He stated the advisor, kind of pulled me aside and said...I mean, in the short version, outside of class, to call him by his first name, which to me was a way of saying he feels we're more peers than the hierarchical student-teacher thing that happens. I feel it's been valuable and I feel it's been positive ...that was validating.

As related to his experiences with female faculty, Frank stated, they are "very nice. They're smart, they're helpful. There's nothing negative."

Derek shared that his relationships with faculty were mostly positive. Derek stated,

We had a difficult professor a lot of people got bugged with. But that was more based on personality, and things like that. There were some good professors we had too. So, and then, I think we got a variety too. I mean, a professor that people didn't like. She did have solid skills in some areas of teaching, just not others. So, I think we got good exposure to the couple different ways of doing counseling theories and all that.

Privilege or benefits of minority gender in counseling programs. Participants were asked to discuss any benefits or privileges they experienced in their program due to 
being a male or due to being a gender minority. Some participants did not believe they experienced any benefits or privilege in their counseling program. Some participants believed there were some benefits or privilege because they were a male or were the gender minority.

Some participants did not believe they had experienced any benefits or privilege due to being a male. Percy stated, 'Privilege. I don't think I experienced any. I probably experienced some hurdles, but I can dig into that if that's a question of yours."

Some participants believed there were some benefits or privilege due to being the gender minority. For example, Quincy stated,

I'd say that what I mentioned earlier, about ... I know when I was applying for my master's program that I spoke with some people. I wasn't sure if I'd get in and all these things, and they said, "You know, men are sort of a rare commodity in the counseling field. They're looking to recruit some men, to some degree at least, because just not that many apply." Having that unique perspective in the field, I think that that certainly helps with that sort of thing. You can present a unique perspective in discussions and in professional settings and things like that. Many participants stated a benefit of being the male minority in the profession is the ease or getting a job. Winston shared this was something he heard to be true. Neal also heard this to be the case. Neal stated,

When I was looking at internship positions, in my master's, and my doctoral program, both of the places said they would be happy to have a male because they had a shortage, and they had male clients who specifically wanted to see a male 
counselor. And they had a shortage of male counselors there. So, that played an advantage, in those roles.

Feel valued. Many participants said a benefit of being a minority is feeling respected and valued for providing a different perspective. Some shared they feel valued through receiving attention because they are a minority gender in their programs. This was true of Winston. Vincent shared similar sentiments. Vincent stated,

I am aware of the fact that sometimes I feel as though I get a little more attention because I'm a guy. And I have been pretty forthright about those experiences with my female classmates and for the most part everyone has been very receptive and appreciative that I am trying to take those efforts to be aware of my own cultural experiences.

Harry shared that he is asked for a male perspective in class discussions. Harry stated, there are benefits due to just having a different point of view from my female classmates like being able to, for one thing, I can think of several examples of being specifically asked for a male point of view on issues like showing emotion and being emotional and teaching that emotional intelligence to children and stuff and where the man is supposed to be and where the woman is supposed to be and stuff like that. I think I'm pretty unconventional in that aspect.

Harry expounded,

I don't feel like less of a man if that makes sense. It doesn't make me question my own gender placement or anything. It's just what you do and I think it will carry over too into the house-home profession once I'm actually with a client and 
I show them that I'm willing to share emotion and be supportive and stuff and those stereotypes will go away.

Harry said he does not feel like a spokesperson for all men. Specifically, Harry stated he is called on,

not as a spokesperson, but more as my perception of the male experience. I think most people in the program are intelligent enough to understand the typical stereotypes that people hold as far as gender goes so, they're aware of these things. But I guess short answer no, I don't feel like I'm speaking for men, I feel like I'm speaking through my experience as a male.

Frank shared that he does not really experience any privileges or benefits due to being a man in his program. Frank explained that he does feel heard, but it is for other reasons. Frank stated,

My personality is, I have a tendency of being involved in what I get involved in, like we're involved in, I don't know, other people I suppose. I don't know. I'm pretty involved so I don't know if that has to do, I get more attention because I answer questions and I read the textbooks and I know the information...I'll follow up with things that are extracurricular I suppose. I have a tendency of getting more attention not overly and kind of unhealthily, but it could be seen possibly that I'm an older man in the class. I don't know if that's reaching or if that's actually true, but I feel heard maybe. I also feel heard because I have a lot of experience. I don't think it has to do with being male. I think none of this has to do with being male. 
Jasper shared that he feels heard too and this is one of the benefits to being a male minority in his counseling program. Jasper said that he is close to a female colleague and they have both found that his opinion is acknowledged more than hers. Jasper stated, We joke around about this, but we also know that that this is the shitty reality. We almost use this to our advantage when we know that there is something that needs to be heard. It is definitely something that is happening and we do it in a conscious way. Sometimes we can go into a meeting and we will discuss it. Then and I'll be like "Is this something that you want me to back you up on or not?" Because I'm like, if she doesn't want my backup, then I'm not going to say anything because like I said earlier, I don't want to step on other people's toes when they want to advocate for themselves.

Mac shared that he believes it's possible he was perceived differently, more positively, when in engaging in certain behaviors versus a female peer engaged in the same behavior. Mac said,

In my group counseling class we had to practice being participants in group therapy. A lot of the time in the group was devoted to the men in the group despite us being a vast minority. I think it reflected the tendency of our culture to value men's opinions, and value men in general, and men's time, and give men more attention than to women.

Mac expounded,

There would be times in one of my classes, like I'm a very, very relaxed and I don't want to say aloof, but just like laid back kind of guy, and there'll be times in classes where we're doing role plays, and I'm stretched out and make myself 
very comfortable. I think if a girl were to do that, this is like a male feature, maybe she might have responded differently to that, maybe she might say, "She's not as invested," but that's speculation. I don't know.

Uri discussed some of the benefits in being the minority gender in his program.

Uri stated,

It's interesting because outside of the multicultural class I think I've definitely felt safer to talk about my experiences as a man in counseling situations, in class situations where I've been the only man in the class. I actually think I feel safer there with the exception of the multicultural class because there's so much other stuff going on.

In addition, Uri stated, In my internship class was all women except for me. When I have opened up about my feelings or someone has ... I have developed the courage to speak up if I think an assumption is being made about a male experience that I think isn't necessarily correct. I've gained more courage to express that. I've definitely felt more supported by my female peers. They definitely, in all cases, have definitely seemed interested and I definitely felt heard by them I would say.

Ivan shared that getting into his doctoral program may have been due to being the minority gender. However, he was not sure if there were other benefits to being the male minority. Ivan stated,

I don't know that, but I pay attention to studies and numbers and figures and stuff. I read some article or headliner that talked about how women who are in education are more likely to get asked to do special favors like professors being 
asked for more time to do a report or a paper by a male than males are asked and that mentors ask for favors less. So, I don't know. I never played that card, but until you asked that question well maybe, I'm...tall, I'm in shape, so if anyone was ever intimidated, and I'm not afraid to speak my mind, so me being a male and having a strong voice and being able to speak intelligently, if that maybe intimidated somebody I don't know, but that might be an advantage in a predominately female field. So, that may be a benefit. But on the other hand, I think that I've experienced some sexism as well. It can go both ways.

Challenges in program not noted elsewhere. Participants were asked to share about challenges they experienced in their counseling programs. Some participants did not experience any challenges related to being a gender minority in their program. Some participants shared challenges. Many of the challenges participants discussed were noted in other areas within this document. However, those that did not fit into another category are listed in this section.

The primary challenges participants shared were feeling lonely and/or isolated; feelings of invalidation and/or discrimination; coping with and addressing male stereotypes held by others in the program; called on as spokesperson of men; and financial concerns related to entering the counseling field, program or profession.

Vincent shared his thoughts about challenges associated with being a male minority. Vincent stated,

In some of my classes, where we specifically talked about the differences I might be experiencing as a man coming through the program compared to many of my female classmates, I still think the overall takeaway, or at least the take away that 
I got was that even though I am in a minority population of this field because I'm so overrepresented I still have a lot of benefits and it is hard to offset those. Well, not really off set them, but being a minority in the field doesn't detract the fact that I am a super majority in societal view. So, no particular challenges. We've talked about that it is different, but nothing that has been noticeably difficult or challenging just because I am a male.

Lonely or isolated. A challenge of being a gender minority is feeling lonely and/or isolated because there are so few men. Some participants had no male peers at all. Elliot shared his concern about the lack of males in counseling programs because he was worried he would have not have anyone he could relate to in the program.

Leroy stated, "I think in my graduate study, it is good because it does make you a bit rare, but it can get very lonely, very quickly. You're like 'Geez, I haven't seen another man in a year, in the class.' That's not uncommon at all." Leroy discussed the importance of male peers. Leroy said, "I think it's the idea of comradery. Like, wow, there's other people that are doing this as well."

Leroy shared that women comprised over $80 \%$ of his program and males made up less than $20 \%$. Leroy added, "I don't want to marginalize women who are in the counseling program, but I do sometimes get concerned about the message men get that we don't, not that we don't get attention, but no one really reaches out to us."

Mac encouraged men to reach out to other men for support while in their counseling programs or in the counseling profession. Mac stated, There's a high female population, and that your experience will be one of being in the minority. It's interesting because lately I haven't had a lot of other men in 
my classes. I've noticed each time there's different cohorts, and so the ones when I was, I've seen many of them come and go because I've been in the program for an extended period of time. But earlier ones, and I don't know if this is a reflection of myself or of the cohort or a combination of the two, but I guess I was less aware of how they interacted and encouraged male students to talk to other male students and befriend them.

Feelings of invalidation and/or discrimination. Some of the participants shared feelings of invalidation and/or discrimination in their programs. Some participants shared that being male, or a White male, may have affected their acceptance into particular programs. For example, Kyle stated,

There was this sense of "Oh my God, I'm not getting in because I'm a White male." That flashed through my mind, but at the same time, at that point I'd already met this professor who was challenging me on my White privilege, and so I was holding those two concepts in my head at the same time, and saying, "Okay, yeah, this may be true. However, there's so much other stuff you've gotten because you're a White male. So, just suck it up and come back and do it again." Quincy shared a similar experience as related to feelings of invalidation and discrimination in his counseling program. Quincy stated,

When I was applying to doctoral programs, I won't say what programs, but there were a couple of programs where I kind of felt like they were specifically recruiting people that weren't like me. To some degree, that's fine. If people bring differing perspectives into the room, I don't have any qualms with that. If that's the value of your program, then I don't really mind either, but then I kind of 
wished I hadn't bought a plane ticket to come to the interview if you weren't going to admit me to your program based on my gender. That's not something I can prove at all or anything like that, but that was just the sense I got after I went to one or two interviews where I was just like, "Oh, they weren't going to admit me anyway." I could've saved myself that plane ticket and I would've been fine. Quincy expounded,

In order to come in as a White man, I would specifically need to hold certain views about the world in order to make up for that identity. That I wasn't free to have my own thoughts and my own ideas about the world.

Quincy said the situation felt like, "Like an echo chamber kind of thing." Quincy continued,

Some others I felt like that they probably specifically did want more men in their program because we may be harder to recruit, you know? It probably balances out on average, but it's just a subtle sense that I got that maybe they were looking for other people. One or two programs, I don't think that's widespread or anything like that, it's just a subtle feeling I got.

Quincy elaborated,

There are times where I've found that people just dismiss ideas as being male ideas or White people's ideas. I find that pretty hurtful sometimes because I embody that, and it feels like it closes off the room to me, I guess.

Quincy continued,

It feels like I come from the one demographic group that it's okay to just dismiss based on characteristics that I have no control over, if that makes sense. 
Rightfully, I think that if you were to say that about pretty much any other group of people, you would get a lot of pushback in the room in counseling circles. I'm totally in agreement with that, but it seems sometimes like that same care and consideration isn't really extended to me.

In addition, Quincy stated, "I feel like that blanket dismissal of something that a White guy said is something I hear a lot, and it hurts. It's a pretty unpleasant experience."

Quincy said he would like to see programs that are more open to different perspectives. Quincy stated,

Especially in my master's program ... and sometimes in my doctoral program, but less so ... I didn't get the impression that openly exchanging ideas and exploring what's true together was valued. I got the impression that there were very specific ideas I needed to hold. I guess it's an empirical question, it could be studied, but I would wonder if maybe an environment like that might be more welcoming to at least the types of men that I spend time with.

Quincy continued,

We live in a pretty polarized time, and we live in a time where I think the Internet and social media have made it such that people are really often confronted with just the ideas that they like, and they don't necessarily encounter opposite ideas. I think that the net effect of that is that we often don't really understand perspectives that differ from our own. Many times, it seems like something I observe, in media and in other people I see in the world, they seem to have pretty negative impressions of the people they disagree with, and I think it could potentially be a major problem in our society going forward. I don't think I'm 
new for saying that, but I worry what would happen in the counseling field if we only learn to counsel very specific types of people, and if we only really value certain types of insight. We wind up in sort of a counseling echo chamber.

Quincy shared,

If we don't consider male perspectives more, I think that we risk coming up with a perspective that is a little bit narrow in terms of the way that we understand the people around us. I think that that's true of many other identities, too. I think it's important to welcome many voices in the room, but there's a definite risk in telling men, the mythical straight White male, that person that that perspective has been shared for generations and doesn't really warrant being shared anymore. I think that that risks its own closed-mindedness.

Quincy concluded,

I'll say that there are a number of men that I've shared this perspective with who generally seem to agree with me. I don't know if that's only because they're men or why that is, but I know that it's not unique to me to be worried about only adopting a very narrow perspective in the field, and not being open to other perspectives.

Ivan shared one of his experiences with women in the counseling profession. Ivan said he was at a counseling meeting and one of the leaders of the organization "was sitting up there joking about how this used to be the good old boys club and no more. It's the good old girls club." He stated he was in a room full of women and only a few males, and I'm thinking "Wow! Did you really just say that?" Yeah, that's an accomplishment, but to suggest that the accomplishment comes from the backs of 
the people sitting in this room. I think that that's unfortunate. I think that we always have to be aware. I really think that there's danger of White men, men being acceptable to display microaggressions toward because I'm hearing it all the time. I'm hearing it all the time in the media.

Ivan also shared his feelings about oppression in his program. Ivan stated,

If the goal is for everybody's voice to be free and equal, as tempting as it might be, you can't try to get back at a person that was once leaving you voiceless because I went through it as a White male. When I felt voiceless, and when I felt like I didn't have a voice, I felt resentment and all that did was it didn't settle anything. So, it's tempting and I think it's tempting when people feel oppressed to get back at other people, but if equality and equity are the goal, then there can't be any revenge.

Ivan continued, "Instead of looking at my Caucasian male self, I should use my privilege to project my voice rather than sound like the victim of something." Ivan said, "It took me a few weeks to process everything and to refocus myself. It was a learning experience and at that time it was tough, but I know a little bit more."

Ivan also shared his fear about his future as a male minority in the field of counseling. Ivan stated,

There was a time... where I really thought "Oh my gosh! I'm in a profession that honestly I'm going to feel like an oppressed individual wherever I go." Wherever I go, my voice is going to be silenced. I am concerned about that especially when the president of the organization said that! Maybe, maybe if somebody sent in two resumes or CVs I'm going to get less of a look at because I'm a male. 
Ivan continued,

In my two years of graduate school, we were reading articles about how to counsel minorities and how to counsel every population except White males. So, maybe there's just some acceptance. That that's okay. You know they're at the top of the food chain or whatever, and I'm telling you in the counseling profession they're not.

Ivan said he is the target of microaggressions. Ivan elaborated about this experience, It was a microaggression toward White men, but it's an accepted microaggression...It's okay for people to think it's okay to stereotype or say prejudiced or biased statements against White men. Microaggressions are not acceptable except when it is directed toward White males.

In addition, Ivan shard about an experience where he had a reaction to an assigned reading. He disclosed to his professor about this reaction and she encouraged him to bring it to class for discussion. Ivan stated, I said something and I definitely got pushback about that and people were like "So, how does it feel to be oppressed and feel oppressed or not have a voice?" And I was like "And I hear that." And what I'm saying is the person who brings up Adler and Rogers and Young and Freud all being White males, she doesn't even realize what she is saying and to me, that's the microaggression. You don't even understand what you're saying and then to read an article like that and nobody speaks up?

Ivan stated, "I was very angry." Ivan said there were a few other males in the class, 
but nobody brought it up, and the one thing is I'm the guy that brings stuff up. If I have something on my mind, it comes out and I'm also open to learning so I bring things up not because I'm agreeing or disagreeing with anybody. It's because I want to learn. But it was also the thought, the suggestion that you should feel that pain because everybody else has felt that pain. That bothered me because I don't think that's what we mean by equality and equity. I don't think the other person has to go through pain. I understand that the pendulum has to swing, but if it, the pendulum swings so far, but if your goal is to oppress the oppressor, then all that's going to do is build resentment because that's what I felt. I felt resentment toward my professor and some of the other students. I've gotten over that...I don't think the answer is to oppress the oppressor or punish the oppressor. I'm the White male calling myself the oppressor you notice.

Ivan continued,

With so much focus on girls and women, with so much focus on oppressed groups, with so much focus on minority groups, are boys and men being left behind? And then I really, it was like a really eye-opening day for me when I read that article. I pushed buttons for the rest of the semester and I got shut down a few times... Ivan concluded, 'I'm going to be writing things and I'm going to publish articles hopefully. Is there going to be some issue? Should I, are people going to look at my writings because I'm a White male?"

Rusty shared at times, when he works within the realm of ACA and CACREP, he feels discriminated against due to being a man. Rusty stated, 
Whatever kind of different styles we have, it seems to be more the ACA realm because this is a LPC, CACREP feeling. Like when I'm integrated with other CACREP members, I notice different discriminatory themes happening. When I work primarily with psychologist, or psychiatrists, male, female, no issue. When I work with no issue as being a male. When I work primarily with social work, it's kind of 50/50.

Male stereotypes. Some of the participants discussed challenges associated with male stereotypes held by those in the program as well as outside of the program. For example, Otto shared about his experiences in work with male clients who were survivors of abuse. Otto stated, I didn't have the language, I didn't have the experience, I didn't have any way of it, I was so completely out of my realm. I was most definitely not setup for success in that way by my program. Had they been a woman and experienced sexual violence by a father or uncle or grandfather, then I was ready. I had to really unpack that in my own mind and unwrap that and say people are people, and helping words are helping words. Helping tools are helping tools, and it doesn't matter gender of alleged offender, or client sitting in front of you do the same thing. It's so interesting to have to unpack that while you are sitting in the room with a client. That's not the best time to do that, the best time to do that is in school.

Sherman said that he has felt the impact of male stereotypes in his counseling program. He said there was an assumption that men will engage in inappropriate 
behavior. Sherman expounded on what he meant by inappropriate behavior. Sherman stated,

like behavior that was sexually inappropriate, unwanted advances, boundary issues...I think the jitterless way to put it is, startlingly common how often things like boundary issues come into play. Things like power differential when a male has an obvious position of power and then chooses to abuse that influence. That's to me really disturbing. Something that I think that is way more common than it should be. Actually, I think the best way to wrap it up is most of it would be, in a neat package is pretty typical chauvinistic behaviors.

Sherman followed up with,

Even though I am not guilty of anything, if somebody said that I did something, because I'm a man, I think people would be more apt to just assume that whatever they're saying is true. That can have potentially dangerous results for me.

Sherman said,

As a guy when somebody reacts to you in that way, I would hope that most guys would first think about, "Well, what did I do to make somebody feel like that?" Then second, it's just a rude awakening to, "Hey, you need to watch your behavior."

Uri also experienced some challenges in his program due to stereotypes of men. Uri said, "The first one that comes to mind is I'm not sure if it's related exactly to the profession or to just masculine norms in general." Uri continued, 
We talked about differences between men and women. My professor, who was a male professor, posed the question, "Do men have as many emotions as women?" Under these emotions, I guess we were talking about our male clients might not be as open and stuff like that.

In addition, Uri stated,

I remember all of the men in the class, including me, we were just totally silent in that moment. I remember my initial reaction to the professor's question was, "Of course not, of course we have just as many emotions as women. That's a weird thing to think." I felt very, I think, just the internal masculine pressure. I didn't say anything because I felt very uncomfortable owning that and claiming that. I remember one female student piped in. She was like, "I just think that men don't have as many emotions like us"...I was like, "My God, that's so not the case. That's so not true." I reflected on that moment a lot because I really wish I had said something. I think especially men going into the counseling profession, any men, I think we're probably more in touch with our emotions and more aware of our emotional experience. I really wish I had had the courage to clarify that.

Uri elaborated about this experience. Uri stated,

I think what I was afraid of, I think this is because, I think this might be the case for other men who went into the counseling profession, is that throughout my life that's been the narrative is that men aren't as emotional, shouldn't be as emotional and stuff like that. I was afraid that if I said like, "No, of course we have emotion," that everyone, including the other men in the class, would look at me like I had three heads. Maybe it is just me, maybe I am just a super emotional man, and no 
one else is like that. I guess I didn't have the perspective to recognize that how I was feeling is how I would imagine a lot of men feel. That they have a lot of emotions to express but there's always pressure to not express. Yes, I was afraid that I would get a lot of like, "Okay, sure," or just weird looks.

Winston shared similar his experiences related to male stereotypes. Winston stated,

I found some of the females lowering their expectations for what men were capable of doing and emotional expression...I found that their expectations for men to understand in a complex situation to, the only thing I can think of is saying undercut what they were capable of in a relationship, whether it was couples counseling or being able to communicate effectively in a relationship. Winston continued,

One thing I've noticed about men and counseling with men and being a male myself is that, You've heard this before, men create a hard exterior to keep up with the expectations that society places on them. I've often found that men are hurting inside because they feel like they cannot keep up with the expectations of the courageousness, the braveness, the financial responsibility. Even having power in relationships when men sometimes don't want power in relationships, but to do that would be emasculating. I think that men are so out of touch with that part of themselves oftentimes. When I can connect with a male who is willing to acknowledge like, "Hey, this is a part I've struggled with, the struggle of being a man." It's really hard because there's just so much expectation of what it means and how to be a man and what that expression looks like." 
Male spokesperson. A challenge noted by some of the participants was being called on as a male spokesperson. The participants did not want to speak for men or be the spokesperson for all men for fear the women in the class, students and faculty, would generalize this information to all men.

Glen shared this one of the challenges he experienced in his counseling program.

Glen stated,

There might be a discussion going about, I mean I actually have these images in my brain about specific moments, in my program where a conversation was talking about that there isn't a normal family system and then we might talk about gender roles and they'd be like, "Well, what do you think?" And I would really always have to preface, "You know, I'm just one person. I'm not representing the population, but here's my opinion."

Glen continued,

So there were some challenges making sure that I wasn't, that I'm not speaking for the whole population or that I'm typical in any way. That we all are, have many intersections. We all are very diverse in different ways. That's the challenge

Glen concluded,

I think by a process, I'm one of those, what do you call them? Highly sensitive people, even though, I present very masculine, I am very highly sensitive. And so, I guess, it's a good lesson for all us and myself even, that the way that we present isn't always what's underneath. We shouldn't let gender stereotype us. 
Glen said a concern he has is how women will perceive him because it can be unpredictable. Glen stated, "I think I'd always, I always have a sense of worry in the back of my mind when I'm interviewing or I'm in the field because I just don't know which way that one's going to go." Glen continued,

They're going to say, are they going to be like some of the research does about male, White pilots, and they are the most competent people to fly a plane, which has no evidence about how their abilities or skills. Or is it going to be the other way? That I represent power, privilege, Eurocentric, patriarchal value systems and maybe somebody in their own personal life, that's the other. You just never know what that is, but yes, unpredictable.

Ivan discussed feeling "singled out" at times and called on as a spokesperson for men. During a discussion on feminism, the professor called on him to share his opinion. Ivan stated, "She picked me out" and asked him to contribute to the discussion. Ivan said, "I felt singled out." Ivan said she questioned his answers and what he offered to the discussion. Ivan stated,

I was just trying to give her an intelligent thoughtful answer. I felt singled out and some of the girls in the class, and I promise you it was very benign what I was saying, it was not controversial, some people just want you to accept it and I'm just not one of those people. I felt singled out, not attacked.

Ivan continued, "Maybe I did become a spokesperson, maybe just for me, but I was probably the opposition point when it was everybody in the class would agree and then I'd raise my hand and I'd say 'What about this?"' Ivan concluded, "I'm trying to stimulate some conversation and learn." 
Financial concerns/challenges. Some of the participants discussed financial challenges associated with going into the counseling program or working in the counseling profession. For example, Barry shared his belief that the pay scale of school counselors needs to change. Barry stated,

I know there are a couple of good school districts...that convince their school district to pay once they got their master's in counseling. They were on a different pay scale than everybody else because of all the hours. It's just common sense.

Barry shared that he interviewed at another school district and it prompted the superintendent to increase his salary. Barry said, "He was trying to pay me to make up the difference for what I had into that master's. But that would have been the only time in all those years that that ever took place. So, he knew." Barry continued, "I'm sure everybody has an argument for getting paid more, but if that piece was leveled out more I think that would help" in recruitment of men into the counseling field. Barry concluded, Hindsight's 20/20, but if you knew, "I have to go so long because here I am maxed out on the pay scale and everyone else, whether it's in curriculum or whatever, they're getting all the benefits and getting higher pay, and I'm not getting the benefits and I'm still paying for classes." So, I don't know that it would have kept me from doing it, but it would have been much more attractive if the pay was more leveled out.

Percy discussed needing to moving in with his mother due to financial difficulties in pursing his education full time. Percy stated, 
I'm not really a part-time student. When I commit to something, I commit, and so I was like, "You know, I really can't do this and work full-time and support myself." I'd have to move back home and move in with my mother, so that's what I did. I applied to graduate schools.

Quincy said he thought about leaving his program due to financial difficulties.

Quincy stated, "I have thought about leaving my program at one time or another, which I didn't do, but I don't think it was really related to gender. Mostly, at least in my doctoral program, it was related to funding and things like that."

Kyle discussed the norm of financial struggles of going to school full-time. Kyle said,

I'm not sure that I had any particular challenges that were different from some of the other students who were older and working, and trying to balance the financial world of trying to move from one profession to another profession. I was fortunate that I had a wife who was employed full-time.

Kyle continued, "And then when I had to go part-time and then stop working, she had insurance benefits, so there was that."

Glen shared a similar struggle with financing his education in counseling and the profession. Glen said,

I've really struggled to make a living wage my whole career. I've worked really hard and making a salary and then looking at gender stereotypes in front of you, really stereotypical, I think that sometimes males would want to obtain a higher wage, but I'm not sure. But, we could be speculative on that. 
Glen continued, "Just because of who our profession is...From the stereotypical perspective, I think our profession has to pay a lot more to attract males. It just has to." Glen said, "I don't believe that a male or a female needs to make more money in a relationship. I just know that our profession is just really struggling in terms of living wages." Glen shared, "Just being able to survive has been rough." Glen has worked and lived in four different large cities in the U.S., and financial struggles were always present. Glen stated, "I do know that I think males are more sensitive to that component, in some ways. So, I think that's an important piece of it."

Challenging topics. Participants were asked to disclose any topics they found challenging. Some participants did not find any topics uncomfortable and they did not find any topics challenging to discuss. Other participants said there were some class discussions they found uncomfortable or challenging.

Percy said he did not recall any topics he was uncomfortable discussing. Percy stated, "I don't recall ever engaging in a really heated debate or topic or whatever. Yeah, I don't think I ever really encountered that."

Harry shared similar sentiments as Percy. Harry stated, “No. I definitely don't speak for other males. There aren't really any topics I'm uncomfortable talking about and there never really has been."

Jasper said he was not uncomfortable with any of the topics that were discussed in class. Jasper said,

I'm pretty comfortable talking about things that are usually categorized as uncomfortable. This could be an uncomfortable situation. There is another guy in my program who has some pretty conservative views, I don't even know if I 
would say conservative, maybe I would say more traditional in the sense of not really fully grasping the concept of White privilege, and privilege and oppression in general, and a lot of the outcomes. So, I feel fine with speaking up and speaking to those things in class and kind of confronting that person in class. Where there could be more discomfort is when there are more people, when there are other people in the class that also have identities who have been historically oppressed, and wanting to allow a space for them to speak up on their own behalf. It's kind of like riding a fine line between wanting to step up and advocating for those, but also not stepping on their toes and allowing them to advocate for themselves.

Jasper continued, I have basically all of my identities are of privilege, White, cis-gendered, ablebodied male. But, I also don't want to sit by and be complicit with it and seem like I'm being complicit through my silence. It's like a delicate balance in how do I speak up and advocate knowing that that people that are marginalized shouldn't have to speak up and on their own behalf, but I also don't want to take an opportunity away...It is very important to me just speaking to that tightrope to walk. It's important either way. It's important for me to speak up on behalf of, but it's also important for me to lean out and allow room for. Yeah, it is kind of like a dichotomy, but it's important in both leaning in and leaning out. Mac shared that the uncomfortableness he experienced in his program was not due to others. Mac said, 
All the uncomfortable experiences I've had, have been with my own unresolved issues. I don't think there's ever been a discussion where women are talking, and they're talking about feminism and I'm like, "Well, men too." That hasn't been the case for me because I'm very much of the mindset that men do have more power and that is the reality of women. They are disadvantaged in a lot of ways. So, I tend to enjoy those conversations and participate in them. I will say that teachers have reminded us, and female teachers have been the ones to say, "Oh, but don't forget about men. They're living in this reality too. Don't forget the ones who are actually doing."

Derek, a counselor educator, shared that he has noticed some male students not sharing on particular topics. Derek stated, There are certain topics... I hate to say politically, but for lack of better words, there are certain political topics that might come up that I can see where a man might be in a minority position about in the counseling programs based on gender scripting in our society. I mean when we talk about working with sex offenders or if we talk about domestic violence, males and females typically have slightly different views of domestic violence ... men will kind of be pressured, for lack of a better word, to just go along with the rest of the class. Their ... views of seriousness of it or what should be done.

Derek also shared about one of his personal experiences in a class discussion.

Derek stated,

There was one class, I don't remember what it was, but it was me and one other guy in class, and I don't even remember what the topic was. But it was one of $t$ 
hose things like, the class discussion on 'What's your opinion of this?' And there's one question that me and the other guy, I think the teacher had us divide on either side of the room. And there weren't too controversial topics...they were like non-controversial either...it wasn't some of the hottest, hottest topics, but so she'd ask the question and then we kind of divide and one side of the room or the other. And there was one question that me and this one guy ended up on the one side and all the females were on the other. It's kind of comical, but then it was a little bit of that gender like, oh, like, you know "We're kind of the dogs in the room"...It was, there was the slight awkward like, "Oooh, all the gals are going to be mad at us on this."

Trent shared that the topic of feminism was challenging for him. He described the experience. Trent said,

We were talking about the feminism topic and I don't want to say I felt uncomfortable, I don't know if that's the right word, but I was getting annoyed with everyone because it turned into a debate about feminism. I just didn't understand the purpose of it all. I guess that is only thing I can think of and like I said, I don't know if I was uncomfortable, I was just annoyed.

Trent continued, "I think it was just that we are here to learn and it just turned into a debate type thing you would see on the internet. I think it was mostly, 'I'm paying a lot of money to be here, and I'm just hearing what I can see anywhere else."” Trent said, "It was all the women in the classroom arguing and all the men are just sitting there and it was just weird." Trent said it felt weird because "I think it was all the women just arguing about what feminism should be and all the guys were just straightforward. We 
were pretty silent throughout the whole thing. It was weird." In sum, it felt argumentative and not educational to Trent.

Vincent shared that he was challenged by one topic while he was in his counseling program. Vincent explained,

I think the only topic that I can really think that has been somewhat challenging for me was when we were in our multicultural class and we were discussing issues related to the LGBT community, simply because I feel as though the community has moved much quicker than my knowledge of the community, and I have often times felt as though my proficiency with working with them hasn't been to the spot where it should be. So, I think that was challenging just trying to make sure that I am learning what I am supposed to be learning and able to work with a population that might need my assistance. In my personal life, I don't really interact with too many people from the LGBT community. I haven't really encountered many people in where I live so most of it was from academic side. So, I think that is really the only challenging topic that I have come across just due to lack of education and lack of experience. Jasper said he would like to see counseling programs engage in more discussions about challenging topics because there were not enough of these experiences in his program. Jasper stated, If I could see something different, I'd like to see them make things more uncomfortable. Speak to feelings that are happening in the classroom or feel weird or things that are uncomfortable and speak openly to it and address students who are presenting or have presented something that is, or might be problematic. 
Just speak to it openly. It doesn't need to be a chastising interaction, but be like "Hey, let's talk about this openly" and that models to us as the students. But, I also think that there's some naiveté in me saying that because I am still a student. I am sure there are some norms that faculty must abide by when it comes to FERPA, and in creating an atmosphere of safety, and being able to still speak up and not going to be called out in the classroom.

Male identity/male privilege/White privilege. For some participants, the challenging discussions were related to male identity, male privilege, and White privilege. For example, Ivan shared that White male privilege was a challenging topic for discussion.

Jasper said the topic of male privilege was challenging for him when he first started his program. Jasper stated,

I feel like when I'm babbling this right now, actual things that were difficult at the time and now seeing them now in context, I feel like I just didn't understand at the time the implications of being a dude.

Elliot shared that White privilege was a challenging topic in his program. Elliot stated,

The idea of White privilege... because obviously being a White male. I was probably hesitant to engage in conversations about it or offering opinion out of fear of someone speaking up and challenging me. So, that's where I would probably tend to just sit back and listen versus be more actively involved in the conversation. That's the one I can think of right now that would be, I know it came up, but I certainly don't think I was an active member in that discussion. 
Winston shared his thoughts on the difficulties of discussing different types of privilege. Winston stated,

I'm not sure if you're familiar with Jim O'Neil. He's a psychologist I think, and he develops a gender role conflicts scale. And when men come into conflict with their gender expectations, he talked about men suffering from their gender rather, because in social justice counseling, men are often said to be the ones in power or the ones who have power over women, have power over society and positions of authority. He got a lot of flak about it from feminist theorists and things like that. Like, "How dare you say that men are suffering or that men could have a difficult time in any experience because they're so privileged." I think it's a hard thing for people to discuss because it's so sensitive. It feels undermining of a woman's experience or of a Black woman's experience or of a homosexual's experience. It's a hard question to ask, and it's really tough for us to talk about because men are so often in places of privilege.

Quincy stated that discussions related to gender and race were challenging for him as well. Quincy shared, I think that topics around identity, gender, race, and things like that were often difficult topics. I think I'm just generally an inquisitive person and a skeptical person, so I don't warm up to ideas very quickly. I need to sit there and weigh them. Sometimes, I do that out loud. I don't want to give off the impression that I hold some sort of way out there alt-right viewpoint or anything like that, but I often felt, around topics of gender, that those were the specific topics where I had to hold very specific viewpoints, and if I didn't, then it wasn't a very comfortable 
experience for me. I had all sorts of insinuations made about my character and things like that, both from students and faculty.

Lastly, the researcher thanked Mac for his contributions to the research study. Mac's response was “Thank you. You know, as a man, I just don’t get enough recognition in this world. I'm just kidding." Mac provided additional information about his response. Mac said,

Maybe that says something about my self-deprecating humor, you know, that I carry this shame. Accepting praise, or whatever...feeling I already have enough and why should I be asking for more. I think that is telling of male culture and male experience.

Being a husband/partner and/or father. A few participants shared challenges due to being a husband/partner and/or father and pursing a counseling degree. Very few men shared this challenge. For example, Derek shared the challenges of having a family and having additional roles that some of his peers didn't have. Derek stated,

I had kids coming through the program. I was already married and had kids. So, that's an interesting topic. It could go both ways. I mean, in counseling programs you have moms who have kids and you have single moms too who come through graduate programs. So, that's a whole other topic. But it's interesting being a guy with kids in the counseling field. Most of my classmates didn't have kids as other males. So, that was an interesting experience too. I don't know what I'd say about it, but then I got married really young. I got married in undergrad. I had a kid in undergrad, so that's a little bit different too. But most people wait a little longer to get married and have kids. So, being a dad in a counseling 
program was an interesting experience. So, a little bit of "How do you balance the work and home life?" Or "How do you balance school and home life type stuff?" So, that was something I dealt with, I guess through college. Where it sets you apart, I guess, is too, is some of the social aspects of you know, when you're in a group of students, they'll be like, “Oh, let's go out for coffee" and I'd be like, "Oh, I got to get home...change a diaper. My wife had him all day and she's going to go stir crazy." You know?

Persistence in counseling programs and the field. Participants were asked to share their experiences related to thoughts of leaving their counseling program or the profession. In addition, despite these challenges the participants persevered. Therefore, the participants were asked to share information that led to their retention in their counseling programs and the profession.

Barry only thought of leaving his program one time. Barry said that the standards changed while in his counseling program, which led to an increase in requirements. Barry stated,

There was no warning ahead of time, like a year ahead of time, so I could be prepared. There were others in there that were also caught off guard. The other times would have been just the grind of trying to get through the program. It wasn't enough to quit, it was just very frustrating. Barry concluded, "That was probably the only frustrating time and they changed the rules on me right when I was about to finish, but I got through it."

Neal never thought about leaving the profession, but questioned which area of specialization was the best fit for him. Neal stated, 
I didn't have any kind of real negative experience or any kind of anything that made me think like "Man, maybe this isn't a good fit, for me." So, I didn't have any kind of major negative, I did have one supervisor, in my doctoral program, that I did not get along with, very well. I didn't appreciate her style of supervision. And so there was kind of a disconnect, there, and felt overly challenged, and underly supported, by her. And I think that, and in kind of the middle of that experience, I did play around with, I was just kind of doing general mental health counseling at that point, I thought, "Man, is there another area of counseling, I would be better at? With career counseling, or something that's a little less emotionally driven, be a better fit, for me?" But I didn’t necessarily think about getting out of counseling. It was just like "Maybe I need to shift my focus in the field." Which I didn't, but there was that little period of ambiguity, around was the mental healthy type work really what I was going to be good at, or what I could do as a counselor.

Neal elaborated,

I was being challenged, really, just on my counseling skills. I think I was being challenged to be more challenging with my clients, and some of it was around emotional work. But some of it was just in terms that counseling skills, being a little more direct with people, confronting them when there was, I remember one particular client, when there were clear discrepancies, between things she was saying, and I remember my supervisor coming in, and pointing out that I was not bringing those out, and working with them directly. So, that's what...she was trying to get me to work on that area. Which, in retrospect, and I think even some 
then, I realized that that was a major growth area for me. I think it was the supervisor's approach to supervision that really made it a challenging experience for me. I think it was absolutely work that I needed to do. But I think it was just the way, that relationship and how it developed, that made it difficult for me to receive that feedback, and apply it in a way that it needed to be applied.

Neal discussed two primary factors that led to his retention in his counseling program. Neal shared, In my master's program...I remember that into the first semester, doing well academically, gave me a sense of self-efficacy that I don't think I had ... or a level of self- efficacy that I don't think I had before. I was a horrible undergraduate student. And was really, felt lucky to get into a master's program. So, I'd never really tested my academic rigor, or my ability to do academic work, like I had, until that first semester of my master's program. So, I think doing well, and getting positive feedback from faculty members, and my instructors, around not only my academic performance, but just how I showed up in class, and interacted with people, and that kind of thing. So, getting some of that positive feedback, as a new graduate student, really helped for me. And I think having had similar feedback, along the way, I just remember a sharp spike in self-efficacy, after that first semester, in the master's program.

Neal also discussed the importance of supportive faculty in his retention. Neal stated,

And I think continued encouragement around the clinical development. To me, some of the counseling skills did not come all that naturally. I think the 
conceptual side was a little easier for me to pick up. So, having supervisors that were both encouraging, and supportive, but also challenging in terms of my clinical development was really helpful. Again, both in my master's, and my doctoral program.

Neal elaborated about the importance of supportive faculty in his retention. Neal stated, talking about the bigger picture, like, "What do you want to do? Here are different options, in the counselor education field, and what those positions might look like, on a day-to-day basis." "Here are some options outside of counseling and counselor ed. that you might explore further down the road." So, having those kinds of relationships, where people were not only focused on my development, as a counselor, and a counselor educator, but really trying to understand what I'm looking for career-wise and what I want to do and helping me explore those options has allowed me to or helped me to finish both my master's and my doctoral degree.

Frank did think about leaving the field, but his reasons were not due to being a male minority in his counseling program. Frank stated, "It's my own personal insecurity. Like I'm not going to be good enough or just because I'm experienced doesn't mean I'll be helpful." Supportive faculty were also important to Frank's retention in his program.

Chris spoke about the factors that led to his retention in his counseling program. Chris stated,

In my experience, we had very strong leadership in the program. There was some curriculum that was more stimulating than others, some that were more growth inducing than others. But, generally, I wanted to make the most of every 
opportunity. So, I think a lot of it is what we make of it. I sought to make the most of my classes in the program. In fact, I was coming back from some difficult overseas experiences. I found the reflection, the sharing, the reading, the program to be therapeutic and rehabilitative. I think I was suffering from some sort of PTSD, lower grade. The program really was a safe, wonderful environment with support of peers and professors to help me process those things, work through issues, and move to a new personal level of growth.

Derek discussed factors that were personally important to his retention. Derek stated,

I thought I could relate to most of my professors and...talk to them. I didn't always like getting feedback about sessions or whatever, but at some point, I got used to it. I didn't really like constructive criticism at all. I mean, it was decent criticism, I eventually just got used to that process and it didn't bother me so much. So, I did feel like I had a decent relationship with my professors. I don't know. I've been good at school. That's a personal thing, but you're good at school, you get to play the A-student game and then you get to grad school, and everyone's kind of playing that game. But I don't know, it seemed to work out. You just kind of play the good student card.

Derek never thought of leaving his program at the master's level but stated, at the doc level, you struggle with it...The doc level is kind of the game. They try to scare the heck out of you ...there's that self, I don't know, that self-struggle and questioning and all that stuff at the doc level. But I don't know, I was pretty committed to finishing though too. 
Winston shared that he frequently thought about leaving his counseling program. Winston stated,

It was always a thought...I was going to school full-time. I was working full-time or working part-time. I was also engaged, and so I always thought about quitting. But I knew I never would, but the thought of quitting never really went away. It was a pressure I always had to fight against. But I never really thought about quitting because I was a male or anything.

Winston continued,

There were some less satisfying moments. I went through some periods of grief I guess you could say. Not serious grief, but when I realized that I wasn't going to bond with my female peers, I was bummed. I thought I was going to have some really great bonding moments with my cohort, and I just did not feel a part of it. I did not feel like I was going to get that. That was tough. After the first semester I think was just like, “Alright, this is about me and my education. It isn't going to be about me creating strong relationship with my cohort anymore." I don't know if it increased my thoughts of quitting, but it definitely decreased my excitement about the educational process. But I stuck it through. I knew I wanted the master's degree. I wasn't going to quit for anything, but it did spur some doubts. I don't know if it decreased my motivation at all, but sometimes it just wasn't as exciting as I thought it could have been.

Winston shared additional factors that led to his retention in his counseling program. Winston said it was because, 
The graduate program that I was in also had a Ph.D. program and so it was very academic-focused. It was very research focused. I felt cognitively and I felt challenged. I felt like I was getting a great education where I was. I knew it was going to benefit me personally as far as an intellectual endeavor. I knew that I was going to come out more informed, more aware, not only of the professional but more aware of who I was as a person, as a male, as a human being. It was definitely a win-win situation for me.

Winston also shared his retention was related to his "love of the profession." Winston continued, I felt really, really confident that I had made the right decision to pursue counseling. Nothing was going to steer me off of that path. I felt like I had been planning on being a counselor for like 10 years, since I was 18 . I had been building up the experiences, gaining the different human service experiences to be where I was. It wasn't just this spur of the moment decision to enter a graduate program. It was a gradual process, so I was committed, and I loved it.

Leroy stated his retention or commitment to the profession was for a few different reasons. Leroy said,

I think just the ability to be able to work with people was something that I wanted to do, to try to give back. But then again, something that was really important for me was to be a male, a male of color that could really bring these skills, this education, and this service back to the field.

Rusty shared about his retention in the counseling field. Rusty said the counseling profession is "incredibly worthwhile. Amazes you about different individual 
to systemic changes that can be had with your education and working with others with similar profession educations."

Vincent shared that he never thought of leaving his program. Vincent stated his retention is because "It's just what I want to do." Vincent elaborated,

We have started seeing clients now and we have only been seeing clients for a while, but now that we have a small caseload building up...I finally feel as though I am to that point where I am no longer graduate student and now I am a fledgling in field and in that realization was very ecstatic and looking back at all this hard work that I have done, and that it has all paid off. I really enjoy doing the work that we do.

Quincy stated his perseverance in counseling, specifically in his doctoral program, was for different reasons. Quincy stated,

I did some work in the field. Some of it I enjoyed and some of it I didn't enjoy, but I suppose the reason I went on to pursue a doctorate is particularly related to ... how to put this ... I really like being able to explore ideas about human thriving, and human struggle, and write about that ... have the flexibility in my career to explore my own ideas. I also really like supervising students and working with ... counselors who are earlier in the development process ... to develop and to be able to go out into the world and help people. I think that that's sort of what has really kept me in the field, at least in the sense that I'm pursuing an academic career. I think that those are the factors that have really influenced me. Glen said he has stayed in the counseling profession are due to, 
those moments, like yesterday ... connecting with a student, having a really good session and realizing that I'm meant to be here in this moment. Those are the things that keep me going, because it's definitely not the pay. I mean, again, being here and being a full-time Ph.D. student, I am struggling financially on a level I cannot even tell you. But I seem to cling to this because it feels like a calling or what I'm supposed to be doing.

Percy shared his thoughts about his retention in the counseling program. Percy stated,

I did have a moment of panic when I thought, "Oh jeez, is this not right for me?" But that was more a combination of the supervision and honestly the lack of supervision. It was a lack of supervision I was receiving at my practicum and supervision that I was getting while I was receiving my individual supervision from my faculty supervisor that was more about my interactions on site, but nothing, it was something I overcame and it was a growing, teachable moment for me, but none of those feelings were related to the fact that I was a man in the profession.

Percy shared that his retention in the counseling field has been due to feeling "athome." Percy stated, Once I got in the program and got into being around counselor educators, and peers of mine were pursuing degrees in school counseling, even mental health counseling folks, it felt more at-home for me, like this is what I was looking for in a career. 
Uri described his reasons for retention in counseling in the following quote. Uri stated,

In my master's program, I remember the first couple classes I took with my advisor in my master's program. I remember feeling like, "Yes." Everything was clicking. "This is it, this is me, I feel like I'm good at this," I feel like I've finally found a field where I mesh. The strengths that I feel I've had, in the past that has always been disvalued is so valued in the counseling field. Things like empathy and relating to people and more emotional and sensitive; those, even things I have gotten either picked on or bullied for, not seen as impressive in the past, but in the counseling field they were important and they were the skills you need. I felt like I fit. There was definitely a moment of like, "Okay, I found where I should be.” That kept me going through my master's program. Uri expounded, "Then continuing into my doctoral program, I knew it was something I would ... It was a lofty goal I had in my mind. I knew it was something I thought I might like to do eventually." Uri did get into his doctoral program and sometimes doubts himself as evidenced in the following quote. Uri stated, I came here straight after my master's program, I didn't spend any time in the field between my master's and my doctoral program; especially my first year and still even a little now, I have a lot of like, "Boy, should I even be here? Should I have waited and spent more time in the field before coming?" Yeah. I have just made it through because it was like, I got in, and I got to finish now. Uri stated he had thought about leaving the field, but it was usually due to his self-doubts. Uri said, 
I never seriously considered leaving the field, but I've had moments where I've been like, "Is this a good fit for me?" I know that when I was having my quarter life crisis I was debating between going with counseling or going with teaching. A few times, rough moments with my program, it has been stuff I've thought about. "Should I stop and just be a teacher? Should I do that?" I think that's more related to my own feelings of competency and that kind of stuff.

Jasper stated that he never thought about leaving his master's program. However, he briefly thought about leaving his doctoral program. Jasper stated,

I wouldn't say that it was so binary like yes or no. I would say it showed up on my radar. Like the Wizard of $\mathrm{Oz}$ and the curtain and I could see behind it and what the world of higher education and counselor education is really all about and "Is this really the line of work that I want to be getting into? Is this something that I can support? How can I ultimately negotiate what I want to do with the things that I have to do in this program or in this profession?" So, I would say that it came up in a small way in the doctorate program, but no, I've been pretty committed to it. I really enjoy what this offers in general and what it is going to offer my career. I'm also open to the potential that I'm going to get into it and after five years it doesn't feel great for some reason, then I feel confident that I can go in a slightly different trajectory and still do what I'm passionate about.

Jasper discussed his retention further. Jasper stated,

I would say that I really enjoy sitting across from someone in the room in a counseling setting and in the counseling relationship, being able to show up for them therapeutically. I just feel like I call it service, and counseling is a service, 
but I almost call it a way of interacting with others that generally as a society we're not taught. We're really not taught to listen. We're not really taught to reflect back contents or feelings. We're really in a sense a reactive society. So, I really enjoy being that, not only showing up for them in a professional sense, but adding adaptive skills to my personal life and using it to better myself as a person. That really cemented counseling for me. Where as far as going the counselor ed. route, I started doing the math and calculating how many clients I am going to see over the course of a year. If that's the average, then how many am I going to see over the course of a year? Over the course of a decade? And how long will my career be? and that number, whatever that number was the perfect size. But I also have this general feeling of wanting to help people and systems on a larger scale. I want to effect positive change on a larger level. So, when I started thinking about counselor ed., it was that this would still give me the opportunity to be a counselor on the side, but I will also be working individually with students who will be able to sit across from and supervise these individuals, and work through their personal issues. If there is any small little nugget of experience or knowledge that I can impart on them through the process, and then they go and take that out to whatever their magic career number is for the amount of clients that they see, then it's like my numbers are almost like exponential. Then my efforts are potentially affecting a lot more people than I could ever do in my career alone.

Sherman shared that he has stayed in his program because "It's a personal thing." He said his perseverance has led to his growth. Sherman stated, 
I don't give up on anything ever. One misstep is not going to be enough for me to call it quits. Really, for me a lot of these things that I've had experiences now with both expectations and other things, some of it is just in learning, these were things that I honestly wasn't particularly aware of until I came to school. I came from a really small community that is more or less a community in a bottle. In the community that I came from, the negative things contained therein, those chauvinistic expectations and things like that, that's just more or less seems normal. Unfortunately, nobody including me stands up to it...especially living in the Midwest in a small rural community, that's just the expectation of this is how life is. Despite some negative things happening, it was also a godsend to come to a university and be put in this program for somebody to tell me, "Hey, that's not okay for people to have these assumptions." For me, it went to a lot of personal development. Instead of it being an environment where I thought I needed to persevere or survive, it was more like it's been more of a growth environment than survival. I think would be the best way to put it.

Ivan shared that despite the challenges in his program, there wasn't anything that would have kept him from continuing in this profession. He said it was in large part due to his calling. Ivan elaborated, "Learning how to be an addictions counselor was what I wanted to do." Ivan concluded, "I'm a fighter and after this last semester, there's a little bit, a tiny bit of social justice that has come from this too."

Otto thought about leaving the counseling profession. Otto stated, "Being a therapist in general, of any gender, is really lonely, because you can't talk about the work you do." Otto said new counselors, 
don't have the resources or the language to be able to talk about how hard the job is, and they are the people that need to talk about it the most. It is, I mean, it was particularly lonely for me...for those years because I was just in a very rural incredibly isolated, and when I say isolated I mean you could drive for two hours and not drive through another town.

Otto elaborated,

Every mental health worker was so incredibly overburdened that you didn't have time to get together with your colleagues. Even if you decided it was incredibly important and valuable for you trying to convince some of your colleagues in town that it was also equally important for them, just not happening. Having someone to talk to about just the difficulties of being a therapist... and then not really knowing how to talk to other people, then in my experience not having anybody to talk to just really sucked. I don't know how I stayed in the field to tell you the truth. I have no idea how I stayed.

Otto continued,

I really love my job, but last week after that woman was screaming at me being a man and I was crying. I know you don't know me, but I'm not really a crier, particularly at work in front of my staff, not a happy place for me. I just had this recurring dream that I quit my job and go become a cake decorator at a bakery because I really like baking.

Glen thought of leaving the counseling field too. He said there are challenges with some of the faculty. Glen stated, 
My current chair here in my program is one that's very difficult, for a number of reasons. I'm not pointing to gender, but it is difficult when, How do I explain this? I need to get done with a dissertation in a number of years. There's significant financial pressure and because this individual is a female and is not friendly or engaging or supportive in any way, that gives me additional pause. So, it impacts my communication. It makes me say, "Well, why do I deal with this? Isn't there a different place where I wouldn't have to deal with this?" And I don't know if that's particularly based on a gender issue, but, or maybe just being unfriendly. Because, again, I've had many chairs of departments that I've worked with that were really friendly and engaging and this was not an issue. I think it's an added layer when that piece is there.

Some of the participants stated they thought about leaving their counseling program, but have not or did not because they have too much invested. Trent said he thought about leaving his program because his program is lacking supportive faculty. Trent shared that he used to have a supportive female faculty in the program, but she left. Trent said,

She had such a warm positive atmosphere that she brought to the entire grad department. Like I said, I could go to her for pretty much any of my problems. I had a lot of health issues, I had a lot of personal family issues that happened last year, and I could go to her and say, "Hey, I need help" and she would say "Let's walk through this together. Let's do this." She left and now that atmosphere, just warmth and caring, is kind of gone in the program. I feel like every professor is almost like "Well, let's get you a degree and get you out of here." The fact that 
that atmosphere is gone is really aggravating and frustrating. It's like I don't feel like I have any confidence in going to these professors if I have a personal problem.

Despite these challenges, Trent said he is not going to leave his program because he wants to be a counselor. Trent said,

You can't really transfer credits and I'm half way through the program. So, I feel like dropping out would be pointless, and I do really want to be a counselor, and I don't want to start over anywhere. I don't want to take the time to find a new college to transfer to.

Sherman thought about leaving his counseling program, but only briefly.

Sherman stated,

I would say that if it had been feasible for me to leave I would have considered it. Overall, that decision would have been pretty unrealistic for where I'm at right now in the program. That would have been pretty highly unrealistic. Mac has also thought about leaving the counseling field. Mac stated, So, for eight weeks straight there would be days where I would get three hours of sleep before my internship just because I was so anxious or so stressed out. I would be very checked out when I was there. Obviously, I was invested in doing the best work that I could with my clients and giving them the best quality care. But sometimes I still think like, How the fuck am I going to do this? Is this how it's going to be after I graduate? Is this just something that I'm dealing with now? Is it the stress of trying to do school and internship? So, that's still a very 
real...reality for me. How am I going to manage the stress and anxiety that comes with this profession? How am I going to find time for self-care?

Despite the challenges, Mac has persevered. Mac stated his retention has been due to being highly invested and having too much to lose if he quit. Mac said, I have to finish my degree. I spent too much time and money to quit now. I need to have a career going forward. These are just imperatives for myself. For my own personal, what's the word, I don't know, future goals.

Mac implied that because his siblings have master's degrees, he is feeling some pressure to get a master's degree too. In addition, he said he did not want to go back to his previous career. Mac expounded, Maybe I'll change careers in the future, but I'm just so close at this point that I would not and cannot let myself do it, even if I have to take a break, even if it turns out this is so stressful that I can't do it. Like maybe my lack of sleep, whatever, maybe that doesn't get resolved by the end of the semester or by the end of my term, I just have to finish it, even if it kills me. I have to finish it and then I can reassess because then I'll have a master's degree, and I can get paid more. Maybe I'll be a substitute teacher or something. I don't fucking know, but I just need to finish this program.

Possible changes in counseling programs. Participants were asked to share advice for faculty and counseling programs that could affect male students. Some participants did not explore this idea. One participant could not think of any advice. For example, Chris stated, "I can't think of anything. I found it to be extremely supportive." 
Some participants had ideas for how counseling programs could make changes in order to support their male students. These ideas included the need for supportive faculty. In addition, the need for faculty to be aware of their biases. Participants also suggested faculty need to make it clear to students they value all perspectives, including their male students' opinions. Many participants shared the importance of discussion about gender topics. In order for these discussions to take place, participants need to feel safe. Participants suggested that faculty make an additional effort to avoid facilitating male students in becoming the spokesperson for males. Lastly, participants believed it could be beneficial to increase diversity in faculty, including more men.

Supportive faculty. Some of the participants shared the importance of increased support of male students, and for faculty to practice empathy and unconditional positive regard toward male students. Trent believed faculty should,

just be caring and be open to the fact that we have lives outside of grad school. I know we have to focus and put in a lot of time and energy to grad school. I'm not saying that let's just neglect our grad school requirements and obligations. But we have lives, and if one of our family members dies, we have to put grad school on hold for a couple days or a week or two.

Leroy believed it is important for male faculty to support male students in counseling programs. Leroy stated,

I think for male staff it's really important to just sort of check in with them because even with the reality, no one's ever pulled me over to the side and said "Hey, Leroy, How is it being the only male in this program?" or "How is it being the only male in the last five classes?" or "How is it being one guy in a class with 
50 people that are female?" No one really ever checked in like that. I'm not sure if that's because people don't think to, or they think it might be inappropriate, or they think it might be suggestive that someone is lazy or weak or whatever. But I think it would go a long way to recognize, "Hey we recognize that you're the only person here. You're one of the very few, we just want to check in and see if there's anything we can do to be helpful. We want you to be here. We want you to do well. We understand that it can be a challenge. What do you think?" Leroy said it would be beneficial for female faculty to support male students too. Leroy said,

Just checking in, like "Hey, obviously we have a new class of 50 students, you're one of two men, we just want to see how you're doing with that. Do you feel comfortable?" Yes, I think that's something for both of them.

Quincy also suggested that faculty should be supportive of male students, academically and personally. Quincy stated,

Often times faculty members have blended roles because that's just the nature of a counseling program. I take things to my professors and I ask for advice, and it's not always about school. Sometimes it's about just the general, "Hey I have this problem in my personal life. What do you think about this?" That's something that certain faculty members will engage you on and then certain other ones absolutely refuse to engage on that sort of thing. When they do, I would hope that things like, for example, I would hope things like confidentiality would matter. If I have an issue I'm struggling with and I take it to a faculty member, I don't think that that's something that anyone else needs to know, but that faculty member. 
Unless, like a normal client, they have some reason that they need to break confidentiality. I realize that professors are human just like counselors are. Winston would like to see male faculty be supportive of male students as well. He said this could be beneficial in male students' experiences in their counseling programs. Winston stated, Just expressing gratitude that they're there and just encouraging them to continue through the program. I wish I had the statistic in my head of how many men are in the field versus women. But I think just whatever type of encouragement they could provide for men to continue on in the profession and also let them know that they're a good resource, that they are wanted in the profession. I work in a clinic right now. I'm the only male therapist. I think it's a huge gap. I think if men knew that this was a need, hopefully it would encourage them to continue in the program, to get the degree, to pursue licensure, and to pursue clinical work. I don't know if we ever really discussed that as an issue in the counseling profession, the lack of men, or anything like that. But maybe increasing awareness about that for male professor to male student could be an encourager, could be a motivating factor to continue.

Winston shared some advice he believed could be useful for female faculty. Winston said, I wish I had the statistic in my head of how many men are in the field versus women. But I think just whatever type of encouragement they could provide for men to continue on in the profession and also let them know that they're a good resource, that they are wanted in the profession. 
Aware of biases. Some participants suggested that faculty need to increase their awareness of their biases and the impact potential biases could have on male counseling students' educational environment. The participants shared that faculty, as role models, should be aware of their biases and not impose their values on the students.

A primary recommendation from Mac was for faculty to be aware of their biases.

Mac recommended faculty,

just be aware of their own biases. That's not saying that they don't already do that. These are people who are Ph.Ds. or Psy.Ds, so I'm not in a place to tell them what they should be doing...The majority of my professors have been female. I've had one class that didn't have a female professor. So, I don't know that I have any different advice for the two of them. In terms of how they might treat male and female students differently, I don't know. Maybe just be aware of how often you're calling on certain students. But, honestly, I really don't think that I have noticed any difference in things like that. I really don't think that I have been treated any differently academically because I'm a male versus because I'm a female. I think the faculty does a really good job of paying attention to culture and gender and how it is impacted in the classroom.

Quincy shared similar advice to counseling program faculty. Quincy said he advises all faculty, not specific to either gender, to be aware of their biases and not impose their values. Quincy stated,

I don't know that it would be specifically directed at female faculty much as just all faculty but, generally, that it's important for people to be able to speak their mind. I think that this is probably something most faculty members already do, 
but I think that there's probably a significant minority that can tend to impose their own value system on students sometimes. I don't know how many faculty members I'm talking about, but just having experienced what I have, I've certainly witnessed faculty members do this. Sometimes I think counseling in particular can be a field where that happens maybe more than others because the truths of counseling are so much harder to pin down. Humans are so complicated, whereas if you're a math professor, there's just a right and wrong answer. I think that the realities of human struggle and human well-being can get so tied up in the politics sometimes that some faculty members may be inclined to tell their students to believe what they believe. I think, ethically, that's just wrong, to put it bluntly. That isn't addressed to female faculty more than male faculty, just faculty in general.

Ivan discussed changes he would like to see in counseling programs that could directly affect male students. Ivan believed a primary needed change is for professors to be aware of their biases too. Ivan stated,

Even textbooks focus on, there's always that section on focusing on minorities, it shouldn't just be a portion of each chapter. There are enough books out there where we could get an entire book on counseling diversity because it's really, really important, but if we're going to accept all of these populations and how they have been oppressed, we need to all check our biases.

Value all student perspectives. Some participants believed it could be beneficial to male students if faculty were obvious in their valuing of all perspectives, including 
male students' perspectives. Some students did not believe their perspectives were valued because they were men.

Ivan shared that not feeling valued was challenging for him. Ivan said he does not believe people were open to what he had to offer in discussions. Ivan stated, For two years, all I heard was, as a White male that when I'm treating or talking with minority clients, I have to be a certain way. I didn't even realize it until someone assigned an article talking about counseling boys and men versus girls and women. I realize right then that the faculty in my school had not assigned an article that was male focused in two years.

Ivan said the assignment of the article felt validating for him as a man. Ivan shared, "I really read it, and I am like "Wow!" And I was really so appreciative of the professor assigning that article because we had some discussions later in the semester." Ivan continued,

It seems like boys in society...boys are constantly taught not to be boys or constantly, or it is constantly suggested that boys shouldn't be boys...I think that affects their self-esteem and identity, and they end up doing, their true feelings become oppressed and they end up eventually doing things that are violent. Ivan elaborated, "I was just really happy to hear that there was some acceptance, that there's a difference, and I know it sounds funny coming out of my mouth, but that there's a difference between boys and girls." Ivan believed boys' natural instincts and behaviors are pathologized. Ivan stated,

It seems like these days, there's a very much emphasis on 'Be yourself whoever you are. Just be yourself and be proud of it.' Whereas, I still hear this thing with 
boys that 'No, that's too aggressive or don't do that.' I don't know. I'm not expressing it exactly how I'm thinking it, but I don't think boys are being told to just be themselves.

Otto shared the importance of training students to be able to work with all individuals, not just female clients. Otto stated,

Two different worlds of advice: one of them is to set up all counselors for success, recognizing that you have people of all genders that will be coming in for services. You are not just training female therapists to work with female clients. So, even if the majority of your clients are female and the majority of future counselors are female, still recognizing that all genders access therapy, particularly working as a lot of us should with very vulnerable populations, you really need to understand how to work with all genders. Then when it comes to training future counselors, like a perfect world scenario is so far outside of my realm of comprehension, the first step in my little world would be just acknowledge that there are male therapists, and there are different ways to communicate.

Otto elaborated about the importance of appreciating different communication styles. Otto stated,

One way isn't better than the other, and so sometimes in our quest to create a safe space for women, we do that at the expense of excluding men. That's not okay. So, how do you create a safe space for all of your students? When I do supervision, the gender of the person sitting on the other chair does not matter to me, but I take it into account. Just like, I take into account that person's communication style and that person's expertise, and that person's previous 
training. When they are talking to me about a client, I'm factoring everything that makes them a person, and everything that makes them a therapist, then I'm tailoring my advice appropriately because that's what I'm supposed to do as a supervisor. If I'm not capable of doing that, then I shouldn't be a supervisor and I say the same for professors. If you are not capable of doing that, go to another field. If you are not capable of seeing all of your students as people, you should not be teaching.

Otto continued,

Usually the men I would notice because it happened to me too, the men were encouraged to speak quieter and softer, and to take more of a backseat role, and to recognize different way of the stereotypical female way of communicating, which is more of a collaborative, more of giving time for people who are hesitant to speak up, and I don't necessarily think there's anything wrong with that because it honestly helped me be a better therapist, learning how to keep my mouth shut. Most definitely helped me be a supervisor too, like sometimes you just legit need to keep your mouth shut even if it's a couple of minutes. Eventually they'll cough out what is really on their mind.

Otto continued, It's this idea, and again this might be because of American society, we are pretty programmed to respect more of this loud, direct my voice is the loudest. Therefore, you are going to listen to me, and I have the most authority style of communication. It's nice to learn a different way, but I think it would be helpful 
to acknowledge that sometimes you do need to use this different style of communication.

Kyle shared an incident where he was the only male in one of his clinical courses, and male client behavior was pathologized. Kyle stated,

It really hit me that when we're done, everybody kept talking about the boy, and "Does he have ADHD?" And that really made me aware of this attitude about boys that seems to be common, because any time he was asked to come over and participate, he did, but if he wasn't directly being addressed, he was around the room looking at other things, and to me that's just simply him being" a little boy. Kyle elaborated,

But for all of my fellow students, and even my supervisor, it was like, "Well maybe he should be evaluated for ADHD" and I had to stand up and say, "Well, no. No. Stop. This is a little boy." So, I thought that was interesting, and having boys now, this was pre being a parent, to me there's a lot of institutional, I don't know what you want to call it, on males. And I think it's important for us, as therapists and counselors, not to totally buy into that...And then in my practice, because I was seeing all the young boys that were coming in. And I would say easily $90 \%$ of the time when I had a boy coming in, at some point, the mom would turn to me and say, "Well, his teacher thinks he has ADHD. Should I get him evaluated for it?" It felt to me like it was almost a knee-jerk reaction to a boy being a boy. So, I think that's something that I try and get my students to think about when we're talking about family issues and that kind of stuff...teachers have got huge pressures on them, and I think one of the huge 
pressures is so-called classroom management. And I think at certain ages, certain boys, they just don't fit into that model. And so, the teacher is caught between a rock and a hard place.

Discussion/communication/safety for discussion. Some participants said they need a safe space for dialogue. Therefore, participants suggested faculty increase safe environments for open discussion.

Frank shared that he believes more communication is necessary in counseling programs. Frank stated,

I think $25 \%$ of school should be about communication, at least, not just a teacher in front of a classroom talking at people. I think that's such a disservice to anyone, but I also understand it's probably intimidating to communicate, so we need stronger teachers.

Mac shared that there needs to be a space to address the human perspective of the counseling and not only the educational component, more time to receive support, and feel validated. Mac stated,

In terms of things that the university could do, maybe offer a group for, like I think that's what the internship class is supposed to be for, but it's being used to help further our education, provide us with resources to help our clients. But I think, I honestly think, that it would be so helpful for people to just have a class or a group where we could talk about our experiences in internship.

Leroy said he sees a need to have safe discussions about men being a minority in the counseling field. Leroy stated, 
I think it'd would be helpful if someone would bring it up that "Hey, there are very limited males in this field. This is what they could bring to the table. We are looking to expand it." But, it's something that we don't really talk about and it's almost like if some programs mention it, it would be a novelty within their programs. So, I think it's something that if it's not ignored, I think that would make men feel more comfortable. I think it might make them recognize, "Hey, yeah, someone's thinking about us. The fact that we're not here and we're not represented in big numbers." I think that can kind of go a long way in having men do the buy-in. So, I think talking about that issue or that challenge of lack of men in the program would be really helpful.

Leroy shared that, in his experience, a discussion about men being a minority is not occurring and,

if anything, I'm usually the person that brings it up. I'm usually the first person in the class and I'll see another male and I'm like "Oh good to see you." I'm like there we go. I'm like "Oh I haven't seen another guy in forever" and I'll need to be very conscious. Say hello to them, ask how they're doing, what brings them to the field, how long you been doing this for? Bring up the fact that there are not many men in the program and it's good to see another guy doing this important work also. So, I sort of bring that to the forefront myself just because no one else thinks to deal with it. And maybe that's because a lot of the field is predominately women, and they just don't think to do it. It's not mindlessness, or carelessness, or even like discrimination. It's not in their priority realm, like maybe it is for myself. 
Male identity, male privilege, and White privilege. Some of the participants said there is a need for a safe space for open dialogue about male identity, male privilege, and White privilege. For example, Kyle spoke of the need to support male students in their identity exploration while in the program. Kyle specifically shared about a female colleague's work with male students. Kyle stated, "I think she's got less tolerance for sort of that male attitude that's struggling with the idea of privilege. And she's expecting these guys to be farther along than I think is realistic, at the beginning of the program." Kyle continued,

She's shared with me about some guys in the program, and my experience with them has been a little different, and I see them more as "Okay, well that's the face they have to put on their White privilege at this point because they're not totally comfortable with deconstructing that identity and rebuilding it." And she wants them to be really aware, and willing to acknowledge their privilege, I think a little bit early in their development, if that makes sense. So, I would encourage faculty members to try to figure out what's the right way to reach some of these guys instead of beating them over the head with the White privilege thing. How you go about it to get that consciousness in, help them come to that so they don't feel attacked as much.

Rusty shared the need for a safe place to discuss male identity. He said that male gender topics have been challenging. Rusty stated,

The only one I've really been uncomfortable with is talking about what it means to be male identified in a counseling program. There's never been an identified space to talk about that. And also when we're talking about male identity, 
rightfully so, we talk a lot about the privilege that comes with that, and then rightfully so, and we don't talk about different ways that this gender can also be discriminated or oppressed.

Rusty shared that when male identity discussions took place, it was more in the realm of all the privileges that males have. Those other aspects of male identity were not discussed. Rusty elaborated,

We'd have conversations about like clear identifying lines that men in our program would not make assumptions or work hard, we'd work hard not to make assumptions about what it meant to be female in this field or female when being oppressed. That same standard wasn't held in our classrooms now that I actually look back on it.

Rusty stated, "The way you identify your male identity is not your end all, be all. And yes, you can be discriminated and oppressed against. And you can also hold a ton of privilege and they can coexist. You're not crazy." Rusty believed that if this dialogue had taken place it would have been comforting, and "It would have saved me about nine months of therapy myself." Rusty shared that he used to feel shame, but now he feels more anger that stemmed from, that dichotomy of being what I saw as, what I believed to be, that shame tied to be different, oppressive behaviors my colleagues had, and that my institutional values had. And then also holding that against the incredible wealth of privilege that I hold. And it was shame because I shouldn't even talk about this. That this can't possibly be real. That this must be an issue with me. That no other men experience this. 


\section{Rusty expounded,}

It would save me from quite a bit of individual therapy. Especially like I, part of my profession is we look at the worst of the majority of perpetrators are men. There was a lot of negative finding of, you know, all men are assholes. That irrational thought that then tied with my irrational thought of "I can't possibly ever be oppressed or discriminated against." When the reality is that, yes, I can be. Yes, I hold privilege and not all men rape. And yes, the majority of rapists are men, at least in my context.

Uri shared that discussions do not always feel safe in his counseling program. Uri stated,

I guess it didn't necessarily feel safe, which is hard for me to say because I think my professor was very conscious of trying to make it a safe space. I was friends with a lot people in the class so I didn't feel overt on safety or judgment or anything. It makes me think, I wonder if there's an additional safety net for discussions for male counselors about emotions and their own experiences and stuff that maybe should explicitly be there to make it a little more safe. I think the masculine pressure of not being emotional or something like that is so big that maybe there needs to be an explicit mention of safety. That this is encouraged and this is a place to do that sort of stuff.

Uri provided an example where creating a safe environment was needed in order to facilitate discussion. Uri said,

Other moments I can remember having a, specifically in the multicultural class, I remember just the whole time I didn't want to say anything. We're learning about 
privilege and we're learning about all these different things. I felt very, I guess I would say afraid. I mean, again, my professor tried hard to make it a safe environment. I know no one was mean or anything. I definitely felt afraid of saying something that would, now having learnt about all my privilege and all that stuff, that would be insensitive or something. I remember in that class specifically being a little more shut down, which I'm not sure if that's a good thing or a bad thing. Just listening more to other people's experiences that might be a good thing. But it definitely felt a little less safe to engage.

Percy also discussed the importance of a safe environment in counseling programs. Percy said, I think, just like any other ... culture group, to be mindful that the man is, if a man is in this profession, it's because they have a certain level of empathy and the caregiving nature, the helper nature within them, and not to scare us away from that. But stating how we have to be cautious with us in our roles as counselors, and as men, and in working with female clients. But not to make us aware of our role as men as a counselor to scare us or to harm us in any way, but to state it as something we need to be mindful of, but not to the detriment of us and our abilities to exude empathy and compassion.

Percy continued,

Maybe that men have to get out in front of that, too. Male faculty need to share that with their students and also share that with their female students as well to say that in terms of, if a client's to be referred, that be mindful of when a male might be appropriate or inappropriate. Not that I don't think that would be totally 
ignored in a master's program, but that there could be an advantage to that, but also a disadvantage as well, just given our nature as men.

Ivan shared about his hesitancy in revisiting a painful discussion. He shared that there was not an environment in his counseling program that was conducive to this discussion. Ivan stated,

I do have to weigh the cost and the benefits. I've brought it up more than once so I'm not going to beat a dead horse so to speak. They know I feel that way and maybe they feel a certain way, but if it comes up in an appropriate way that will help the cohort move forward, I'll do that, but if it's just my own benefit, then I don't think it's worth bringing up. If it's just venting, then I don't see value in that, but if something comes up, a good discussion comes up, I'll say "Hey, I got to be honest, I felt a little powerless when this was going on." I would never throw... and I don't want to play tit for tat or anything like that.

Jasper also believed it is important for counseling programs to have more discussion on gender, specifically male gender. Jasper stated, There needs to be more education for men and women, but in large part for men on gender socialization and how being a man in our current society and what that means, and what that does for them, and what that does to people that are not men. I think there is room for a lot more honesty in the case of male privilege, White privilege, and that that can certainly be explored and explored at a much deeper level, really at all educational levels, than what is currently being done.

Neal said it would be beneficial to students in counseling programs if there were an increase in gender topic discussions. Neal stated, "Simple things like having open 
discussions about gender, in the classroom, and in peer interactions, but also in the counseling work, and the counselor education work, I think can be helpful."

Glen shared the importance of talking about the male gender in class discussion as well. Glen stated,

I guess, if I was to be really honest, it would be more around valuing that the male gender is something important to talk about. Not that it's not talked about, but gender differences I think can always be an important discussion piece or a focus of a program. And because we know that males seek therapy way less than females, maybe an emphasis, maybe a male track. Can you imagine a male track in counseling? Male issues or something track. I don't know. Because, it's almost like it's a minority population in the field and that definitely males are accessing services less. And it's really funny, there was this campaign, I don't know if you heard about it, but they did this really unique campaign to attract males to counseling, because of a lot of suicides. So, I think there's an untapped opportunity to really look at attracting males. Not only male counselors, but maybe males to therapy and the benefits of that.

Mac shared he too would like to see programs discuss gender more, male gender in particular. Mac said, I want to say paying attention to more male issues. I think a lot of my couples class was devoted to, well, that's not true, we did have a section where we talked about male issues, toxic masculinity, and stuff like that. But I think focusing on that, I don't know if that sounds selfish or not, because men already get so much of our attention in this society. But maybe talking, maybe having a class about 
male counselors counseling men, I think would be really interesting, really valuable. I don't know. Maybe having a group, like if that group was continued for men in the counseling field just to talk about their experience of being men. I think that would be really cool. I would definitely participate in it. I don't know what major changes could be made in the educational setting.

Uri said he believes it is important to increase education about male gender in counseling programs too. Uri stated,

I think we could do a lot more education of counselors in regards to male socialization and male development. I think it would help in two ways. I think that would help all counselors in working with men and restraining the stereotypes we have about men and how they experience emotions and stuff like that. It often feels like we do a lot in the multicultural class, which of course is important about working with different populations and how to work with them. Also, not making generalizations just because someone is from a certain background or gender or anything, that they're going to be a specific way. That isn't necessarily highlighted with me. A lot of times when I hear people talking about male clients or even in supervising working with male clients it's like, "Men like to talk shoulder to shoulder and they like to do activities and you have to get at it this way, this is going to be addressed as anger." That's not the case always. That just feels like sweeping generalizations that might be true in a lot of cases, but I think it's dangerous to say that's true in all cases. I think it helps in that case in one way.

Uri expounded, 
I think in another way, doing more education about male socialization and gender role conflict and all those things I think would help male counselors get a little more in touch with their experiences, as a man, and how they have been socialized. To think about their emotions in a certain way and vulnerability and empathy, it might help in their development or in feeling a little more comfortable talking about negative topics we talk about in counseling, more vulnerable, emotional topics, because they have the knowledge to back up that "It's okay for me to talk about this." The reason I feel uncomfortable is because of all these rules and social things that get put upon me. It might make things feel a little more open. Those are some things that I've definitely thought about.

Avoid male students as the spokesperson for males. Some participants suggested that faculty should avoid calling on male students as the role of a male spokesperson. Participants shared this experience was uncomfortable for them. These participants said they were concerned their peers would generalize their responses to all men. For example, Leroy advised female faculty to not make male students the spokesperson for all males. Leroy stated, I think something that would probably be really good is that, it's good that you have a male in your class to give you the male perspective. But then also sometimes preface that with, "Leroy you don't represent every male in the world, but I'm wondering if there's something here that you might be able to add to this conversation."

Leroy continued, 
I think even a little kind of disclaimer can be really important because sometimes for men we don't want to muddy the waters just with our opinion and have everyone think it's everyone else's opinion. I may say something that is insensitive or inaccurate or just not great, and I don't want that to reflect on other males in the profession when they see something differently. So, that's what I would tell women, female staff, if they're able to almost give a disclaimer like that.

Winston shared that it is important to him to not make a male student the spokesperson for all males, but faculty should still call on them for their individual perspective. Winston stated,

I think it would be important for faculty in dialogue and in discussion and classes to draw upon the male experience. I know in some social justice classes I've taken that you don't want to use a minority in the room to be a perspective for a whole population. That can put a lot of pressure on someone. You don't want to speak for a whole group of people because you're the only person in the room. But I think often times men do have great perspectives to lend, especially if it's a case study of a male. Men share the same types of pressures of we don't want to be breadwinners, but society expects us to be breadwinners. Men don't want to be masculine. Society expects them to be masculine. That can be an anxietyproducing experience, to be successful, to be strong, to be brave. That's what men are expected to do. If men don't feel like they're achieving that, then there's mental health consequences. I think men know that, but I don't think it's a 
common experience in counseling because men are often seen as the ones with power, the ones that have power over women. I think that gets pathologized. Winston continued,

I think men often struggle over the expectations that are placed upon them from society. I guess, to get back to your question, I think faculty members could leverage men's experiences as a way to understand the human development of what it means to be a male or what it means to be a man. I think men can offer that authentic experience and empathize with other men clients.

Increase diversity in faculty. Some participants suggested that an increase in diversity of faculty could be beneficial to counseling programs. In particular, the participants said they would like to see more male faculty. For example, Frank shared that he would like to see more diversity because currently he sees a majority of White women teaching. Frank said,

I think more people need to have, and I'm going to be a minority on this, less White women teaching. Not because I'm against White women. I was raised in most of my educational experiences by White women and that, to me, is really disheartening as far as, you know, the rest of the world is not White women. My parents were decent parents, but when you spend eight hours of your day, five days a week, around a certain minority, you're going to learn that perspective. And that's not the world we live in, especially for the minorities, whether they be African American or Native American or Muslim or whatever. We got a huge population here. I like that there's diversity, some White males don't. 
Otto also suggested the need for more diverse faculty because students need representation or role models similar to them. Otto suggested that faculty, open yourself up to being a mentor, even if that's something, if you are not capable of doing individual mentorship, which I whole heartedly know how much of a commitment it is, emotional, time all that stuff. At a bare minimum, like maybe just creating a group for men to come in.

Otto continued with sarcasm in his voice, "Which of course you have to be careful because nobody wants to talk about safe spaces for men, because men don't need it." Otto expounded,

If that means you want to be inclusive of all people, so also creating groups for women maybe partnering up with a female faculty member to do a group for women, and then hopefully if it's fortunate enough to have an LGBTQ faculty member. Particularly if you have a trans faculty member that could do a group. It's so incredibly important to see that there are people of your gender in your field. And it's also so incredibly important to hear that your colleagues are experiencing the same thing, so that you don't feel like you are a freak or that it's just you. Then you ruminate on it, I guess everybody is experiencing the same thing then, cool, find a way to move through that together.

\section{Experiences in the Profession}

The participants were asked to discuss their experiences, as a man, in the counseling profession. This included students' experiences in internship, master's and doctorate programs, as well as participants' experiences post-graduation. 


\section{Privilege or benefits of minority gender in the counseling profession.}

Participants were asked to discuss any benefits or privileges they experienced in the counseling profession due to being a gender minority. Very few participants said there were no benefits to being a man or a minority gender in the counseling profession. Some participants said there were benefits to being the minority gender in the profession.

No benefits. Some participants said there were no benefits to being a male minority in the counseling profession. Derek said there are standard male privileges in society. However, he could not think of any that were specific to the counseling profession. Chris had similar sentiments as Derek. Chris said he has never noticed any privilege or benefits due to being a male in the counseling profession. Chris stated, My wife and I have talked about it. When I hear her experience in her workplace, and one of the things she says is she has only worked for White males. She has never had a female boss. I hadn't really ever thought about that until she mentioned it. In the banking industry and in education, many times the males that are involved are in the management, which is totally unjust because there is no valid reason for that except for the bias in the industry. Here, our principal, who hired me, was a female and very capable. I don't think gender limits a person's capabilities. But in the industry, you do see that and I think that is privilege. Benefits. Many of the participants believed there were benefits to being the minority gender in the field. For example, Mac shared,

There's societal benefits, like I'll probably get paid more than a woman. I'll probably be taken more seriously by some. I know that people may believe the 
word of a male over a female. I know that I sound like an asshole. I really don't mean to come off as so self-involved and self-important.

Mac explained that these are some of the realities in society because he is a male. Mac provided one specific example, "My internship site tries to pick one male and one female intern each year. So, that in and of itself, I don't know if it's fair, but if there's less men, I have a higher chance of being selected."

A primary benefit almost all participants noted was clients need and want to see male counselors. For example, Abbot stated,

Being in the 7 through 12 building, in the k- 6 building, since the elementary side is fairly thin on male staff members, there have been a few times where I've had the opportunity and have been requested to interact with some elementary boys. I think they wanted that from the standpoint of giving the boys a person who is a male to work with them.

Abbot elaborated,

Boys have come in and asked questions because it was a boy issue. I can think of many times where we have a conversation about interactions in their behaviors with girls, when they are at that age of trying to figure out the whole boy and girl thing. I think it might have been easier for them to hear it come from a guy. "Hey, this is how you need think about moving forward when you think about moving forward in relationships with female classmates. So, I think that might have given me a little bit of an advantage there.

Elliot discussed his relationships with male clients and how many male clients need and/or prefer a male counselor. Elliot stated, 
I don't know if it's just this evolving culture of "Men keep your shit together and don't be vulnerable, suck it up and move on." That's one really cool thing, not to get sidetracked here, my work now at the V.A. is working primarily with men and being able to just be honest and talk about emotions and kind of dig, and I can tell a lot of times it's uncomfortable. But yet, I think doing it in a way that's very respectful and pointing out, hey, you know, certain changes they can do to help them be more emotionally available.

Elliot expounded about his relationship with male clients. Elliot stated,

A lot of the people I've seen over the years, particularly now, here ... I don't know, just common language. If I got somebody that's coming in and they're cussing like a sailor, literally, not that I'm repeating back everything that they're saying, but just kind of using some of that language along with them. And again, there are certainly limits to that. But I've had a lot of guys tell me, "Yeah, exactly." So, I think there's a common mindset that helps me connect with some people. And then, I think once people can feel that connection, like, "Hey this person understands where I'm coming from" then I've got a better angle to try to challenge them on maybe some alternatives. Different ways on behaving or doing things, trying to problem solve.

Kyle discussed the need for male counselors at his place of employment. He said he was in high demand. Kyle stated,

For a long time in the agency I was working at, for a long time I was the only male in the practice, which was interesting because it got me clients that other people wouldn't take. Some of them were interesting, some of them I took them 
because I was male, and the client particularly was male and looking for a male therapist.

Uri shared that there were benefits to being a male in the counseling field. For example, he said he was in high demand with certain clients. Uri stated, I remember in my internship I was the only male counselor, I was an intern, but I was the only male counselor there whatsoever. They definitely, my supervisors, valued my perspective and definitely made me feel comfortable. Often times there would be clients who only wanted to see a male counselor and I felt very supported. A lot of the times they needed to be seen and they might have been a little, their presenting issues would've been a little above my comfort level. I wanted them to be able to see someone. I definitely feel like I had the extra support of my female supervisors and everyone there to step up. They would give me extra support to deal with that. I think that's definitely been nice. I definitely feel supported in that way.

Some clients needed a male and Mac was referred to these clients during his clinical experiences. Mac stated, At my internship site, there have been times when one of my supervisors has said to me, "Oh, I think it might be good for him to have a male figure." So, not necessarily being used as a substitute for father figures or for individuals who don't have male figures in their lives, but there is this expectation that, "Oh, okay. Well, you're going to have to provide some positive, free education, or positive experiences as a male for this other male or for this female." 
Leroy attracts male clients because he is a male counselor and because he is a man of color. Leroy stated,

I thought "well, if there are people from the inner city, men of color, who maybe, I believe aren't engaged in mental health treatment or education or whatever it is because they may have a stigma about it, if they see me, a person of color who is a practitioner in this field, will that work towards a better therapeutic alliance? Will that make them feel more comfortable?" And that's actually how I get a lot of calls to my practice, because I do in-home visits, which is usually like a wife or a girlfriend says "Hey me and my husband want to do counseling. He refuses to go anywhere, but he sees that you're a dude and thinks you might be more objective."

Leroy expanded, I'm sure there's some people that are fine and it's inconsequential as long as I'm available for the treatment, but I have had people call me and say "Oh, I see you're a guy. I think that's so great. There are not enough male therapists that do this." And then the other part that I think is important to highlight is, they'll say "Wow, this is cool because you're a man of color, and I'm having this specific issue and I think you may be able to relate to this" or "You may be able to help me work through this stuff as a man or as a couple of color" as well. Participants shared there are female clients who need and want to talk to male counselors too. For example, Elliot shared that there are benefits of being a male when working with female clients. Elliot stated, 
One job I had previous to this was working with a group of individuals diagnosed with borderline personality disorder, and one of my supervisors would tell me how valuable my presence is. I might be uncomfortable dealing with a lot of emotions, but yet, by me being able to be a calming presence, and being able to listen and continue on with conversation and a therapy session, it can help to retrain this general idea, this mistrust that women have towards men like a relearning process, or a different option than what maybe they've thought men to be.

Leroy discussed his experience in working with female clients and the need for male counselors. Leroy stated,

Don't assume that because you're a male that when you are working with a female client that you are or are not going to be able to relate them. I know that's a bit of a tricky statement, but there are going to be things that women are going through that all we can do is have an empathic ear, and that's okay. And there's going to be things that they are going through that we might be able to connect with them on. And either way, whatever it is, it's all grist for the mill, it's all good as long as you're doing good work with them. And I think sometimes, our gender can be really helpful in those situations, particularly, women who have been in domestic violence situations after they have come out of it and they are looking for treatment or whatever, I've had women say "It's been really good to be able to speak with a man who is able to articulate himself, and it helps give me hope that there are people out there that I can connect with that are men, that are able to be thoughtful and compassionate." 
Glen shared his experience in working with females and males. For him, it was easier to work with females than males. Glen stated,

I think it's more women seeking male therapists just to do, I guess, in my opinion, it would be to do some restorative or corrective relationship issue stuff. So, I do know there's a number of people that I've seen, and I can't give you any data on that, but often females requesting male therapists.

Leroy said there are benefits to being a male gender minority in the counseling profession and this was due to the high need for male counselors.

If you are secure, within your own professional identity and you are savvy enough to navigate that, then yes, there are benefits. Because also there may be women who call on you because they might not want to work with a female therapist or they've had like a bad break-up with a boyfriend and they really just want to have a positive experience with a male. And sometimes it can be just good for them to able to have that interaction with someone whose objective and happens to be a male, find that to be a very powerful experience.

Derek found that it is not challenging to work with female clients even though he believed it would be. Derek stated, "What's surprising to me is it's not a challenge" to work with female clients. Derek said,

What's surprising to me is how many females will open up to me about their abuse, say sexual abuse, sexual assault from a man. I mean some gals will obviously seek out a female counselor, but a lot of gals will just open up and tell me about their abusive experience. You know individuals will go into more details. Some will go into detail and some won't. You know, that's not based on 
gender necessarily either. Some people need to process the details. Some people don't. So, that's been interesting to me. The fact that "Hey, I'm a guy. And people are still, at least female clients are sharing some of these things with me." I thought they would prefer a female counselor, but they're still talking to me about it.

Otto found that a benefit of being a male minority in the counseling profession has been quick promotion. Otto stated, "Once I made it into the field, I absolutely was promoted very first and that's partly my temperament, but I'm able to be as driven and pushy as I am because I'm a man." Otto stated, “That's been the interesting thing about being a male therapist, it is harder to get into the field, but then you rise so much faster."

Kyle believed a benefit for him is he is more respected as a male, in his program and in the profession. He thought it might also be due to being older. He noticed the way he is treated seemed to be different than his female peers treatment. Kyle stated, I think with some of my clients, because I look older, I've got that distinguished look, and so it was easier for me in some respects, being a male that looked a certain way, for my clients to say, “Oh wow, this person knows what they're doing," even though I was still just a student. So, I think I benefited from that. And part of it may have been being male, part of it was definitely being older and looking a little older as well. And I watched, while I was going through the program, I watched some of my younger fellow students, especially women fellow students who were younger, really struggling with clients who clearly were more guarded with them because they assumed somebody as young, and I guess maybe female like this, "What do they really know?" 
Kyle concluded, "And I'm sure there were gender stereotypes built into that, too."

Neal shared what might have been some benefits to being a man in his program.

Neal stated,

I'm just drawing from my own experience, things I've been told, and I don't know that these are because I'm a male. I think people perceive, or experience, a higher level of emotional stability ... and I'm thinking, honestly, more of my role as a counselor educator, than I am a counselor. But, in terms of working with student conflict, or working with client conflict, and being able to curb my own emotional reaction to that. I don't know if there's an assumption that there is a higher degree of emotional regulation, as a male. But I've gotten that impression, that that is the way people view it. Some of that also just has to do with my personality. I'm pretty even-keeled. So, that might be a little bit of that coming in there as well.

Many Participants shared that a benefit to being a male in the profession is they are easily employed. Winston stated,

I heard from people like, "Oh, I'm sure you'll be great. They always need males in those types of jobs." I believed that. I didn't know it to be true, but I kind of believed that was the case, that I wouldn't have any trouble finding work because I was a male.

Barry was hired because the school he interviewed with was looking for a male school counselor. Apparently, they already had one female school counselor and desired a male counselor. Barry said he believed his hiring was more likely due to one male and female being able to meet the needs of the student body. Abbot experienced something 
similar to Barry. Abbot said that being a male was an advantage in his employability because the school was looking for a male counselor.

Neal shared that being a male minority may have influenced getting hired as well. Neal stated,

I'm the only male faculty. So, when they were recruiting, they were hoping to find a male faculty member because there wasn't one on the faculty. And male students didn't have that kind of role model. Didn't have someone that fit their demographic, in terms of gender, on the faculty. So, I think it probably was advantageous in that respect too.

Jasper shared that he has experienced an additional benefit. Jasper said that if he wants to get out of certain responsibilities in his profession, he can. He said this was the case in his counseling program too. Jasper stated, "I would say that there are definitely more responsibilities skirted and that often fell onto the laps of women."

Glen was treated differently, at times, than his female peers. Glen stated, It's not empirical in any way, but, when I worked in the clinic, which was my culminating experience to do my, I think it was called practicum, before my internship. I had a doctor who was my supervisor. And there seemed to be gender differences based on what I did, and what my colleagues would do. So, we would do an hour session. They would have us come back at the half time, and they could call into the room at any time to have us do something different. And I've also noticed a bit in my career that with certain folks, certain individuals, that I get away with more than other people do. So, I would come back and my supervisor would be like, "You're just doing the best that you can. You're doing 
a great job, blah, blah, blah" ... And then my colleague, who I was watching their session and seemed to be doing a great job, would come back and there would be some more criticalness to their experience. And I was just like, "Where is that coming from?" So, I think I've noticed that a bit as well in my life.

Glen expounded,

I think it can go one of two ways. Sometimes individuals see me differently in a positive light. And sometimes, I've had the experience, like in my current doctoral program where they see me in a negative light because of what I represent, because of what I look like...And I think that's based on our own Freudian, our own projections, our own transference. So, I think I've seen both sides. But in my master's program, in one particular incidence in the clinic, I was given the benefit of the doubt more than not. And I think my classmates noticed that and we talked about it.

Challenges in the profession. The participants were asked to share the challenges they experienced as a male in the profession. According to participants, there are challenges associated with being a male minority in the counseling profession. These challenges included a lack of trust of male counselors; possible female clients' preference for female counselors; pigeonholed to male clients; male counselor/male client relationship; not hired/lack of employment opportunities; male input/perspective overlooked or not sought; emotional expression; and lack of research about males to inform practice.

Lack of trust of male counselor. Some male participants shared they are not trusted in the counseling field because they are men. This can be challenging for the men. 
For example, Percy discussed the challenges he experienced at his site and the lack of trust projected toward him. Percy stated,

I know my one colleague, my other buddy, we were a bit more conscientious of our interactions with our female students. He was a school counseling student as well. Especially during our clinical... experience is we had to be a lot more mindful. So, I know I had a ... I remember at my internship, because I worked with kids who were emotionally disturbed on some level ...When my supervisor... wasn't in her office with me, I know I had to keep the door ajar, and we were in a quad office so I was in the eyesight of one of the counselors across the hall from the office I was in too. So, I had to be very cautious because, as a man, it seemed like you almost couldn't trust the atmosphere that I was in and just working with the female students. Even just in session when my supervisor was there, I had to be mindful of transference occurring with me ... I mean, countertransference as well. I wasn't neglecting it, but I felt the transference was a bit more sensitive, I guess you could say.

Percy expounded,

I think the fact that sexual harassment issues that pop up are generally more with the man as the aggressor... I don't have numbers, but that was certainly out there. Again, not overtly communicated to us, but ... Well, actually it might have been one time. Yeah, I think it was just one time communicated with me to be cautious. Again, that might have been because that student had a history. Either way, yeah, so that was certainly a hurdle for me.

Percy concluded, 
It certainly hinders, in my opinion, my ability to be viewed as compassionate and empathetic to a female client because of this underlying, What's the word I'm looking for? Underlying misnomer that something I say or do is going to get misconstrued into being some type of a sexually inappropriate verbiage or conduct in some way. I don't know if that's thought of much, that men might be at a bit of a disadvantage in that regard. The way it was communicated to me, I didn't take any offense. I knew that my supervisor was reminding me to be mindful because I think, especially for the female population that I worked with, dads were absentee. So, all the more reason for me to be mindful that a male figure in their lives could easily be looked at as a father figure and that's a very fine line that can be perhaps healthy, but also very quickly that could be not. Otto shared similar experiences about perceptions of some male counselors in the counseling profession. Otto stated,

Particularly working in the rape crisis field, there's an idea with a lot of the people who work and/or volunteer at rape crisis centers that it should only be a safe space for women ... There was a woman that called and all I said was "Hi, my name's Otto... I'm returning your phone call." Then she informed me that there's no, I'm going to curse here, there's no fucking way I was going to work with her daughter and fuck all men. I mean she's screaming at me, and I was like "okay." It's so weird in those moments.

Otto discussed how he is treated now as man versus as woman, prior to "gender correction." He stated, "This happens a lot to me now, so I'm very aware of the 
difference between how women are treated and how men are treated because I've experienced both." Otto said, "So, many had a problem with my gender."

Otto continued,

This idea that all men rape and I must be a terrible monster too is indirectly reinforced every single time a staff member ... would say like, "Of course if you are uncomfortable with a man..." No. I am a trained trauma therapist. I am one of the most experienced people ... "Do you want your clients getting the best care, or do you want them going to some crappy person in the community just because that person happens to be the right gender?" Why is that okay?

Otto concluded, "This shouldn't happen, but it does."

Female clients possibly preferring female counselors. Many participants talked about some female clients preferring female counselors. Elliot said that some female clients will request a female counselor over him because he is a male. Elliot stated, Some people, if they're wanting ... counseling they say, "Oh, request a female provider." That obviously eliminates me. In my experiences, it doesn't happen a lot, luckily. But I know those challenges do come up, or those barriers, where I can't be helpful just based off someone else's preference.

Leroy provided an example of a former client who fired him because he was a man. Leroy stated,

Sometimes, women, I did have a lady that was working with me and then fired me the next session because she said she had a lot of things that she only thought a female could discuss with her. It was something related to fertility, I think. It was something about anatomy and maybe reproduction that she felt a bit shy 
about talking to a man about. There are instances where it can be disqualifying, but I think that's okay. I think people are going to look for who they look for.

Pigeonholed to male clients. Some of the participants shared that they had been "pigeonholed" to seeing male clients. This limited the diversity of the clients they were able to see in their work. Rusty shared that he wished male counselors were looked at as potentially healing instead of harmful. He shared that he believes there are benefits to male counselors working with all populations, not just certain populations. Rusty stated, I would love to see a policy change about ... I have some trepidation about even saying it, because it gets a lot of harsh feedback at times, but I'd like to see the practicum and internship, especially that clients are set with therapists, they're not set with genders. My gender is important, as a process therapy, yes. It is important and it has no bearing on if I'm a good therapist or not. I severely remember the amount of clients that, you know, my colleagues would never identify my gender if I was female, and watch this multiple times. And then anytime it was myself, or any of my male colleagues, it was “Oh, well he's male." And then right there, "Well, he's weaker than ..." or those are the assumptions that are placed in that comment. And it makes sense. Men need to know how to work with any gender, just as females, just as non-binary... we need to know how to work with people. That's how we improve our diversity. That does get quite the push back.

Rusty continued,

And a lot of people say things like, "Well clients are going to have adverse reactions" Or "They have trauma or triggers." Well as a trauma therapist, that's 
where the work can begin. I mean those are the good skills to have. Well "Yes, I am male" and "How's your reaction ... you're having because of that?" Like, that's the therapeutic tool. So, I think we adversely are programed, so adversely that us, male colleagues, are not to have those opportunities. I appreciate working here ... because we don't bring up gender when assigning clients. I think holding ... going to ... basic counseling skills, we can challenge when individuals or colleagues, or even clients, they say "but" "Okay, let's hold on" and "yes, he's male and this could be curative this way" and, the female counselor, this could be curative in that way.

Male counselor/male client relationship. Some participants experienced some challenges in their relationships with male clients. Glen stated, I actually find it more difficult to work with male clients. I don't know if it's that I've been in this field for so long I'm just used to seeing more female clients or that with males, we seem to have these gender stereotypes or unwritten rules about connecting. That sometimes can be difficult to negotiate in that first session or first couple of sessions. It's almost like it's a negotiation game. I call it man code, or unwritten rules of masculinity. That in our culture, when you have two males that come together, that may be from more stereotypical male backgrounds, there is some social dynamics that are a bit tricky. And so, making sure to navigate those in a way can be important to the outcome of counseling. Being respectful, letting the relationship sometimes develop more slowly or more indirectly, I think, are some of the issues.

Glen continued, 
I worked with a young male around sexual performance issues. That was a fascinating case on how our, just his and my dynamics around that and how we could talk about it. It was slow. It was indirect. Good work was done, but it was more difficult and more challenging, I think, in some ways... and I think it might be on both sides. They are trying to negotiate my presentation in some ways, as well.

Not hired/lack of employment opportunities. Some of the participants said there are some jobs they will not be hired for because they are male counselors. Leroy stated, I think sometimes that can be disqualifying, as much as being a man in this profession is good, it can be a disqualifying factor as well. Like for instance, sometimes when you're trying to come out of grad school and you're trying to get a job, you're not going to get any of the jobs in the DV shelters. Now, that's understandable for the nature of the work, but it's also disqualifying. And also taking about maybe 30 jobs in your community away from you, just off the fact of your gender. So, sometimes that can be somewhat disheartening. I'll say "Awww that is a door that is shut for me." But my female colleague, she has all the other opportunities to collect those. And even in the male shelters, they will hire female caseworkers there or counselors because there are more females than men. So, I remember kind of thinking about that like that kind of sucks that I'm not able to apply for some of those jobs that maybe other women could get. Otto shared that he has a male colleague who struggles with being hired in counseling. He said his colleague "has not been able to get a job." Otto said his colleague is as qualified as him 'So, the fact that he wasn't even able to get an offer is 
some bullshit and I think it's because of his gender." Otto elaborated, "We know that men experience sexual violence and obviously at a much less degree, but it's not zero, so why aren't there more men being hired at rape crisis centers? That's pretty obvious."

Male input/perspective overlooked or not sought. Some participants didn't believe their input, their perspective, was sought or it was overlooked in the profession. Elliot stated,

I think too it might be in different groups or different meetings that people might look more towards the female therapist or psychologist to ... add in, and I don't know if it's a challenge of just generally male counselors, but I tend to be one that just sits and likes to think through something versus just coming right out and just speaking my mind first thing. I take a little bit longer to digest and think about what I want to say, which some people then maybe get a little impatient and just move on to the next person.

Elliot elaborated,

I always think that men and women have their strengths in whatever field, but I think more in psychology or counseling, men have a lot of good, really helpful and valuable insight that isn't always accessible when, maybe, there's more females than there are males.

Emotional expression. Some participants shared their experiences with emotional expression in the counseling field. Barry discussed the challenges of being nurturing. Barry stated, "Females are more nurturing than males to start with. When I look at my wife, she's just more nurturing than men. It just takes a special kind to do that." Barry expounded his thought by adding, 
One of the best male counselors I know...comes from a different background and he is fantastic. I'm more the administrator type. I could handle all the paperwork and ... he was really good at the grief part and mental health part. He could see the whole picture, he could really see the kids, he could see the teachers, and he was able to get the resources for providing support to everyone in the school system. When I think of a school counselor... he is the epitome of what $\mathrm{c}$ counselors are supposed to be. He doesn't do all that scheduling and paperwork, but he meets the needs of everyone in the school. Now there's so many mental health issues. It's a whole different ball game than 25 years ago.

Barry concluded,

I am not the most open with my emotions. With the middle school kids, it's like when they come to me with the drama, it's hard for me to work through some of those things. The key is, like any good teacher, is you care about them. I guess that's probably my strength.

Derek discussed the number of men he sees, as a counselor educator in counseling programs, who are not emotionally expressive. Derek stated, "As I train students, the one thing I noticed, there's still the gender scripting at play, so a lot of guys tend to have that more logical thinking mind and they need to get in touch with their feelings." He said that he frequently sees this issue. For example, he discussed facilitating a group class. Derek said the women,

all shared and the guys shared a little bit, but they didn't really share until the last, toward the end of the session. And then when they did, they didn't go quite as deep as the gals did. So, I think there's some gender scripting at play there. You 
know where there are some communication differences. Not for all guys and all girls because there are some gals who won't share deep or whatever ... I mean I see it in my classes. There's that experience where, oh, there's one or two or three guys, and there's 10 or 17 girls.

Elliot discussed his work on emotional expression, while in his counseling program. Elliot stated, I'm thinking with my male supervisors, because of maybe a better understanding about some of the struggles why all men kind of coming to a program are a little bit behind the curve as far as emotional or skill development.

Elliot continued, "I can best remember, pointing that out early on and challenging me early on, saying, 'Hey, these are areas if you're going to continue to flourish, you got to get a better handle on these."' Elliot said he remembered being asked by one of his supervisors,

"If I asked your wife how emotionally available you are, what would she say?" I still remember that conversation and then coming home that night and asking my wife and she's like, "Yeah, you're a little behind." That's what I appreciated about him. He caught that early on, something that I wasn't even aware of. I think I was too focused on doing it right and not just connecting, not listening in between the words, rather than just kind of focused on, "Well, what am I going to say next?" "What's going to be my intervention?" More of that, like a problem solver versus ... That's how I tended to operate and I think he helped me look at the problem, or define the problem, differently. 
Elliot shared that he was not sure if he would have been as receptive if the feedback had come from a female faculty member. Elliot said, "I don't know if I would have been as receptive. I might have taken it less instructively and more like, oh shit, I don't know." Elliot expanded, "But it seemed like coming from another man, this is going to be constructive feedback. You're not going to necessarily like it, but it's what you need to hear."

Lack of research about males to inform practice. Another challenge that was presented is there is a lack of research on males that can be utilized in the counseling profession. Derek said that he has found most research in the counseling field is on female counselors and female clients. Derek shared about male sexual abuse survivors and the lack of research. Derek stated,

One of three victims is male. So, one in six boys and one in three girls are abused sexually, but $98 \%$ of the research is about females victims. So, $2 \%$ of the research is about male victims but only $1 \%$ of that is male only victims. So, $1 \%$ is male and female victims. And $1 \%$ was male only victims. And maybe that's changed some because I mean, I'm talking research from 10 years ago. But, so I guess in studying some of the, looking at some of the research, I mean, there's a huge gap in research on male clients, I think too. So, it's a weird thing because a lot of the psychology theories we use... all those were all males, but at the same time, in practice on the ground, a lot of the research is female counselors and female clients.

Derek added, "Then a lot of male client research is about males as offenders ... So, that's at play too." In sum, Derek stated that male counselors and male clients are 
vastly underrepresented in the research. However, research on male clients, in his experience, is about male clients as offenders, for the most part.

Experiences with colleagues in the counseling profession. Participants were asked to discuss their experiences with colleagues in the profession. The participants shared examples of their relationships in the profession. Barry did not differentiate between male and female colleagues. Barry stated, "If they were good, I respected them male and female. There is no difference." Chris did not differentiate between colleagues either. Chris stated,

People are people. We do have different personalities. There might be some female peers or colleagues and counselors who I would engage in with more easily than others, but I don't think that's a gender issue. I think that's more of a personality issue just like there are some male counselors that I would connect with more than others, and likewise with professors. Many of the male participants' professional experiences have been primarily positive.

Glen shared that his relationships with his female colleagues is positive. However, he also shared the importance of male counselor relationships. He said that due to the intensity of his work with clients, sometimes being with his male colleagues feels calming. There is less emotionality taking place and this allows him an opportunity to recharge. Glen stated,

I guess my journey is really wanting to be somebody who is centered and calm. I guess maybe stoic or logical. I buy into stoicism, but not by the word stoic. Stoicism is something different. It's like what you can control and what you can't 
control. I think at times, the environments that I work in are really traumatic and chaotic. And a lot of words, a lot of talking ... which is nice sometimes ... Right? Like talking, being passionate is really important. But there seems to be a different dynamic when I'm with some of my male counterparts and that's really being stereotypical. That's not every experience, but that's just some generalizations...We work in a profession where we are dealing with thoughts, feelings and emotions, in intensity ... When I'm not seeing clients, I need to be able to recharge. And I'm introverted, so that might be part of that as well. But if I was to be really generalizing ... And this is not every clinician I've ever met ... Some of my favorite, most calm people are females too, right? But there seems to be a little bit of an intensity around that, in the work environment.

Experiences with female colleagues. Participants were asked to discuss their experiences with females in the profession. Many participants' professional experiences with women were positive. Percy's experiences were primarily positive. He could only think of one woman he had a negative experience with, and believed it was due to a personality conflict, not because she was a woman. Percy said his relationships were "wonderful" and,

I'm very comfortable with women, working with women, so having female as the majority that I work with in the field is all fine and good with me. I don't have any negative feelings of, “Oh, jeez, I'm in this female-dominated profession and it's a struggle for me," it's actually quite comfortable.

Rusty discussed abuse of power by women in the counseling profession, even though men have privilege as a majority in society. Rusty stated, 
Power and control knows no gender. It operates very similar to different innerpsych identities that pressure tactics can happen to anyone, and to help validate that for males who do experience it. We had an executive director who openly discriminated against male colleagues. And very similar to the victim blaming we see in sexual violence, the same thing happens often, as I've learned, from other male colleagues who've experienced that victim blaming of a male colleague being harassed by a female supervisor who totally gets away with it because there's the assumption that men want it or that it couldn't possibly happen because men hold all the power. If it could be in a message in a bottle, it would be that oppression, again, it doesn't discriminate. It goes against everyone. And, that men are incredibly privileged.

Rusty continued,

Working with other helping professionals, social workers, counselors, who are also a majority identified as female. A lot of having to prove oneself, lot of kind of testing. For instance, when I first started here..., I met with one of the local groups from our state organization, having a lot of surprise that there was a male therapist in this field.

Otto has experienced some challenges with his female colleagues as well. He stated, "This is one of the ways I talk about being hung out to dry." One of his clients made a complaint about Otto's use of masculinity and made a report to the agency. Otto was forced to apologize to the client and then the client was offered a new counselor. Otto felt betrayed by this interaction with his female colleague. 
Rusty shared he has some challenging relationships with female colleagues in the profession too. Rusty stated, "A lot of little knit picking at different things that I do. 'Oh, it's okay because you're a guy. Don't worry about it."'

Experiences with male colleagues. Participants were asked to discuss their experiences in the profession with males. Many participants said their professional experiences with men were positive. Mac shared about his male colleague relationships. Mac stated,

There's only one other guy. He is the director of the program, and he is very warm and compassionate and open and inviting and accessible. I don't think I'm treated any differently than my female counterpart. I really haven't noticed any difference. If there is one, I'm not aware of it.

Glen shared that some of his male/male relationships have been challenging.

Glen stated,

I do have male therapists that I hang out with, counselors, I just think that because of, again gender stereotypes, around being ... masculine, being hyper masculine. Depending on the client and myself in the dynamics, I identify as more hyper masculine. I think that creates some additional hurdles to get through. It's not that we can't overcome those. But there's some interesting dynamics around male/male relationships that in the counseling room, can be, for me, challenging.

Otto discussed the importance of his male colleagues. Otto stated, "It is so incredibly important to have a supportive environment, and in my current job I actually supervise another male therapist." However, Otto only has one male colleague. 


\section{Similarities and differences in experiences in counseling program versus the}

profession. Participants were asked to discuss how the profession is different from or similar to their experiences in their counseling programs. Participants' thoughts on this question varied. Quincy said a primary difference he has noticed is there are more males in the profession than was in his program. Quincy stated,

Honestly, when I've worked actually in the field, most of the places I've worked have been pretty well balanced. Much more so than the programs that I've inhabited...I don't know why. I don't know why that is. I wouldn't say it's been $50-50$ or anything like that. But my cohort in my master's program started at 25 and went down to about 20. I think by the end of it there were three men in the program. I mean that's what $15 \%$ of the program is male versus 30 or $40 \%$ in the clinics I've worked in?

Ivan shared that a difference between his program and professional experience is his professional experience has been better than his experience in his counseling program. Ivan stated,

The experience I'm having as a new professional is better than what I had in school. I think, and I honestly believe, that academia is just like what I wrote in my first paper and that is I grew up in a White suburban bubble. I learned that I used to be the person who threw out the microaggressions, prejudices, and everything, without knowing it. Learning that in school helped me, but as I look back, and I'm still in academia, and I see it as its own bubble. I look at the counseling profession, the higher education part of the counseling profession, as a female bubble. 
Ivan elaborated,

I credit my supervisors because it is men, women, Black, White, everybody, and it's just really good and I enjoy it. Compare that to my program where it is a little less diverse, a lot less diverse, where I had less of a voice.

Quincey has found some differences between his program and the profession as

well. Quincy stated,

I don't know if I've noticed any major patterns. I think you're a little bit more isolated, and in my experience, at least, you know a little bit less about what other people's beliefs about the world are. To me, I think I have much more professional relationships. There's some strengths to that, but also it's a little more distant, generally, in the field, in my experience, than in the seemingly more intimate environment of a counseling program where you're doing group therapy together and you're counseling each other so you know a whole lot about those people. Maybe the boundaries are up a little more in the field than they are in, At least in my experience.

Quincy continued,

It's a pretty different environment. I think, sometimes, the academic context is so, it's almost like you're looking at the world through a window, but you're not actually out in the world when you're in your master's program. At least for most people, if they're in a master's program, they're in a wealthy environment and it's a pretty, I guess privileged would be a way to put it versus, a lot of times, you wind up out in the world and it can be much harsher, it's a lot harder. Sometimes, in your program, people's perspectives are valued a lot, but there's not a whole lot 
of time in a mental health clinic, a lot of the time at least, to have a lot of your own opinion. It's really just about completing your paperwork and helping your clients. I would say that that's a pretty big difference, and maybe one that counselor ed. programs could think about in some ways. I'm not sure if there's much to do about it, but that's something I've noticed.

Leroy has found that a primary difference between his program and the counseling field is being a man was not as much of an issue in his program as it is in the profession. Leroy stated,

I think in my program my sex is not really engaged very much. In my program, it's kind of more so inconsequential. In my profession, it can be very helpful or very isolating. Sometimes people say 'I'm looking for you because you're a guy and my husband needs it," or "I don't want to work with you because my daughter's 12." And I think it sometimes might be a married couple and the wife might say "Yeah, my husband objects to me being alone with another male in the room, sorry." So, there are those challenges also.

Jasper has noticed a difference between his program and the counseling field. Jasper stated,

The program I am in has a developmental component to it as far as developing counselors' teaching and supervising, which I would say is not necessarily present in the counseling profession where you're just working with clients. That would be a big structural difference. I think that I see more emphasis on diversity and what that actually means and putting that into practice and social justice in the counselor ed. world than in the counseling world alone. I think that is in large 
part because counselor educators and supervisors play this role of emphasizing what needs to take place in the profession and so that trickles down to the counselors. I think it hasn't been that many years social justice and advocacy have come into play in the ACA code of ethics. As a profession, we're still trying to figure out what that means and its practical use. Oftentimes, I think when I ask counselors what social justice and advocacy look like a lot of times their answers are stereotypical counseling behaviors that counselors should be doing anyway. Locating strategies that are inherently different than what they have been doing, that might be different. There is more emphasis on that in the counselor ed. than in the counseling world.

Chris shared that he has noticed there are differences between counseling programs and the counseling field. Chris stated,

I'm a school counselor, not an LPC, and that was by choice. I was not interested in being an LPC. I wanted the structure of a school and also the hours, but that being said, I was not prepared for the education environment and that has taken time to get used to, the pace and intensity of life from when the bell rings in the morning until when the bell rings in the afternoon. It is different than where I have worked before. As a pastor, I've dealt with tragedy, death, and difficult things, which has prepared me for some of the challenges in the school like suicide. So, that's similar to having to work and deal with some of those issues, but the intensity of life in the school day is different as well as the turnover of staff that is unusual in comparison to other professions. I think that part of that is that people move, things change. That first year I was not prepared for "so 
and so is leaving," "so and so is leaving" and it was a grief process. But I have learned to adapt to that.

\section{Themes}

Through data analysis of the qualitative data, a number of themes emerged. The 23 participants included students and professionals in the counseling field. Some of the participants were current students in master's or doctoral counseling programs. Some of the doctoral students were also working in the counseling profession. Some of the participants were working in the counseling profession and no longer students. While not all data collected from the interviews were consistent across all participants, there were numerous commonalities. The themes that emerged are inspiration, benefits, challenges, and retention.

\section{Inspiration}

All of the participants discussed their inspiration to pursue an education and career in counseling. Although participants' motivation to enter the counseling field were not the same, each was inspired in some way to pursue counseling. Many participants were motivated due to a drive to help others. Some of participants were drawn specifically to work with children. Other participants felt a calling to the field frequently due to spiritual or religious values. Some participants discussed the influence of personal and/or family experiences. Some participants were attracted to counseling due to role models.

Help others. A primary reason men are attracted to counseling is the desire to make an impact and help others. Some of the participants had specific populations they 
wanted to help such as veterans, children, survivors of abuse, and individuals with a history of addiction.

Mac reported that he came from a family of helpers and "It's just in my blood to want to help people." Mac also had a negative experience in his first career choice so he switched to the counseling field. Mac stated,

I am helping not just one person, but affecting many lives; and hopefully, if a child comes with their family, I'm helping to set up that family for success and that child's success for the future for many, many years to come.

Neal also wanted to help others and said, "I was attracted to how the mind works and how humans develop" and he liked working directly with people. Mac stated, "I wanted to help people in some kind of meaningful way."

It was important to Otto to be able to help others, and specifically veterans and men. Otto stated,

There's a large number of men who have experienced sexual violence, either by men or women. They don't feel like they have a place to go. And so, that particular population really resonated because it's the same thing here with some combat veterans, is they don't feel like they fit anymore.

Otto continued,

It's really important to me that the rape crisis centers I work at are inclusive of the entire population that experience sexual violence, not just Whites, gendered 18 to 25 year old women, which sexual violence impacts everybody, everybody deserves equal care that means everybody deserves equal care. 
Some of the participants described the desire to help as specific to children. Barry was attracted to the counseling field because he wanted to help children with their futures. Barry stated, "I like the idea of working with kids with their schedule post-secondary, along those lines. So, that's why I drifted more to the high school.”

A calling. Some of the participants described their attraction to the counseling field as a calling. The callings tended to be spiritual or religious in nature. The participants described their callings in different ways. Chris said, "It is amazing when a human being has a calling and you get to do what you love, and have an income, and may even have a retirement income. That is pretty cool."

Trent was also attracted to the counseling profession due to a calling. Trent said, "I enjoy helping people and felt like God was leading me into counseling. So, I went there and I enjoy it a lot so far."

Kyle said the counseling profession was a calling for him too. He was inspired to help others due to this calling. Kyle stated,

For me, I talk about this as not being a profession, I talk about this being a vocation, and so that's what I try and model, is you don't get into this because you want to make money or anything like that, you get into this because it's a calling.

Personal or family experience. Some men were attracted to the counseling field due to their life experiences with substance abuse and mental health issues, either their own experience or someone they knew. Ivan stated, "I've had mental health issues and addiction issues in my family and not necessarily a stranger to addiction issues myself."

Leroy stated his family had issues with mental health and substance abuse that went untreated due to limited access and stigma of mental health services. Leroy said, 
Nowadays, you see the thing with the opiate crisis, as like this really national crisis for people. But back in my day, when there was less information, it was primarily people of color and primarily people of a low social economic habit. The opiate crisis, they would just call them junkies. And we kind of relegated them to being moral failures, moral defects that needed to be rejected or to be in church. I saw that and even though I was a young child, I knew there was a component here missing. There had to be somebody who works on these things within the community.

Role models. Some of the participants' reasons for pursing the counseling profession were due to role models who came from books, mentors, and counseling experience. For example, Vincent was attracted to the profession due to his own counseling. Vincent said,

That was really the first moment where the idea of being a therapist really kind of came into mind. When I thought previously it was all about the research and the clinical side and more of the scientific parts of it, but that experience really was the first because we talked about it briefly when I was seeing him. And so, that was really the first moment where I was thinking maybe this is something that I would be interested in. As I continued my undergrad, it just continued to foster that idea and then when I was applying for different graduate programs I just liked looking at the program description and listening to what other people in the program actually do and I said, "This is what I have always wanted. This is what I want to do." 
Derek's family, who are in the mental health field, in part, influenced his attraction to the counseling field. He stated, "It's something I'm naturally good at, growing up in my family, at least I thought I had some skills and knowledge of mental health issues and all that stuff."

\section{Benefits}

The theme of benefits emerged from the data analysis. Many participants shared that there are benefits available to them because they are a gender minority or a man in counseling programs and the counseling profession. These benefits fell under three subthemes, which included highly marketable, valued, and unearned privilege.

Highly marketable in the profession. Most participants stated they are highly marketable, as a minority gender, in the counseling profession. Kyle said, "We desperately need more men, and we need more men who are going to be open and caring practitioners. Yeah, that's the big thing." Winston said, "I've noticed there's a need. I've heard several times men who've felt relieved to have a male counselor to talk to."

Some participants suggested that men are needed because they provide a perspective that is different and needed in the field. Percy stated, "That just as much as we need to have multiculturalism as part of our continuing dialogue as a profession, there needs to be an open understanding that men bring qualities to the field that women cannot, just like any other individual from some other cultural group can bring to the field and to serving clients too."

Feel valued. Participants stated they feel valued by peer, faculty, and colleagues. Harry stated there are benefits and it includes being valued. Harry stated, 
just having a different point of view from my female classmates like being able to, for one thing, I can think of several examples of being specifically asked for a male point of view on issues like showing emotion and being emotional and teaching that emotional intelligence to children and stuff and where the man is supposed to be and where the woman is supposed to be and stuff like that. I think I'm pretty unconventional in that aspect.

Frank shared similar thoughts in feeling valued in his counseling program. Frank stated,

My personality is, I have a tendency of being involved in what I get involved in...I'm pretty involved so I don't know if that has to do, I get more attention because I answer questions and I read the textbooks and I know the information...I'll follow up with things that are extracurricular I suppose. I have a tendency of getting more attention not overly and kind of unhealthily, but it could be seen possibly that I'm an older man in the class. I don't know if that's reaching or if that's actually true, but I feel heard maybe. I also feel heard because I have a lot of experience. I don't think it has to do with being male. I think none of this has to do with being male.

Unearned privilege. Some of the participants recognized there were unearned advantages to being a male in the counseling field. Examples included getting out of responsibilities, receiving attention, behaviors interpreted more positively than female peers' behavior. Jasper shared that he feels heard and believes he is listened to more than female peers. Jasper stated, 
My voice is heard more than that of my colleagues. The person that I'm closest with is a woman. We talk openly about this, and how she'll bring something to the table at a meeting and it doesn't really get a whole lot of attention. If I back her up or I repeat it, a very similar message, but in similar terms, what I say garners more attention and more authority.

Jasper said he also believes he experiences other benefits too. He shared that he believes he could shirk certain responsibilities and pass them off to others. Jasper stated, "They could have fallen on other people, potentially other women in my department."

Some participants shared that they believe they get more attention than female peers because there are fewer males in their program. Mac said, "In my group counseling class we had to practice being participants in group therapy. A lot of the time in the group was devoted to the men in the group despite us being a vast minority."

Some participants speculated that their behaviors were interpreted more positively than female peers. Mac shared that he believes it's possible he was perceived differently for engaging in the same behavior as female peers. For example, his behavior may be interpreted as relaxed whereas a female peer's might be interpreted as aloof.

\section{Challenges}

A common theme in this study was the challenges the participants experienced due to male gender identity and being the minority gender in comparison to women. Challenges included feelings of being lonely or isolated; feelings of invalidation and/or discrimination; male spokesperson, challenging topics, financial concerns, male stereotypes, and clients. 
Lonely or isolated. Some participants stated that a challenge of being a gender minority in the counseling field is feeling lonely and/or isolated. For example, Leroy stated, "We're special in this field and we can do really good work, even though sometimes it's going to be lonely and it's going to be isolating." Leroy said, "I think in my graduate study, it is good because it does make you a bit rare, but it can get very lonely, very quickly. You're like 'Geez, I haven't seen another man in a year, in the class.' That's not uncommon at all." Leroy discussed the importance of male peers. Leroy said, "I think it's the idea of comradery. Like, 'Wow, there's other people that are doing this as well.'”

Feelings of invalidation and/or discrimination. Some of the participants stated they experienced feelings of invalidation and/or discrimination. Rusty stated, "Unfortunately your male identity will lead you to have different experiences in your field than female colleagues. And that's not you, that's the system. Or that's not you, that's someone else."

Quincy shared that he has felt oppressed and/or invalidated in his program. Quincy stated, “There are times where I've found that people just dismiss ideas as being male ideas or White people's ideas. I find that pretty hurtful sometimes because I embody that, and it feels like it closes off the room to me, I guess."

Rusty also felt discrimination in his program and discussed the challenges he experienced. Rusty said,

I was struggling because I didn't have a male identified role model in our program to kind of say like, 'Am I crazy? Like is this real? Is this going on? Because this feels really similar to when we were having conversations about 
discrimination in our classroom, like these are the same themes.' And also holding the fact that I come from a really, really privileged background, White, heterosexual. There was a lot of guilt wrapped up in...A lot of guilt around should I even, 'Can I even identify this as an oppression?' And over the past year, I've talked with different male colleagues and female therapists, and was 'No, this is oppression. There are different themes and that power of control. No, you're not crazy. This is what's up.'

Male spokesperson. A challenge noted by some of the participants was being called on as the male spokesperson. Participants struggled with this because it was uncomfortable at times and some believed there was danger peers and faculty made generalizations about men based off of their perspectives. Leroy said that when he is called on for the male perspective that it is a "big load to carry." In addition, Leroy said, From my perspective, I'm a man of color, I'm a liberal...that's going to be very different from maybe another man who's had a different experience. So, sometimes, it can be kind of hard. I want to give you guys information about a male perspective, but I'm only one guy and I don't know if I'm the best representation of a sample.

Challenging topics. Participants disclosed topics they found challenging to discuss due to being the male minority. Some examples of challenging topics included subjects specific to women, sexual attraction, feminism, sexuality, and privilege Leroy said that there are some topics that he is not very vocal, which tend to be subjects that are specific to women. Leroy said 
When we are talking about women's issues, I tend not to be very vocal because I don't have a first person experience. It's a true learning experience from, I don't know, and I understand that some of these specific challenges or some of these topics that are relevant to women specifically, I can't know them from a first person standpoint. So, I may have some questions, but I'm primarily a listener. Neal said that sexual attraction can be uncomfortable for him because he is the minority in the room in these conversations. Neal stated,

I still feel a tinge of discomfort whenever I talk about attraction, like sexual attraction because I am usually, when I'm having that conversation in the classroom, I'm having it in a classroom that is, if not all, mostly female. And so, there is a little, I just feel some discomfort, around that.

Trent shared that the topic of feminism was challenging for him because "I think it was all the women just arguing about what feminism should be and all the guys were just straightforward. We were pretty silent throughout the whole thing. It was weird." In sum, Trent said it felt argumentative and not educational.

Male identity and/or privilege was the specific topic many participants found uncomfortable or challenging. Winston stated privilege is challenging because, I think it's a hard thing for people to discuss because it's so sensitive. It feels undermining of a woman's experience or of a Black woman's experience or of a homosexual's experience. It's a hard question to ask, and it's really tough for us to talk about because men are so often in places of privilege.

Financial concerns. Some of the participants discussed financial challenges associated with going into a counseling program or working in the counseling profession. 
Although a question about financial concerns was not specifically asked, a number of the participants shared this was a challenge for them. For example, Chris discussed his financial concerns with going into his counseling program and how he addressed the challenges. Chris stated,

One thing that helped a lot, was a lot of it was my own resourcefulness, is I sought out a graduate assistantship position. That really helped out my family financially, throughout my program. That was for the first two years of my program. I was fortunate enough to get a position...my last year of my program. Economically, I didn't feel like I was a liability on my family. It worked out wonderfully.

Chris elaborated about his financial concerns at that time of his entry. Chis stated, I had zero assets built up. My children were on free and reduced lunch at that time. The graduate assistantship and the...position helped a lot. I probably would not have done it if I would have had to have gone into debt. I was not that motivated to become a school counselor. I'm pretty sensitive about those issues. The graduate assistantship working out was the green light. I went as hard as I could for two years. Then this other position opened up, I interviewed at several places, but I was finally hired... and it worked out.

Chris concluded, "I find it difficult to imagine me being willing to go into significant school debt to go into this field."

Glen shared that there are financial challenges too. Glen stated, "I mean, again, being here and being a full-time Ph.D. student, I am struggling financially on a level I cannot even tell you." Glen continued, 
I do know that our professor, the first day... really set some expectations around what you would make financially. And I don't know if that's it, but there were a couple of other guys that didn't show back after the first class. I don't know if it was because of the financial piece or because of the ratio of males to females, but I didn't have any particularly strong reaction to that, initially.

Male stereotypes. Some of the participants discussed challenges associated with male stereotypes held by those inside and outside of the counseling field. Some of these stereotypes were related to men's inability to express or perceive emotions of others, male offenders versus victims, and men engaging in sexual behavior.

Derek shared some challenging experiences specific to his gender and gender stereotyping. Derek stated,

When I would talk to some professors at the master's level, I would kind of say, "Hey I want to, you know, go on for the doctorate and research male victims." And like one of my female professors kept switching it in her head. It was really weird because she's like, "Oh yeah, yeah, we need a lot of help with male offenders." It was like this automatic switch when I said 'male sex abuse victims' it was like there could only be male offenders in her mind. And it happened in more than one conversation. I don't think she was intentional on her part...there's that gender scripting surrounding certain topics. And I did experience that with counselors over the years. And typically female counselors where it would be the, yeah if you were a male victim, some were helpful and empathetic, but then some definitely were not. Like it's not like they could conceive of male victims or maybe as their own counter transference, they 
couldn't, you know, whatever it was, but it was there... societal gender scripting. And other research shows it's mirrored. And we like to think we're better as counselors, but a lot of research shows we do still hold a lot of the same biases that the greater society does.

Otto also discussed male stereotypes. He shared that it can be challenging to address them. Otto stated,

It's again that having to shrink yourself and having to take that backseat. Having to indirectly be blamed for everything that men do, the violence that men do. When we were talking about working with people who've experienced personal violence, it's always dads who inflict the violence on their children. Men who inflict violence on their female partners. In my program, there was almost no discussion about personal violence in same gender and same sex couples, and there was no discussion about the violence that moms can inflict on their children. Winston shared that some women in his program stereotyped men. He said that these were challenging times when this occurred. Winston stated, I found that when we were doing case consultations about specific clients, who were men, I noticed that the women often stereotyped males and had a hard time acknowledging the limitations that come with being a male in society. I think woman see men as often the ones who have power in relationships and have power over women. I think that's also a struggle men have, too, and it creates a lot of anxiety. Men often feel inept and weak in a lot of situations because they find it hard to achieve the stereotypical male characterization in their relationships and their families and their careers. I found myself empathizing with a lot of 
men in our case studies, and I found some of the female students undercutting them in their challenges. It was interesting for me to speak up for men because men are often characterized as being privileged for being male. I think a lot of times it's tough as well. It created some interesting dialogue and it was good. Lack of trust. Some participants shared that they did not feel trusted because they were men. The stereotype seemed to be that men are not trusted due to sexual urges they cannot or do not control. For example, Leroy stated, "Some of the challenges in my counseling profession are, usually if I get a mother who calls me and they want treatment for their child, and this is like a 12-year-old girl, mothers are very uncomfortable with me working with their 12-year-old child, particularly unsupervised."

Rusty discussed the lack of trust he has experienced, in the counseling profession, due to being a male. Rusty stated,

This is an amplified a bit in the realm of working with survivors of sexual violence. First and foremost, there's always a shock and awe of the "Oh, there are male counselors and there are male therapists?" Oftentimes, a lot of questions of “'Okay, so you're a counselor, but you're male, you're not a psychologist. You're not a psychiatrist." A lot of fear based reactions about other associations that individuals have had based on other men's actions and that's a lot of transference. Transference that gets placed on any relationship that I build. Many relationships that I build.

Kyle spoke of a challenge he experienced as a male when working with females. Kyle stated, 
When I was supervising, at one point we had an issue with dress with one or two of the students, and being a male supervisor, I was really glad that my faculty supervisor was a woman, because I was able to talk to her about how do we approach this because, as a male, I don't want to come across like I'm overly attending to this, but certain things needed to be talked about. So, that was a bit of a challenge at times.

Sherman said that he has felt the impact of male stereotypes in his program. He said some people make assumptions that he will engage in inappropriate behavior because he is a man." Sherman said, "It really is just based on maleness. It's the expectation that this happened to me one time and the perpetrator was a man so I assume you're probably going to do it too."

Clients. Some participants stated there are challenges associated with being the male gender in the counseling field surrounding clients. Some participants noticed that female clients sometimes prefer a female counselor. Other participants noticed there are challenges in working with men due to both identifying as men. Some participants have been branded or pigeonholed to work with male clients by other counseling professionals.

Female clients preferring female counselors. Some participants have experienced female clients preferring female counselors and how this can be a challenge to their practice. Abbot discussed the challenge of some female clients needing or wanting a female counselor. Abbot stated, "the challenge side, probably this is true for all males, I always ask if the girls would be more comfortable talking with a woman." Abbot said, "I would give the students the option of talking to one of the females instead 
of me. There might have been a few instances where the female students felt more comfortable talking to a female as opposed to a male."

Elliot shared similar experiences. He has found that there are some clients who do not want to see a male counselor. Elliot stated, "I know those challenges do come up, or those barriers, where I can't be helpful just based off someone else's preference."

Male counselor/male client relationship. Some participants have experienced some challenges in their relationships with male clients. These participants said these relationships can be more challenging due to communication that adheres to stereotypes of men in society. Winston shared about his experiences with working with male clients. Winston stated,

One thing I've noticed about men and counseling with men and being a male myself is that...men create a hard exterior to keep up with the expectations that society places on them. I've often found that men are hurting inside because they feel like they cannot keep up with the expectations of the courageousness, the braveness, the financial responsibility. Even having power in relationships when men sometimes don't want power in relationships, but to do that would be emasculating. I think that men are so out of touch with that part of themselves oftentimes. When I can connect with a male who is willing to acknowledge like, 'Hey, this is a part I've struggled with, the struggle of being a man.' It's really hard because there's just so much expectation of what it means and how to be a man and what that expression looks like.

Pigeonholed to male clients. Some of the participants shared they have been branded to male clients by counseling professional referrals. Leroy said that many of his 
referrals are for boys and men. He found this to be challenging because it limited the clients he was able to see. Leroy stated,

Usually, when I'm working with female professionals, the referrals I usually get from them are problematic boys or disengaged husbands. So, they'll kind of put me, which isn't bad, at least it's a referral, but it's also getting kind of frustrating at that. It kind of makes me feel like I'm the only person that, not the only person, like that's the only category I'm good for. So, that's where my value is at, and I do have value there, but I think I am much larger than that ... I've worked with children, I've worked with women, adolescent girls, and stuff like that. So, sometimes I do feel like females see me as a good referral source for problematic boys and men. Like I said, it isn't bad, but I think sometimes it disqualifies me from other potential candidates that I might be very helpful with. And that can be shortsighted.

Leroy advised, "You don't want to market yourself to only working with men or only working with boys, because that's going to really isolate you to a certain population and you might want to do bigger things than that, right?"

The participants of the study reported that there are numerous challenges to being a male gender minority in their programs and in the counseling profession. Participants stated these challenges included feelings of being lonely or isolated; feelings of invalidation and/or discrimination; male spokesperson, challenging topics, financial concerns, male stereotypes, and clients.

\section{Persistence}


Many of the participants shared that their counseling programs and the profession are challenging. However, despite these challenges, the participants have persisted in the field. Hence the third theme: Persistence. Participants communicated two primary reasons for their continuation in the counseling field. One reason is because their program and the profession are rewarding. The second primary reason for persistence is they have supportive peers, faculty, and professional colleagues.

Rewarding. Many participants shared that their counseling programs and the counseling profession are rewarding and this is a primary reason for persistence. Neal stated, "It really is incredibly rewarding, and it really is a great job. I hope more people get into mental health. It's a really fantastic field." Jasper also discussed how rewarding he finds the field. Jasper stated, "I would say that I really enjoy sitting across from someone in the room in a counseling setting and in the counseling relationship, being able to show up for them therapeutically." Otto said, "Every time I get a client that gets better it is totally worth it, and every time I have a staff member that truly finds a great place of joy with their career, it is worth it." Chris said, "It is deeply rewarding and enriching to connect with human beings and to have them trust you with their most meaningful thoughts and feelings at a certain stage in the journey."

Supportive peers, faculty, and professional colleagues. Some participants stated that a reason they have persisted in the counseling field is due to supportive peers, faculty, and professional colleagues. Derek described his retention as, "I thought I could relate to most of my professors and you know, talk to them." Glen stated, "I think about great friends I've developed." 
Chris stated, "I thought the professors were outstanding. Their supervision and leadership in the classroom was excellent. They were very responsive to any feedback or needs. Definitely it's top-flight leadership of the program. So, that was huge." Chris said, "In my experience, we had very strong leadership in the program" and "The program really was a safe, wonderful environment with support of peers and professors to help me process those things, work through issues, and move to a new personal level of growth."

Neal also discussed the importance of supportive faculty in his counseling program. Neal stated, Having supervisors that were both encouraging, and supportive, but also challenging in terms of my clinical development was really helpful. Again, both in my master's, and my doctoral program, I think having relationships with faculty members ... Again, most of these have been male, but there's been ... I can think of two or three female faculty members, that I've had those kind of relationships, where we got to talk about bigger, professional direction issues. Elliot shared his retention in his counseling program was due to having supportive peers and faculty. Elliot stated,

I had a great group of people that I was going through classes with, similar people. I felt like I had supportive supervisors that would challenge me ... Yeah, I think a good chunk is the peer, the cohort that I had. The people I could talk to when ... Just be open and honest with where I was and what I was struggling with and similar difficulties they had. 
In summary, participants stated their persistence in counseling programs and the counseling profession is for two reasons. The first reason is because the participants find it rewarding. The second reason for retention in the field is because they feel supported by peers, faculty, and/or colleagues.

\section{Summary of the Themes}

Qualitative data analysis revealed four themes relevant to men in the counseling field, including students and professionals. These themes included inspiration, benefits, challenges, and persistence. Participants have been inspired to pursue the counseling field. Participants have encountered benefits due to being a gender minority. However, they have also encountered challenges. Despite the challenges associated with being a gender minority in the field, there is persistence and retention in their programs and the profession.

\section{Research Question Answers}

The purpose of this qualitative case study was to understand the shared experiences of male counseling students and male counseling graduates as related to their decisions to apply to counseling programs, while in counseling programs, and postgraduation. The research questions guiding this inquiry were as follows:

1. What attracts men to the counseling field?

a. What role did overt or covert recruitment strategies play in choosing a counseling program?

b. What recruitment strategies could be beneficial to attract men to the counseling field?

2. What is the experience of men in counseling programs? 
3. What is the experience of professional male counselors?

\section{Research Question One}

Research question one for this study was "What attracts men to the counseling field?" This research question was addressed by asking participants questions during their interviews, observations in CACREP accredited programs, and artifact/document analysis. All of the participants discussed their inspiration to pursue an education and career in counseling. Although participants' motivation to enter the counseling field was not the same, each was inspired in some way to pursue counseling. Participants were inspired in some way to pursue counseling. The desire to help others was a general theme. Many of the participants had specific catalysts that led to their desire to help others. These included a calling, personal or family experience, and role models.

Help others. All of the participants discussed their inspiration to pursue an education and career in counseling. All participants' motivation to enter the counseling field was because they wanted to help others. For example, Quincy wanted to help people. He stated he wanted to do "altruistic work" and he "wanted to be able to give, as well, with my career." Mac stated, "I decided that I would do something selfless and rewarding and noble." Jasper stated, "I always had this inclination toward working with kids. So, I just tried to harness things that I felt I was good at and/or enjoyed."

A calling. Some of the participants described their attraction to the counseling field as a calling, which was spiritual or religious in nature. Their calling led them to want to help and support individuals. Due to their calling, these participants had selfefficacy and pursued the counseling profession, which is demonstrative of socialcognitive factors (Lent et al., 1994, 2000). For example, Trent stated, "I enjoy helping 
people and felt like God was leading me into counseling. So, I went there and I enjoy it a lot so far."

Kyle was also called to the counseling profession due to having a calling. Kyle said,

For me, I talk about this as not being a profession, I talk about this being a vocation, and so that's what I try and model, is you don't get into this because you want to make money or anything like that, you get into this because it's a calling.

Personal or family experience. Some men were attracted to the counseling field due to their life experiences with substance abuse and mental health issues, either their own experience or someone they knew. They were affected by their life experience and they wanted to use their experiences to help others who were going through similar circumstances. Despite how challenging some of these life occurrences had been, it was these experiences that manifested confidence in their ability to help others. Therefore, these participants pursued the educational goal of the counseling field.

For example, part of the reason Frank was attracted to the counseling field was because he is in "recovery." Furthermore, he has experience working in mental health facilities specializing in substance abuse recovery. This is where he found "that he got good at it. Because I've been in recovery, I know the language or I know the world from an experiential perspective." Frank went on to say, "I got probably a Ph.D. in the school of hard knocks. So, I'm pretty well versed in the chaos of addiction and depression and learning disorders. Yeah, experience is very valuable at this point."

Role models. Some of the participants' attraction to the counseling field was due to role models who came from books, mentors, and counseling experience. 
Environmental influences such as career role models affect goal pursuit (Lent et al., 1994) and, therefore, influence the development of self-efficacy and outcome expectations (Lent et al., 2000). Role models were clearly an important factor in some men's attraction to the counseling field.

Otto stated he had "a fantastic mentor during my bachelor's degree." Otto elaborated further,

I've always had really phenomenal male mentors and they have cleared the way and opened up some obstacles. Even before they knew that I was a trans guy, because like my professors didn't know, I wasn't out just yet. Even before they knew, they absolutely took me under their wing, and helped me out in ways that I am supremely grateful for. Without their help, I think I would have left the field a long time ago.

Research question one, sub question one. Research question one, sub question one was "What role did overt or covert recruitment strategies play in choosing the counseling field and/or a counseling program?" This research question was answered by participants' individual interviews. The majority of the participants did not notice any type of overt or covert strategies in the recruitment of males. Many participants did not see anything that was "welcoming" toward men. Some men shared that they didn't feel welcomed, but they also did not feel unwelcomed. Instead, these participants thought the recruitment strategies were neutral. Some participants discussed the importance of seeing men on the counseling program's website. Other participants discussed the significance of male faculty in their interviews. Regardless of where the participants saw the men associated with the counseling field, they were an important factor in the participants' 
initiation of the career development process; the process of forming and eventually developing educational and career interests (Lent et al., 1994).

No specific male recruitment. Most participants did not recall any specific recruitment strategies that seemed directed toward men or welcomed men. For example, Leroy did not notice recruitment strategies that welcomed men. He said, "I never got that message like 'Hey, you guys, we want to have you here." Otto's response was "No. God no, not even a little bit" when he was asked if there was anything he saw or heard that sent the message of men being welcome in the counseling profession. Winston stated, “There was no overt message about 'Men apply here.' I didn't get that message."

Neutral recruitment. Some of the men stated that they did not necessarily see anything that indicated men were welcome. However, there was not anything that indicted men were not welcome. Quincy stated, “I wouldn't say that anyone went out of their way to do that. I don't know that I got the opposite impression either." Percy shared,

Nothing that said, "Hey, men can be counselors, too," or nothing to that effect, and nothing that was exclusionary either that said, "You know, we really just kind of want females, so thanks, but no thanks." I think that's fair to say as well.

Male faculty in recruitment. Some of the participants discussed the importance of male faculty in recruitment. For example, Neal said that seeing male faculty was instrumental in his decision to apply to certain counseling programs. Neal stated, "Someone that looks like me, someone who fits demographically, fits some of the categories that I fit into, did make me feel like, 'alright, this is probably an okay place for me to go and learn."” 
Research question one, sub question two. Research question one, sub question two was "What recruitment strategies could be beneficial to attract men and retain men?" This research question was answered by participants' individual interviews. Participants were asked to share ideas on possible recruitment of males into the counseling profession.

All participants agreed that male recruitment is needed in order to increase the number of males attracted to counseling programs and the profession. Most participants had ideas for male recruitment. Participants' suggestions for male recruitment included informing prospective students they are needed and highly marketable; visibility of men on program websites, brochures, and in counseling programs; and increased awareness of the counseling field. Some participants believed recruitment techniques might need to change. A small number of participants were not sure how to recruit males.

Male counselors are needed. Many of the participants believed men need to know they are needed, and counseling programs would likely recruit more males. Participants indicated male perspectives are needed because they provide another important viewpoint. Male counselors are also needed because clients need and sometimes prefer male counselors. For example, Jasper shared that he believes men need to know "their presence and perspectives are needed." Derek stated, "Men are really needed. I mean, in the field they are vastly underrepresented. I think a lot of clients want male counselors." Percy shared, "Just as much as we need to have multiculturalism as part of our continuing dialogue as a profession, there needs to be an open understanding that men bring qualities to the field that women cannot, just like any other individual from some other cultural group can bring to the field and to serve clients too." Percy 
expanded, "I think it's a benefit to our profession that those points of views exist and that it's not all one-sided, but that there's a balance...to a given issue."

Highly marketable. Most participants shared that they are highly marketable as a male minority in the counseling profession. Participants believed it could be beneficial to inform prospective male students how marketable they are. Barry stated, "You don't have to be at the top, you can be average and you're going to be wanted...I had people interested in me just because I was a male and they wanted a male in that spot.” Neal said, "When I was looking at internship positions... both of the places said they would be happy to have a male because they had a shortage, and they had male clients who specifically wanted to see a male counselor."

Male presence on websites/brochures, and programs. Some participants suggested having a visual of males on websites, brochures, and in programs. They thought more male presence would recruit more male students. Male peers were instrumental in feelings of connection, commonality, and someone they could relate. Seeing and having male faculty was important for the same reasons. This was a significant factor in their recruitment, and could be in the recruitment of future male students.

Neal stated, "If you can have pictures of students or pictures of male therapists somewhere on the website that might be helpful, again, just to give another visual of some kind of norm that males are welcome, as counselors." Neal elaborated,

If you look at the faculty webpage, and see that there are a variety of people there, there's a male there, a female there, I think that helps to encourage males to enter the field. And, I think maybe just a simple statement about the program, or about 
the type of students that are welcome to apply to the program, and including males in that. Just explicitly saying that the program wants to foster a diversity of demographics, whether it be gender, or ethnicity, or sexual orientation, or whatever, that the program really thrives when they have that diversity. Increased awareness about the counseling field. Some participants shared the belief that in order to recruit men, there is a need to increase awareness about the counseling field. Participants believed many people do not understand the differences between the helping professions. Participants also suggested reaching out to undergraduate programs to educate about counseling programs to decrease stigma associated with the counseling profession.

Vincent said, "I think a greater public awareness would help a lot. I think a lot of people are still not really sure of what counseling is, especially compared to some of the other mental health fields." Vincent said he believes men are more attracted to psychology or social work so increased knowledge about counseling could be beneficial to male recruitment. Vincent stated, "I think greater public awareness and more information that it is a viable career choice for anyone that is interested in it."

Elliot suggested increasing awareness in undergraduate programs to attract males and "reduce the fear of going into professions like this, that that may draw them in a little bit more, that it's not just the engineering and the construction and all these stereotypical male professions."

Need to recruit differently. Some participants believed men need to be recruited differently. These participants believed using different terminology could help to reach and recruit more men, and lower the stigma associated with counseling. For example, 
Mac stated, "Well, I know that strategies for getting men into counseling, in general, to attend as clients, using verbiage such as coaching, like men coaching or live coaching, those are less threatening terms." Mac suggested, "Maybe a bigger focus on career counseling" and "describing it as a way to help people with everyday problems or assist people in becoming better versions of themselves or helping people achieve the goals that they want in their life versus working with emotionally focused trauma therapy."

Not sure how to recruit. Some of the participants believed more men need to be recruited, but did not have ideas on how to recruit. These participants expressed the lack of male counselors as a larger issue, and recruitment will most likely not address the problem.

Otto shared his exasperation about the lack of males in counseling and its connection to a larger societal issue,

There's this hidden bias in American society that men are supposed to go more for the doctorate degrees. Psychology programs tend to do a little bit of a better job of having men and women photos, and on their panels, and in their professorships. Master's degree programs are more filled by women, and therefore I think schools are just responding to that. That if $80 \%$ of our incoming students have consistently been women, then we should probably advertise more towards women. I understand why it's happening. I don't know how to fix it.

\section{Research Question Two}

Research question two sought to determine the experience of men in counseling programs. The participants discussed their experiences with peers and faculty within counseling programs, as well as benefits and challenges associated with being a male 
minority. This question was answered by first addressing overall experiences with peers and faculty. First, experiences with female peers varied a great deal amongst participants. Second, interactions with male peers were limited due to low numbers in programs. These relationships also varied, many said they were positive, and there was a sense of comradery. However, some male/male peer relationships were challenging due to communication, competition, or insecurity. Third, experiences with male and faculty varied. Many participants' experiences with male and female were positive, and there were no differences in interactions, based on gender of the faculty. However, some of the participants' experiences with faculty varied due to the peer/faculty gender interaction, which led to some positive and negative experiences. One theme that emerged related to faculty was the importance of male faculty in their recruitment and retention. Fourth, there are benefits which included acceptance into counseling programs, obtaining internships easily, being asked for perspectives and receiving attention, behaviors being interpreted more positively than female peers' behaviors. Fifth, participants also shared challenges, which included feelings of being lonely or isolated, feelings of invalidation and/or discrimination, male spokesperson, challenging topics, financial concerns, and emotional expression.

Experiences with peers. Most of the participants stated they had overall positive experiences with their peers, male and female, in the counseling programs. However, there were some reported challenges too.

Female peers. Participants shared that many of their female peer relationships were positive. Some participants were purposeful in being equitable with female peers; they acknowledged their privilege and did not utilize it with female peers. Many 
relationships varied with female peers based on the individual personality of the peer. Some participants' relationships with female peers were challenging.

Experiences with female peers varied. Many were positive. Some participants were purposeful in being equitable with female peers; they acknowledged their privilege and tried to not use it as advantage. Many said their relationships with female peers was determined by the personality of the peer. Some participants said their relationships with female peers were challenging.

Purposeful. Some of the participants were purposeful in their way of interacting with female peers to not leverage their privilege. For example, Kyle stated, From my perspective, I think I did okay with my female peers. Because of this one professor making me aware of my privilege, I think I tried very hard to do things like be aware of not dominating conversations and stuff like that. And I can only speak for my own perspective of how successful I was at that.

Varied. Many of the participants said the relationships varied and usually depended on the person. Jasper stated,

They've been positive, but I don't know if I would encapsulate interactions with women so generally because I really think it depends on the individual. Because I have had great, I would say that the majority of my experiences have been positive, but there have been some interactions with women that I have butted heads with.

Challenging. Some participants said their relationships were challenging with their female peers. Leroy shared that his experiences have been mostly positive, but a "screening process" takes place. Leroy stated, 
My female peers have all been pretty supportive. They've all been pretty good. I think initially, when we get to meet each other, they're kind of feeling me out to see "Okay, well what level of knowledge does this person have about counseling?"... and "Okay, why is this guy here in counseling?" I think sometimes, they can be quite grateful and quite welcoming that they have the male presence. But, there is definitely no "There's a guy here! Let's embrace the person." I think there's usually this feeling of "Okay, what do you know? Why are you here? Are you qualified to do it?"

Male peers. The majority of the participants stated their interactions with males were limited due to low numbers in programs. Many of the participants' relationships with males were positive. Some participants felt a sense of comradery with their male peers. Some of the participants shared that their relationships with men had challenges in communication, competition, or insecurity.

Positive/comradery. Male peer relationships were positive for many of the participants. For example, Quincy spoke of a common shared experience with his male peers. Quincy stated, In my doctoral program, I have some male peers who I really connect with. We share a lot of worthwhile ideas with each other, work on publications together, and things like that. There weren't that many male peers...there were only two other men in my cohort in my master's program.

Quincy expounded, "I think that there can be male bonding that can occur if you are the only men in a program and it's primarily female, that there's a shared experience there."

Challenging. Some participants stated relationships with male peers could be 
challenging. For example, Elliot said, "I did identify a couple male peers that I probably talked to more closely than probably any other males... I probably wasn't really connected." Elliot shared,

I was still maybe trying to prove to myself that I knew what I was doing, and I wanted to try to portray that. I was hesitant to speak up with males if I didn't know something. Like, if I say this and they know it then I'm inferior to them. Elliot expounded that he had a fear of "saying something stupid or something that gets this reaction of, "What were you thinking?"”

Experiences with faculty. Participants shared about their experiences with faculty, male and female, in their counseling program. Some participants said their experiences with male and female were positive and there were no differences in interactions, based on gender of the faculty. Many of the participants' experiences with faculty varied due to the peer/faculty gender interaction. This interaction could lead to a positive or negative experience for the students.

No differences. Some participants stated there was no difference in their experiences as related to the gender of the faculty member. For example, Vincent stated, "I don't think there were any significant changes or different interactions because they happen to be male or female."

Male faculty. The participants shared varied interactions with male faculty. Some of the relationships were positive and some were challenging. Some of the participants discussed the importance of male faculty in their recruitment and retention.

Positive. Many participants' experiences with male faculty were positive. Leroy stated, 
I probably had about three male professors in my graduate experience. So, when you come across some of these men, 'It's you, look,' and they give you kind of a code wink, like "Wow! You're here, me too." And it's almost kind of like we're going to try to make this work for each other. "I want you to do really well here." So, I think that when I get the male faculty, not that they favor me, but I do think like, "Oh wow! There's another guy here."

Varied. Some participants' experiences with faculty varied. Quincy stated, "I'd say it varies. I'm still close with one of the male faculty members in my master's program.” Quincy elaborated,

I had another male faculty member who I had some particular disagreements with that run along the lines of some of the things I've already shared. There was almost an evangelism to his beliefs about the world. I felt like it was very much not a classroom environment that was open to differing ideas. It was very much that this is how the world works and you must believe this, otherwise you are X. Obviously, $\mathrm{X}$ is not a, you can imagine the words, but it's not described in a positive way, what you would be if you don't agree with him. I found that pretty unpleasant, generally, to be in that environment, because I don't like that. I particularly don't like feeling manipulated, like somebody's trying to force me to believe something. That's not a pleasant experience for me.

Challenging. Some experiences with male faculty were challenging for the participants. Kyle stated,

We had very few male faculty in the program I was in...there were two male faculty." Kyle said of one of the male faculty, "I got along with him" at first, but "I 
thought he ended up being a total prick...because he had this whole frat boy approach...of, “Well, if you're going to go through this, I was hazed, so I'm going to haze you' type of thing." Kyle stated, "He did things that I thought were unfair. So, that wasn't good."

Female faculty. Many participants had positive experiences, and some said they were not only positive, but they felt supported. However, many participants' experiences depended on the faculty member. Some participants shared some negative experiences.

Positive. Many of the participants' experiences with female faculty were positive. Quincy's experiences with female faculty were positive. Quincy said,

I would say I had pretty overwhelmingly positive experiences with at least one of the faculty members there in my master's program. The other one I didn't know all that well, so I just didn't take a lot of classes with her. I would say my experiences, at least in my master's, were overwhelmingly positive. Varied. Some of the participants' experiences with female faculty varied. Glen shared that his experiences with faculty depended on the faculty member. Glen stated, I think in my current program, I have both ways. I have some faculty that see me as, really just give me the benefit of the doubt, really positive towards my gender, and then I think I have both. And I have to really be careful to figure out what that is.

Challenging. Some participants had challenging experiences with female faculty. Ivan shared one experience he had with a female faculty. Ivan stated, From day one, we were taught to check our biases. I think that professors understand there's a power differential. This last semester was the first time, in 
over 2 years, I experienced a professor taking advantage of a power differential, and it wasn't a good feeling.

Privilege or benefits of minority gender in counseling programs. Participants

shared benefits or privileges they experienced in their program they believed were due to being a male or due to being a gender minority. Some participants did not believe they experienced any benefits or privilege due to being a male in their counseling program. Some participants believed there were some benefits or privilege due to being a male or the gender minority.

No benefits or privilege. There were few participants who believed they received no benefits or privileges due to being a male or minority gender in their counseling programs.

Benefits and/or privilege. Many of the participants shared benefits they may have received due to being a male and/or as a minority gender in their counseling programs, which included entry into counseling programs, obtainment of internships, asked for their perspectives and attention, and behaviors interpreted more positively than female peers' behaviors. For example, Ivan stated,

When I went into the initial information meeting, I knew I was going to apply and I noticed there was me and another guy and everybody else was a woman.

There's just me and one other guy out of 20 people. I thought maybe my chances of getting in are...I thought maybe my chances are going to be better that I'm going to be accepted. I figured when I applied to the doctoral program that it would give me a tiny edge. Now, I needed everything else too, but I knew that it wasn't going to hurt me being a male. 
Jasper shared an example of privilege he believed he experienced due to being a man or male minority. Jasper stated,

Some of the things are subtle. I think that if I wanted to get out of some certain responsibilities I could have, like certain duties within the department, or some things that haven't been mandatory that I have stepped up and volunteered for. I think I definitely could have gotten out of those responsibilities. They could have fallen on other people, potentially other women in my department.

Challenges. Most participants shared challenges to being a male minority in counseling programs. Some participants did not experience any challenges related to being a gender minority in their program. Some participants shared challenges that included feeling lonely and/or isolated; feelings of invalidation and/or discrimination; coping with and addressing male stereotypes held by others in the program; and called on as spokesperson of men.

Lonely or isolated. For example, Leroy stated, "We're special in this field and we can do really good work, even though sometimes it's going to be lonely and it's going to be isolating." Leroy stated,

I think in my graduate study, it is good because it does make you a bit rare, but it can get very lonely, very quickly. You're like “Geez, I haven’t seen another man in a year, in the class." That's not uncommon at all.

Feelings of invalidation and/or discrimination. Some of the participants experienced feelings of invalidation and/or discrimination. Quincy stated,

There are times where I've found that people just dismiss ideas as being male ideas or White people's ideas. I find that pretty hurtful sometimes because I 
embody that, and it feels like it closes off the room to me, I guess.

Ivan provided another example where a participant felt invalidated or

discriminated. Ivan stated,

If the goal is for everybody's voice to be free and equal, as tempting as it might

be, you can't try to get back at a person that was once leaving you voiceless

because I went through it as a White male. When I felt voiceless, and when I felt

like I didn't have a voice, I felt resentment and all that did was it didn't settle

anything. So, it's tempting and I think it's tempting when people feel oppressed

to get back at other people, but if equality and equity are the goal, then there can't be any revenge.

Male stereotypes. Many participants shared experiences of coping with male stereotypes. For example, Sherman stated a woman,

told me that being a male therapist that once I graduate I'm going to be in high demand. Then they added something that I thought was strange. Is that they added to that statement, their full statement was something like, "Being a guy, as long as you're able to keep ethical boundaries you'll be in high demand."

Sherman continued,

If you can make it and keep your boundaries then you'll be in high demand. Instead of just telling me, "As a male you're going to be in high demand." I didn't really respond at the time. I was just like, "Yeah that seems right I guess." Thinking about it in this context, it certainly reinforces the idea that maybe I would be more inclined to, I don't know, ethical failure I guess. That's the only term I could think for it. 
Male spokesperson. Some participants discussed the challenge of being called on as a male spokesperson. Glen stated,

In the counseling program where I was the minority person in my classes, often I had to speak from the male perspective, as one person, and that was challenging at times. And also, I'm Caucasian so understanding privilege and how I'm perceived and not being always how I appear, as I'm pretty hyper-masculine in terms of my appearance, and being privileged or the White majority and the power differentials. Sometimes I felt like I had a label of who I needed to speak for, but wasn't actually who I was.

Challenging topics. The majority of the participants shared that there were challenging topics. Discussions on privilege were a challenging topic for many. For example, Leroy stated,

I think specifically when we come up to topics like if we're talking about something like post-abortive counseling and things like that. You can sense that, not that it's not a place that men cannot speak, but it's a place that men have to be very careful in the way that they broach the topic, the way that we talk about it. I think for good reason. It's a part of the process that ... It's something that we can't experience in the way another woman can. So, I do understand that to a degree. But, it's certainly not treated the same way as like if my female colleagues had an opinion; I think it'd be looked at differently than if I said something. It's almost like screening process.

Leroy concluded, “I don't think it's coming from a negative or discriminatory place, but I do recognize that I am the odd man out most of the time." 
Privilege. Some participants stated the most challenging discussions were related to male identity, male privilege, and White privilege. Quincy shared that discussions related to gender and race were challenging. Quincy said,

I often felt, around topics of gender, that those were the specific topics where I had to hold very specific viewpoints, and if I didn't, then it wasn't a very comfortable experience for me. I had all sorts of insinuations made about my character and things like that, both from students and faculty.

\section{Research Question Three}

Research question three sought to determine the experience of professional male counselors. The participants shared their experiences about professional colleagues. Experiences with colleagues in the counseling profession varied. Many of the professional counselors' experiences were similar to the student participants' experiences in their counseling programs. Participants also shared benefits and challenges associated with being a male minority. The benefits were primarily that clients need and want to see male counselors, and they are highly marketable. The challenges were lack of trust of male counselors, female clients possibly preferring female counselors, and being pigeonholed to male clients.

Experiences with female colleagues. Participants' experiences with female colleagues were primarily positive, but some experienced challenges.

Positive. The majority of the participants' experiences with female colleagues were positive. For example, Percy's relationships were "wonderful.” Percy said, I'm very comfortable with women, working with women, so having female as the majority that I work with in the field is all fine and good with me. I don't have 
any negative feelings of, “Oh, jeez, I'm in this female-dominated profession and it's a struggle for me," it's actually quite comfortable.

Challenging. Some of the participants experienced challenges in working with female colleagues. For example, Rusty stated, Power and control knows no gender. It operates very similar to different innerpsych identities that pressure tactics can happen to anyone...We had an executive director who openly discriminated against male colleagues. And very similar to the victim blaming we see in sexual violence, the same thing happens often as, I've learned from other male colleagues who've experienced that victim blaming of a male colleague being harassed by a female supervisor who totally gets away with it because there's the assumption that men want it or that it couldn't possibly happen because men hold all the power. If it could be in a message in a bottle, it would be that oppression, again, it doesn't discriminate. It goes against everyone. Experiences with male colleagues. Many participants' professional experiences with male colleagues were positive, and some participants said their male colleague relationships were needed. Other participants had some male colleague relationships that were challenging.

Positive. Many participants had positive experiences with their male colleagues. Glen stated,

I am more comfortable in female settings. I've noticed that about myself. It's just been, kind of my whole career. But at times, I miss male settings, as well. But I also know that male settings aren't great all the time either. So, I think that 
one of the things that we talk about in my office, here, is just getting time to be males.

Glen expounded, "We don't actually talk about male issues, we just spend time together. And so, that might indicate to me that there are times where being in a completely female environment and switching over to a male one for a while is nice."

Challenging. Some of the participants' experienced challenges with male colleagues. Leroy shared about his experiences with male colleagues. Leroy stated, I think male colleagues, we can be very tribal and even cut off from each other. And I don't know if that's a function of being a male or a function of, I guess, we get so busy and sort of wrapped up, it can be hard for us to communicate and network with each other. I do notice my female colleagues seem to communicate much better. And my male colleagues, if I do see them or I do reach out to them, it's very much in passing. I don't think we value networking in the way that female colleagues do network. But I also think that we do talk about things such as, okay, well obviously we are men, sometimes we're counseling women, these are challenges that come up, these are some of the good things that come up as well. And I think we are able to share those stories and interact and sometimes bounce difficult situations off each other that are related to our sex or to our gender.

Benefits. Many of the participants stated there are benefits to being the minority gender in the counseling profession. The benefits were primarily that clients need and want to see male counselors, and they are highly marketable. 
Clients need and want to see male counselors. Many of the participants have found that there are clients who need and desire to see a male counselor. For example, Winston stated,

I always assumed that men would want female counselors, maybe it's just me because I like the mothering type of relationship. I find that a lot of my clients who are men prefer men counselors. They're like, "I feel like I could talk to you about things." I've noticed that they don't feel as open with females. I never would have imagined that would be the case.

Highly marketable. The majority of the participants have found they are highly marketable. For example, Abbot said the school he applied to was looking for a male counselor. Abbot stated,

I think that at that time the school I am at now had three previous female counselors, prior to me, over the span of six or seven years. Not that they didn't do a good job. I'm sure they did a wonderful job. I think at that point though that was something, maybe they were looking for. Not that they told me that, I just kind of got that feeling.

Challenges. There are challenges associated with being a male minority in the counseling profession. The challenges were lack of trust of male counselors, female clients possibly preferring female counselors, and being pigeonholed to male clients.

Lack of trust of male counselor. Many of the participants shared that they have found they are not trusted in the counseling profession because they are men. Mac shared about an experience he had with a female client's mother when they were discussing video recording the counseling session. Mac stated, 
She made a comment..."Oh, you know, well you got to in this day and age, everything's got to be recorded to make sure nothing happens.” So, I experienced that as maybe her being concerned that, as a male, I might take advantage of the client or not being trusted; whereas a female might be.

Mac continued,

I guess, for me, it was more like, “Oh, wow." Like, sometimes I forget that I am a man, being a gay man. Sometimes I forget that I am a full man and people are going to have their ideas of what men do, or have done, to them. And so, it was just like a, "Huh." It was a wake-up or a reminder.

Female clients possibly preferring female counselors. Many of the participants shared that it can be challenging because there are many female clients who prefer female counselors. Leroy shared an experience he had with a female client. Leroy stated, "I did have a lady that was working with me and then fired me the next session because she said she had a lot of things that she only thought a female could discuss with her."

Pigeonholed to male clients. Many of the participants experienced receiving primarily male client referrals. For example, Neal stated,

One thing I've found, in the clinical work I've done, is that in being one of the few males at the places I have worked at, clinically, I have been kind of pigeonholed, as the male who sees the males. And so, I don't think I've had quite the diversity of clientele, or maybe even an accurate representative sample of clients, in terms of who's receiving counseling... one of my doctoral internships, I literally did not have a female client, the entire time I was there. It was all males because there was such a high demand for it, and such a short supply of male 
therapists. So, in terms of my...clinical exposure, I think that might've been a disadvantage, the flip side of the coin, that I was seeing mainly males.

\section{Conceptual Framework}

Men were asked to discuss concerns, if any, about going into the counseling field. More specifically, they were asked to discuss any experiences of pressure, familial, cultural, societal, etc. in regards to pursuing a field where women were the majority identified gender.

\section{No Social Cognitive Challenges}

Some of the participants did not have any issues or pressures related to entering the counseling field, although men are the minority gender between male and females. Abbot, Percy, and Quincy did not experience any type of pressure. Derek did not experience any pressure either. Part of the reason he did not feel any social cognitive dissonance was because he had an older brother who went through a counseling program four or five years before he went through his program.

Trent did not experience any social cognitive pressures about entering the counseling field. Trent stated,

I guess I never really have been one to say "Oh, there are more females in this

field. I better avoid that" or "there are more males I have to do that." It was like "I enjoy this field so I don't really care what the gender ratio is."

Uri shared similar sentiments about going into the counseling profession. Uri stated, “Going into the counseling program, I didn't feel any weirdness that I was male going into the profession or not feeling welcome or anything." 
Mac shared that his mother wanted him to pursue a profession as a doctor. However, after attempting a few classes, he informed his mother he could not do it. Mac stated,

I think she's happy I am that I am in a helping field. I think, like I was saying before, it has a similar level of prestige as being a nurse or being a teacher. I don't know if prestige is the right word, but like you know the nobility, like doing something selfless.

In addition, Mac stated,

I think in terms of culture. I don't know, being a gay male and just being very in tune with my emotions, has made it easier to want to go into counseling. I think it's helped me a lot. I think people are very impressed when I tell them I'm studying counseling. There's never any shame or anything attached with it. I've never felt shamed, or "Oh, do something else."

Jasper stated he never felt any social cognitive pressure about becoming a counselor. Jasper stated,

It wasn't that it was deterred early on through my undergrad and it wasn't something that was on my radar, but it's very possible that at some deeper subconscious level there were reasons for that, but none that I'm aware of. None that I'm... that I was aware of at the time. I think that once I found a line of work that felt really good to me, it felt right. I can't recall ever feeling like those societal norms or expectations about being a man in our society made me or gave me pause about going into the field. Once I found it, I was pretty much on board 
with it. Yeah, I don't think I ever had doubts that you know "Is this going to be perceived negatively societally and in my closer and wider circles?"

Kyle stated he did not experience social cognitive pressure or dissonance as related to entering the counseling field. Kyle said,

My whole upbringing, my father was raised in the forties... and he tried to bring me up in sort of cultural norms/stereotypes of what a male is, and it always rubbed me the wrong way, so I was always frustrated with that. By the time I hit my mid-twenties, I guess I got over most of it when I realized I needed to go to counseling therapy myself. And at the time I was doing that, there was still a certain stigma attached to seeking counseling, especially for men, but I'd been all through that crap of boys don't cry and all that kind of stuff as a child. So, it didn't bother me too much. And then, especially in my master's program, I had one professor who was just really, really good at helping me examine my dominant cultural privilege. And so even though I'd never felt comfortable, in certain respects, as far as what society expects of men, this counterbalancing of yeah, okay, maybe not, but you're still part of dominant culture male, and so you have to deal with that. And so, that would help me with a good balance in my master's program. So no, I ate it up. I enjoyed it a lot. I didn't feel uncomfortable.

Chris shared that he did not feel any cognitive pressure about entering the counseling profession either. Chris stated, I know that culturally the stereotype of the male seems to be one who doesn't cry and maybe withholds feelings. Personally, I don't buy that and one of the things I 
appreciate about the counselor education program is we are all about embracing tears and emotional expression. Sometimes, culturally, we have a stereotype that females do that more easily than males, and there may be something to that. I know that there are females that also struggle with emotional expression. I'm not hung up about that being a gender issue, but I'm not hung up by that or limited by that.

Elliot did not feel any pressure from his family. He was surprised he didn't receive any pressure from his father. Elliot stated,

He'd ask me questions about it and shared some of his experiences, so that was cool. I wasn't necessarily expecting that. Societal pressures, I probably had some of my guy friends that were in construction or doing engineering or more that was male-dominated that might have made some side comments about, "Hey, how are your crazies doing?" or "How are all of your emotional clients doing?" I think probably just kind of good-natured ribbing, you know, that they're trying to poke at me. But I never took that as something that would cause me to back out of the profession. I still felt more of a pull towards the profession than kind of like, well maybe I'm not doing the right thing.

Jasper implied there might have been some social cognitive dissonance at the master's level, but once at the doctoral level he did not experience it. Jasper stated, "I think part of it too is just me not abiding by societal norms as much by the time I went to my doctoral program, not being pressed upon by those pressures as much."

Harry shared that he did not feel any social cognitive pressure about entering the counseling field. Harry stated, 
I've never run into a situation telling somebody what I'm studying or what I'm going to school for where they've said, “Oh, well isn't that what women do?" I've never gotten the impression that for example, suppose a man went to school to become a nurse. Assume nurses a predominantly females, I have no idea whether they are or aren't, but if I were to say 'I'm going to school to become a nurse," I think people would naturally think, “well, why not become a doctor, because men are doctors, women are nurses" that kind of thing. I've never had somebody say, "don't women become therapists?"

Harry pondered if there is any social-gender stereotype about counselors. He thought it might be possible there is no stereotype about counselors being women because there is a lack of awareness that men are the minority gender amongst counselors. Harry stated,

I think there's a lot of men in modern media that are associated with the field. I think in general people don't really understand the difference between a psychiatrist, psychologist, and a counselor. I think most people don't differentiate between those things. So, I question often if there really is a "therapists are women" type of stereotype in the field.

Harry elaborated,

Aside from the general stereotype that women are more comfortable talking about feelings and stuff and people assuming that therapy is all you do is talk about feelings, therefore, women should be therapists. There really is an assumption and that could be again the male privilege that I have never really considered that. That's only from my perspective. There could be one that I'm just not aware of. 


\section{Social Cognitive Challenges}

Some participants answered in the affirmative that there was some pushback or pressure about entering the counseling profession. Percy did not feel any pressure when first asked. However, Percy added,

The only stereotypical pressure, or drawbacks, that I got was family members commenting how I won't make a lot of money in this field, but again, just because that's how the field is characterized in not being a lucrative career field. That was really the only thing that I had, so nothing to do about my gender as a male in the field.

Vincent's experience was similar to Percy's experience in social cognitive pressure. Vincent stated, I don't think that I've really experienced any backlash or any kind of influence because of the fact that it's more populated with women. I think what I have experienced more is the perception that it isn't a super prestigious occupation. For example, I got a lot of those “Oh, you shouldn't do psychology. You shouldn't do counseling that won't pay well; no one really knows what it is. You should be a doctor or a lawyer instead like societally valued positions." But in terms of the male thing, I can't really think of any examples. Not like how I know a lot of male nurses receive it. I know a lot of male nurses are often times are disparaged because it is traditionally seen as a female oriented occupation.

Uri did feel some pressure about entering the counseling field, and classified it as “internalized pressure." Uri said, 
I think any pressure I've felt has definitely been internalized pressure. I don't think I've ever had anyone outwardly say to me when I told them I want to go into the counseling profession, I never got any advice from anyone or anything that that would be unacceptable or weird as a man going into the counseling profession. I would say that definitely being... throughout life, it's been pressure to perform to male norms. Entering the profession, it probably was in the back of my head that, "What is this going to mean for me? How are people going to see this?" Stuff like that.

Leroy explained the social cognitive pressure he has felt in the counseling field. Leroy stated, I mentored one of my people that came from my neighborhood also, and he's actually pursing a degree in sport's psychology. I don't know if we get there without another guy who's under you, because when you think of social workers and caseworkers in the real, and the raw, and in the wild, they always win it. So, I think that's kind of weird. It's kind of like male nursing, "Oh that is a woman's job.” I think counseling can have a similar feel to it.

In addition, Leroy said,

It's weird because I am Puerto Rican and because I am Puerto Rican, we have a very machismo sort of attitude. So, when I saw there weren't very many males there, I'm kind of thinking, "This is weird." And I was like, "What are my parents going to think? I'm in this field with all these women." This is going to give me a chance to somehow think of other jobs that are similar to ones that women dominate, like an airline stewardess, even though there are males that do 
that, or like sports' cheerleading. I'm like, am I going to be one of those people that's an odd guy out, and that kind of thing? So, that did go through my mind. Uri believed other men feel pressure about entering the counseling field due to patriarchy and gender stereotyping. Uri stated, I think in many ways men suffer from the patriarchy in that we're not ... It restricts us from being whole people who are able to be vulnerable and have emotions and do certain things and like certain things like... honestly, the counseling profession. I'm sure there are many men who have felt maybe it would be something they would be interested in, but have felt a little restrained from doing it because it crosses the line with masculine norms. Maybe they thought they'd be great as a counselor and they have a wellness mindset and a developmental mindset and it really clicks with them, but they opt to do a psychiatry program or a clinical psych program because that's seen as more medical and logical and masculine I guess.

When Neal was thinking about pressures he might have felt about entering the profession he stated, I think I did feel them ... I remember introducing the idea to ... to the general manager, letting him know that I was going to make a career change, and that kind of thing. And I remember, even feeling some hesitation, or some, I don't know, some stigma, around that introducing, like, "Hey, I'm thinking about entering the counseling field." Because we were in a very, I would call it, a very masculine culture. It was manufacturing, it was very business-oriented and to introduce it, there. So, I felt a little ... I don't even ... I'm trying to think of the 
right word, to describe it, but stigma is the only thing that comes up, for me. Like I was violating a social norm, of moving from that position, into a more "feminine" field.

Neal expanded further by saying,

But I'm trying to think of other places ... I felt that when I initially talked with some of my friends, about it. I consider myself a pretty masculine-oriented guy. I play sports, and I like a lot of very culturally traditional masculine things. And fit a lot of those cultural, more masculine categories. So, there was a bit of a ... Like I feel like I'm stretching the boundaries, here. But even talking ... introducing that idea to my friends, about, "I'm going in to be a counselor." So, I did feel it, there. In those, that ... my initial work setting, and some on the social side. Neal did not feel any stigma from his family. Neal stated, "I did not feel any of that with my family" and he said he, "grew up with a certain comfort level, around talking around emotions, and sitting with people, in various emotional states. So, I think that kind of took the edge off of things, in terms of the family side of things."

Abbot stated that when he thinks about male's selection of career, he is not sure why some men pursue some careers more than others. Abbot was unsure why male teachers might gravitate more toward administration versus school counseling careers. Abbot said,

Maybe there was more of a natural tendency, for whatever reason, for men to gravitate toward administration. This is just my opinion based on what I thought about over the last few weeks. When I think back, after I got my bachelor's, I don't know why I automatically had the thought that I was going to start working 
on my Administration degree. I don't think I gave any thought to counseling when I first came out of college.

Winston discussed the need for boys and men to see male role models in order to decrease the stigma of counseling and going into the profession. Winston stated, I guess another perspective just might be the importance of having male clinicians in counseling offices. Men are going to be clients. They're going to come in seeking mental health counseling, couples counseling, marriage counseling. I think, even kids looking up to their counselors, male kids. I think it's important for them to see males in the profession and consider that as an option because I think a lot of the times men are going to be drawn to professions where they see other men and think, "Oh, that's what I should do. That's what men do." I think if boys don't see men in counseling roles, then they're going to think that's not okay or right or possible. That's why I think men should enter the profession. Men should stay in the profession and even work with kids and school counseling and in child clinics or family clinics so that they can see that as an option for an occupation for themselves.

Quincy said he "definitely" experienced social cognitive pressure about entering the counseling field. Quincy stated,

From an early age, pushed by pretty heavily about the men can't have and boys can't have feelings and can't cry jazz. I thought that was ridiculous because it was really similar to my female peers. You know from a really early age, and definitely still feel that influence even today. It's quite interesting how this system doesn't appear to ever go away for some individuals. 
When Quincy was asked where these messages that caused social cognitive pressure were coming from Quincy stated,

I would be hard pressed... to be honest, hard pressed to say where they're not coming from. On an individual level, they've been really common passively. They've come from caretakers, teachers. They've come from media and societal viewpoints on men, emotions, empathy, and such. And then reaffirmed in interactions with different helping professionals. 
Amber Faithe Lancaster was born December 31, 1971 at 11:02 PM in Kansas City, Missouri. Her mother made every attempt to give birth to her after midnight, but she was unable to do so. If Ms. Lancaster had not been so stubborn, persistent, and meeting her own goal of seeing the world when she chose, her parents, Shirleen F. Herrick and James E. Lancaster may have been awarded the first baby of the New Year prizes. However, Ms. Lancaster's stubbornness and persistence are one of the reasons she is earning this doctorate degree.

Ms. Lancaster did not begin her college education until she was almost 23 years old, due to financial constraints. She started this journey in Scottsdale, Arizona. She then moved back to Missouri because her grandmother Brickey was sick with cancer. Despite the challenges of transferring her college credits from Scottsdale Community College, she stubbornly persisted and started again at Longview Community College where she earned her Associates degree in the Arts. She then continued her education at the University of Missouri- Kansas City where she earned her Bachelor's degree in Psychology in 2000.

Ms. Lancaster then applied and was accepted at the University of South Dakota (USD) where she earned her Master's in Community Agency Counseling in 2004. She then was accepted to the Counselor Education and Supervision doctoral program at USD. She completed all course requirements, passed her comprehensive exams, and wrote over 100 pages of her dissertation. Despite these accomplishments, she did not complete her dissertation and ran out the graduate clock for completing her doctorate in 2013. 
Therefore, her doctoral credits were applied to an Education Specialists degree in Counselor Education and Supervision.

Ms. Lancaster was at a crossroads at that point in her career and education. She had been teaching in Counselor Education for seven years and loved it. She also knew she wanted to continue her career in higher education. After much thought, reflection, and research on different doctoral programs, she decided to supplement her Counselor Education and Supervision degree with a doctorate in Educational Leadership and Policy Analysis through Missouri University-Columbia.

There have been many challenges in Ms. Lancaster's educational journey. Her persistence, stubbornness, and never losing sight of the goal were huge assets in accomplishing this goal. However, she would have never entertained the idea of higher education, because it was anomaly in her family, if it had not been for supportive people in her life. These supportive individuals included family and friends, teachers, and professors. They were the true catalysts. Individuals never know what will be remembered, what will take hold, what influence they could and do have. It is for this reason we should always be kind, supportive, and caring toward others. You just might be the catalyst for someone's journey. Ms. Lancaster is forever grateful to all the supportive and caring people who believed in her. 